\title{
The British Society of Gastroenterology
}

The 46th Annual Meeting of the British Society of Gastroenterology was held at the University of Newcastle upon Tyne from 18-20 September 1985, under the presidency of Professor E L Blair. Out of the papers submitted, the Programme Committee of the Society selected 136 for presentation as posters, and 52 for oral presentation; the abstracts* are printed below. Further details of the meeting appear in the News column on p. 1098.

BSG/BASL LIVER

W1-13

W1

Erythrocyte aldehyde dehydrogenase activity in health and disease and its value as a marker for hepatic aldehyde dehydrogenase activity

K MATTHEWSON AND C O RECORD (Gastroenterology Unit, Royal Victoria Infirmary and University of Newcastle upon Tyne) Considerable controversy surrounds the role of hepatic aldehyde dehydrogenase in alcoholic liver disease. Its activity is reduced and this could be a pre-existing abnormality or simply a non-specific consequence of alcohol consumption. Erythrocytes contain an enzyme identical to the hepatic cytosolic enzyme which could prove to be an accurate marker of the hepatic enzyme with the added advantage of ready availability. Using a spectrophotometric technique, erythrocyte aldehyde dehydrogenase was assayed in 15 healthy controls, seven actively drinking alcoholics (ADA), five subjects with alcoholic liver disease currently abstaining (AALD) and seven with non-alcoholic liver disorders (NALD). In addition the hepatic cytosolic enzyme was also assayed in 18 of the subjects. The ADA group had significantly reduced erythrocyte enzyme activity $(\mathrm{p}<0.01)$ but the AALD and NALD groups did not. The correlations between erythrocyte and hepatic cytosolic activity for all subjects considered together, for the NALD group alone, and for the ADA and AALD groups considered together were all insignificant. In the control group alone, however, there

* Because of the time lag between acceptance of abstracts and the meeting, the data presented at the scientific sessions may not correspond exactly to the information contained in the abstracts. was a significant positive correlation $(r=0.943, p<0.05)$. We conclude that erythrocyte aldehyde dehydrogenase activity is reduced in actively drinking alcoholics but that red cell activity gives a poor indication of hepatic cytosolic activity in subjects with liver disease. In contrast, it appears a good marker of hepatic activity in normal subjects, and might therefore be used to study enzyme activity in 'prealcoholic' subjects.

\section{W2}

Decreased red cell aldehyde dehydrogenase activity in patients with alcoholism

N R TURNER, S THOMAS, M J P ARTHUR, AND R WRIGHT (Professorial Medical Unit, Southampton General Hospital, Southampton) Acetaldehyde has been implicated as a mediator of hepatic injury in alcoholic liver disease. Alcoholics develop higher blood acetaldehyde concentrations than normal subjects after drinking alcohol. Reduced activities of aldehyde dehydrogenase (AldDH) have been reported in liver samples from alcoholic subjects. An enzyme similar to the cytoplasmic AldDH of liver cells is present in red blood cells and shows a similar reduction of activity in alcoholic patients. If this reduction is specific for excess alcohol consumption, it may be useful in the detection and follow up of patients with early alcoholism.

The red cell AldDH activities of patients with a history of alcoholism (ALC, $n=35$ ) were compared with those activities found in patients with non-alcoholic liver disease (NALD, $n=21$ ) and a group of normal controls $(\mathrm{NC}, \mathrm{n}=32$ ). AldDH activities in the ALC group were significantly lower than those in both the NALD $(\mathrm{p}<0.05)$ and NC $(p<0.01)$ groups. Moreover, patients with clinical evidence of continued drinking had the lowest activities. Activi- ties in the NALD group, however, were themselves lower than those in the NC group $(p<0.05)$. These results suggest that decreased red cell AldDH activity is of some value in the detection of alcoholism but its major clinical potential is as a marker of continued drinking in alcoholics.

\section{W3}

Immunoregulatory defects and aberrant cellular reactivity to liver cell antigens in families of patients with autoimmune chronic active hepatitis

C J O'BRIEN, S VENTO, A L W F EDDLESTON, AND R WILliams (Liver Unit, King's College Hospital and School of Medicine \& Dentistry, Denmark Hill, London) The finding of a $T$ suppressor cell defect specific for liver membrane antigens in autoimmune but not $\mathrm{HBsAg}$ positive chronic active hepatitis (CAH) raises the possibility that a discrete defect in immunoregulation may be fundamental to the pathogenesis of this condition. As nonspecific disturbances in immune function have been observed in relatives of patients with autoimmune $\mathrm{CAH}$, we have assessed $T$ lymphocyte responses to liver derived antigens and their suppressor $T$ cell (Ts) control in healthy relatives and spouses of patients with autoimmune $\mathrm{CAH}$. Using an indirect $\mathrm{T}$ lymphocyte migration inhibitory factor assay it was found that $18 / 18$ patients, $8 / 41$ relatives, $3 / 11$ spouses and $0 / 23$ unrelated controls exhibited sensitisation to a liver membrane lipoprotein (LSP) complex. In contrast to all nine patients studied, none of the LSP sensitised relatives exhibited sensitisation to the asialoglycoprotein receptor - a purified constituent of LSP. In T cell co-culture experiments, using patient and non-patient cells in a 9:1 ratio, $T$ lymphocytes from 20/41 relatives and $1 / 11$ spouses $(p<0.05)$ were 
unable to suppress $T$ cells from patients sensitised to LSP. These studies suggest that a Ts cell defect for liver membrane antigen(s) is a genetically determined marker of susceptibility for autoimmune $\mathrm{CAH}$. Clinical disease only arises when in addition to the defect, $T$ cell sensitisation to the asialoglycoprotein receptor appears.

\section{W4}

Natural killer (NK) cell activity in acute viral hepatitis

L CHEMELlo, M MONDELLI, F BORTOLOTTI, E SCHIAVON, A ALBERTI, E G RONDANELLI, AND G REALDI (Istituto di Medicina Clinica, Cattedra di Clinica Medica II, University of Padua, and Department of Infectious Diseases, IRCCS Policlinico S Matteo, University of Pavia, Italy) Recent experiments in animal models suggest that natural killer (NK) cells play an important role in resistance to viral infections. In this study, we have investigated natural cytotoxicity for the NK-susceptible K562 target cells in 24 patients with acute hepatitis B (AHB) and in 11 with acute non-A, non-B hepatitis (NANBH), using a standard ${ }^{51} \mathrm{Cr}$ release assay. Simultaneously, serum levels of $\alpha$-interferon ( $\alpha$-IFN) were determined by radioimmunoassay. Peripheral blood mononuclear cells showed significantly increased cytotoxicity in patients with AHB at all effector to target cell ratios ranging from $10: 1$ to $80: 1(p<0 \cdot 01)$. Percent specific lysis was significantly higher in patients tested within 20 days of clinical onset compared with those tested during convalescence, in whom cytotoxicity was not statistically different from healthy controls (mean \% cytotoxicity \pm SEM: $20 \cdot 7 \pm 2 \cdot 5$, $34 \cdot 3 \pm 3 \cdot 5,50 \cdot 5 \pm 3 \cdot 7,65 \pm 3 \cdot 2$, and $12 \pm 1$, $21 \cdot 3 \pm 2 \cdot 2, \quad 32 \cdot 3 \pm 3 \cdot 4,46 \cdot 2 \pm 4 \cdot 6$, respectively, $\mathrm{p}<0.01)$. In contrast, patients with NANBH, all studied in the early phase, showed normal cytotoxicity. Serum concentrations of $\alpha$-IFN were normal in both groups of patients. These functional studies support recent data showing increased proportions of lymphoid cells with NK phenotype in the liver infiltrate of patients with AHB. The finding of enhanced cytotoxicity in the early phase of AHB suggests that NK cells may be important in controlling $\mathrm{HBV}$ infection before virus-specific cytolytic $T$ cells become fully operative. Non- $A$ and non-B agents do not generate significant NK activity and this may be one of the factors contributing to frequent progression to chronicity. Serum concen- tration of $\alpha$-IFN was unrelated to NK cytotoxicity, at least in this setting.

W5

Clinical and experimental studies of the influence of ethanol on paracetamol hepatotoxicity

J M TREDGER, HEATHER M SMITH, R B READ, B PORTMANN, R WILlIAMS (Liver Unit, King's College Hospital and School of Medicine \& Dentistry, Denmark Hill, London) Repeated ethanol ingestion is thought to potentiate paracetamol hepatotoxicity while ethanol taken concomitantly with paracetamol may reduce liver damage. Of 247 patients seen at King's College Hospital after paracetamol overdose, alcohol was used in $60(24 \%)$. There was no significant difference in clinical course or outcome between patients consuming alcohol either chronically ( $>80 \mathrm{~g} /$ week), concomitantly with paracetamol or both chronically and concomitantly. In mice, however, ethanol had pronounced effects on paracetamol metabolism and hepatotoxicity evaluated using semi-quantitative histology (scale 0-5). Concomitant ethanol administration prevented liver damage (score: $0 \pm 0$ vs $3 \cdot 2 \pm 0.5$ after paracetamol alone) and decreased the production of toxic paracetamol metabolites. Ethanol had no effect on paracetamol covalent binding in vitro. Chronic ethanol consumption potentiated paracetamol hepatotoxicity (score: $3.9 \pm 0.8$; mortality $27 \%$ $(0 \%$ in control); $p<0.05)$ but did not induce the enzymes catalysing paracetamol intoxication. In mice given ethanol both chronically and concomitantly, paracetamol was mildly hepatotoxic (score: $1 \cdot 1 \pm 0.7 ; 0 \%$ mortality) and the acute metabolic effects of ethanol were reduced. Interindividual variations in dosages of ethanol and paracetamol, in the use of antidotes and in metabolising activity, may explain the differences between our human and animal data.

\section{W6}

Partial hepatectomy enhances proliferation of ectopically sited liver cells in experimental animals

S GUPTA, R JOHNSTONE, Y PRICE, H DARBY, A C SELDEN, AND H J HODGSON (Department of Medicine, Royal Postgraduate Medical School, Hammersmith Hospital, London)
Experimentally, isolated hepatocytes transplanted into the spleen in syngeneic animals eventually proliferate, forming confluent hepatic cord structures. This procedure offers a model for exploring control of hepatocyte growth in a vascular bed not receiving portal blood, and also offers a potential therapy for metabolic disorders. We have explored the effect of partial hepatectomy, the strongest known stimulus to hepatic regeneration, on established ectopic grafts of liver cells in August rats. Ten months after implantation, two groups of animals $(n=6)$ underwent $70 \%$ partial hepatectomy or sham laparotomy. Cell proliferation was assessed 24 hours later by autoradiography, after administration of colchicine and $3 \mathrm{H}$-thymidine. In normal liver, $<2$ cells $/ 1000$ were labelled, compared with 300 cells/1000 in regenerating liver. Ectopic hepatocytes in spleens without the stimulus of partial hepatectomy, were in a state of proliferation shown by a greater labelling index in comparison with normal liver ( 9 cells/ 1000 ), which moderately increased after partial hepatectomy $(20$ cells/1000). These results show that the regenerative stimulus of partial hepatectomy reaches the systemic circulation, and ectopic hepatocytes respond to this stimulus albeit not to the same degree as the liver itself. Either local factors, or the presence of nutrients in portal blood, may account for this difference.

\section{W7}

Can dynamic liver scanning replace liver biopsy in methotrexate patients?

E ANN BINGHAM, M D O'HARA, R FERGUSON, J D LAIRD, D BURROWS, AND M E CALLENDER (Royal Victoria Hospital, Belfast, Northern Ireland) Because methotrexate therapy for psoriasis can produce hepatic fibrosis and cirrhosis without disturbance of serum liver function tests these patients require serial liver biopsy, bridging fibrosis or cirrhosis being a contraindication to the initiation or continuation of methotrexate therapy.

The 'dynamic liver scan' indicates hepatic dysfunction by a reduction in the portal vein contribution to total hepatic blood flow assessed by computer analysis of hepatic and splenic uptake of ${ }^{99} \mathrm{Tc}$-colloid injected intravenously.

Sixty paired dynamic liver scans and liver biopsies were obtained in 46 patients with psoriasis and a single pathologist assessed 
the degree of fibrosis 'blind'. All patients had normal serum liver function tests and normal static isotope scans.

In 54 cases where the biopsy showed no fibrosis or only periportal or pericentral fibrosis the dynamic scan was normal in 44 . In six cases where the biopsy showed bridging fibrosis or cirrhosis the dynamic liver scan was normal in one. Although the predictive value of an abnormal dynamic scan is low at $5 / 15(30 \%)$, the predictive value of a normal dynamic scan is high at $44 / 45(97 \cdot 8 \%)$.

It may thus be possible to reduce liver biopsies by $75 \%$ in psoriasis patients by biopsying only those with an abnormal dynamic liver scan.

\section{W8}

Effects of portasystemic shunting on hepatic haemodynamics in the cirrhotic rat

S A JENKINS, J N BAXTER, P DEVITT, AND R SHIELDS (Department of Surgery, University of Liverpool, Liverpool) The aim of selective portasystemic shunts is to reduce portal pressure while maintaining a satisfactory liver blood flow. As there is little evidence to support the theoretical advantages of selective shunts we compared the effects of different types of portasystemic shunts on hepatic haemodynamics in the cirrhotic rat. Rats with dimethylnitrosamine-induced cirrhosis underwent one of the following shunts: end-to-end portacaval $(n=10)$; side-to-side mesocaval $(n=10)$; mesocaval H-graft $(n=10)$; or splenopancreaticocaval $(n=10)$. Liver blood flow (LBF) and wedged hepatic venous pressure (WHVP) were measured before, immediately after and four weeks following shunting. Immediately following end-to-end portacaval shunting there were significant reductions $(\mathrm{p}<0.05$ Student's $t$ test $)$ in WHVP $(13.9 \pm 0.4$ to $6.5 \pm 0.5 \mathrm{mmHg})$ and LBF (18.6 \pm 1.3 to $10 \cdot 1 \pm 1.7 \mathrm{ml} / \mathrm{min} / 100 \mathrm{~g})$. After side-to-side mesocaval shunting LBF and WHVP fell by approximately the same magnitude. Mesocaval H-grafting preserved liver blood flow to a greater extent $(19.3 \pm 1.2$ to $14.7 \pm 0.9 \mathrm{ml} / \mathrm{min} / 100 \mathrm{~g})$ and reduced WHVP from $12 \cdot 8 \pm 0 \cdot 7$ to $8 \cdot 9 \pm 1 \cdot 1$ $\mathrm{mmHg}$. However, $60 \%$ of the grafts became thrombosed. Most marked preservation of LBF followed splenopancreaticocaval shunting, but the reduction in WHVP was the least, falling from $13 \cdot 8 \pm 0 \cdot 6$ to $10 \cdot 3 \pm 0 \cdot 9 \mathrm{mmHg}$. No further significant changes occurred one month after operation. These results suggest that shunt operations for cirrhosis with portal hypertension which maintain liver blood flow may not decompress the splanchnic circulation as effectively as portacaval shunts.

\section{W9}

Effects of a long acting analogue of somatostatin (SMS 201-995) on hepatic haemodynamics in the pig and on intravariceal pressure in cirrhotic patients

S A JENKINS, J N BAXTER, W A CORBETT, AND R SHIELDS (Department of Surgery, University of Liverpool, Liverpool) SMS 201-995 is a new analogue of somatostatin with a longer biological half life. Furthermore, preliminary studies have shown that SMS 201-995 is more potent than somatostatin in inhibiting glucagon and insulin release and gastric secretion. In view of the greater potency of SMS 201-995 we studied the effects of the analogue on hepatic haemodynamics in the pig and on intravariceal pressure in patients with cirrhosis.

Pigs $(n=6)$, received iv infusions of 250 $\mu \mathrm{g} / \mathrm{h}$ of SMS 201-995. Portal venous flow, hepatic artery flow, portal pressure (PP), systemic blood pressure and cardiac output were measured before and after the infusion of the SMS 201-995. In six patients with cirrhosis, intravariceal pressure was measured before and after iv administration of $50 \mu \mathrm{g}$ SMS 201-995.

In pigs, systemic administration of 250 $\mu \mathrm{g}$ SMS 201-995 significantly reduced PP $(15 \cdot 6 \pm 2 \cdot 4$ to $12 \cdot 3 \pm 2 \cdot 5 \mathrm{mmHg}$ ), portal venous flow and hepatic artery flow. In nine patients with cirrhosis, a bolus injection of $50 \mu \mathrm{g}$ SMS 201-995 significantly $(\mathrm{p}<0 \cdot 05$, Student's paired $t$ test) reduced the intravariceal pressure $(27 \cdot 4 \pm 2.5$ to $15 \cdot 8 \pm 2 \cdot 1 \mathrm{mmHg})$. Furthermore, in one patient undergoing an elective portacaval shunt, the PP was reduced from 29 to 22 $\mathrm{mmHg}$ following iv administration of $50 \mu \mathrm{g}$ SMS 201-995.

These results suggest that SMS 201-995 is effective in lowering PP and may be of value in the control of acute variceal haemorrhage.

\section{W10}

Effect of acute and chronic propranolol administration on antipyrine and paracetamol clearance in chronic liver disease

P C HAYES AND I A D BOUCHIER (University Department of Medicine, Ninewells Hospital and Medical School, Dundee, Scotland) The effect of propranolol on hepatic drug metabolism was examined in 12 patients with chronic liver disease in a placebo controlled double blind study. Clearance of antipyrine and paracetamol which are oxidised and conjugated respectively by the liver was determined before, after $120 \mathrm{mg}$ of propranolol over 24 hours and after six and 12 months of a long acting proporanolol preparation (Inderal LA $160 \mathrm{mg}$ ).

Propranolol therapy caused an acute reduction in antipyrine clearance $(1586 \pm 1177$ to $1349 \pm 1198 \mathrm{ml} / \mathrm{h}$ ) compared with the placebo treated patients $(1202 \pm 534$ to $1444 \pm 229 \mathrm{ml} / \mathrm{h}, \mathrm{p}=0 \cdot 01)$. This reduced clearance, however, did not persist with chronic administration.

The clearance of free paracetamol remained unchanged throughout the treatment period but clearance of total (free and conjugated) paracetamol fell on propranolol from $5824 \pm 2249$ to $4101 \pm 1898$ $\mathrm{ml} / \mathrm{h}$ compared with the placebo group $(4551 \pm 1202$ to $4421 \pm 1148 \mathrm{ml} / \mathrm{h}, \mathrm{p}<0.05)$. The reduced clearance of total paracetamol was probably because of impaired renal excretion of the conjugated metabolite and was accompanied by a rise in serum urea in the propranolol group which became significant after 12 months therapy.

Propranolol therapy therefore has an acute effect on hepatic drug metabolism which is not maintained with chronic administration although renal excretion of drug metabolites may be modified.

\section{W11}

Prophylactic sclerotherapy of oesophageal varices: a preliminary report

D R TRIGER AND A G JOHNSON (University Departments of Medicine \& Surgery, Royal Hallamshire Hospital, Sheffield) Fifty three patients (age 21-70) with cirrhosis and oesophageal varices which had not bled were subjected to wedged hepatic vein pressure (WHVP) measurement. Those with WHVP $\geqslant 12 \mathrm{mmHg}$ were randomised to either sclerotherapy $(n=19)$ or observation $(n=18)$. Groups were comparable with regard to age, aetiology, presence of ascites and Child's grading. Cirrhosis was due to alcohol (21), PBC (16), CAH (10) and others (6). Patients with WHVP $<12$ $\mathrm{mmHg}$ were not randomised $(n=16)$. Patients in any group who subsequently presented with variceal bleeding were treated by sclerotherapy. During a mean follow up of 28 months survival in those receiving prophylactic sclerotherapy was slightly better than in the control group (one year $81 \%$ vs $62 \%$; two years $67 \%$ vs 
$45 \%$ ). This was entirely due to improved survival in the alcoholics receiving sclerotherapy. Survival in the non-randomised group was $89 \%$ at one year and $77 \%$ at two years. Variceal haemorrhage occurred in $6 / 19$ undergoing sclerotherapy, $7 / 18$ in the control group and $3 / 16$ in the nonrandomised group. Size of varices correlated poorly with WHVP and was a poor predictor of haemorrhage. Only $6 / 16$ deaths to date have been due to variceal bleeding. No patient in the nonrandomised group has died of bleeding varices. Preliminary results do not suggest that prophylactic sclerotherapy in nonalcoholic cirrhosis prolongs survival; the beneficial effect in alcoholic cirrhosis might be related to alteration in alcohol consumption. Longer follow up with larger numbers of patients is required.

W12

Prophylactic propranolol therapy in chronic liver disease

P C HAYES AND I A D BOUCHIER (University Department of Medicine, Ninewells Hospital and Medical School, Dundee, Scotland) The effect of long term propranolol (Inderal LA-160 mg) therapy in patients with chronic liver disease was examined in a double blind placebo controlled study. Ninety five patients (41 alcoholic cirrhosis; 18 primary biliary cirrhosis; nine chronic active hepatitis; six cryptogenic cirrhosis and 21 'others'), predominantly Child's group A \& B, took part in the study, 47 in the propranolol and 48 in the placebo group. The groups were well matched for age, sex and severity of liver disease. Twenty five patients were withdrawn because of adverse reactions (13 placebo; 12 propranolol) and 64 patients completed 12 months in the study. Fifteen patients were changed to half strength trial medication. Eleven patients died during the 12 month study period, eight in the placebo group $(17 \%)$ and three in the propranolol group (6.5\%).

Four of the deaths in the placebo group were related to upper gastrointestinal haemorrhage and/or hepatocellular failure compared with none in the propranolol OESOPHAGUS

group. Hepatoma and cardiovascular P1-17

deaths appeared with similar frequency. There was no consistent change in Child's category in either group and the only significant change between the two groups was a fall in serum testosterone on propranolol $(p=0 \cdot 02)$.

Long term propranolol therapy in patients with chronic liver disease is free from serious side effects, does not impair liver function and may improve survival.

W13

Enhanced respiratory burst activity of $C$ parvum elicited hepatic macrophages compared with normal Kupffer cells in the rat

M J P ARTHUR, P KOWALSKI-SAUNDERS, AND R WRIGHT (Department of Medicine, Southampton University Medical School, Southampton) We have previously shown that oxygen derived free radicals promote hepatocellular necrosis in the $C$ parvum/ endotoxin rat model of liver injury. The aim of this study was to compare the respiratory burst activity of normal Kupffer cells (KC) with $C$ parvum $(28 \mathrm{mg} / \mathrm{kg}$, given iv, six days previously) elicited hepatic macrophages (CPHM). These were isolated by collagenase perfusion of the portal vein and purified by centrifugal elutriation. Respiratory burst activity was studied in the 'resting' state and after stimulation with phorbal myristate acetate (PMA) by 1 14C-glucose oxidation via the hexose monophosphate shunt (HMPS). This reflects the production of oxygen derived free radicals.

There was a significantly increased yield of CPHM (mean $\times 10^{6} \pm$ SD, 376 \pm 145$)$ compared with normal KC $(47 \pm 24$, $p<0.001)$. CPHM $(n=8)$ demonstrated enhanced HMPS activity compared with normal KC $(n=8)$ both in the resting state and after PMA stimulation (mean \pm SD, CPHM vs $\mathrm{KC}$ : (a) resting, $3.41 \pm 1.65$ vs $1 \cdot 12 \pm 0.33$, $\mathrm{p}<0.01$ : (b) PMA stimulated $5 \cdot 35 \pm 2.99$ vs $1 \cdot 18 \pm 0 \cdot 31 \quad \mathrm{CPM} \times 10^{3} / \mathrm{mg}$ protein $/ 60 \mathrm{~min}, \mathrm{p}<0.001)$.

The increased number of CPHM and their enhanced respiratory burst activity demonstrate a substantially increased potential for release of cytotoxic oxygen derived free radicals in this model of liver injury.

P1

Abnormal response to distension in oesophageal clearance disorders

G P N KENDALl AND D G THOMPSON (St Mark's and The London Hospital, Lon- don) Motor responses to oesophageal distension were studied in 13 normal subjects and five patients with poor oesophageal clearance without structural abnormality. Oesophageal manometry was performed, both proximal and distal to a balloon sited $10-15 \mathrm{~cm}$ from the gastrooesophageal junction, during five minute periods of balloon inflation (I) and deflation (D). During distension, primary peristalsis was unaltered proximally, but was reduced distally ((D) $7 \cdot 5 \pm 1 \cdot 8$ (mean contractions $/ 5 \min \pm \mathrm{SEM})$ vs (I), $3.9 \pm 1 \cdot 4$, $\mathrm{p}<0.05)$. Secondary peristalsis increased proximal to the distension ((I) $22 \cdot 8 \pm 3 \cdot 9$ vs (D) $2.5 \pm 1.3, \mathrm{p}<0.001)$ with a small distal reduction ((D) $5 \cdot 2 \pm 1 \cdot 5$ vs (I) $3 \cdot 5 \pm 1 \cdot 3$ ). Powerful aboral propulsion of the balloon was induced.

Supine radionucleotide transit was prolonged in all patients. One patient with corkscrew oesophagus, exhibited no distal inhibition. In two patients with hypomotility and two with normal manometry, distension induced neither a proximal increase in contractions nor aboral propulsion of the balloon.

These results show a propulsive response to balloon distension in the normal oesophagus, resembling the in vitro 'peristaltic reflex'. Abnormalities of this response may be a cause of impaired oesophageal clearance. Addition of balloon distension to standard manometry thus appears useful for identifying specific propulsive abnormalities in such patients, particularly when other manometric parameters are normal.

P2

Barium radiology in gastro-oesophageal reflux disease - a reappraisal

R J SEllar, J S DE CAESTECKER, AND R C HEADING (Department of Radiology and Department of Medicine, Royal Infirmary, Edinburgh) Forty six patients (24 with heartburn, 22 with non-cardiac chest pain) were studied using radiology, endoscopy and 24 hour ambulatory intraoesophageal $\mathrm{pH}$ monitoring. Barium radiology was carried out using a 'physiological' method (rolling the patient into the right decubitus position) and a 'compression' method (abdominal binder inflated to $100 \mathrm{mmHg}$ ) to induce reflux. Double contrast oesophograms were also obtained.

Thirty one patients had significant acid reflux by $\mathrm{pH}$ probe. Using this as a standard, the 'physiological' method detected 17, the 'compression' method 23 and 
endoscopy 14 refluxers, with three, five and one false positives respectively. 'Compression' barium was the most sensitive (74\%) and accurate $(71 \%)$, while endoscopy was the most specific ( $93 \%$ ) but least accurate $(58 \%)$ in detecting acid refluxers. Using double contrast barium technique, measurement of the internal diameter of the cardiac oesophagus [(IDCO); $\geqslant 25 \mathrm{~mm}$ abnormal] had a sensitivity of $67 \%$, specificity $91 \%$ and accuracy $74 \%$ in detecting acid refluxers. When the results of 'compression' method and measurement of the IDCO were combined, sensitivity was $87 \%$, specificity $69 \%$ and accuracy $81 \%$. These results suggest that, by combining a test to provoke reflux with a double contrast technique to measure IDCO, barium radiology becomes a sensitive screening test for reflux disease.

\section{P3}

Endoscopic ultrasonography in the investigation of oesophageal strictures

P J SHORVON, R A FROST, W R LEES, AND P B COTTON (Departments of Radiology and Gastroenterology, The Middlesex Hospital, London) Diagnosis of oesophageal strictures is made by barium swallow and endoscopy, but neither method supplies information beyond the mucosa. Endoscopic ultrasonography (EUS) enables assessment of the depth of mucosal lesions and the detection of associated enlarged lymph nodes.

We have carried out EUS on five patients with oesophageal strictures, using the prototype Olympus ultrasonic endoscope which has a $7.5 \mathrm{MHz}$ transducer. Three patients had known oesophageal carcinoma. In one EUS demonstrated a small resectable tumour with no enlarged lymph nodes, confirmed at operation. CT had suggested more advanced disease. In the other two patients the ultrasonic endoscope could not be passed beyond the tumour despite prior endoscopic dilatation in one. Inoperability was demonstrated by visualisation of an extensive tumour extending into the mediastinum and an enlarged subaortic node in one, however. In the other no associated lymph nodes were seen above the tumour, and this was confirmed at operation.

One patient had an oesophageal stricture proximal to the anastomosis of an oesophagogastrectomy two years before. No mucosal abnormality was visible and EUS clearly showed that the stricture was be- cause of compression by surrounding enlarged lymph nodes.

The last patient had a recurring benign stricture despite dilatation. It was decided to diathermy the stricture endoscopically and this was adjudged safe after demonstration of the depth of fibrosis by EUS.

Endoscopic ultrasonography gives unique information about oesophageal strictures and a study is in progress to assess its accuracy in staging of oesophageal cancer.

\section{P4}

Gastro-oesophageal reflux in the irritable bowel syndrome

H L SMART, D NICHOLSON, AND M ATKINSON (University Hospital, Queen's Medical Centre, Nottingham) The irritable bowel syndrome (IBS) and symptomatic gastrooesophageal reflux (GOR) are common gastrointestinal disorders which may be related. To investigate this possibility we examined oesophageal symptoms, endoscopic appearances and undertook oesophageal manometry and $\mathrm{pH}$ recording in 25 consecutive patients with IBS. Weekly symptoms of GOR were significantly more common $(p=0.0003)$ in IBS patients $(52 \%)$ than in age and sex matched controls $(17 \%)$. Similar significant differences were observed for globus and dysphagia. Endoscopy revealed macroscopic evidence of oesophagitis in eight cases and microscopic oesophagitis in a further 11 subjects. Patients with IBS had a significantly lower $(p<0.001)$ lower oesophageal sphincter pressure $\left(14.0 \pm 5.3 \mathrm{cmH}_{2} \mathrm{O}\right.$ (mean \pm standard deviation)) than 25 age and sex matched controls $\left(19 \cdot 4 \pm 5 \cdot 1 \mathrm{cmH}_{2} \mathrm{O}\right)$ without symptoms of GOR. No other significant manometric abnormalities were found. Ambulatory radiotelemetric oesophageal pH monitoring revealed abnormal reflux in 16 of 21 IBS patients. Two of 13 patients with frequent GOR symptoms had a normal pH study, whereas five of eight with infrequent symptoms had an abnormal study.

We conclude that GOR is significantly commoner in IBS and that the lower oesophageal sphincter pressure is significantly lower in IBS. These two findings may be causally related.

\section{P5}

Comparison between three methods of oesophageal pH recording in the diagnosis of gastro-oesophageal acid reflux

G BIANCHI PORRO, F PACE, S BARONI, F PARENTE, AND M LAZZARONI (Gastrointestinal Unit, L Sacco Hospital, Milano, Italy) Oesophageal $\mathrm{pH}$-monitoring is the most sensitive method of detecting and quantitating gastro-oesophageal reflux (GOR). Prolonged $\mathrm{pH}$ testing is usually done as a $\mathbf{2 4}$ hour investigation, in order to take into account postural or other circadian changes in oesophageal $\mathrm{pH}$. The superiority of a 24 hour period of study over shorter tests, however, such as overnight or postprandial test, has not extensively been evaluated in terms of specificity and sensitivity. The purpose of this study is therefore to assess if these two shorter tests retain the diagnostic validity of a 24 hour test. Oesophageal $\mathrm{pH}$ testing was undertaken for 24 hours (with subjects in upright position during the day and supine when retiring) in 20 patients (14 men, six women, mean age 46 years, range 18-64 years) with endoscopic and/or histologic diagnosis of oesophagitis, and in 20 healthy volunteers (nine men, 11 women, mean age 25 years, range 19-42 years) free of any symptoms of GOR. The 24 hour test, as well as the 12 hour and the postprandial ones, yielded no false positive results, with a $100 \%$ diagnostic specificity and a $100 \%$ positive predictive value. Twelve hour and postprandial tests showed a lower diagnostic sensitivity than the 24 hour test $(50 \%$ and $70 \%$ vs $81 \%$ ), respectively).

We conclude that a 24 hour oesophageal $\mathrm{pH}$ monitoring is the most accurate and desirable clinical test of GOR.

\section{P6}

Oesophageal dysmotility after myocardial infarction

J K RAMAGE, M DEAKIN, R EDGE, L JENKINS, AND J G WILliAMS (Departments of Gastroenterology and Nuclear Medicine, RN Hospital, Haslar, Gosport, Hants) The relationship between oesophageal chest pain and the pain of cardiac ischaemia has not yet been fully established.

We have measured the time to clear $90 \%$ of a liquid bolus of ${ }^{99 \mathrm{~m}}$ Technetium sulphur colloid from the oesophagus in 13 patients with ischaemic heart disease (proven on exercise testing or angiography) and 37 patients within 10 days of myocardial infarction (MI). Mean ages were 60.3 years (infarcts) and $54 \cdot 3$ years (IHD). 
Of the patients with recent $\mathrm{MI}, 70 \%$ had abnormal transit times (greater than 17 seconds) and $40 \%$ had transit times greater than 120 seconds. In the ischaemic heart disease group, only one was abnormal at 47 seconds, the rest being less than 17 seconds. There was no correlation of transit time with age, sex, drug therapy with the beta blockers, maximum enzyme rise or site of infarct. Six of the infarct patients were studied again more than two months later. Five of these improved (four returned to normal) and one remained the same at 20 seconds. Four patients had died before they could be restudied - all had acute transit times greater than 120 seconds.

Oesophageal transit time is abnormal after myocardial infarction, indicating dysmotility which may be a cause of episodes of chest pain in the postinfarct patient.

P7

Does dilatation of benign oesophageal strictures (BOS) affect gastro-oesophageal reflux?

R PENAGini, M Al Dabbagh, P $F$ eVAns, I $F$ TROTMAN, AND J J MISIEWICZ (Department of Gastroenterology and Nutrition, Central Middlesex Hospital, London) The role of oesophageal dilatation in the management of peptic oesophageal strictures is well established. Dilatation improves dysphagia but it is not known if it has any effect on gastro-oesophageal reflux.

We studied nine consecutive patients (median 61 years; range 29-77 years, five men), with a BOS, admitted to hospital for oesophageal dilatation. Before and four days after the procedure each patient had a standard meal composed of foods with different consistency to assess dysphagia (score 0-20), a standard swallow with a high density barium suspension to measure the diameter of stricture and 22 hour intraoesophageal $\mathrm{pH}$ monitoring (Synectics system). All dilatations were undertaken using the Celestin dilator to $18 \mathrm{~mm}$. Analysis of results was done with the paired Wilcoxon test.

After dilatation the dysphagia score improved from (mean \pm SEM) $10 \cdot 2 \pm 2 \cdot 0$ to $18.9 \pm 0.7(p<0.01)$, the diameter $(\mathrm{mm})$ of the stricture increased from $7.7 \pm 0.7$ to $9.4 \pm 0.6(p<0.05)$, while $\%$ of time intraoesophageal $\mathrm{pH}$ was $<4$ in the upright, supine and upright + supine position did not change significantly, being respectively $13 \cdot 7 \pm 2 \cdot 7$ vs $20 \cdot 1 \pm 6 \cdot 2,18 \cdot 2 \pm 6 \cdot 2$ vs $19 \cdot 7 \pm 7 \cdot 0$ and $15 \cdot 6 \pm 3 \cdot 2$ vs $19 \cdot 3 \pm 4 \cdot 7$.
We conclude that oesophageal dilatation has a minor effect on radiologically determined bore of BOS, does not make gastrooesophageal reflux worse and has a striking effect on dysphagia.

P8

Computed tomography evaluation of oesophageal carcinoma - intubate or operate?

G P MCENTEE, J P DUIGNAN, D A O'CONNELL, E o'MALLEY, AND D BOUCHIER-HAYES (Mater Misericordiae Hospital, Dublin, Eire) Recent studies have recommended placing peroral endoprostheses in patients with extensive oesophageal carcinoma, thus avoiding unnecessary surgery. This study analysed the role of computed tomography (CT) in evaluating oesophageal cancer with respect to other organ involvement and tumour resectability. Fifty patients with histologically proven disease (17 middle third, 33 lower third) were assessed using CT and subsequently re-assessed at surgery. The findings were correlated by an independent observer and the accuracy of CT determined separately for middle third and lower third lesions.

The accuracy of CT in evaluating organ involvement in middle third tumours was $84 \%$ (false positives five, false negatives four, total observations 51) compared with 94\% for lower third tumours (false positives four, false negatives six, total observations 165). Regarding tumour resectability, the accuracy of CT for middle third tumours was $64.7 \%$ (false positives 0 , false negatives six) compared with $.90 \%$ for lower third lesions (false positives 0 , false negatives three). Tumours deemed resectable on CT were always resectable at surgery, but nine tumours deemed unresectable on CT were in fact resectable at operation.

In conclusion $\mathrm{CT}$ provided useful information pre-operatively regarding extra-luminal tumour spread but was not sufficiently accurate to replace surgery as the final arbiter of tumour resectability.

P9

Oesophageal ulceration after extravasation of sodium tetradecyl sulphate and ethanolamine oleate during endoscopic sclerotherapy

J D R ROSE AND P M SMITH (Department of Gastroenterology, Llandough Hospital, Penarth, $S$ Glam) It is said that $3 \%$ sodiı:m tetradecyl sulphate (STD) pro- duces more ulceration during oesophageal sclerotherapy than 5\% ethanolamine oleate (EO). Twenty cirrhotic patients with oesophageal varices were randomly treated with either EO or STD, and at weekly injection sessions the volume of sclerosant used, the number of radiologically demonstrable extravasations of a contrastsclerosant mixture and the number of ulcers were recorded. The 10 patients in each group were similar, except for their initial variceal score, being higher for those receiving EO (mean 19.9, range 9-32) than those receiving STD (mean $14 \cdot 2$, range $7-20 ; p<0 \cdot 05)$. Two patients from each group did not complete the trial; two requiring oesophageal transection and two dying of hepatic failure.

Four oesophageal ulcers developed after 56 EO extravasations and four after 44 STD extravasations (NS). The mean number of treatments required to obliterate the varices was 6.4 (range 4-10) for EO and 4.5 (range 2-6) for STD but allowing for initial size of the varices, the two agents were equally effective.

We conclude that EO and STD and equally effective for oesophageal sclerotherapy, and, in small quantities, are equally safe.

\section{P10}

Endoscopic sclerotherapy for bleeding gastric varices

YASSIN M YASSIN, MOHAMED S EITA, AND ABDEL MONEIM T HUSSEIN (Gastroenterology Unit, Medical Academy General Hospital, Kobri-El-Kobba, Cairo, Egypt) Gastric varices are often associated with oesophageal varices in portal hypertension, but bleed less frequently and seem to be more difficult to control. The results of endoscopic sclerotherapy to control their bleeding are reported. Total obliteration of all gastric variceal channels was possible in only six of the 35 cases reported $(17 \cdot 1 \%)$, otherwise it was limited to bleeding and distended columns. The main complication was large deep sclerotherapy ulcers in eight cases $(25.7 \%)$ with four deaths; two of uncontrollable haemorrhage and two of rupture. Three more patients died in hospital of intra-procedural cardiac arrest, failure to stop bleeding, and hepatic failure. Bleeding renewed early in five more cases, two only from their gastric varices, and one died eventually of a bleeding antral ulcer. Hospital deaths totalled eight $(22.9 \%)$. During a one year follow up, bleeding recurred in five patients (only one 
from gastric varices); two died. Two more patients died of hepatic failure. The one year survival rate was $65.7 \%$. These results indicate that the serious complications of endoscopic sclerotherapy for bleeding gastric varices including recurrent bleeding are numerous and frequently fatal. We suggest it should be limited to selected cases. Necrotic complications are greater with old age and poor hepatic function.

P11

Flow cytometric analysis of the DNA content of gastric cancer

K C BALLANTYNE, P D JAMES, R A ROBINS, R W BALDWIN, AND J D HARDCASTLE (Departments of Surgery \& Histopathology, University Hospital, Nottingham, and Cancer Research Campaign Laboratories, Nottingham) Abnormal tumour cell DNA content (aneuploidy) is associated with worse prognosis in a variety of cancers and in a recent Japanese study only $17 / 54(32 \%)$ gastric cancers were aneuploid.

Seventy two consecutive patients, median age 67 years (43-88 years) who underwent gastrectomy between 19791982 were studied. DNA content was measured by flow cytometry after disaggregating representative paraffin embedded sections $(2 \times 20 \mu)$ with diaminidophenylindole hydrochloride.

Forty four $(61 \%)$ had a significant population of cells $(<10 \%)$ with an abnormal DNA content (aneuploid). Two separate tumour blocks were examined in 22 cases and concordance found in $17(77 \%)$. No correlation was found between DNA content of primary tumours and histological type, histological grade or pathological stage. Curative resection was carried out in 40 cases. Twelve patients survived over two years and nine remain disease free. The median survival was 17 months $(n=13)$ for diploid tumours and 18 months $(n=27)$ for aneuploid tumours.

We conclude that factors other than tumour cell DNA are responsible for the aggressive nature of gastric cancer. Only $39 \%$ of cancers studied were diploid compared with $68 \%$ of tumours in Japan; this may reflect a difference in the geographical pattern of this disease.

P12

Therapy in symptomatic advanced gastric carcinoma

G RUSTIN, E S NEWLANDS, R H J BEGENT, K D
BAGSHAWE, J L MATTHEWS, AND T COOKE (INTRODUCED BY A PARKINS) (Charing Cross Hospital, Fulham Palace Road, London) Effective therapy is required for symptomatic unresectable or recurrent gastric carcinoma. Following the response of a gastric cancer producing HCG to a drug regimen used in choriocarcinoma, we have assessed its efficiency in further patients.

Twelve patients with advanced gastric carcinoma received a weekly schedule of etoposide, methotrexate and actimomycin D (EMA) alternating with cyclophophasmide and vincristine (CO). Treatment continued for 12 weeks unless there was evidence of progression. In 10 tumours DNA ploidy values were determined by microdensitometry after Feulgen staining and DNA histograms plotted and classified as aneuploid or diploid. Response to chemotherapy was determined symptomatically and by WHO criteria.

Five of the seven patients $(71 \%)$ with objectively assessable disease responded. Only two patients in the total group had progressive disease during the three months of chemotherapy. Of the five patients without assessable disease, symptoms improved with complete pain relief, loss of ascites or relief of obstruction and in two, marked improvement at repeat gastroscopy. By manipulating dosage appropriately, chemotherapy was well tolerated.

Six patients had both measurable disease and DNA ploidy estimations. Four had aneuploid tumours and responded, two patients with diploid profiles had progressive disease.

The initial results using this novel chemotherapy regime suggests it may be of value to patients with gastric carcinoma.

\section{P13}

Local gastric antibodies to Campylobacter pyloridis

B J RATHBone, J I WyATt, B WORSLEy, S SHIRES, L K TREJDOSIEWICZ, R V HEATLEY, AND $M S$ LOSOWSKY (Departments of Medicine and Pathology, St James University Hospital, Leeds, and Department of Microbiology, University of Leeds, Leeds) The association between Campylobacter pyloridis $(\mathrm{CP})$ and active chronic gastritis is now well established. The colonisation of normal gastric mucosa and the subsequent development of gastritis has also been demonstrated. We have previously identified raised circulating IgG and IgA antibodies in $\mathrm{CP}$ + ve patients, but this sys- temic immune response probably has little relevance to events at the mucosal level.

Using immunohistochemical techniques and an enzyme linked immunosorbent assay (ELISA), local antibodies to CP were studied both in gastric biopsies and gastric juice. Twenty two dyspeptic patients were studied: seven out of $13 \mathrm{CP}$ +ve patients had demonstrable $\operatorname{IgA}$ to $\mathrm{CP}$ in their gastric juice, IgM was shown in three + ve patients. No IgG antibody was detected in any patient.

IgG, IgA and IgM antibodies were consistently shown coating the surface of organisms on inflamed mucosae. No antibody labelling could be detected on organisms deep in the gastric pits, however.

The local antibody response to CP does not appear to inhibit bacterial colonisation. One possible reason is that the organisms situated deep in the gastric pits are, by their position, protected from the secreted antibody.

\section{P14}

Ranitidine for stress ulceration: effect of bolus or infusion administration

D L MORRIS, S MARKHAM, A BEACHEY, FIONA HICKS, K SUMMERS, P LEWIS, AND A BYRNE (Department of Surgery, University Hospital Nottingham) Stress ulcers are a common problem in critically ill patients and may largely be prevented by antacid or $\mathrm{H}_{2}$ antagonist administration. The optimal mode of ranitidine administration is unknown. Forty patients who all required respiratory support on our intensive care unit underwent an untreated control period of 12 hours and were then randomly allocated to (1) ranitidine $50 \mathrm{mg}$ six hourly by iv bolus, (2) ranitidine infusions $0 \cdot 125$ $\mathrm{mg} / \mathrm{kg} / \mathrm{hr}$, or (3) ranitidine infusion 0.24 $\mathrm{mg} / \mathrm{kg} / \mathrm{hr}$. Gastric juice was aspirated hourly for $\mathrm{pH}$ measurement. Serum concentrations of ranitidine were assayed by HPLC.

$\mathrm{pH}$ Data is currently available in 20 patients and good $\mathrm{pH}$ control was achieved $(>\mathrm{pH} 4)$ in all but three patients. Sixteen of 140 samples were $<4$ in group 1 compared with two of 100 in group 2, and 19 of 101 in group 3.

High peak serum concentrations (mean $2359 \mu \mathrm{g} / \mathrm{l} \pm 1593$ SD) were seen immediately after bolus administration with a mean trough concentration of $243 \pm 49$ at six hours. In the infusion groups a much steadier serum level was achieved. Mean serum concentrations at four and 12 hours were 280 and $461 \mu \mathrm{g} / \mathrm{l}$ for group 2 and 429 
and $740 \mu \mathrm{g} / \mathrm{l}$ for group 3 .

Ranitidine infusion produces adequate $\mathrm{pH}$ control and has possible pharmacokinetic advantages over bolus administration.

\section{P15}

SK\&F 93574 - Preliminary evaluation of a potent and long-acting parenteral $\mathrm{H}_{2}$ receptor antagonist in man

W L BURLAND, JANE G MILLS, LINDA RICHARDSON, AND KATHIE WAREHAM (Smith Kline \& French Research Ltd, The Frythe, Welwyn, Hertfordshire) SK\&F 93574 is a potent and specific histamine $\mathrm{H}_{2}$-receptor antagonist in animals with a long duration of action. The parenteral administration of an antisecretory compound with such a profile of activity could offer therapeutic advantage in several indications, including (1) the management of patients at risk from developing stress-related lesions of the upper gastrointestinal tract; (2) the reduction of gastric acidity and volume, which are associated with morbidity and mortality in the event of pulmonary aspiration.

Two studies have been conducted in healthy male subjects. Inhibition of the heart rate response to the intravenous injection of impromidine $300 \mathrm{mcg}$ was used to establish an effective dose-range for SK\&F 93574 in man and to examine the time course of the response. Eleven subjects aged 24-41 years were studied on three or four separate occasions when they received doses of 10 to $60 \mathrm{mcg} / \mathrm{kg}$ by 15 minute intravenous infusion: SK\&F 93574 $\geqslant 25 \mathrm{mcg} / \mathrm{kg}$ inhibited the response to impromidine, the effect was dose related and appeared to be maximal after two to three hours. At doses $\geqslant 50 \mathrm{mcg} / \mathrm{kg}$ the increase in heart rate was reduced by at least $50 \% 30$ minutes after the start of the infusion; 20-24 hours after SK\&F 9357450 or $60 \mathrm{mcg} / \mathrm{kg}$ the heart rate response to impromidine was reduced by $48 \%(n=4)$.

SK\&F $935742.5-15 \mathrm{mcg} / \mathrm{kg}$ had no significant effect on impromidine stimulated gastric acid secretion; three hours after the start of the infusion of SK\&F $9357425 \mathrm{mcg} / \mathrm{kg}$ stimulated gastric acid output was reduced by $69-78 \%(n=3)$; within the first hour of the infusion of SK\&F $9357450 \mathrm{mcg} / \mathrm{kg}$ acid output was reduced by 36 to $52 \%(n=4)$ increasing to 96 to $100 \%$ in the second hour with 59 to $80 \%$ inhibition still present during the sixth hour. The iv administration of SK\&F 93574 was well tolerated.
P16

A new role for polyacrylates in gastric mucosal protection

P W DETTMAR, A G LYNN, E C LEACH, AND J G LLOYD-JONES (INTRODUCED BY A ALLEN) (Departments of Pharmacology and Clinical Sciences, Reckitt \& Colman, Hull) The role of polyacrylates in preventing ethanolinduced gastric necrosis and their ability to bind to gastric mucus adherent to the gastro mucosal surface of the rat has been investigated. These studies showed that there was a synergistic effect when the sodium polyacrylate carbomer $934 \mathrm{P}$, which is a high molecular weight non-absorbed polymer, was administered together with the anti-ulcer agent carbenoxolone sodium with a resultant increase in gastric mucosal protection.

The minimum dose of carbenoxolone to significantly protect against the ethanolinduced gastric necrosis was $60 \mathrm{mg} / \mathrm{kg}$ (69.1\% protection, $p<0.01$ ), carbomer possessed only weak mucosal protection activity maximal at $50 \mathrm{mg} / \mathrm{kg}(39.1 \%$, $\mathrm{p}<0.02)$. When $50 \mathrm{mg} / \mathrm{kg}$ carbomer was combined with an inactive dose of carbenoxolone $(5 \mathrm{mg} / \mathrm{kg})$ significant protection $(92.5 \%, \mathrm{p}<0.001)$ was produced - that is, synergism was exhibited.

Alcian blue was used to detect the presence of carbomer binding to mucus adherent on the surface on the rat gastric mucosa. At the above dose carbomer binding increased by $118.9 \%(p<0.001)$ compared with control treatment and persisted for up to five hours.

The gastric mucosal protection afforded by a combination of carbomer and carbenoxolone is currently being clinically evaluated for the treatment of gastritis.

\section{P17}

Early and median term results of vertical banded gastroplasty in the management of morbid obesity

E R T C OWEN, F D BEGGS, AND A E KARK (INTRODUCED BY A G COX) (Department of Surgery, Northwick Park Hospital, and Clinical Research Centre, Harrow, Middlesex) We report the results of 21 cases of vertical banded gastroplasty undertaken with modification of the Mason technique. Essential technical features are exposure, pouch size construction and accurate outlet banding which will be illustrated. At presentation patients were between $30 \%$ and $154 \%$ above their ideal weight (mean $96 \cdot 3 \%$ ).
One death occurred six weeks after leaving hospital from pulmonary embolism, seven patients had minor wound infections, but nine had a cholecystectomy carried out at the same operation. One patient had a wound dehiscence. The average hospital stay was nine days.

The mean follow up period was 12 months. Mean weight loss for all patients during this period was $27 \mathrm{~kg}$ (range 8.5-47 $\mathrm{kg}$ ). At 26 weeks patients were a mean of $57 \%$ above their ideal weight. These figures compare favourably with other forms of gastroplasty.

After weight loss many patients have had cosmetic procedures - a total of 12 operations have been carried out.

We conclude that vertical banded gastroplasty is a relatively safe, simple and reliable procedure. Surgeons performing bariatric surgery should appreciate the inevitable further multiple cosmetic procedures which are necessary following weight loss.

BASIC SCIENCE

P18-34

P18

Gastric mucosal protection by a thromboxane synthesis inhibitor (TXSI)

C J HAWKEY, R P WALT, R T KEMP, B FILIPOWICZ, J DAVIES, AND N K BASKAR (Department of Therapeutics, University Hospital, Nottingham) Prostaglandins (PDs) are protective to gastric mucosa but thromboxane synthesis enhances damage. We have investigated whether the $T \times S I$ dazmegrel affords protection. Male Wistar rats $(200-220 \mathrm{~g})$ were dosed orally with vehicle or dazmegrel 1.5 or $25 \mathrm{mg} /$ rat $(n=8$ all experiments). After two hours they were challenged with sodium taurocholate $100 \mathrm{mM}$ in $\mathrm{HCl} 0.2 \mathrm{~N}$ and mucosal damage subsequently graded 'blind'. Other rats were killed two hours after dosing and $e x$ vivo release of $T \times \mathrm{B}_{2}$ and $\mathrm{PGE}_{2}$ from gastric mucosal fragments measured by radioimmunoassay.

Dazmegrel $1 \mathrm{mg} / \mathrm{rat}$ inhibited $\mathrm{T} \times \mathrm{B}_{2}$ synthesis by $23 \pm 8 \%$ (mean $\pm S E M$, $\mathrm{p}<0 \cdot 05$ ), did not significantly affect $\mathrm{PGE}_{2}$ synthesis $(122 \pm 24 \%$ control) and reduced mucosal damage (median grade 2.5 to 1.5 , $\mathrm{p}<0.05)$. Dazmegrel $5 \mathrm{mg} / \mathrm{rat}$ inhibited $\mathrm{T} \times \mathrm{B}_{2}$ synthesis (by $34 \pm 5 \%, \mathrm{p}<0.0001$ ), did not affect $\mathrm{PGE}_{2}$ synthesis $(102 \pm 16 \%$ control) and reduced mucosal damage 
(grade 2.5 to $1, \mathrm{p}<0 \cdot 01$ ). Dazmegrel 25 $\mathrm{mg} / \mathrm{rat}$ inhibited synthesis of both $\mathrm{T} \times \mathrm{B}_{2}$ (by $46 \pm 7 \%, \mathrm{p}<0.001$ ) and $\mathrm{PGE}_{2}$ (by $27 \pm 9 \%, p<0 \cdot 05)$, without significant effect on mucosal damage (grade $2 \cdot 5$ to 2 ).

Thus, lower doses of dazmegrel selectively inhibit thromboxane synthesis and protect gastric mucosa. At higher doses both selectivity and protection may be lost. Assessment of T $\times$ SI's in man is worthwhile.

\section{P19}

Antigenic determinants of wheat protein in coeliac disease

C O'MAHONEY, C O'FARRELLY, M MANSFIELD, D G WEIR, A WHELAN, AND C F FEIGHERY (Departments of Immunology and Clinical Medicine, St James's Hospital, Dublin, Eire) Wheat protein antibodies are found in patients with untreated coeliac disease (CD). The major antigenic determinants of this antibody response are found in crude gliadin - a complex mixture of alpha, beta, gamma, and omega gliadins. Interest has recently focused on $\alpha$-gliadin, due to its remarkable amino acid sequence similarity to adenovirus 12 - a virus which may be implicated in the aetiology of coeliac disease.

Using two assay systems we tested fractions of crude gliadin (obtained by ion exchange chromatography) with sera from patients with coeliac disease (23) and normal controls (5).

(1) In the enzyme linked immunosorbent assay sera from patients with untreated CD reacted with most of the gliadin fractions. The highest antibody levels were, however, found using the $\alpha$-gliadin fraction.

(2) Crude gliadin and its fractions were further separated on agarose isoelectric focusing and then immunoblotted onto nitro cellulose paper strips. The strips were then incubated with sera from patients and controls. The areas of reactivity were stained by immunoperoxidase. Again, all major antigens were contained in the $\alpha$ gliadin fraction. Finally, a monoclonal antibody to $\alpha$-gliadin reacted to several bands of fractionated $\alpha$-gliadin suggesting the presence of a recurring identical antigenic moiety.

This work confirms that $\alpha$-gliadin is the major antigen of crude gliadin. This may be due to a repeating antigenic site on the molecule. Thus is a susceptible individual, a damaging immune response, first elicited by a viral infection, could be perpetuated by immune activity against cross-reactive $\alpha$-gliadin and cause the enteropathy of coeliac disease.

\section{P20}

Does gastric fundic pH or distension effect ileal absorption?

A BILGE AND J B ELDER (University Departments of Surgery, Manchester Royal Infirmary and University of Keele, Keele) No data are available on the influence of gastric fundic $\mathrm{pH}$ or gastric distension on ileal absorption. Male Sprague-Dawley rats were prepared under general anaesthetic with a $4 \mathrm{~cm}$ ileal loop and the gastric fundus isolated by ligation of the oesophagogastric junction and cross clamping of the antrofundic junction. Five minutes after the introduction of tracer $(100 \mu \mathrm{CiTc}$ $99 \mathrm{~m}$ ) to the ileal loop, $0 \cdot 1 \mathrm{ml}$ portal blood samples from an indwelling cannula were obtained at five minute intervals for 50 minutes. The IVC was cannulated and infused with $0.154 \mathrm{M} \mathrm{NaCl}$ containing $0 \cdot 1 \%$ albumin at $3 \mathrm{ml} / \mathrm{h}$. Thirty four control rats (fasting gastric fundic $\mathrm{pH}(\mathrm{GF} \mathrm{pH})$ $1 \cdot 5-5$, no gastric distension), and four groups each of six rats with GF $\mathrm{pH}$ buffered at $\mathrm{pH} 1 \cdot 2,4,7,9$ and a group with $\mathrm{GF} \mathrm{Ph}$ in the fasting resting range but with the gastric fundus distended by injection of $3 \mathrm{ml}$ air were studied. When GF $\mathrm{pH}$ was held at four ileal tracer absorption increased by $27 \%$ at 10 minutes and $32 \%$ at 15 minutes $(p<0.001)$; when the gastric fundus was distended by air ileal absorption after 15 minutes was $38 \%$ above control $(\mathrm{p}<0 \cdot 001)$. Alkaline GF pH reduced ileal absorption $(p<0 \cdot 01)$. Four weeks after truncal vagotomy and pyloroplasty the increased ileal tracer absorption noted after gastric fundic distension was abolished $(n=5)$, but the effect of intraluminal acid (GF pH, $n=5)$ enhancing ileal absorption remained. These data suggest a humoral effect from the gastric fundus on ileal absorption in the rat.

\section{P21}

Correlations between the acute effects of thioacetamide on hepatic morphology and on hexokinase activity and isoenzymic composition in the rat

M A JEPSON, G M LAWRENCE, AND D G WALKER (INTRODUCED BY R COLEMAN) (Department of Biochemistry, University of Birmingham, Birmingham) In normal adult rat liver, four hexokinase isoenzymes contribute to total glucose-phosphorylating activity. The major, high- $\mathrm{K}_{\mathrm{m}}$ form, glucokinase, constitutes $88 \%$ of the total activity, is entirely cytoplasmic and occurs only in hepatocytes where it has a predominantly perivenous zonal distribution. The remaining, low- $\mathrm{K}_{\mathrm{m}}$, activity is largely confined to non-parenchymal cells. Ten per cent are tightly associated with the outer mitochondrial membrane and up to $70 \%$ are due to type I hexokinase.

During the two to three day period after a single $200 \mathrm{mg} / \mathrm{kg}$ body weight injection of thioacetamide, there is a $300-500 \%$ increase in low $-K_{m}$ hexokinase activity whereas high- $\mathrm{K}_{\mathrm{m}}$ activity decreases to 10 $20 \%$ of control values. Up to $20 \%$ of the raised low $-\mathrm{K}_{\mathrm{m}}$ activity is mitochondrially bound and the type II and type III isoenzymes predominate in both the soluble and the particulate fractions.

Recovery begins three to four days after treatment and low- and high- $\mathrm{K}_{\mathrm{m}}$ activities return to control levels six to seven days later.

The early changes in hexokinase activity correlate with rapidly developing perivenous hepatocytic necrosis and with the proliferation of non-parenchymal, oval cells. The return to normality coincides with the disappearance of the proliferating zones, the reappearance of the original parenchymal cell morphology and the reemergence of normal metabolic zonation patterns.

\section{P22}

Permissive role for the vagus nerves in the genesis of antro-antral reflexes in the anaesthetised ferret

D GRUNDY, D HUTSON, AND T SCRATCHERD (Department of Physiology, The University of Sheffield, Western Bank, Sheffield) An increase in antral motility after distension of the stomach depends, in part, on a vago-vagal reflex activated by mechanoreceptors in the corpus. In the present study we have considered the possible reflex effects of antral distension.

The experiments were carried out on urethane $(1.5 \mathrm{~g} / \mathrm{kg})$ anaesthetised, splanchnectomised ferrets. Antral motility was recorded manometrically from a catheter inserted through the pylorus. Antral distension was achieved by passing saline through a second catheter inserted through the mouth and secured in the antrum by a ligature across the incisura. Antral distension with $5-10 \mathrm{ml}$ of saline increased the amplitude of antral contractions. Vagal blockade, achieved by cooling the cervical 
vagi to $<4^{\circ} \mathrm{C}$, caused a fall in antral tone and attenuated the contractions evoked by antral distension. This might implicate a vagal reflex in the genesis of the evoked contractions. In vagotomised animals, however, close arterial infusions of acetylcholine sufficient to return antral motility to basal levels allowed the reflex to again become manifest. We conclude, therefore, that the increase in antral motility following antral distension is mediated by local reflexes which require a tonic vagal input.

P23

Secretin stimulates gastric mucus barrier thickness without increasing luminal mucus

N J H CARROLL, A ALLEN, AND B H HIRST (Department of Physiological Sciences, Medical School, University of Newcastle upon Tyne) The anaesthetised rat provides a suitable model for studying simultaneous changes in the protective adherent mucus barrier and the output of luminal mucus. Ligated stomachs were perfused via a double lumen orogastric tube, and gastric contents recovered and analysed for mucus glycoprotein. The thickness of the adherent mucus barrier was measured on unfixed gastric mucosal sections.

Secretin, $4 \mathrm{U} / \mathrm{kg} / \mathrm{h}$ iv, caused a significant progressive rise in adherent mucus thickness reaching a maximum median value of $175 \mu \mathrm{m}$ (quartile values 165-230) $(\mathrm{n}=6)$, compared with controls $100 \mu \mathrm{m}(60-130)$ $(n=6)$. Significant increases in adherent mucus thickness were also observed with topical 16,16-dimethyl prostaglandin E2 (dm-PGE2 $5 \mu \mathrm{g} / \mathrm{ml})(44 \%$ increase) and carbachol $(100 \mu \mathrm{g} / \mathrm{kg}$ ip $55 \%$ increase $)$. Luminal mucus glycoprotein output was unchanged following secretin infusion; $0 \cdot 17 \pm 0.02 \quad(n=6) \mathrm{mg} / 30 \mathrm{~min}($ mean \pm 1 SEM) compared with control values of $0.14 \pm 0.02(n=6) \mathrm{mg} / 30 \mathrm{~min}$. In contrast dm-PGE2 resulted in a seven-fold rise in luminal mucus glycoprotein output.

These experiments show a novel stimulatory affect of secretin on gastric mucus barrier thickness. Further, increases in adherent mucus thickness are not necessarily associated with increased luminal mucus output.

\section{P24}

Mechanism for the mucosal protective action of polyacrylate on the gastric mucus barrier

S N E FOSTER, A ALlen, AND J P PEARSON
(Department of Physiological Sciences, University Medical School, Framlington Place, Newcastle upon Tyne) Carbomer $934 \mathrm{P}$, a polyacrylate $\left(3 \times 10^{6}\right)$ acts synergistically with carbenoxolone, protecting against ulceration.

Carbomer $(1-10 \mathrm{mg} / \mathrm{ml})$, when added to gastric mucus glycoprotein (range $0 \cdot 5-10$ $\mathrm{mg} / \mathrm{ml}$ ) in isotonic $\mathrm{pH} 2$ buffer, produced a large synergistic increase in mucus viscosity rising with mucus and carbomer concentration to over $1000 \%$ of the theoretical additive viscosity (mucus/carbomer both at $10 \mathrm{mg} / \mathrm{ml}$ ). Carbomer also caused a smaller synergistic increase in the viscosity of the pepsin degraded glycoprotein (95\% increase).

Pepsin activity at $\mathrm{pH} 2 \cdot 2$ was inhibited by carbomer $(45 \%$ inhibition of albumin hydrolysis at carbomer $4 \mathrm{mg} / \mathrm{ml}$, pepsin 1.0 $\mu \mathrm{g} / \mathrm{ml}$ ). Two methods (centrifugation and ultrafiltration) which measured bound pepsin compared with free showed this inhibition can be explained primarily by reversible binding of pepsin to carbomer. Ft low pepsin concentrations $(0.01-0.4 \mathrm{mg} / \mathrm{ml})$ the percentage bound to carbomer $(4 \mathrm{mg} / \mathrm{ml})$ rose linearly plateauing at higher pepsin concentrations $(1-5 \mathrm{mg} / \mathrm{ml})$. Pepsin binding was also dependent on carbomer concentration - for example, for pepsin 2 $\mathrm{mg} / \mathrm{ml}$, carbomer 4 or $0.4 \mathrm{mg} / \mathrm{ml}$, percentage bound $=73 \%$ and $31 \%$ respectively.

The above results show that carbomer may act in mucosal protection by physically strengthening the mucus barrier and by inhibiting degradation by pepsin.

\section{P25}

Mechanism of acetate absorption in normal rat jejunum

A J M WATSON, M J Kelly, M WILKS, M J G FARTHING, AND P D FAIRCLOUGH (Department of Gastroenterology and Department of Bacteriology, St Bartholomew's Hospital, London) Acetate has been proposed as an alternative to bicarbonate in oral rehydration solutions for correction of acidosis due to diarrhoeal disease. Our previous experiments show that in the normal rat jejunum acetate, like glucose, stimulates sodium and water absorption. Although acetate is absorbed at a similar rate to glucose, its transport mechanism is still unclear. Studies of the absorption kinetics, competition with propionate, and ion dependency have therefore been performed using steady state perfusion of the normal rat jejunum in situ. Acetate absorption from isotonic solutions containing
5-150 mmol/l of acetate apparently followed saturation kinetics (Vmax $=13$ $\mu \mathrm{mol} / \mathrm{min} / \mathrm{g}, \mathrm{Km}=47 \mathrm{mmol} / 1)$. Competition experiments showed that acetate absorption from a $30 \mathrm{mmol} / \mathrm{l}$ solution was inhibited by $70 \mathrm{mmol} / \mathrm{l}$ propionate $(5.2 \pm 0.3 \mu \mathrm{mol} / \mathrm{min} / \mathrm{g}$ vs $2.9 \pm 0.3 \mu \mathrm{mol} /$ $\mathrm{min} / \mathrm{g} ; \mathrm{p}<0.01)$. Absorption of propionate from a $70 \mathrm{mmol} / \mathrm{l}$ solution was also inhibited by $80 \mathrm{mmol} / \mathrm{l}$ acetate $(9.9 \pm 1.5 \mu \mathrm{mol} /$ $\mathrm{min} / \mathrm{g}$ vs $5.6 \pm 0.4 \mu \mathrm{mol} / \mathrm{min} / \mathrm{g} ; \mathrm{p}<0.01)$. Ion substitution experiments (sulphate replacing chloride, and choline and lithium replacing sodium) failed to show chloride or sodium dependence in this model.

Demonstration of saturation kinetics and inhibition by propionate are compatible with carrier-mediated transport of acetate by the rat small intestine.

\section{P26}

Secretion of adherent mucus gel by amphibian gastric mucosa in vitro

J P KEOGH, S MCQUEEN, A ALLEN, AND A GARNER (Department of Physiological Sciences, Medical School, Newcastle, and ICI Pharmaceuticals Division, Alderley Park, Macclesfield) The secretion of adherent mucus gel has been studied in vitro using gastric mucosal sheets (mounted in Ussing chambers) and stomach sacs (oesophageal intubated, pylorus ligated) from Rana temporaria.

In control mucosal sheet preparations mucus thickness increased over one hour by 2.7 fold (from mean $72 \pm 11 \mu \mathrm{m}$ to $92 \pm 16 \mu \mathrm{m})$, while in the stomach sacs no increase was observed (from $83 \pm 6 \mu \mathrm{m}$ to $71 \pm 8 \mu \mathrm{m})$. This may be related to mucosal stretching when mounted in the Ussing chambers since distension of stomach sacs by applying a luminal hydrostatic pressure $(3 \mathrm{~cm})$ caused a $2 \cdot 2$ fold increase in mucus thickness after one hour.

16,16-dimethyl prostaglandin $\mathrm{E}_{2}\left(10^{-5}\right.$ M) significantly stimulated mucus thickness after one hour on mucosal sheets and stomach sacs (dose dependent) by 1.4 fold and 2.7 fold respectively over the corresponding one hour control values. Carbachol $\left(10^{-3} \mathrm{M}\right.$, nutrient side) also significantly increased adherent mucus thickness by 1.4 fold in mucosal sheet preparations, a response inhibited by atropine. Addition of cimetidine $\left(10^{-4} \mathrm{M}\right.$, nutrient side $)$ did not affect mucus thickness on mucosal sheets after one hour although acid secretion was inhibited.

These results are the first demonstration in vitro of stimulated secretion of adherent 
mucus by prostaglandins, cholinergic mechanisms and mucosal distension.

\section{P27}

Effects of eicosanoids on amphibian duodenal luminal alkaline secretion in vitro

J P KEOGH, A M STANIER, J R HEYLINGS, A ALLEN, AND A GARNER (Department of Physiological Sciences, Medical School, Newcastle, and ICI Pharmaceuticals Division, Alderley Park, Macclesfield) Epithelial bicarbonate secretion is believed to be an important mechanism in duodenal mucosal protection against luminal acid. We have compared the stimulatory effects of various eicosanoids on bicarbonate secretion in the duodenum in vitro.

Segments of Rana catesbeiana proximal duodenum were mounted as cylinders in glass chambers and rates of luminal alkalinisation measured by continuous back titration to $\mathrm{pH} \mathrm{7.4}$. Cumulative dose responses were determined to serosal administration of eicosanoids. Prostaglandin $\mathrm{E}_{2}(1 \mu \mathrm{m})$ was administered at the end of each experiment to elicit a maximal response in order to standardise responsiveness between individual mucosae. The following agents (10 $\mu \mathrm{m})$ produced significant increases in alkaline secretion, expressed as percentage of $\mathrm{PGE}_{2}$ maximal response: $\mathrm{PGE}_{1}(100 \%)$, $\mathrm{PGI}_{2}(68 \%), \mathrm{PGF}_{2 \alpha}(64 \%), \mathrm{PGD}_{2}(62 \%)$, arachidonic acid $(60 \%) 6$ keto-PGF 1 o $(55 \%)$, leukotriene ${ }_{D_{4}}(48 \%)$, PGA $_{2}$ $(48 \%)$, thromboxane $\mathrm{B}_{\mathrm{B} 2}(42 \%)$. Linoleic acid and leukotriene ${ }_{B 4}$ (lum) were inactive. Indomethacin (lum) attenuated arachidonic acid response and enhanced that to $\mathrm{PGE}_{2}$.

While prostaglandins of the $\mathrm{E}$ series are the most potent stimulants of $\mathrm{HCO}_{3}^{-}$secretion a variety of other eicosanoids are also active.

\section{P28}

Effects of protein kinase $\mathbf{C}$ activation on intestinal fluid transport and blood flow

J D FONDACARO, J S STEFANKIEWICZ, L S HENDERSON, AND A SJOQVIST (Smith Kline and French Laboratories, Philadelphia, $P A$, USA) Studies were designed to examine the effects of protein kinase $C$ (PKC) stimulation on fluid transport and blood flow in the small intestine of the anaesthetised cat. The phorbol ester $4 \beta$ phorbol 12,13-dibutyrate (PDB) was used to activate PKC. Intraluminal administration of PDB into a segment of isolated small bowel produced a copious intestinal secretion and a concomitant mesenteric hyperaemia. Net fluid movement in the intestine was converted from absorption in the control state to secretion following PDB. Intravenous atropine reduced PDBinduced secretion by $56 \%$; clonidine abolished the remaining secretory response. Intra-arterial administration of PDB produced intense vasoconstriction. Furthermore, intraluminal PDB caused increased segmental contractions in the bowel segment, which were totally inhibited by atropine. In Ussing chamber studies of the rat ileum, PDB increased short-circuit current, inhibited net $\mathrm{Na}^{+}$and $\mathrm{Cl}^{-}$absorption and increased serosal-to-mucosal $\mathrm{Cl}^{-}$flux. These studies demonstrate that stimulation of PKC produces a full secretory response in the small intestine. Secretion is likely to be a result of inhibition of $\mathrm{Na}^{+}$and $\mathrm{Cl}^{-}$ absorption and stimulation of electrogenic $\mathrm{Cl}^{-}$secretion. Evidence suggests that this secretion is accompanied by a metabolic hyperaemia. We propose that PKC plays an important role in the regulation of intestinal fluid transport.

\section{P29}

Duodenal brush border membrane $\mathrm{HCO}_{3}^{-}$ ATPase, implicated in $\mathrm{HCO}_{3}^{-}$secretion is an expression of alkaline phosphatase

J M WILKES, A GARNer, AND $T$ J PETERS (Clinical Research Centre, Watford Road, Harrow, Middx, and ICI Pharmaceuticals plc, Mereside, Alderley Park, Macclesfield) $\mathrm{HCO}_{3}^{-}$-activated ATPase has been implicated in duodenal $\mathrm{HCO}_{3}^{-}$-secretion, an important process in mucosal protection against acid. Rat duodenal brush border membrane (BBM) was isolated by $\mathrm{Ca}^{2+}$ precipitation, forming tightly sealed rightside-out vesicles capable of $\mathrm{Na}^{+}$-dependent glucose transport. The BBM was enriched 16 -fold in $\alpha$-glucosidase, with a $30 \%$ recovery. $\mathrm{HCO}_{3}^{-}$-ATPase was enriched seven-fold, confirming an association with the BBM. The activity was strongly inhibited by $10 \mathrm{mM}$ L-phenyl-alanine, an inhibitor of alkaline phosphatase.

$\mathrm{BBM} \mathrm{HCO}_{3}^{-}$-ATPase, solubilised in Triton $\mathrm{X}-100$, was subjected to anion exchange, gel exclusion and phenyl boronate column chromatography. In all cases $\mathrm{HCO}_{3}^{-}$-ATPase co-eluted with alkaline phosphatase. A number of detergents used over a range of concentrations failed to show significant latent $\mathrm{HCO}_{3}^{-}$-ATPase in intact BBM vesicles. Brush border membrane alkaline phosphatase shows similar activation by $\mathrm{HCO}_{3}^{-}$as $\mathrm{Mg}^{2+}$-dependent ATPase activity. Detergent solubilised duodenal $\mathrm{BBM} \mathrm{HCO}_{3}^{-}$-ATPase therefore appears to be an expression of alkaline phosphatase activity.

\section{P30}

Site of kinin action in the intestine

G WARHURST, M LEES, N HIGGS, AND L A TURNBERG (Department of Medicine, Hope Hospital, University of Manchester School of Medicine, Salford) Kinins as mediators of the inflammatory response are potent secretagogues and may, therefore, be important in secretory diarrhoea associated with inflammatory diseases. Their mechanism of action involves an increase in the production of prostaglandins. We have examined the cellular site of these actions by studying the influence of kallidin on isolated rat enterocytes and subepithelial tissues. Kallidin increased cyclic AMP concentrations in a dose-dependent manner in whole mucosa (epithelium + subepithelial tissue) $(4 \cdot 11 \pm 0.52$ in control tissues to $9 \cdot 85 \pm 0.81$ at $10^{-5} \mathrm{M}$ and $12.5 \pm 1.56$ at $10^{-4}$ $\mathrm{M} \mathrm{pm} / \mathrm{mg}$ protein, $\mathrm{n}=5$ ). Kallidin did not, however, influence cyclic AMP concentrations in isolated epithelial cells alone. Prostaglandin $E_{2}$ and forskolin, however, did stimulate cyclic AMP concentrations in whole mucosa and epithelial cells. Kallidin stimulated a 30 -fold increase in prostaglandin $E_{2}$ production in whole mucosa within one minute $(0.036 \pm 0.02$ in control tissues and $1 \cdot 18 \pm 0 \cdot 12 \mathrm{ng} / \mathrm{min}$ after $1 \times 10^{-6}$ $\mathrm{M}$ kallidin). Prostaglandin release was partially inhibited by the removal of $\mathrm{Ca}^{2+}$ from the bathing medium. Kallidin failed to stimulate prostaglandin $\mathrm{E}_{2}$ production in suspensions of epithelial cells alone. We conclude that kinins raise prostaglandin production by subepithelial tissues and that the prostaglandins then activate epithelial cell adenylate cyclase and cyclic AMP production so leading to ion secretion.

\section{P31}

Effect of electrical field stimulation on bicarbonate secretion by isolated amphibian duodenum

J R CRAMPTON, L C GIBBONS, AND W D W REES (Department of Medicine, Hope Hospital, University of Manchester School of Medicine, Salford) Electrical field stimulation (EFS) is a technique used to provoke release of neurotransmitters from endogenous neurones in both gut and exocrine 
glands. Using an in vitro chamber preparation, the effect of EFS on bicarbonate secretion by a $2 \mathrm{~cm}$ segment of bullfrog (Rana catesbeiana) proximal duodenum has been examined. Repetitive trains of impulses were passed longituding through the mucosa by a pair of plantinum electrodes in contact with the epithelium. Preliminary experiments established thresholds of pulse wavelength $(0.5 \mathrm{~ms})$, voltage $(50 \mathrm{~V})$ and frequency $(5 \mathrm{~Hz})$ below which no change in secretion occurred. A stimulus of one train per second with train length of $0.5 \mathrm{~s}$ containing square waves of 2 ms duration and $100 \mathrm{~V}$ amplitude at a frequency of $10 \mathrm{~Hz}$ was found to give an increase in the rate of alkali secretion of $50 \pm 28 \% \quad$ (mean $\pm S E, n=5, p<0.005)$. With cessation of stimulation secretion returned to basal levels. Repeat stimulation produced a similar response for as long as the tissue remained viable. Addition of the specific neurotoxin tetrodotoxin $\left(10^{-6}\right.$ $M)$ reduced the secretory response to EFS by $68 \pm 18 \%$ (mean $\pm S E, n=5, p<0.005)$ indicating that the mode of action is primarily related to excitation of endogenous neurones and may be due to release of neurotransmitter. This study shows that EFS is likely to prove a useful method of determining the role of enteric neurones in the control of bicarbonate secretion.

\section{P32}

Cisapride inhibits the secretory action of serotonin (5-HT) in mammalian small intestine

K J MORIARTY, N B HIGGS, M WOODFORD, G WARHURST, AND L A TURNBERG (Department of Medicine, Hope Hospital, University of Manchester School of Medicine, Salford) Cisapride is a synthetic drug which stimulates gastrointestinal motor activity in animals and man. This effect may be mediated in part by inhibition of serotonin (5-HT). Furthermore, cisapride has been shown to bind in vitro to type 2 serotonin receptors. We examined the influence of cisapride on ion transport across intestinal mucosa in vitro and studied its effect on the action of 5-HT. Segments of ileum of male Sprague-Dawley rats were stripped of muscle layers and mounted in flux chambers. The addition of cisapride $\left(5 \times 10^{-5} \mathrm{M}\right)$ to the mucosal and serosal aspects of the mucosa had no effect on the short-circuit current, transmural potential difference, resistance or sodium and chloride fluxes across the mucosa. The application of serotonin $\left(10^{-5} \mathrm{M}\right)$ to the serosal aspect of the mucosa caused a rapid increase in short-circuit current and potential difference. Cisapride, however, inhibited this response in a dose-dependent manner and blocked it completely at a concentration of $5 \times 10^{-5} \mathrm{M}$. Serotonin $\left(5 \times 10^{-5} \mathrm{M}\right.$ serosally) increased serosal to mucosal flux of chloride from $12 \cdot 6 \pm 0.8$ to $15 \cdot 2 \pm 0.6$ $\mu \mathrm{mol} / \mathrm{cm}^{2} / \mathrm{h}(\mathrm{p}<0 \cdot 025)$, thus reducing net chloride absorption from $4.65 \pm 0.81$ to $1.49 \pm 1.04 \mu \mathrm{mol} / \mathrm{cm}^{2} / \mathrm{h} \quad(\mathrm{p}<0.05)$. This effect was completely blocked by cisapride $\left(5 \times 10^{-5} \mathrm{M}\right)$. In summary, cisapride inhibits the secretory action of 5-HT in the rat small intestine, possibly by blocking type 2 serotonin receptors.

\section{P33}

Is cholera toxin-induced intestinal secretion mediated via a neurogenic mechanism?

K J MORIARTY, N B HIGGS, M WOODFORD, AND L A TURNBERG (Department of Medicine, Hope Hospital, University of Manchester School of Medicine, Salford) Cholera toxin is thought to stimulate intestinal secretion by direct activation of mucosal adenylate cyclase. Lundgren and coworkers, however, provide evidence that cholera toxin stimulates secretion in vivo indirectly via enteric neural reflexes. We examined this hypothesis further by studying the influence of neuronal blockade on cholera toxin-induced changes in fluid transport across rabbit ileum in vitro. Mucosa, stripped of muscle layers, was mounted in flux chambers and crude cholera toxin ( $1 \mu \mathrm{g} / \mathrm{ml}$ mucosally) caused a delayed but sustained rise in the shortcircuit current and electrical potential difference (PD). The nerve blocking drug, tetrodotoxin $\left(10^{-7} \mathrm{M}\right.$ and $5 \times 10^{-6} \mathrm{M}$ serosally), failed to influence the subsequent response to cholera toxin and addition of tetrodotoxin at the peak response to cholera toxin also had no effect. That tetrodotoxin could block neurallymediated secretagogues was confirmed by the demonstration that the short-circuit current and PD responses to neurotensin $\left(10^{-7} \mathrm{M}\right)$ were blocked by tetrodotoxin $\left(5 \times 10^{-6} \mathrm{M}\right)$. Furthermore, the response to cholera toxin of segments of ileum, which included circular and longitudinal muscle layers as well as enteric neurones, was not influenced by tetrodotoxin. An analysis of sodium and chloride flux responses to cholera toxin in the presence and absence of tetrodotoxin suggested that the effects of cholera toxin on ion secretion were not inhibited by neuronal blockade.
We conclude that cholera toxin-induced intestinal secretion in vitro is not mediated via a neurological reflex arc.

\section{P34}

Electrophysiological recording along the crypt-villus axis of rat ileum in vitro

C P STEWART AND L A TURNBERG (Department of Medicine, Hope Hospital, University of Manchester School of Medicine, Salford) In this study, surface epithelial cells at different sites on the crypt villus axis were impaled with micro-electrodes under visual control. Using an in vitro preparation of stripped rat ileum at $31^{\circ} \mathrm{C}$, the middle and basal third of the villus were punctured, as well as cells at the crypt openings and at a short distance within the crypt. In glucose-free medium, transmural potential difference $\left(\mathrm{V}_{\mathrm{ms}}\right)$ declined with time to $<1 \mathrm{mV}$. The brush-border membrane potential $\left(\mathrm{V}_{\mathrm{a}}\right)$ was $45.9 \pm 4.4 \mathrm{mV}$ $(n=7)$ in mid- and $52.8 \pm 1.7 \mathrm{mV}(\mathrm{n}=25)$ in base-villus cells, whereas at the crypt opening and within the crypt itself, $\mathrm{V}_{\mathrm{a}}$ was $58.2 \pm 2.0 \mathrm{mV}(\mathrm{n}=23)$ and $59.2 \pm 2.8 \mathrm{mV}$ $(n=5)$ respectively. Tissue resistance $\left(R_{T}\right)$ was $100 \pm 11 \cdot 2 \Omega \mathrm{cm}^{2}(\mathrm{n}=10)$, and fractional resistance $\left(\Delta \mathrm{V}_{\mathrm{a}} / \Delta \mathrm{V}_{\mathrm{ms}}\right)$ was $0.61 \pm 0.05$ $(n=15)$, indicating that more than half of $R_{T}$ resides in the brush-border membrane. The response to $10 \mathrm{mmol} / \mathrm{l} \mathrm{D}$-glucose was assessed during some impalements. Serosal glucose had no effect on the above parameters, but mucosal addition caused a partial depolarisation of $\mathrm{V}_{\mathrm{a}}$ in some villus cells but not in crypt openings. $\Delta \mathrm{V}_{\mathrm{a}} / \Delta \mathrm{V}_{\mathrm{ms}}$ and $R_{T}$ did not change significantly. The results show that it is possible to characterise transporting epithelial cells along the crypt-villus axis in rat small intestine by means of electrophysiological recordings.

SMALL BOWEL

P35-51

\section{P35}

Osteoporosis in patients with inflammatory bowel disease

D JUDD, W EVANS, E O CRAWLEY, C EVANS, J RHODES, AND J E COMPSTON (Departments of Gastroenterology, Radiology and Medical Physics, University Hospital of Wales, Heath Park, Cardiff) The prevalence of oesteoporosis in patients with inflamma- 
tory bowel disease (IBD) has not been accurately established. Using single photon absorptiometry of the radius and vertebral quantitative computerised tomography to measure bone mineral content (BMC) we have determined the prevalence of cortical and trabecular osteoporosis in 58 patients (25 men) with large bowel $(n=17)$ or small bowel $(n=14)$ IBD.

Osteoporosis defined as $>2$ SD below mean BMC was shown in 13 patients (eight women) with mean age 43 years (range 21-77 years). Four had both cortical and trabecular osteoporosis, six cortical only, and three trabecular only. Of these, two women aged 33 years and 38 years had severe clinical osteoporosis with loss of height and multiple vertebral fractures: three other patients had one or more vertebral fractures. All 13 patients with low BMC had small bowel IBD with previous resections and 10 had received large doses of steroids ( $>10 \mathrm{~g}$ total). Three of the seven premenopausal females with low BMC were amenorrhoeic.

In this group of patients with IBD, cortical and/or trabecular osteoporosis was present in $22 \%$, with severe clinical disease in two young women. Patients with small bowel IBD and previous resections who have received large doses of steroids appear to be mainly at risk. Within this category, premenopausal women with amenorrhoea may develop severe clinical osteoporosis and oestrogen replacement therapy should be considered in such patients.

\section{P36}

Effect of codeine and loperamide on carbohydrate malabsorption in postvagotomy diarrhoea (PVD)

J D O'BRIEN, D G THOMPSON, H IBBOTSON, W R BURNHAM, AND E WALKER (Departments of Gastroenterology, The London and Oldchurch Hospitals, London) Codeine phosphate $(60 \mathrm{mg})$ is more effective than loperomide $(4 \mathrm{mg})$ in reducing the speed of upper gut transit in normal subjects $(\mathrm{Br} J$ Clin Pharmacol 1985; 19: in press). Our aim was to examine the effects of these drugs in patients with diarrhoea after truncal vagotomy, a disorder in which symptoms are associated with rapid upper gut transit and nutrient malabsorption.

Orocaecal transit was studied in seven patients and in seven matched controls by exhaled breath hydrogen $\left(\mathrm{H}_{2}\right)$ sampling after a $20 \mathrm{~g}$ lactulose containing meal. Control transit was $63.3 \pm 2.9 \mathrm{~min}$ (mean \pm SEM) $v s$ PVD, 28.1 $\pm 1 \cdot 5 \mathrm{~min}$, $\mathrm{p}<0 \cdot 01)$

The functional absorptive capacity for carbohydrate was then studied using a meal comprising $50 \mathrm{~g}$ glucose in $250 \mathrm{ml}$ water. No control showed a breath $\mathrm{H}_{2}$ rise, indicating complete absorption. In contrast, all patients showed a breath $\mathrm{H}_{2}$ rise ( $>20 \mathrm{ppm}$ ) with subsequent diarrhoea, indicating incomplete absorption. Repeat studies with barium added to the meal and caecal screening, confirmed that this $\mathrm{H}_{2}$ rise was due to rapid transit, not bacterial overgrowth. Prior administration of codeine $(60 \mathrm{mg})$ abolished the $\mathrm{H}_{2}$ rise and diarrhoea in all patients, indicating improved glucose absorption. Loperamide (4 mg) had no effect. After one month codeine therapy, all patients reported symptomatic relief. Codeine thus seems to be a more rational therapy than loperamide for reducing carbohydrate malabsorption in PVD.

\section{P37}

Galanin in gut peptide secreting tumours and its diagnostic value in phaeochromocytomas

F E BAUER, G W HACKER, T E ADRIAN, J M POLAK, AND S R BLOOM (Departments of Medicine and Histochemistry, RPMS, Hammersmith, London) The new intestinal peptide galanin, originally isolated from porcine gut with potent biological actions on smooth muscle contractility and inhibition of insulin secretion, was found in significant quantities in the gastrointestinal tract of different species including man. Therefore, we investigated galanin-IR in gut peptide secreting tumours and phaeochromocytomas with a newly developed radioimmunoassay with both $\mathrm{N}$ and C-terminal directed antibodies and by immunocytochemistry. In none of the pancreatic endocrine tumours was galanin significantly raised compared with normal pancreatic tissue. In phaeochromocytomas, however, the galanin content was significantly higher (tissue: $21 \pm 2.3 \mathrm{pmol} / \mathrm{g}$, $\mathrm{n}=11, \overline{\mathrm{x}} \pm \mathrm{SEM}$, plasma: $161 \pm 21.5 \mathrm{pmol} / \mathrm{l}$, $n=6$ ) than those of normal adrenals (2.6 $\pm 0.9 \mathrm{pmol} / \mathrm{g}, \mathrm{n}=4)$ and plasma of volunteers $(<50 \mathrm{pmol} / \mathrm{l}, \mathrm{n}=6)$. Gel chromatography and HPLC of adrenal and phaeochromocytoma extracts revealed two molecular forms compared with one form in the porcine standard. The C-terminal antibody did not detect human galanin suggesting C-terminal molecular differences. Immunocytochemistry localised
galanin-IR to cells in phaeochromocytomas. There is no evidence that galaninIR is produced by peptide secreting gastrointestinal tumours. The raised galanin levels in phaeochromocytomas, however, may be responsible for some symptoms that is, abdominal pain, constipation and hyperglycaemia. Plasma galanin could be a marker in the diagnosis of these tumours.

P38

Comparison of modular elemental and polymeric liquid diets on growth, nitrogen (N) balance, $\mathrm{N}$ wastage, faecal residue and hepatic lipid in rats

R H R PARK, A DUNCAN, G MITCHELL, W EAST, AND R I RUSSELL (Gastroenterology Unit, Royal Infirmary, Glasgow) New modular enteral liquid diets offer greater flexibility of nutritional therapy. A controlled metabolic study was carried out to investigate their metabolic and nutritional effects. Vivonex HN (VHN), enteral 400 (E), elemental 028 (ELE), pepdite (P), MCT pepdite (MCT), and control rat chow (Oxoid 41B) (O), differing in composition, were fed to 36 rats (six rats in each group) for 28 days in isocaloric amounts $(62 \mathrm{kcal}$ $(260 \mathrm{~kJ})$ per rat per day). Mean weight gain (mean \pm SEM \% of initial weight) was less

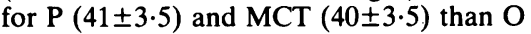
$(59 \pm 4 \cdot 3) \quad(\mathrm{p}<0.01)$, VHN $(52 \pm 3 \cdot 3)$ $(\mathrm{p}<0.05$ and $E(68 \pm 3.4) \quad(\mathrm{p}<0.001)$. N balance (mmol/24 h) was significantly increased with VHN $(26 \cdot 7 \pm 1 \cdot 37)$ compared with E $(17.4 \pm 1.5) \quad(\mathrm{p}<0.001)$, ELE $(14.7 \pm 0.56) \quad(p<0.001), \quad P \quad(15.5 \pm 0.81)$ $(p<0.001)$ and MCT $(16.9 \pm 0.99)$ $(\mathrm{p}<0.001)$. No significant differences were observed for mean $\mathrm{N}$ wastage ( $\mathrm{N}$ excretion as $\%$ intake). Faecal residue $(\mathrm{mg} / 24 \mathrm{~h}$ dry faecal weight) for VHN (203 \pm 5$)$ was reduced significantly compared with ELE $(304 \pm 8)(\mathrm{p}<0.001), P(386 \pm 22)(\mathrm{p}<0.001)$ and MCT $(267 \pm 5) \quad(p<0 \cdot 001)$. Hepatic lipid (mg/g liver) was increased significantly with the elemental diets VHN and ELE $(57 \cdot 8 \pm 4 \cdot 6$ and $56 \cdot 5 \pm 5 \cdot 1$ respectively) compared with the polymeric diets $E$ $(41.4 \pm 1.8) \quad(p<0.01)$ and $P(42.7 \pm 4.5)$ $(p<0.05)$. New modular enteral liquid diets do not offer extra nutritional advantages and VHN remains the diet of choice for very low faecal output.

\section{P39}

$\alpha$-1-antitrypsin (AT) and 51-CR-albumin (CrA) in the assessment of faecal protein loss 
E M M QUIGLEY, I N ROSS, M R HAENEY, I B HOLBROOK, AND M N MARSH (University Departments of Medicine and Chemical Pathology and Department of Immunology, Hope Hospital, Salford) Although faecal AT has been proposed as a reliable measure of enteric protein loss the accuracy and reproducibility of this method remains uncertain. Our aim was to compare AT excretion with the standard ${ }^{51} \mathrm{Cr}$ labelled albumin technique. $\alpha$-1-antitrypsin and $\mathrm{CrA}$ excretion were compared in: (i) single 24 hour stool samples from 20 normal subjects, (ii) five day stool collections pooled from each of 35 patients with various GI diseases, and (iii) eight serial 24 hour collections from each of seven patients with small intestinal disease. Faecal $\mathrm{CrA}$ was expressed as \% injected dose excreted during the collection period. $\alpha$-1-antitrypsin was measured by single radial immunodiffusion and expressed as: (i) faecal excretion ( $\mathrm{mg} / \mathrm{g}$ dry weight or $\mathrm{mg} / \mathrm{ml}$ faeces), and (ii) intestinal clearance $(\mathrm{ml} \mathrm{AT} / 24 \mathrm{~h})$. Mean values for excretion and 24 hour intestinal clearance of AT in normal subjects were $0.7 \mathrm{mg} / \mathrm{g}$ dry weight (range $0 \cdot 1-6), 0 \cdot 3 \mathrm{mg} / \mathrm{ml}$ faeces $(0 \cdot 03-2 \cdot 3)$ and $5.2 \mathrm{ml} / 24 \mathrm{~h}(0.4-73.4)$ respectively. In the GI patients sensitivity and specificity of AT excretion in defining excess protein loss were $44 \%$ and $88 \%$ respectively, compared with $\mathrm{CrA}$. Measuring AT excretion in serial 24 hour collections did not improve its accuracy indicating that sampling error alone cannot explain the poor sensitivity. We conclude that while excretion of AT is significantly increased in patients with various gastrointestinal diseases, there is considerable overlap with the control range so that correlation with $\mathrm{Cr} A$ loss is extremely weak $\left(r^{2}: 0 \cdot 02-0 \cdot 34\right)$. In individual patients AT excretion underestimates true protein loss and is therefore an unreliable test.

\section{P40}

How does dietary lipid lower blood alcohol levels?

I MCL WELCH, A MCFARLANE, L POOLEY, AND N W READ (Clinical Research Unit, Royal Hallamshire Hospital, Glossop Road, Sheffield) To determine the mechanism, whereby food lowers blood alcohol levels, gastric emptying and blood alcohol profiles were measured in six healthy male volunteers after ingestion of a $200 \mathrm{ml}$ solution of vodka and orange juice containing $0.5 \mathrm{~g} / \mathrm{kg}$ alcohol. Subjects were studied on two separate occasions during infusion of isosmotic solutions of either intralipid or saline into the ileum. Gastric emptying was significantly delayed by ileal infusion of intralipid $\left(\mathrm{t}_{2}^{1}: 149 \pm 17\right.$ vs $46 \pm 6 \mathrm{~min}$, $\mathrm{p}<0.005)$ and the peak blood alcohol levels were significantly depressed $(24 \pm 4$ vs $37 \pm 3$ $\mathrm{mg} / 100 \mathrm{ml}, \mathrm{p}<0 \cdot 01)$. Similar effects were observed in three subjects when the solutions were infused into the duodenum $\left(t_{2}^{1}\right.$ : $126 \pm 28$ vs $34 \pm 6 \mathrm{~min}$ ) (peak alcohol $19 \pm 4$ vs $36 \pm 3 \mathrm{mg} / 100 \mathrm{ml}$ ). The results suggest that the reduction in alcohol absorption by lipid in food does not depend on the physical relationship between the alcohol and lipid or between the lipid and absorbing epithelium, but is probably caused by a delay in the delivery of alcohol to the upper small intestine where it is rapidly absorbed.

\section{P41}

IgG subclass antibodies to wheat gliadin in patients with coeliac disease

P J CICLITIRA, H J ELLIS, AND M J KEMENY (Gastrointestinal Unit, Department of Medicine, The Rayne Institute, St Thomas' Hospital, and Department of Medicine, Guy's Hospital, London) Circulating antibodies to dietary antigens including wheat gliadin are present in coeliac patients. Untreated coeliac jejunal mucosa secretes more $\mathrm{IgG}, \mathrm{M}$ and $\mathrm{A}$ antibodies to gliadin than casein. IgG can be divided into four subclasses of which IgG1 and 3 can bind and therefore activate complement while IgG2 can to a lesser extent and IgG4 cannot.

Titres of circulating IgG1, 2, 3 and 4 subclass antibodies to gliadin and casein, a dietary control protein, were measured by ELISA in normal subjects $(n=12)$, treated $(n=12)$ and untreated coeliac patients $(n=12)$. Untreated coeliac patients had greater IgG1 titres to gliadin and casein $(p<0.01)$ than controls with results from the treated patients falling in between. IgG2, 3 and 4 antibodies to gliadin and casein could only be detected in a minority of subjects; the results for these subclasses were not significantly different for the three subject groups.

The majority of circulating IgG gliadin and casein antibody in untreated coeliac patients is IgG1. This suggests that circulating complement fixing gliadin antibodies are not involved in the disease mechanism but does not exclude a pathogenetic role for locally produced specific antibody. The presence of raised circulating IgG1 antibodies to both gliadin and casein in untreated coeliac patients implies that these antibodies are because of dietary antigen absorption.

\section{P42}

Postprandial gut hormone profile after intestinal glycosidase inhibition

R H TAYLOR, H M BARKER, E A BOWEY, J E CANFIELD, AND K D BUCHANAN (Department of Gastroenterology and Nutrition, Central Middlesex Hospital, London, and Department of Metabolic Medicine, Queen's University, Belfast) Postprandial gut hormone profile is determined by meal composition, volume and other factors. The purpose of this study was to measure changes in this response to a standard meal given with intestinal glucosidase inhibitors.

Six healthy subjects took a standard test breakfast three times with either placebo, BAY m1099 $50 \mathrm{mg}$ or BAY o1248 $20 \mathrm{mg}$ in random order. These are potent, reversible glycosidase inhibitors of different substrate specificity. Blood samples were taken for 3 hours for measurement of glucose, insulin, GIP, N-terminal glucagon-like immunoreactivity (N-GLI), C-GLI and gastrin. Breath hydrogen was measured as an indirect index of carbohydrate malabsorption compared with lactulose $25 \mathrm{~g}$ alone.

Both inhibitors reduced the postprandial glucose peak (placebo $7 \cdot 2 \pm 0.5 \mathrm{mmol} / \mathrm{l}$; m1099 5.3 $\pm 0 \cdot 1$ ( $<<0.01 ; 012485 \cdot 9 \pm 0 \cdot 2$ $(p<0.05))$ and the serum insulin peak (placebo $89 \pm 13 \mathrm{mU} / \mathrm{l} ; \mathrm{m} 109939 \pm 3$ $(\mathrm{p}<0.01) ; 0124837 \pm 3(\mathrm{p}<0 \cdot 01)$. Insulin release was reduced significantly from 30 $120 \mathrm{~min}(\mathrm{p}<0 \cdot 05)$. GIP release was reduced significantly between 30 and $150 \mathrm{~min}$ and peaks .fell from $995 \pm 395 \mathrm{ng} / \mathrm{l}$ to $260 \pm 50$ (m1099) and 305 \pm 60 (o1248). NGLI rose from $60 \mathrm{~min}(\mathrm{~m} 1099)$ and $90 \mathrm{~min}$ (o1248) to $134 \pm 7 \mathrm{ng} / \mathrm{l}$ (placebo, 222 \pm 31 $(\mathrm{m} 1099, \mathrm{p}<0.05)$ and $190 \pm 19$ (o1248, $\mathrm{p}<0.05)$ at $180 \mathrm{~min}$. Gastrin levels rose in all groups and C-GLI did not change. Breath hydrogen indicated carbohydrate malabsorption of $10 \pm 4 \mathrm{~g}(\mathrm{~m} 1099)$ and $21 \pm 9 \mathrm{~g}$ (o1248).

We conclude that glycosidase inhibition slows digestion, reducing insulin and GIP release, but unabsorbed nutrients stimulate N-GLI distally. Slow absorption does not affect gastrin or C-GLI release. These experimental changes simulate those found in digestive impairment due to enzymic or mucosal abnormality.

\section{P43}

Regulation of ileal $\mathrm{Na}^{+}$-dependent bile acid transport in man 
F W M DE ROOIJ, J W O VAN DEN BERG, A J P VAN TILBURG, AND M VAN BLANKENSTEIN (Department of Internal Medicine II, Erasmus University, Rotterdam, Rotterdam, The Netherlands) We are interested in the regulation of ileal $\mathrm{Na}^{+}$-dependent bile acid transport (INBAT) in gastrointestinal diseases. In 177 patients undergoing colonoscopy, ileal biopsies were taken from which brush border membrane vesciles (BBMV) were prepared. INBAT was measured in vitro as the uptake of ${ }^{3} \mathrm{H}$ taurocholate $(4 \mu \mathrm{M})$ into $\mathrm{BBMV}$ in the presence of a $100 \mathrm{mM} \mathrm{NaCl}$ gradient. Uptake was followed during one minute. INBAT was quantified in pmoles taurocholate $/ 20 \mathrm{sec} / \mathrm{mg}$ membrane protein.

Patients were placed in 10 diagnostic categories. Mean INBAT values in six categories did not differ significantly, three categories had a significantly decreased INBAT, ileal disease $(n=11,19 \cdot 4 \pm 7 \cdot 4)$, ileal resection $(n=5,17 \cdot 4 \pm 9 \cdot 4)$, and constipation $(n=8,37 \cdot 3 \pm 6 \cdot 0)$. Increased INBAT was found in patients $(n=8)$ with bile acid losing diarrhoea with an endoscopically and histologically normal ileum $(123 \cdot 5 \pm 17 \cdot 3)$.

Our results show that in patients with increased faecal bile acid loss (FBAL) INBAT is high, while in constipated patients, presumed to have a low FBAL, INBAT is low. This suggests that INBAT is regulated by the availability of bile acids to the ileal enterocytes.

\section{P44}

Improvement of abnormal lactulose/rhamnose permeability in active Crohn's disease of the small bowel by an elemental diet

I R SANDERSON, P BOULTON, I MENZIES, AND J A WALKER-SMITH (Department of Child Health, St Bartholomew's Hospital, Institute of Child Health, St Thomas' Hospital, London) Elemental diet is as effective as steroids in the induction of remission of small bowel Crohn's disease in children, as judged by disease activity, ESR, CRP and albumin. Intestinal sugar permeability is an objective marker of small bowel function which can assess the efficacy of elemental diet during treatment. Fourteen children aged 11-17 years with active small bowel disease (proven by radiology and ileal histology) were given an elemental diet for six weeks. All had the following sugar permeability study undertaken before and after treatment. An $80 \mathrm{ml}$ solution containing $5.25 \mathrm{~g}$ lactulose $(\mathrm{L})$ and $0.75 \mathrm{~g}$ rhamnose (R) was ingested after an overnight fast. $L / R$ ratio was calculated from the percentage recovery of each of the sugars in a 5 hour urine collection. Seven children with no disease of the small intestine acted as controls. They had $L / R$ ratios below 0.08 , the upper limits of normal found by Beach et al. All 14 children with Crohn's disease had an abnormally raised permeability ratio $(0.256 \pm 0.037)$ before treatment which fell significantly $(p<0.001$, paired Student's $t$ test) after elemental diet $(0.93 \pm 0.012)$. This coincided with marked clinical improvement assessment by disease activity index. An elemental diet produces marked reduction in the severity of small bowel Crohn's disease as measured objectively by sugar permeability.

\section{P45}

Does glycine content affect the efficacy of amino acid solutions in TPN?

R G REES, G K GRIMBLE, P FROST, F AL-UBAIDI, AND D B A SILK (Departments of Gastroenterology and Nutrition and Chemical Pathology, Central Middlesex Hospital, London) Despite the fact that the value of glycine as a source of nitrogen for protein synthesis is disputed, it often represents a significant proportion of non-essential nitrogen in amino acid solutions for TPN. If glycine $\mathbf{N}$ is not retained, but channelled to urea, lower levels of $\mathrm{N}$ balance and plasma proteins might be expected when glycine-rich solutions are used.

We have prospectively compared two solutions of differing glycine content in a heterogeneous group of seven patients (24-63 years) who required TPN. All were metabolically stable without significant organ failure and received two consecutive five-day feeding regimes in random order. Amino acids were supplied as Vamin $\mathrm{N}$ or 'old' formula Synthamin providing $14.1 \mathrm{~g}$ and $14.3 \mathrm{~g} \mathrm{~N}$ with $2.7 \%$ and $23 \%$ respectively, contributed by glycine. The regimes were isocaloric and provided $2200 \mathrm{Kcal} /$ day from a $45 \% / 55 \%$ energy lipid/glucose mixture.

Twenty four hour total urinary $\mathrm{N}$ and urea and serum urea were measured daily. Plasma albumin, prealbumin and transferrin were measured on day five of each regime.

There were no differences between matched pairs for any parameter. Values for Vamin and Synthamin (mean \pm SEM) were $N$ balance (cumulative) $-4.0 \pm 9$ vs $-14 \cdot 8 \pm 13 \mathrm{~g}$; urinary urea $\mathrm{N} /$ total $\mathrm{N}$ $80 \pm 2 \%$ vs $82 \pm 2 \%$; alb $26 \pm 2$ vs $26 \pm 2$ g/l; prealb $122 \pm 17$ vs $107 \pm 19 \mathrm{mg} / \mathrm{l}$; transferrin
$2 \cdot 2 \pm 0 \cdot 1$ vs $2 \cdot 1 \pm 0 \cdot 2 \mathrm{~g} / 1$; BUN $12 \cdot 2 \pm 1 \cdot 6$ is $14 \cdot 6 \pm 2 \cdot 8 \mathrm{mmol} / \mathrm{l}$.

We conclude, from these data, that there is no nutritional disadvantage for parenterally fed patients when significant amounts (up to 23\%) of total amino acid $\mathrm{N}$ is provided as glycine.

\section{P46}

Intestinal absorption and laxative threshold of lactitol - a new hydrogenated derivative of lactose

D H Patil, G K GRImble, AND D B a SIIK (Department of Gastroenterology and $\mathrm{Nu}$ trition, Central Middlesex Hospital. London) Lactitol is a high soluble disaccharide with excellent taste properties. As animal studies suggest that it is poorly absorbed, it has potential as a bulk sweetener of a low calorific value in the food industry. This potential has been investigated by characterising its assimilation by the human small intestine and by determining its laxative threshold.

In vivo jejunal perfusion experiments were carried out in normal human subjects $(n=6)$. Intestinal uptake from isotonic solutions containing $10,30,60$ and 100 mmol lactitol/l was not significantly different from zero.

To determine laxative thresholds, 21 healthy volunteers entered a single blind randomised cross over trial, taking, in divided doses, increasing amounts $(10 \mathrm{~g}$ day) of lactitol, sorbital or placebo. The laxative thresholds of lactitol $(74 \cdot 7 \pm$ SEM. $6.3 \mathrm{~g} /$ day) and sorbitol $(71.9 \pm 4.9)$ were similar and the incidence of gastrointestinal side effects were not significantly different on similar doses of sorbital and lactitol. We conclude that as lactitol is not absorbed in the small intestine and has a laxative threshold of $>40 \mathrm{~g} / \mathrm{day}$, its potential as a low calorie bulk sweetener in the food industry is confirmed. At high doses (>70 g/day) Lactitol could find an important place as an osmotic cathartic agent.

\section{P47}

Low phytate wheat bran inhibits zinc absorption less than standard bran

M J HALL, D ENE, D FARAH, ANI 1. DOWNS (University Department of Medicine, Bristol Royal Infirmary, Bristol) Binding of zinc in the intestine by the phytate and/or fibre content of cereal products can lead to zinc deficiency which has been increasingly 
reported in gastrointestinal disorders. We have compared the effect of a new wheat bran, Testa Triticum Tricum, containing $80 \%$ fibre but low in phytate, with phytate rich standard bran on zinc absorption in healthy fasting volunteers.

Twenty subjects in two equal groups each took zinc sulphate $220 \mathrm{mg}$. Plasma zinc was measured beforehand and up to six hours afterwards by atomic absorption spectrophotometry. The experiment was repeated with group 1 taking, in addition, $17 \mathrm{~g}$ standard wheat bran and group 2 a similar quantity of low phytate bran. A control group of six subjects took Rice Krispies instead of bran.

Zinc absorption expressed as area under the plasma zinc time curve (AUC) fell from (mean \pm SEM) $99 \cdot 6 \pm 8 \cdot 8$ to $-4 \cdot 6 \pm 2 \cdot 1$ $(\mathrm{p}<0.001)$ after standard bran, from $74.6 \pm 7.4$ to $18 \cdot 5 \pm 4.2(\mathrm{p}<0.001)$ after lowphytate bran and from $105.9 \pm 10.7$ to $47 \cdot 3 \pm 10 \cdot 1 \quad(p<0.05)$ after Rice Krispies. Mean percentage reduction in AUC after standard wheat bran was significantly higher than after low-phytate bran $(104.9 \pm 1.9$ vs $75.9 \pm 4.8 \%, \mathrm{p}<0.001)$.

We conclude that wheat bran is a potent inhibitor of zinc absorption which can be improved by reduction of the phytate content.

\section{P48}

Effect of somatostatin analogue SMS 201995 on fluid and electrolyte transport in a patient with secretory diarrhoea

C A EDWARDS, P A CANN, N W READ, AND C D HOLDSWORTH (Gastrointestinal Unit, Royal Hallamshire Hospital, Sheffield) SMS 201-995, a long acting analogue of somatostatin can be administered subcutaneously and has been shown to be of benefit in the treatment of diarrhoea secondary to tumours secreting vasoactive intestinal polypeptide (VIP). We used steady state perfusion techniques to investigate its effect on fluid and electrolyte transport in the jejunum and ileum of a patient with a VIPoma. Fifty micrograms of the analogue was given subcutaneously following a 60 minute control period and measurements repeated after a $\mathbf{4 0}$ minutes equilibration. In the jejunum, endogenous flow was abolished $(110.4-0 \mathrm{ml} / \mathrm{h})$, net fluid absorption increased $(4 \cdot 2-73 \cdot 8 \mathrm{ml} / 25$ $\mathrm{cm} / \mathrm{h})$, sodium secretion reversed $(-1 \cdot 2-$ $+10 \cdot 1 \mathrm{mmol} / 25 \mathrm{~cm} / \mathrm{h}$ ), potassium absorption increased $(0.14-0.49 \mathrm{mmol} / 25 \mathrm{~cm} / \mathrm{h})$ and chloride absorption increased $(0.5-$ $6.56 \mathrm{mmol} / 25 \mathrm{~cm} / \mathrm{h}$ ). Ileum: endogenous flow (488.4-283.8), net fluid absorption $(24 \cdot 5-86 \cdot 3)$, sodium $(1 \cdot 6-12 \cdot 2)$, potassium $(0 \cdot 1-0 \cdot 3)$ and chloride $(3 \cdot 3-19 \cdot 3)$. Plasma VIP fell from $168 \mathrm{pmol} / \mathrm{l}$ (control) to 99 $\mathrm{pmol} / \mathrm{l}$ (end of test period). Clinically the patient was able to return to a normal diet and leave hospital on a regime of $50 \mu \mathrm{g} \mathrm{tds}$. He maintained a stool output of less than 1 litre daily during treatment, enabling him to live normally until the eventual resection of the tumour four months later.

\section{P49}

Intestinal transit times and stool output during intake of a hypocholesterolaemic dose of guar in man

$R$ PENAGINI, $P$ VElio, AND $P$ A BIANCHI (INTRODUCED BY J J MISIEWICZ) (Cattedra di Patologia Medica III, Istituto di Clinica Medica I, University of Milan, Italy) Guar gum is generally believed to prolong mouth-to-caecum transit time (MCTT) and this has been suggested to play a role in its metabolic effects. Previous studies of MCTT used liquid meals and large doses of guar. Whole gut transit time (WGTT) and stool output are reported to be unaffected by guar, but data are scanty.

Six healthy male volunteers, aged $21-28$ years, ate a controlled diet $(2721 \mathrm{Kcal}$ and $22 \mathrm{~g}$ dietary fibre daily) for two periods of two weeks (CD1 and 2) with a two-week interval on unrestricted diet; during CD2 guar gum 5.7 gbd was given daily in crispbread during the two main meals. Daily stool weight and WGTT (measured with radio-opaque markers given on three consecutive days) were determined in the second week of CD1 and CD2 and total serum cholesterol at the beginning and the end of each $C D$ period. After both $C D$ periods, MCTT of a solid test meal (554 Kcal) was measured using the hydrogen breath test; guar gum $5.7 \mathrm{~g}$ in crispbread was added to the second test meal. Results were analysed using the paired Wilcoxon's test and expressed as mean $\pm \mathrm{SD}$. Serum cholesterol changes were $-5.5 \mathrm{mg} / \mathrm{dl} \pm 14.6$ and $-30 \pm 17.6(\mathrm{p}=0 \cdot 05)$ in CD1 and CD2 respectively. MCTT (276.7 $\mathrm{min} \pm 112.7$ vs $266 \cdot 7 \pm 128)$, WGTT $(46 \cdot 2 \mathrm{~h} \pm 8 \cdot 5$ vs $53.8 \pm 17 \cdot 6)$ and daily stool output $(67 \cdot 9 \pm 15 \cdot 4$ vs $76 \cdot 2 \pm 35 \cdot 2)$ showed no significant variations.

We conclude that guar exerts its hypocholesterolaemic effect without any significant change in MCTT and does not affect WGTT and stool output in healthy humans.
P50

Bile salt uptake by Giardia lamblia: possible role in fat malabsorption

C E W HALLIDAY, P M G INGE, J WEBB, AND M J G FARTHING (Department of Gastroenterology, St Bartholomew's Hospital, London) Our preliminary observations indicate that Giardia lamblia (GL) trophozoites take up bile salts (BS) in vitro. Although the biological implications for the parasite are as yet unknown, we have attempted to characterise this uptake process and estimate its potential impact on intraluminal BS concentration and on the BS pool. Giardia lamblia trophozoites were cultivated axenically and BS uptake investigated with respect to time $(0-4 \mathrm{~h})$, temperature $\left(4\right.$ and $\left.37^{\circ} \mathrm{C}\right)$, trophozoite fixation (1\% glutaraldehyde), parasite growth phase (active or stationary) and BS concentration (glycocholic (GC) acid, 0·1$10 \mathrm{mmol} / \mathrm{l})$. Glycocholic uptake was determined using ${ }^{14}[\mathrm{C}]-\mathrm{GC}$ and expressed per unit number of organisms. Glycocholic uptake plateaued at one hour, was inhibited $\sim 50 \%$ at $4^{\circ} \mathrm{C}$ and almost completely abolished by glutaraldehyde fixation. Uptake was greater during stationary growth phase $\left(50.6 \mathrm{nmol} / 10^{8}\right.$ trophs/h from 2 $\mathrm{mmol} / \mathrm{l} \mathrm{GC}$ ) than during active multiplication $\left(2 \mathrm{mmol} / 1\right.$ uptake $-29 \cdot 4 \pm \mathrm{nmol} / 10^{8}$ trophs/h). Uptake was concentration dependent and appeared to follow saturation kinetics $(\mathrm{Km}=0.45 \mathrm{mmol} / 1$; Vmax $=$ $0.55 \mathrm{mmol} / \mathrm{min} / 10^{8}$ trophs) compatible with an active transport process. This $\mathrm{Km}$ for GC is similar to published data for intact human and rat ileum. Infection with $10^{12}$ organisms would result in the consumption of $1 \mathrm{mmol}$ GC per day which represents $\sim 20 \%$ of the normal adult BS pool. Chronic infection may lead to reduction of intraluminal BS concentration which might contribute to fat malabsorption in giardiasis.

P51

Trypsin-sensitive surface ligand mediates attachment of Giardia lamblia (GL) to rat enterocytes

P M G INGE, A D PHILLIPS, AND M J G FARTHING (Department of Gastroenterology, St Bartholomew's Hospital, London) We have shown previously with an erythrocyte model of attachment that GL has surface lectin-like activity which may be important in mediating parasite-enterocyte interaction. We have now further characterised this ligand and its intestinal receptor using 
isolated rat enterocytes. Cultivated GL trophozoites and citrate-EDTA eluted rat enterocytes $\left(\sim 10^{5}\right.$ cells of each) were incubated $1: 1$ in microplates and parasite attachment was quantified by phase microscopy. Attachment was maximal after one hour at $37^{\circ} \mathrm{C}$, was markedly inhibited at $4^{\circ} \mathrm{C}$ but remained unaltered in the absence of divalent cations. Relatively high concentrations of D-mannose $(0 \cdot 1 \mathrm{M})$ and the mannose-rich glycoprotein mannan $(10 \mathrm{mg}$ / $\mathrm{ml}$ ) inhibited attachment by $49 \pm 1.0 \%$ and $48 \pm 10 \%$ respectively, whereas other sugars were without effect. Subagglutinating concentration $(1: 256)$ of heat inactivated, non-cytotoxic rabbit polyclonal antigiardia antiserum with surface specificity also inhibited GL attachment $(42 \pm 9.0 \%$ inhibition), confirming the importance of surface determinants for attachment. Trypsin pretreatment $(1 \mathrm{mg} / \mathrm{ml}, 30 \mathrm{~min})$ of $\mathrm{GL}$ significantly reduced attachment $(10 \cdot 6 \pm 1.8 \%)$ trophozoites attached vs $19.4 \pm 1.8 \%$ control, $\mathrm{p}<0.001)$, although viability was unchanged. However, short term $(4 \mathrm{~h})$ recultivation of trypsin-treated GL normalised their ability to attach to enterocytes. We conclude that attachment of GL to rat enterocytes is mediated by a trypsin sensitive, lectin-like surface ligand whose intestinal receptor may include $D$ mannosyl residues.

GASTRODUODENAL

P52-68

\section{P52}

Effects of single nocturnal doses of pirenzepine on overnight gastric secretion

C W HOWDEN, D W BURGET, C SILLETTI, M DICKEY, AND R H HUNT (Department of Gastroenterology, McMaster University, Hamilton, Ontario, Canada) Treatment of DU has focused on single nocturnal dosing with $\mathrm{H}_{2}$ antagonists but pirenzepine (Pir) has not previously been evaluated in this manner.

In a double-blind randomised study, six healthy men were given a three day course of placebo (Pla), Pir $100 \mathrm{mg}$ nocte and Pir $150 \mathrm{mg}$ nocte. On day three, nocturnal hydrogen ion activity $\left[\mathrm{H}^{+}\right]$, and acid output (AO) were measured. Inhibition by Pir was assessed by percentage reduction of mean $\left[\mathrm{H}^{+}\right]$, and the area under the $\mathrm{H}^{+}$activity/ time curve (AUC) (linear trapezoidal rule).
Mean $\left[\mathrm{H}^{+}\right]$was $36 \cdot 1 \pm 7 \cdot 9 \mathrm{mmol} / \mathrm{l}$ on $\mathrm{Pla}$, $16.7 \pm 8.6$ on Pir $100 \mathrm{mg}(-54 \%, \mathrm{p}<0.01)$ and $16 \cdot 6 \pm 6.0$ on Pir $150 \mathrm{mg}$ nocte $(-53 \%$, $\mathrm{p}<0 \cdot 01)$. Acid output was reduced by $67 \%$ by both doses $(\mathrm{p}<0 \cdot 001)$. Volume was reduced by $47 \%$ and $52 \%$ by Pir 100 and $150 \mathrm{mg}$ respectively. Pepsin output was not altered. AUC was $251 \cdot 9 \pm 55 \cdot 2 \mathrm{mmol} \mathrm{H} \mathrm{H}^{+}$ $\mathrm{h} / \mathrm{l}$ on Pla, $115 \cdot 8 \pm 59.7$ on Pir $100 \mathrm{mg}$ $(-54 \%, \mathrm{p}<0.05)$ and $110.7 \pm 38.6$ on $\mathrm{Pir}$ $150 \mathrm{mg}(-56 \%, \mathrm{p}<0.05)$. Side effects of dry mouth occurred only with Pir $150 \mathrm{mg}$.

Pirenzepine given as a single night time dose significantly reduced nocturnal acid secretion. There was no significant difference between the doses studied. As side effects were frequent with Pir $150 \mathrm{mg}$, the optimal night time dose is $100 \mathrm{mg}$. This dose should be evaluated in a controlled clinical trial.

\section{P53}

Efficacy of $\mathrm{H}_{2}$ receptor antagonists $\left(\mathrm{H}_{2} \mathrm{RA}\right)$ in gastric ulcer (GU) is independent of antisecretory effect

C W HOWDEN, D B JONES, AND R H HUNT (Department of Gastroenterology, McMaster University, Hamilton, Ontario, Canada) Although patients with GU usually have normal or reduced gastric acidity, they are often treated with antisecretory drugs such as $\mathrm{H}_{2} \mathrm{RA}$. This study examines whether a relationship exists between $\mathrm{GU}$ healing and suppression of $24 \mathrm{~h}$ or nocturnal acidity. We analysed the results of over 40 controlled clinical trials of $\mathrm{H}_{2} \mathrm{RA}$ in GU. The highest healing rates were obtained with 10 to 12 weeks' treatment with standard doses of $\mathrm{H}_{2} \mathrm{RA}(88.9$ to $93.8 \%)$. Placebo healing rates after four, six and eight weeks were $36 \cdot 1 \%(n=208), 49 \cdot 2 \%$ $(n=65)$ and $61.5 \% \quad(n=65)$, suggesting natural healing of $\mathrm{GU}$ with time. From an analysis of 11 studies of 24 hour and nocturnal intragastric acidity with various dose schedules, therer was found to be no correlation between healing after four, six or eight weeks and suppression of 24 hour or nocturnal acidity. At six weeks, healing rates versus suppression of 24 hour acidity yielded $r=-0 \cdot 3908 ; p=0.553$. With nocturnal acidity, $r=-0.3397: p=0 \cdot 514$.

There is no relationship between GU healing and suppression of 24 hour or nocturnal acidity. Prolonging treatment results in maximal healing rates. Placebo healing also improves with time; the response to $\mathrm{H}_{2} \mathrm{RA}$ may simply reflect an accelerated natural healing rate. As efficacy in healing is not related to acid suppres- sion, $\mathrm{H}_{2}$ RA may heal (iU through some other mechanism.

P54

Are there immunological forms of duodenal ulcer (DU) as a consequence of gastric parietal cell stimulating antibodies (PCSAb)?

F DE LAZZARI, R MIRAKIAN, ( VHNIIRI. V BORTOLAMI, R NACCARATO, D) DONIA(H, ANI) G f BotTazzo (Gastroenterology Depart ment, Padova University. Itals, Immuno logy. Department, Middlesex Hospital Medical School, London) Previous re ports indicated that $\mathrm{Ig}(\mathrm{i}$ obtained from some patients with DL stimulate acid secretion when injected into rats by an action on the histamine receptors $\left(H_{2}-\mathrm{R}\right)$ on gastric parietal cells (PC). We invest. gated this stimulatory activity directly ho measuring cAMP responses in P( enriched cultures from guinea pig gastric mucosa Ammonium sulphate precipitated Igs from 30 DU patients and 20 healthy control. have been studied. The DU cases were selected on the basis of pentagastrin stimulated (MAO) hyperacidity or high serum pepsinogen-I levels. and response to treatment (cimetidine or ranitidine). The PC suspensions were obtained by step collagenase digestion (0).5 $\mathrm{mg} / \mathrm{ml}$ Worthington type IV) of selective body mucosa to avoid contamination with antral endocrine cells. After several washes and centrifugations, the enriched $\mathrm{PC}$ prepar ations $(45-55 \%)$ were cultured overnight to allow their full recovers and incubated for four hours with 2 and $4 \mathrm{mg} / \mathrm{ml}$ of $\mathrm{Ig}$ with added 2 mM 3-isobuthyl-1-methyl-xantinc (IBMX). cAMP was measured by RIA (Amersham kits). Control cultures contained IBMX only, positive. negative and controls Ig were included in every batch of tests and all samples were tested in duplicate. $10^{-3} \mathrm{M}$ histamine produced maximum cAMP stimulation at $30 \mathrm{~min}$. Pentagastrin and G1-17 had no effect. Igs from 13 of the 30 DU cases produced a significant dose related increase in total cAMP indicating the presence of $\mathrm{PC}$ stimulating antibodies (PCS-Ab) similar to the well known thyroid stimulating antibodies of (iraves disease (TS-Ab). 8/13 stimulating-antibodypositive DU patients were non responders to anti-H2-R drugs as compared with $3 / 17$ of the negative cases. Pepsinogen-I serum levels were over $100 \mathrm{ng} / \mathrm{ml}$ in $10 / 13$ positive cases and in $6 / 17$ of negative cases. These results suggest that in some patients, particularly those resistant to cimetidine 
hypersecretors, duodenal ulcer disease may result from an autoimmune stimulatory receptor antibody, acting selectively on the histamine-2-receptor.

\section{P55}

Peptic ulcer in Bangladesh - an endoscopic survey

M HASSAN, SHAH MD K ALI AND A K AZAD KHAN (Department of Gastroenterology, Institute of Postgraduate Medicine and Research, and Department of Epidemiology, Bangladesh Institute of Research and Rehabilitation in Diabetes, Endocrine and Metabolic Disorders, Dhaka) A survey on peptic ulcer was carried out in a rural community in Bangladesh. All subjects of 15 years or above $(n=2675)$ were surveyed by a questionnaire and those with ulcer dyspepsia $(n=1106)$ were selected on the basis of predetermined criteria. A random sample $(n=313)$ of these subjects were chosen for endoscopy and 283 of them $(89.5 \%)$ have been endoscoped.

Duodenal ulcer was found in 48 , duodenal erosions in nine, deformed bulb in 23 and gastroenterostomy in two subjects. The prevalence of duodenal ulcer disease was $11.9 \%$. Gastric ulcer was found in 24 (prepyloric 14, antral eight, body two) subjects, the prevalence rate being $3.5 \%$. Both duodenal ulcer and gastric ulcer subjects were predominantly males. No case of carcinoma of the upper GI tract was detected.

Duodenal ulcer is common but gastric ulcer is uncommon in this population. Reasons for the high prevalence of duodenal ulcer remain unknown. Those with and without ulcer have been identified in a defined population and further studies on genétic and environmental factors can now be undertaken.

\section{P56}

Pathogenic role of campylobacter-like organisms in duodenal ulcer

W M HUI, S K LAM, P Y CHAU, J HO, M T NG, $C$ L LAI, AND A LOK (Departments of Medicine, Pathology and Microbiology, University of Hong Kong, Queen Mary Hospital, Hong Kong) Campylobacter like organisms have been associated with antral gastritis and duodenal ulcer. To study the pathogenic role of these organisms in duodenal ulcer, endoscopic biopsies, two from the first part of duodenum, four from antrum, and four from body and fundus were taken in random order before and after four weeks of cimetidine treatment $(1.2 \mathrm{~g} /$ day $)$ from 49 patients with active duodenal ulcer that healed at the end of the treatment period. The biopsies were examined for the presence and severity of any inflammation histologically, and for campylobacter-like organisms by smear and culture. Before treatment, inflammation was present in $71 \%, 98 \%$, and $25 \%$, while the organisms were present in $37 \%, 89 \%$, and $82 \%$ of the duodenal, antral and fundal biopsies respectively. With complete healing of duodenal ulcer, inflammation was present in $64 \%, 100 \%$, and $27 \%$, while the organisms were positive in $39 \%, 83 \%$, and $81 \%$ of the respective mucosae. With ulcer healing, duodenitis and antral gastritis became milder and significantly so for antral gastritis. These findings indicate that healing of duodenal ulcer is not influenced by the presence of campylobacter-like organisms, which are frequently found in the gastroduodenal mucosa of patients with duodenal ulcer, but do not appear to be associated with mucosal inflammation except in the antrum.

P57

Neutral micro-climate lines human gastroduodenal mucosa in vivo

E M M QUIGLEY AND $L$ A TURNBERG (Department of Medicine, Hope Hospital (University of Manchester School of Medicine, Eccles Old Road, Salford) Gastroduodenal mucosa may protect itself by maintaining a neutral zone in the mucous layer. The demonstration of a neutral $\mathrm{pH}$ on the mucosa in vitro and in vivo in animals lends credence to this hypothesis and we now present evidence for a similar phenomenon in vivo in man. In 21 normal subjects (aged 22-86 years) pH was measured using a flexible $\mathrm{pH}$ electrode (OD $1.35 \mathrm{~mm}$ ) passed through the biopsy channel of an endoscope. At six sites (lower oesophagus, fundus, body, antrum, duodenal cap and loop) $\mathrm{pH}$ was recorded with the electrode (a) in the lumen and (b) touching the mucosa. In nine subjects duodenal recordings were repeated during luminal acidification. In five subjects electrical potential difference (PD) readings were taken at the same sites. Lumen (L) to mucosal $(\mathrm{M}) \mathrm{pH}$ gradients were identified in oesophagus ( $L \quad 3 \cdot 29 \pm 0.32$ vs $M$ $4 \cdot 18 \pm 0.25 ; \mathrm{p}<0.006$ ), gastric fundus (L $2.01 \pm 0.17$ vs $M \quad 4.84 \pm 0.37 ; \mathrm{p}<0.003)$, body (L $1.82 \pm 0 \cdot 12$ vs $5 \cdot 50 \pm 0 \cdot 15 ; \mathrm{p}<0.001)$ and antrum (L 3.52 \pm 0.34 vs M 5.42 \pm 0.29 ; $\mathrm{p}<0.004)$. In duodenum, luminal and mucosal $\mathrm{pH}$ were near neutral but on luminal acidification a gradient was detected in both cap (L $2.57 \pm 0.15$ vs $\mathrm{M}$ $6.74 \pm 0.13 ; \mathrm{p}<0.005$ ) and loop (L $2 \cdot 44 \pm 0.14$ vs $6 \cdot 39 \pm 0.20 ; \mathrm{p}<0.0001)$ Potential difference $(\mathrm{mV})$ in the lumen and at the mucosa were similar in oesophagus ( $\mathrm{L}-15 \pm 3$ vs $\mathrm{M}-15 \pm 4)$, body ( $\mathrm{L}-23 \pm 3$ vs $\mathrm{M}-24 \pm 4)$, antrum ( $\mathrm{L}-19 \pm 5$ vs $\mathrm{M}$ $-22 \pm 6)$ and duodenum ( $L-5 \pm 2$ vs $\mathrm{M}$ $-5 \pm 2)[N B: 1 \mathrm{pH}$ unit $=61 \mathrm{mV}]$. We conclude that lumen-to-mucosal $\mathrm{pH}$ gradient is present in the human upper gut and supports the importance of surface factors in mucosal protection.

\section{P58}

Luminal and mucosal $\mathrm{pH}$ in patients with duodenal ulcer, reflux oesophagitis and antral gastritis

E $M$ M QUIGLEY AND $L$ A TURNBERG (Department of Medicine, Hope Hospital (University of Manchester School of Medicine, Salford). We sought evidence for a defect in the 'mucus-bicarbonate' barrier in upper GI diseases by recording juxtamucosal $\mathrm{pH}$ with a flexible $\mathrm{pH}$ electrode (ED $1.35 \mathrm{~mm}$ ) passed through the biopsy channel of a standard endoscope. Luminal and mucosal pH were measured in lower oesophagus, fundus, body, antrum, duodenal cap and loop and repeated in duodenum and oesophagus during intraluminal acidification in patients with untreated duodenal ulceration (DU) $(n=5)$, reflux oesophagitis (RO) $(n=7)$ and antral gastritis (AG) $(n=7)$ and compared with values in 21 normal subjects. Duodenal ulcer patients exhibited lower luminal pH in antrum (mean $\pm \mathrm{SE}$, DU vs normals: $1.88 \pm 0.37$ vs $3.52 \pm 0.34, \mathrm{p}<0.03$ ), duodenal cap $(5 \cdot 28 \pm 1.43$ vs $6 \cdot 89 \pm 0 \cdot 20, \mathrm{p}<0.05)$ and loop $(4 \cdot 67 \pm 1 \cdot 81$ vs $6 \cdot 84 \pm 0 \cdot 19$, $\mathrm{p}<0.04)$. Mucosal $\mathrm{pH}$ was lower in gastric body $(3.52 \pm 0.76$ vs $5.50 \pm 0.15, \mathrm{p}<0.005)$ in DU, but was similar to normals at all other sites. In $\mathrm{RO}$ luminal $\mathrm{pH}$ in antrum was lower $(2.27 \pm 0.29$ vs $3.52 \pm 0.34$, $\mathrm{p}<0.04$ ) while in $\mathrm{Ag}$ luminal $\mathrm{pH}$ in gastric body was raised $(2.54 \pm 0.49$ vs $1.82 \pm 0.12$, $\mathrm{p}<0.05$ ). Luminal $\mathrm{pH}$ at other sites and mucosal $\mathrm{pH}$ at all sites for $\mathrm{RO}$ and $\mathrm{AG}$ were similar to normals.

We conclude that in DU patients, though antrum and duodenum are exposed to more acid the juxtamucosal neutral zone is preserved; mucosal $\mathrm{pH}$ in gastric body, in contrast is depressed. No deficiencies in the ability to maintain juxtamucosal neut- 
rality could be identified in patients with reflux oesophagitis or antral gastritis.

P59

Isolated pyloric contractions (IPC) in fasted and fed human subjects

N W READ, L A HOUGHTON, R HEDDLE, G J MADDERN, J DENT, J DOWNTON, J B WYMAN, AND T TOOULI (Departments of Medicine and Surgery, Flinders Medical Centre, and Royal Adelaide Hospital, Adelaide, Australia) It is controversial whether phasic pyloric contractions occur in humans independently from antral and duodenal contractions. We have recorded pyloric pressures in nine healthy subjects with a $4.5 \mathrm{~cm}$ long sleeve sensor, positioned by measurements of transmucosal potential difference. Pressures were also measured with perfused side holes at four sites in the duodenum and three sites in the antrum.

Under fasting conditions five subjects exhibited sequences of between 18 and 89 regular pyloric contractions (frequency, 2.9 to $3.3 \mathrm{~min}$ ) which were not associated with contraction in the antrum or duodenum 1 $\mathrm{cm}$ from either end of the sleeve. IPCs occurred immediately before the onset of phase III of the MMC in four subjects and within 15 minutes of the end of phase III in four subjects.

Ingestion of $300 \mathrm{ml}$ chocolate milk elicited IPCs in all subjects (19 to 153 contractions occurring between 2.5 and 2.9 min) postprandial IPCs occupied $25 \pm 8 \%$ (SEM) of recording time compared with $7 \pm 4 \%$ during fasting. Postprandial IPCs were also more likely to be interspersed with episodic peristaltic waves which swept from the antrum into and along the duodenum. Isolated pyloric contractions may play a role in the control of transpyloric flow, especially in the fed state.

\section{P60}

New evidence for the pathophysiology of postvagotomy diarrhoea

S A RAIMES, V SMIRNIOTIS, E J WHELDON, C W VENABLES, AND I D A JOHNSTON (University Department of Surgery, Newcastle upon Tyne) Diarrhoea is more common after truncal vagotomy than after other gastric operations, but there is no satisfactory explanation for this. The hypertonic glucose 'dumping provocation test' reproduces diarrhoea in those patients for whom this is an important complaint. We have investigated the malabsorption of glucose during this test by measuring changes in breath hydrogen. Four groups of unselected male subjects were studied -42 after truncal vagotomy and pyloroplasty $(\mathrm{TV}+\mathrm{P}), 14$ after proximal gastric vagotomy (PGV), 12 after Bilroth I gastrectomy (BG) and 10 healthy controls. Glucose malabsorption was significantly more common in the TV+P group (39/42 vs PGV: 5/14; $\mathrm{p}<0.001$, vs BG: $4 / 12 ; \mathrm{p}<0.001$ and vs controls: $0 \cdot 10 ; \mathrm{p}<0.001$; Fisher exact test). Small bowel colonisation by hydrogen producing bacteria was excluded by repeating tests with lactulose. Twenty patients experienced diarrhoea during the test, all but one in the TV $+\mathrm{P}$ group. In the $\mathrm{TV}+\mathrm{P}$ group those patients with diarrhoea had a greater fall in plasma volume (median $13 \%$ vs $8 \%$; $p=0.001$; Mann-Whitney Test) and a shorter mouth-caecum transit time (median 15 minutes vs 20 minutes; $\mathrm{p}<0.048$; Mann-Whitney Test).

We conclude that patients after TV $+P$ do not fully absorb a hypertonic glucose load. This is abnormal and helps to explain the pathophysiology of postvagotomy diarrhoea.

\section{P61}

Emergency peptic ulcer surgery - an association with NSAIDs

A J WALKer AND E P DEWAR (Professorial Surgical Unit, RN Hospital, Haslar, Gosport, Hants) The elderly have a disproportionately high mortality from complications of peptic ulceration. They may have more concomitant diseases, be treated less aggressively or be prescribed more ulcerogenic drugs, particularly NSAIDs.

For three years all patients admitted with an episode of upper GI tract haemorrhage or perforation of a PU who required emergency surgery were studied.

Sixty patients were admitted with 64 ulcers. Thirty two (25 DU, seven GU) operations for haemorrhage and 32 (17 DU, $15 \mathrm{GU})$ for perforation were performed.

Fifty per cent of the patients were taking NSAIDs, the incidence in women double than in men. Sixty seven per cent were over 60 years old, women significantly older than men.

Perforation in association with NSAIDs in the over 60s was double that in the under 60 s.

In an aggressive surgical policy the mortality from haemorrhage was $3.4 \%$ and from perforation $\mathbf{9 . 7 \%}$. Contrary to surgical tradition only four partial gastrectomies were performed. Of three deaths from perforation, all were over 60 and all taking NSAIDs.

A low incidence of serious complications associated with NSAIDs is claimed. There is an associated serious morbidity, however, requiring emergency surgery and a mortality. Prescribers should be made aware of the benefit/risk ratio.

\section{P62}

Does cimetidine alter the prognosis after perforated duodenal ulcer?

C J SIMPSON, G LAMONT, I MCDONALD, AND I S SMITH (Victoria Infirmary, Glasgow) Sixty consecutive patients with perforation of a duodenal ulcer undergoing emergency simple closure were randomised to receive full dose cimetidine for eight weeks, followed by maintenance of $400 \mathrm{mg}$ nocte for a further 18 weeks, or, not to receive any anti-ulcer therapy. Follow up on all patients took place at one month, two months, six months and 12 months and endoscopy was undertaken on symptomatic patients. Both groups were comparable in age, pre and postoperative smoking habits, prior treatment with ulcer healing agents, dyspeptic history and duration of perforation before surgery. Although cimetidine did not affect immediate recovery, there being three $(10 \%)$ deaths in the cimetidine group and five $(16 \%)$ in the control group, the cimetidine group did enjoy a significant benefit $(p<0.001)$ in the long term. Eleven $(45 \%)$ patients in the control group developed recurrent ulcer symptoms, three requiring emergency surgery for bleeding or reperforation and eight requiring medical treatment. The cimetidine group remained symptom free for 12 months.

\section{P63}

Effect of glucomannan on postprandial reactive hypoglycaemia after gastric surgery

W P M HOPMAN, G M P HOUBEN, P A J SPETH, AND C B H W LAMERS (Departments of Gastroenterology-Hepatology, Universities of Nijmegen and Leiden, The Netherlands) Presently no satisfactory treatment is available to patients who suffer from postprandial reactive hypoglycaemia after gastric surgery. A-glucoside hydrolase inhibitors (acarbose) are poorly tolerated because of side effects due to carbohydrate malabsorption, while pectin is unpalatable 
and effective only when ingested in very large doses. Glucomannan, a polysaccharide consisting of glucose and mannose, is tasteless and has strong gel-forming properties. In a double-blind study of eight patients (21-61 years) with reactive hypoglycaemia after gastric surgery we have compared the effect of 5.2 g glucomannan, $2.6 \mathrm{~g}$ glucomannan and $2.6 \mathrm{~g}$ placebo, and $5.2 \mathrm{~g}$ placebo added to a normal carbohydrate-rich breakfast on plasma glucose, plasma insulin and breath hydrogen excretion. Glucomannan had no significant effect on the peak glucose increment $(4.4 \pm 0.6 \mathrm{mmol} / 1$ with placebo, $4.2 \pm 0.5$ $\mathrm{mmol} / \mathrm{l}$ with $2.6 \mathrm{~g}$ and $3.9 \pm 0.5 \mathrm{mmol} / \mathrm{l}$ with $5.2 \mathrm{~g}$ of the fibre). On the other hand, glucomannan induced a dose dependent significant $(p<0.05)$ inhibition of the postprandial decrease in plasma glucose $(2 \cdot 2 \pm 0.3 \mathrm{mmol} / 1$ during placebo, $1 \cdot 5 \pm 0 \cdot 2$ $\mathrm{mmol} / 1$ during $2.6 \mathrm{~g}$ and $0.7 \pm 0.9 \mathrm{mmol} / \mathrm{l}$ during $5.2 \mathrm{~g}$ of the substance) and of the peak insulin increments (154 $\pm 19 \mathrm{mU} / \mathrm{l}$ during placebo, $80 \pm 16 \mathrm{mU} / \mathrm{l}$ during $2.6 \mathrm{~g}$ and $75 \pm 21 \mathrm{mU} / \mathrm{l}$ during $5.2 \mathrm{~g}$ of glucomannan). Six of the patients had a breath hydrogen excretion of more than $15 \mathrm{ppm}$ during placebo, three after $2.6 \mathrm{~g}$ and one after $5 \cdot 2$ glucomannan.

We conclude that glucomannan is highly effective in preventing postprandial reactive hypoglycaemia in patients with previous gastric surgery.

\section{P64}

RP 40749 in the treatment of duodenal ulcer and its influence on serum gastrin, serum pepsinogen $I$ and gastrin content of the antral mucosa

G F NELIS, C B H W LAMERS, AND G PALS (INTRODUCED BY J J MISIEWICZ) Sophia Ziekenhuis, Zwolle, Radboud Ziekenhuis, Nijmegen, and Institute of Human Genetics, Free University, Amsterdam) We evaluated the effectiveness of two doses of a new $\mathrm{H}^{+}-\mathrm{K}^{+}$-ATPase antagonist (RP 40749, pyridyl-2-tetrahydrothiophene) in the treatment of 20 patients with duodenal ulcer. Treatment was prescribed doubleblind either as $100 \mathrm{mg}$ or $200 \mathrm{mg}$ as a single daily dose for four weeks. Blood samples and gastric biopsies were taken immediately before treatment and at the last day of treatment. There was a rapid clinical improvement and after four weeks all ulcers were healed endoscopically, except for one in the $100 \mathrm{mg}$ group. Side effects did not occur, there were no changes in the routine laboratory parameters and gastric histology.

We evaluated the influence of RP 40749 on basal and meal-stimulated serum gastrin and serum pepsinogen $I$ and the gastrin content of the antral mucosa. After treatment there was a significant rise in basal serum gastrin $(55.6$ vs 83.8$)$ and pepsinogen I (59.0 vs 136.7), meal-stimulated serum gastrin $(96.0$ vs 144.4) and antral gastrin $(17.2$ vs $27 \cdot 1)$. There were no major differences between the 100 and $200 \mathrm{mg}$ group.

\section{P65}

Effect of $\mathrm{H} 2$ receptor antagonists on prostaglandin E2 and leukotriene B4 production in duodenal ulcer disease

J P WALSH, F J BLOOMFIELD, W J MAXWELl, F P HOGAN, D KELLEHER, AND P W N KEELING (Department of Clinical Medicine, TCD Medical School, St James' Hospital, Dublin, Eire) Prostaglandins $(\mathrm{Pg})$ may play a role in the prevention and treatment of duodenal ulcer (DU) disease by antisecretory and cytoprotective mechanisms. The effects of pro-inflammatory leukotrienes (LT) have not yet been quantified. This study examines PgE2 and LT B4 production by peripheral blood monocytes (PBM) of DU patients, stimulated with opsonised zymosan, before and after four weeks treatment with $\mathrm{H} 2$ antagonists.

Twenty patients with active DU were studied. Reduced PgE2 production was seen in untreated DU compared with normal control subjects (CS) $(n=20$, $18 \cdot 2 \pm 1 \cdot 8$ vs $\mathrm{n}=20,40 \pm 8 \cdot 0 \mathrm{ng} / 10^{6} \mathrm{PBM}$, $\overline{\mathrm{x}} \pm \mathrm{SE} \mathrm{p}<0.001$, DU vs CS), with a rise after DU treatment to $19 \cdot 7 \pm 2 \cdot 45 \mathrm{ng} / 10^{6}$ PBM. Leukotriene B4 production was markedly raised in untreated DU compared to CS $(n=20,6 \cdot 1 \pm 1$ vs $n=10$, $1 \cdot 3 \pm 0.2 \mathrm{ng} / 10^{6} \mathrm{PBM}, \mathrm{p}<0.001$, DU vs CS) with a significant reduction to $3.94 \pm 0.60$ $\mathrm{ng} / 10^{6} \mathrm{PBM}$ after DU treatment.

Reduced PgE2 production in the untreated DU may result form diversion of arachidonic acid substrate to an activated lipoxygenase pathway with consequent enhanced LT B4 production. LT B4 may be of pathogenic importance in the persistence of chronic inflammation. Reversal of these abnormalities by $\mathrm{H} 2$ antagonists suggests an additional mode of action for these agents.

\section{P66}

Effect of sucralfate on isolated amphibian gastroduodenal bicarbonate secretion
J R CRAMPTON, L C GIBBONS, AND W D W REES (Department of Medicine, Hope Hospital (University of Manchester School of Medicine), Salford) Sucralfate is a basic aluminium salt of sucrose sulphate which exhibits ulcer healing and cytoprotective properties in man and experimental animals. There is evidence that its cytoprotective activity may be, in part, prostaglandin mediated and gastric luminal prostaglandin $E_{2}$ release has been shown to be stimulated by the drug. As prostaglandins of the $E$ series have been shown to stimulate gastroduodenal alkali secretion the effect of sucralfate on the rate of bicarbonate secretion by stripped bullfrog (Rana catesbeiana) antral, fundic and duodenal mucosa has been examined. An isolated chamber preparation has been used enabling $\mathrm{pH}$ stat titration of the luminal solution and recording of transmucosal potential difference. Addition of sucralfate $0.5 \mathrm{~g} / \mathrm{l}$ at $\mathrm{pH} 7.4$ to the mucosal side solution induced, within 15 minutes, an increase in the rate of bicarbonate secretion by fundus (mean \pm SE: $183 \pm 87 \%$, $\mathrm{n}=4, \mathrm{p}<0.05$ ) and antrum (mean $\pm \mathrm{SE}$ : $156 \pm 58 \%, n=5, p<0.005)$. At this concentration there was no effect on duodenum (mean \pm SE: $4 \pm 15 \%, n=6$, NS) but in a higher dosage of $1 \mathrm{~g} / 1$ there was an increase in alkalinisation (mean \pm SE: $42 \pm 15 \%$, $n=6, p<0 \cdot 05$ ). Transmucosal potential difference was not altered in these studies. These results suggest that the cytoprotective and anti-ulcer activity of sucralfate may, in part, be mediated by an increase in mucosal bicarbonate secretion and enhancement of the mucus-bicarbonate barrier.

\section{P67}

Measurement of increased pepsin degradation of mucus by gastric juice in peptic ulcer patients

D A HutTon, J P PEARSON, A ALLEN, W J CUNLIFFE, $C W$ VENABLES, AND $R$ WARD (Departments of Physiological Sciences and Surgery, University Medical School, Framlingon Place, Newcastle upon Tyne) The integrity of the protective adherent gastric mucus gel barrier is a balance between its secretion and its erosion by luminal pepsin and/or mechanical shear.

We have developed: (1) a sensitive assay for pepsin activity which measures new $\mathrm{N}$-terminal groups from cleavage of peptide bonds. (2) An assay for mucolytic activity of pepsin based on the fall in viscosity and the accompanying increase in new $\mathrm{N}$-terminal groups when gastric mucus 
is incubated with juice. (3) Quantitation of the different pepsin types in gastric juice by electrophoretic separation on agar gels, elution and asssay of pepsin activity.

At $\mathrm{pH} 2.0$ pepsin 1 had twice the mucolytic activity of pepsin 3 . At $\mathrm{pH} 4 \cdot 0$ pepsin 1 had six times more mucolytic activity than pepsin 3 and caused substantial mucolysis up to $\mathrm{pH} 5 \cdot 1$. Gastric juice from duodenal ulcer patients exhibited substantial mucolytic activity between $\mathrm{pH} 2$ to 5 , similar to pepsin 1 . Gastric juice from non-symptomatic volunteers exhibited little mucolytic activity above pH 4 .

These studies suggest increased peptic degradation of the mucus barrier, associated with higher pepsin 1 activity, could be important in the pathology of peptic ulcer patients.

P68

Treatment of duodenal ulcer by $\mathrm{H} 2$ blockade, large single daily dose, how much and when?

M DEAKIN, H GLENNY, J K RAMAGE, JANE MILLS, W BURLAND, S P GRAY, J BILLINGS, AND J G WILlIAMS (Department of Gastroenterology, Royal Naval Hospital, Haslar. Smith Kline and French Research, Welwyn,. Herts.) The therapeutic efficacy of a single night time dose of $\mathrm{H} 2$ antagonist is proven but treatment is usually given on retiring. During a 24-hour period the longest period of unbuffered intragastric acidity covers the evening and night. It is possible that more effective inhibition would be achieved by higher or earlier dosing.

We have undertaken identical studies of 24-hour intragastric acidity, nocturnal acid and pepsin output in two groups of volunteers with duodenal ulcers in remission, dosing at either $1800(n=8)$ or 2300 hours $(n=10)$.

Compared with placebo mean hourly hydrogen ion activity during the evening and overnight period (1800-0730) was decreased by $51.4 \%$ (cimetidine $800 \mathrm{mg}, 2300$ hours), 54\% (C800 mg, 1800 hours), 54\% (cimetidine $1600 \mathrm{mg}, 2300$ hours), $78 \%$ (C1600, 1800 hours) and 80\% (ranitidine $300 \mathrm{mg} 1800$ hours). Despite considerable reduction in overnight acid output by dosing at 1800 hours, decrease in pepsin output was less marked than following a 2300 hours dose. After dosing at 1800 hours $\mathrm{pH}$ readings ranged from $3-6$, (making significant denaturation unlikely), whereas after 2300 hours dosing with cimetidine $1600 \mathrm{mg}$ all specimens were anacidic, and denaturation of pepsin probably occurred.

While more effective overall control of intragastric acidity is achieved by 1800 hours dosing, we would not recommend dosing at this time because overnight acidity is sufficient to allow peptic activity to remain.

INFLAMMATORY BOWEL DISEASE

P69-84

\section{P69}

Serological studies in Crohn's disease

J P IBbotson, $R$ N ALlan, AND P PEASE (The Gastroenterology Unit, General Hospital, Steelhouse Lane, Birmingham) It has been suggested that cell-wall deficient forms of Pseudomonas maltophilia might be involved in the aetiology of inflammatory bowel disease. In addition, certain serotypes of Yersinia enterocolitica cause a selflimiting ileitis which resembles Crohn's disease. The aim of this study was to measure antibody levels to these organisms and to Klebsiella aerogenes, a common inhabitant of the gut, in sera from inflammatory bowel disease paitients.

Serum samples were obtained from 20 patients during exacerbation of Crohn's disease and from 20 age- and sex-matched patients with active ulcerative colitis and 20 healthy controls. Antibody levels were measured using an enzyme linked immunosorbent assay.

In comparison with control groups, a highly significant number of patients with Crohn's disease had raised antibody levels to $Y$ enterocolitica and $K$ aerogenes. Levels to $P$ maltophilia were not significantly raised. Patients with ileal Crohn's disease had significantly higher levels than those in other groups. There was no correlation between antibody levels and disease activity.

Although the raised antibody levels may be due to leakage of normal gut flora across a damaged mucosa, it could be that a range of organisms are primarily involved in the aetiology of the disease.

\section{P70 \\ Patient education in Crohn's disease}

H L SMART AND J F MAYBERRY (University
Hospital, Nottingham) Three hundred and fifty patients with Crohn's disease were offered an information booklet about their condition. This provided information on symptoms, investigations and treatment together with addresses of self help organisations. A copy was requested by 232 patients and 175 of these completed a questionnaire assessing its value. The majority of patients $(85 \%)$ who completed the questionnaire found the booklet helpful. but required more information about complications of the disease, long term prognosis, cancer risk and inheritance of the condition. Seventy eight per cent of the patients felt that such a leaflet should be given to all patients shortly after diagnosis. One year later a further survey was conducted to assess the effect this booklet had on anxiety and consultation levels. One hundred and sixty of the original group of 175 patients who completed the questionnaire were contacted and $78 \%$ responded. There was a significant reduction in anxiety; $30 \%$ of patients felt less anxious compared with $13 \%$ who were more anxious $\left(\chi^{2}=10.2 \mathrm{p}<0.005\right)$ and this was associated with a reduction in consultation rates by $17 \%$ of the patients compared with an increase by $5 \% \quad\left(\chi^{2}=8.5 \mathrm{p}<0 \cdot(005)\right.$. Improved patient education may alter the clinical management of this disease in the future.

\section{P71}

Expression of MHC Class I (HLA-A,B,C) and Class II (HLA-DR) antigens by colonic epithelium in human intestinal schistosomiasis

S BADR EL-DIN, L K TREJDOSIEWICZ, J OAKES, R V HEATLEY, AND A ABOU-KHADR (Depart ments of Medicine,, St James's University Hospital, Leeds, and Alexandria University, Egypt) The role of the expression of MHC antigens by epithelial cells has recently received considerable attention, and it has been shown that expression of HLA-DR is increased in epithelial cells of organs affected by some autoimmune diseases. In the bowel, HLA-DR expression by enterocytes is known to increase in Trichinella spiralis infection and in inflammatory bowel disease, although alteration of expression HLA-A,B,C has not been reported.

The expression of MHC antigens in colonic epithelium was studied by immunofluorescence with monoclonal antibodies on mucosal colonoscopy biopsies of 13 patients with intestinal schistosomiasis 
(six with schistosomal polyposis) and five normal Egyptian controls.

Normal colonic epithelium was negative for HLA-DR, but become HLA-DR + in schistosomiasis patients, expression being strongest by glandular epithelium. HLA$\mathrm{DR}+$ epithelium was observed in colonic mucosae of schistosomal colitis and shistosomal polyposis patients, as well as in the polyps themselves. By contrast, expression of HLA-A,B,C was high in the surface epithelium of controls, and only slightly weaker in the glandular epithelium. Essentially, no differences in HLA-A,B,C expression was observed in the patients, irrespective of whether polyposis was present.

These data suggest that colonic epithelium expresses Class II MHC antigens as a consequence of parasitic egg deposition, which in turn may allow the HLA-DR+ epithelial cells to act as antigen-presenting cells in the development and maintenance of local anti-parasite immunity.

\section{P72}

T-lymphocyte subsets in the colonic mucosa of patients with intestinal schistosomiasis

S BADR EL-DIN, L K TREJDOSIEWICZ, J OAKES, R V HEATLEY, G JANOSSY, AND A ABOU-KHADR (Departments of Medicine, St James's University Hospital, Leeds, and Alexandria University, Egypt, and Academic Department of Immunology, Royal Free Hospital, London) The mechanisms of immune resistance to schistosomiasis are not fully understood, and it is not known why, in chronic intestinal schistosomiasis, about $10 \%$ of patients develop multiple colonic polyposis. Little is known of the role of $\mathrm{T}$ cell subpopulations in the local immune responses to parasite eggs.

$\mathrm{T}$ cell subsets were studied by doublelabel immunofluorescence in cryostat sections of colonoscopy mucosal biopsies using a panel of monoclonal antibodies. Thirteen patients with schistosomiasis (seven with schistosomal colitis and six with schistosomal colonic polyposis) and five normal Egyptian controls were studied, as were the actual polyps from two patients. In schistosomiasis, there were marked changes in the intra-epithelial $T$ cells: there was a significant increase $(p<0.05)$ in all patients in the percentage of $\mathrm{T}^{+}$(helper/inducer) cells, the majority of which co-expressed the T2 marker of T lymphocyte stimulation. There was also an increased tendency for the $\mathrm{T}^{+}$(cytotoxic/ suppressor) cells to co-express the $\mathrm{T} 1$ 'pan- $\mathrm{T}$ ' marker $(\mathrm{p}<0.01$ in schistosomal polyposis). In the lamina propria, there were no major differences between controls and schistosomal colitis patients, however, although in polyposis, the T4:T8 ratio was significantly decreased $(p<0.05)$, whereas paradoxically in the actual polyps, the T4:T8 ratio was greatly increased $(7: 1$ versus $2: 1$ ).

These results show that there are considerable alterations in immuno-regulatory $\mathrm{T}$ lymphocyte subpopulations in the colonic mucosa in chronic intestinal schistosomiasis. Polyp formation may be a function of infiltrating $\mathrm{T}^{+}$cells, which migrate from the lamina propria of the colonic mucosa.

\section{P73}

Enhanced prostaglandin E3 production by colonic epithelial cells and resident macrophages in inflammatory bowel disease

W J MAXWELL, F J BLOOMFIELD, F P HOGAN, J P WALSH, D KELLEHER AND P W N KEELING (Department of Clinical Medicine, TCD Medical School, St James's Hospital, Dublin, Eire) Prostaglandin $(\mathrm{Pg})$ produced in the colon may have important modulatory functions in inflammatory bowel disease. $\mathrm{PgE} 2$ is produced by both colonic epithelial cells and resident macrophages and has important cytoprotective and secretory effects. As recent evidence suggests that Pgs also act as immunomodulators in inflammatory bowel disease (IBD), the aims of this study were to assess the relative production of prostaglandin E2 (PgE2) by colonic epithelial cells and tissue fixed macrophages, isolated from inflamed (In) and non-inflamed (NIn) tissue from patients with IBD and challenged with opsonised zymosan. As controls, cells isolated from tumour free resection margins of colonic cancer (CC) were used.

PgE2 production by In colonic epithelial cells was enhanced relative to NIn cells $\left(\mathrm{n}=5,7 \cdot 8 \pm 1 \cdot 8\right.$ vs $\mathrm{n}=5,3 \cdot 3 \pm 1 \cdot 0 \mathrm{ng} / 10^{6}$ cells, $\overline{\mathrm{x}} \mathrm{SE}$, In $v s$ NIn $\mathrm{p}<0.02)$. Similar enhancement was seen by macrophages from In mucosa in response to $Z y(n=5$, $21 \cdot 8 \pm 5 \cdot 2$ vs $\mathrm{n}=5,8.9 \pm 1.9 \mathrm{ng} / 10^{6}$ cells In $v s$ NIn, $\mathrm{p}<0.02$ ). Control (CC) $\mathrm{PgE} 2$ production by epithelial cells was $9 \cdot 1 \mathrm{ng} / 10^{6}$ cells and macrophages $14 \pm 1 \mathrm{ng} / 10^{6}$ cells. PgE2 production by stimulated macrophages in this study were higher than those previously reported for spontaneous secretion indicating an enhanced response to immune challenge.

In conclusion, these data support the concept that increased local production of prostaglandins in areas of disease activity may be of pathogenic significance in the chronic inflammatory response.

\section{P74}

Inhibition of PgE2 secretion by Salazopyrin and prednisolone in normal and Crohn's disease monocytes

W J MAXWELL, F J BLOOMFIELD, F P HOGAN, J P WALSH, D KELLEHER, AND P W N KEELING (Department of Clinical Medicine, TCD Medical School, St James's Hospital, Dublin, Eire) Salazopyrin (SP) reduces intestinal prostaglandin $(\mathrm{Pg})$ secretion in Crohn's disease (CD). Salazopyrin and its active moiety, 5 amino salicylic acid are, however, both weak cyclooxygenase inhibitors. We studied the in vitro effects of direct addition and 24 hour preincubation with SP and prednisolone (Pred), a phospholipase A2 (PLA2) inhibitor on PgE2 secretion by peripheral blood mononuclear cells (PMBC) stimulated by opsonised zymosan $(\mathrm{Zy})$ or $\mathrm{Zy}+10 \mathrm{mMol}$ arachidonic acid (AA) for $30 \mathrm{~min}$ at $37^{\circ}$. Secretion was corrected for the number of esterase positive PBMC.

Crohn's disease monocytes had significantly enhanced $\mathrm{PgE} 2$ secretion compared with normal subjects (NS) when stimulated with $\mathrm{Zy}\left(\mathrm{n}=7,70 \pm 15\right.$ vs $\mathrm{n}=7,21 \pm 5 \mathrm{ng} / 10^{6}$ monocytes, $\overline{\mathrm{x}} \pm \mathrm{SE}, \mathrm{p}<0.001, \mathrm{CD}$ vs NS), and $\mathrm{Zy}+\mathrm{AA} \quad(\mathrm{n}=7,2343 \pm 577$ vs $\mathrm{n}=7$, $322 \pm 123 \mathrm{ng} / 10^{6}$ monocytes, $\mathrm{p}<0 \cdot 001$ ). Direct addition of SP resulted in a non significant increase in $\mathrm{PgE} 2$ secretion by both $\mathrm{CD}$ and NS monocytes using $\mathrm{Zy}$ stimulation only. Pred added directly had no effect on PgE2 secretion. Twenty four hour preculture with Pred, however, resulted in marked reduction of $\mathrm{PgE} 2$ secretion in both CD and NS using Zy stimulation $(78 \%$ and $69 \%$ reduction, $C D$ and NS respectively, partially reversible on addition of AA (16\% and $31 \%, C D$ and NS). A less marked inhibition of $\mathrm{PgE} 2$ secretion was seen following preculture withSP on Zy stimulation $(39 \%$ and $26 \%, C D$ and NS) which was reversible on addition of AA (2\% and $3 \%, \mathrm{CD}$ and NS).

Both Pred and SP reduced PG production by 24 hour cultured monocytes. This is not because of cyclooxygenase inhibition as it is reversible by addition of exogenous AA. Reduced PgE2 production by SP may be because of PLA2 inhibition. Alternatively because mixed mononuclear cells are used, it may be due to an indirect effect on intercellular signalling. 


\section{P75}

Factors affecting suppression of cell mediated immunity in inflammatory bowel disease

C AINLEY, J CASON, R A WOLSTENCROFT, B M SLAVIN, AND R P H THOMPSON (The Gastrointestinal Laboratory, Department of Immunology, and Department of Chemical Pathology, St Thomas's Hospital, London) There is abnormal suppression of cell mediated immunity (CMI) in ulcerative colitis (UC) and Crohn's disease (CD), but the factors involved are unknown. We have investigated the effect of spontaneous suppressor cell activity (SSCA) and indomethacin sensitive suppression (ISS) on lymphocyte transformation (LT) in relation to lymphocyte populations (LP) and nutrition in 24 controls (CO), 14 patients with UC and 31 patients with CD. Lymphocyte populations were estimated using OKT monoclonal antibodies. Lymphocyte transformation with phytohaemagglutinin (PHA) and Concanavalin A (Con A) were carried out in parallel (1) control LT; (2) 24 hour preincubation (SSCA assay); (3) with $1 \mathrm{mcg} / \mathrm{ml}$ indomethacin (ISS assay). Seventeen CD patients were normally nourished (nCD) and 14 malnourished, being $<90 \%$ of ideal body weight. The percentage OKT3 cells, and the OKT4:OKT8 ratio were normal in CD, but in UC the ratio was reduced (CO $1.93 \pm 0.07$ vs UC $1.12 \pm 0.19, \mathrm{p}<0.001)$. Control LT responses were reduced in malCD (PHA $\mathrm{p}<0.01$, Con $\mathrm{A}<\mathrm{p} 0.01$ ), but not in $\mathrm{nCD}$; in UC responses to Con A only were reduced $(p<0 \cdot 05)$. There were small increases in ISS in both UC and CD. In $\mathrm{UC}$ and $\mathrm{nCD}$ there were small reductions in SSCA. In malCD SSCA was increased (PHA p $<0.05$, Con $<A$ p 0.01), and was partially responsible for the reduced control LT of malCD.

In UC, LT is reduced with an abnormal OKT4:OKT8 ratio, but SSCA and ISS are normal. In $\mathrm{nCD}, \mathrm{LT}, \mathrm{SSCA}$ and ISS are normal. In malCD, $L T$ is reduced, in part due to increased SSCA. Malnutrition underlies abnormal CMI in CD.

\section{P76}

Peripheral blood $\mathrm{T}$ cell subsets in sclerosing cholangitis (PSC) and ulcerative colitis (UC)

G K SACHDEV, $R$ W G CHAPMAN, AND D P JEWELL (Gastroenterology Unit, Radcliffe Infirmary, Oxford) Previous studies of T cell subsets in patients with ulcerative colitis have produced conflicting results.
One explanation may be methodological because subsets have been evaluated using mononuclear cell suspensions. $T$ cell subsets have now been re-examined using whole blood smears.

Patients with UC ( $n=40$, remission 27 active 13), and PSC with UC in remission (eight) were compared with normal healthy control subjects (15) and patients with the irritable bowel syndrome or peptic ulcers (17). Blood smears were air-dried, fixed with acetone-methanol and stained with monoclonal antibodies: Dako-T1 (panT), Dako-T4 (helper), Dako-T8 (suppressorcytotoxic, CR23/43 (Ia).

Patients with active UC showed a significantly $(\mathrm{p}<0.001)$ lower proportion of $\mathrm{T}^{+}$ cells $(16 \%)$ than those in remission $(25 \%)$, the healthy controls $(27 \%)$ or disease controls $(24 \%)$. This difference was related to disease activity and not to length of history or therapy. Patients with PSC, whose UC was in remission, had significantly fewer $\mathrm{T}^{+}$cells than healthy controls $(19 \cdot 2, \mathrm{p}<0 \cdot 02)$. There were no differences between the groups for $\mathrm{T}^{+}, \mathrm{T}^{+}$or $\mathrm{CR} 23 / 43^{+}$cells.

We conclude that reduced proportions of peripheral blood lymphocytes of suppressor-cytotoxic phenotype are associated with active UC and PSC regardless of activity of the UC.

\section{P77}

Peanut lectin binding and dysplasia in multicolonic biopsies from patients with ulcerative colitis complicated by carcinoma

J B J FOZARD, S B GRIFFITHS, M F DIXON, A T R AXON, AND G R GILES (University Department of Pathology, Department of Surgery, St James's University Hospital, Leeds, and Gastroenterology Unit, Leeds General Infirmary, Leeds) The demonstration of dysplasia in the mucosa of patients with ulcerative colitis (UC) is important in cancer surveillance and may determine the need for surgery. There are problems in the interpretation of dysplasia especially in the presence of inflammatory changes. In a preliminary study using an immunoperoxidase technique we assessed 11 lectins for the identification of dysplasia in colectomy specimens from patients with UC peanut lectin bound in all cases of dysplasia.

We have now studied peanut lectin binding and dysplasia in 165 colonoscopic biopsies from patients with UC complicated by carcinoma $(n=6)$ and cancer free controls $(n=10)$. A significant increase in peanut lectin binding was found in biopsies from the cancer group $81 / 89(83 \%)$ compared with controls 43/67 (64\%) $\mathrm{p}=0.005$ $\chi^{2}$. Comparable rates of dysplasia occurred in the cancer $(32 / 98,32 \%)$ and control groups $(20 / 67,30 \%$. High grade dysplasia was absent, however, in the control group and universally present in the cancer group.

Peanut lectin binding is a sensitive indicator of cancer complicating UC, but lacks specificity. High grade dysplasia indicates the presence of carcinoma.

P78

Detecting premalignancy in the colon

J MATTHEWS, T COOKE (INTRODUCED BY A PARKINS) (Department of Surgery, Charing Cross and Westminster Medical School, London) We have previously reported that in an animal carcinogenesis model the mean DNA content per epithelial cell in the upper regions of the colonic crypts increases as carcinogenesis progresses. We have now studied the DNA content of colonic mucosa in patients with colorectal carcinomas.

Using microdensitometry, DNA content was measured in the cells in the proliferative and functional zones of histologically normal Feulgen stained sections taken adjacent to and distal from colonic carcinomas, and related to stem cell DNA content. DNA content was measured similarly in cytological brushings from the same areas and the percentage of $2 \mathrm{~N}$ cells calculated.

There was a significant increase in the amount of DNA in the proliferative cells adjacent to the tumours $(100 \% \pm 1 \cdot 3) \mathrm{com}$ pared to distally $(91 \% \pm 2 \cdot 0, \mathrm{p}<0 \cdot 002)$. Although a similar increase was seen in the functional cells adjacent to the tumours compared to distally the difference was not significant. In cytological preparations there was an increase in the proportion of dividing or aneuploid cells in the transitional mucosa $(7 \cdot 3 \%+1 \cdot 2)$ compared with distal mucosa $(3.5 \pm 0.9, \mathrm{p}<0.02)$ and to the mucosa of patients with non-cancer related bowel problems $(2 \cdot 1 \% \pm 0 \cdot 5, \mathrm{p}, 0 \cdot 001)$.

These techniques appear to be reliable in detecting early malignant or pre-malignant changes in the colonic mucosa patients.

\section{P79}

111 Indium granulocyte scanning in acute graft versus host disease after bone marrow transplantation 
S H SAVERYMUTTU, C O'BRIEN, J GOLDMAN, E GORDON-SMITH, A M PETERS, V CHADWICK, AND H J F HODGSON (Royal Postgraduate Medical School, Hammersmith Hospital, London) The successful use of bone marrow transplantation to cure aplastic anaemia and certain haematological malignancies has been hindered by acute graft versus host disease (GVHD), which affects primarily the gastrointestinal tract in addition to the liver and skin. Because intestinal GVHD displays many of the histological features of acute inflammatory bowel disease we have investigated the value of ${ }^{111}$ Indium granulocyte scanning in diagnosis and management.

Ten patients with suspected or definite GVHD after bone marrow transplantation were studied and scans compared with histological grading of rectal histology. Six patients with active GVHD showed extensive abnormal bowel activity on ${ }^{111}$ Indium granulocyte scan (both small and large intestinal activity) and five subsequently died. Rectal histology was abnormal in all six cases but in half the cases underestimated the severity of the disease. Three further patients were studied after treatment with methylprednisolone, when GVHD was quiescent and showed just localised ileocaecal involvement while rectal histology was normal. The remaining patient had a normal ${ }^{111}$ Indium granulocyte scan and subsequently GVHD was excluded.

${ }^{111}$ Indium granulocyte scanning shows clear differences between active and quiescent GVHD and appears to be a promising non invasive technique for assessing disease severity and prognosis in this difficult group of patients.

P80

Colonic permeability to ${ }^{51} \mathrm{Cr}$-EDTA in inflammatory bowel disease

R T JENKINS, D B JONES, R L GOODACRE, R H HUNT, AND J BIENENSTOCK (Intestinal Disease Research Unit, Departments of Pathology and Medicine, McMaster University, Hamilton, Ontario, Canada) The purpose of this study was specifically to measure colonic permeability to ${ }^{51} \mathrm{Cr}$-EDTA in Crohn's disease (CD) and ulcerative colitis (UC) after rectal administration. Five volunteers (four men, one woman; aged 21-43 years) served as the control group. Seven patients (four men, three women, aged 22-44 years) with colitis (one ileocolonic $C D$, one colonic $C D$, and five subtotal or total UC) also were studied. No bowel preparation was used. After normal evacuation of the bowel just before the test, $25 \mathrm{uCi}$ of ${ }^{51} \mathrm{Cr}$-EDTA in $30 \mathrm{ml}$ of normal saline $(\mathrm{pH} 6 \cdot 2,280 \mathrm{mOsm} / \mathrm{kg})$ was instilled into the rectum via a $30 \mathrm{~cm}, 8 \mathrm{~F}$, paediatric feeding tube, while the patient was supine in the left lateral position. Urine was collected for 24 hours. Volunteers were requested to retain the enema for at least two hours. Food and drink were allowed ad libitum. In the control group, urinary excretions of the probe ranged from 0.23 $1.42 \% / 24 \mathrm{~h}$ (mean $0.69 \% / 24 \mathrm{~h}$, SD $0.51 \%$ / $24 \mathrm{~h})$. In the patients with colitis, the 24 hour urinary excretions of the probe ranged from 2.95 to $21.57 \% / 24 \mathrm{~h}$ (mean $8 \cdot 17 \% / 24 \mathrm{~h}, \mathrm{SD} 6 \cdot 49 \% / 24 \mathrm{~h}$ ). The difference between the control group and patients was signifcant $(p<0 \cdot 03)$. This study emphasises that colonic absorption of ${ }^{51} \mathrm{Cr}$ EDTA does occur in health and that increased permeability may be found in patients with extensive colitis.

\section{P81}

An audit of ulcerative colitis in a district general hospital

H W JONES, J GROGONO, AND A M HOARE (Wycombe General Hospital, High Wycombe, Bucks) Previous reports have shown a high mortality for ulcerative colitis (UC) in district hospitals. We have carried out an audit of all patients with UC in one health district (pop 270000 ) between 1975-1984. The incidence and prevalence were 6.7 and $70 / 100000$ respectively. Ninety six patients required 114 admissions with acute colitis. Before admission $37.5 \%$ were undiagnosed. Nineteen per cent required emergency surgery. There were no deaths from acute colitis suggesting an improved prognosis for colitis in district hospitals. Three hundred and two patients were followed for 1151 patient years. Colonoscopy performed routinely eight to 10 years after diagnosis detected two Dukes' A carcinomas and one severe dysplasia. Seventeen per cent of patients initially assessed as having distal colitis were found to have extensive disease including the two with malignancy. Of 99 patients lost to follow up two represented with carcinomas, one died, being the only colitis related death. Therefore, close follow up and routine colonoscopy even of patients with apparent distal disease appears worthwhile. In this district the workload to examine all patients 10 years after diagnosis, and subsequently those with extensive disease biannually, requires an estimated 30 colonoscopies/year.

\section{P82}

Clinical importance and complications of the early postoperative water-soluble contrast enema

I G HAYNES, M GOLDMAN, S H SILVERMAN, J R LEE, J ALEXANDER-WILLIAMS, AND $M \quad R$ KEIGHLEY (The General Hospital, Birm: ingham) The early postoperative watersoluble contrast enema (WSCE) is a well established technique to assess the integrity of large bowel anastomoses. We have assessed the safety and accuracy of a WSCE from a prospective series of 117 consecutive patients undergoing colorectal operations.

Twenty four radiological leaks $(24 \%)$ were detected and 14 clinical leaks $(12 \%)$ occurred. In four patients (3\%), however, with clinical leaks, the anastomosis was radiologically intact. The overall accuracy of a WSCE was $84.6 \%$ (false positive $11.9 \%$, false negative $3.4 \%$; sensitivity $71 \%$; specificity $86 \%$ ).

Septicaemia occurred in five patients (4.2\%) after WSCE, one of whom died and only one patient had a radiological leak.

Fifty two patients $(44 \%)$ had a stapled anastomosis, and in 12 patients $(23 \%)$ the ring was disrupted on plain radiograph. All the clinical leaks after stapled anastomosis were identified by this non-evasive technique.

This study of postoperative WSCE indicates that the investigation is potentially dangerous and does not always identify clinically important anastamotic dehiscence.

\section{P83}

An analysis of anal sphincter competence by measurement of anal compliance

C P GIBBONS, A TROWBRIDGE, J J BANNISTER, AND N W READ (Departments of Surgery, Physiology and Medical Physics, University of Sheffield, Sheffield) The circular smooth muscle of the anal sphincter is required to contract sufficiently to close the anal canal in order to preserve continence, but also to stretch sufficiently to allow the passage of a stool. These functions depend upon the elastic properties of the sphincter, which have been little investigated. Anal distensibility was assessed in 14 normal men and 11 normal women by measuring sphincter pressures via perfused catheters, 
set into probes of increasing diameter $(0.4$ to $3.0 \mathrm{~cm}$ ) and connected to pressure transducers. Sphincter pressures during rest, maximum voluntary contraction, and inflation of a $100 \mathrm{ml}$ rectal balloon (minimum residual pressure) rose with increasing anal diameter between 0.4 and $2.0 \mathrm{~cm}$ $(p<0.001)$. Thereafter resting and squeeze pressures reached a plateau. The estimated sphincter tension was proportional to diameter over the whole studied range. The slope of this relationship (men $70 \cdot 5 \pm 4.4$ $\mathrm{g} / \mathrm{cm}^{2}$; women $57.5 \pm 2.3 \mathrm{~g} / \mathrm{cm}^{2}$; mean \pm SEM) increased $(\mathrm{p}<0.01)$ during squeezing (men $177 \cdot 1 \pm 3 \cdot 6$; women $126 \pm 12 \cdot 6)$ and decreased $(\mathrm{p}<0 \cdot 01)$ during rectal distension (men $32 \cdot 8 \pm 3 \cdot 5$; women $31 \cdot 0 \pm 2 \cdot 8)$. These results conform to a mathematical model of the anal sphincter as a thin elastic tube whose elasticity and intrinsic diameter change with the state of sphincter contraction. The model predicts that the smooth muscle itself cannot close the anal canal and shows the importance of the bulk and turgor of the vascular anal cushions in the maintenance of continence.

P84

Patients with pruritis ani leak liquids from the anal canal more readily than normal subjects

N S Ambrose, A ALlan, S SILverman, AND M R B KEIGHLEY (Department of Surgery, The Genral Hospital, Birmingham) We have assessed the physiological abnormalities in the anorectum of 20 patients with pruritis ani compared with 12 age matched controls.

A saline infusion $(1500 \mathrm{ml})$ test showed that leakage started after infusion of $425 \mathrm{ml}$ in patients with pruritis ani, compared with $1500 \mathrm{ml}$ in controls $(\mathrm{p}<0 \cdot 001)$.

The anal canal high pressure zone was greater in patients $(4 \mathrm{~cm})$ than controls $(3$ $\mathrm{cm})$. The resting anal canal pressures were also greater in patients $\left(100 \mathrm{~cm} \mathrm{H}_{2} \mathrm{O}\right)$ than controls $\left(82 \mathrm{~cm} \mathrm{H}_{2} \mathrm{O}\right)$. A similar trend was found with regard to the maximum squeeze pressures $(280 \mathrm{~cm}$ of water and $213 \mathrm{~cm}$ of water respectively). The degree of perineal descent was $1.5 \mathrm{~cm}$ in patients compared with $1.4 \mathrm{~cm}$ in controls. The rectoanal inhibitory reflex was absent in five of the patients $(25 \%)$ compared with only one control $(8 \%)$, however, the percentage reduction of anal pressure after $50 \mathrm{ml}$ inflation of a rectal balloon was greater in the patients with pruritis ani $(40 \%)$ compared with controls $(23 \%)$.

Results indicate that patients with prur- itis ani leak liquids through the anal canal more readily than controls, despite apparently normal sphincter pressures.

BSG/BASL: LIVER

P85-100

P85

Partial purification of a high molecular weight hepatotrophic factor from human serum

A C SELDEN, $R$ JOHNSTONE, S GUPTA, H DARBY, AND H J HODGSON (Department of Medicine, Royal Postgraduate Medical School, Hammersmith Hospital, London) Several circulating low molecular weight hepatotrophic factors have been associated with liver regeneration after partial hepatectomy including insulin, glucagon and epidermal growth factor (EGF). In contrast, we have partially purified a high molecular weight (approx 150000 daltons) factor from human serum taken 24 hours after partial hepatic resection. Hepatotrophic activity was shown on rat hepatocytes cultured in supplemented Williams E by $3 \mathrm{H}$-thymidine incorporation into DNA. The hepatotrophic factor, prepared by gel filtration and heparin-sepharose affinity chromatography, or EGF and insulin, were added 20 hours postplating of the cultures.

The 'hepatotrophic factor' stimulated DNA synthesis in a dose dependent manner $\left(161 \mu \mathrm{g} / \mathrm{ml}, \quad 0.42 \times 10^{6} \mathrm{dpm}{ }^{3} \mathrm{H} / \mathrm{mg}\right.$ protein, $320 \mu \mathrm{g} / \mathrm{ml}, 0.54 \times 10^{6} \mathrm{dpm}{ }^{3} \mathrm{H} / \mathrm{mg}$ protein), to a greater extent than dexamethasone alone $\left(0.293 \times 10^{6} \mathrm{dpm}{ }^{3} \mathrm{H} / \mathrm{mg}\right.$ protein). At concentrations studied the factor was $20 \%$ as potent as optimal concentrations of EGF plus insulin. A similar high molecular weight hepatotrophic factor from rat serum afer partial hepatectomy reached $60 \%$ the potency of EGF+insulin, suggesting either partial species specificity, or differing timerelationships of production of these factors after hepatic resection in different species.

\section{P86}

Effects of chenodeoxycholic (CDCA) and ursocholic (UCA) acids on gall bladder (GB) emptying

P HOWARD, G M MURPHY, AND R H DOWLING (Gastroenterology Unit, Division of Medi- cine, UMDS of Guy's and St Thomas's Hospitals, London) We previously showed that ursodeoxycholic acid treatment reduces GB emptying after a CCK infusion of a Lundh meal, in gall stone patients. We recently found, however, that net GB emptying after a liquid+solid meal is complex with early emptying, refilling and late emptying phases, superimposed on which are minute-by-minute episodes of filling and emptying. As the effect of other bile acids on this complex pattern is unknown, we studied the $\mathrm{GB}^{\circ}$ response to a meal of baked beans on buttered toast with milk before, and after six weeks treatment (15 mg per/kg per/d) with either CDCA (five men and two women) or UCA (four men). Treatment consistently increased preprandial GB volumes from $11 \cdot 2 \pm$ SEM $2.97 \mathrm{ml}$ to $19.6 \pm 3.20$ on CDCA and from $17 \cdot 6 \pm 9 \cdot 30$ to $32 \cdot 1 \pm 5 \cdot 58$ on UCA $(\mathrm{p}<0.05)$, and late nadir volumes from $2 \cdot 09 \pm 0 \cdot 86$ to $5 \cdot 36 \pm 0 \cdot 5 \mathrm{ml}$ on CDCA and $4 \cdot 23 \pm 0 \cdot 6$ to $12 \cdot 4 \pm 2 \cdot 2 \mathrm{ml}$ on UCA $(p<0.05)$ with corresponding changes in the early nadir and refilling volumes. The overall emptying time was not altered by CDCA, though with UCA is decreased from $122 \pm 5 \cdot 8$ to $88 \pm 9 \cdot 2$ minutes $(p<0 \cdot 05)$. The minute-by-minute changes in GB volumes were also greater during therapy so that the net flux of bile thorugh the GB increased in six of seven CDCA- and three of four UCA-treated subjects.

In summary we conclude that treatment with CDCA and UCA markedly increases GB size and flux of bile through the GB. UCA also shortens GB emptying time. These changes may relate to choleretic properties of the bile acids and to resultant changes in bile volume loads handled by the gall bladder.

\section{P87}

$\mathrm{HBV}$ infection and alcohol abuse: a synergic effect leading to a more severe liver disease or a casual association?

M CHIARAMONTE, A FLOREANI, D MARTINES, M SALVAGNINI, E PORNARO, AND R NACCARATO (Department of Gastroenterology, Policlinico Universitario, Padova, Italy) Eighty six (77 men) heavy drinkers - 29 HBsAg+ve, 13 antiHBs/antiHBc+ve, 14 antiHBc+ve, 30 negative for any HBV marker - were studied to verify whether: (1) the HBV can be responsible for chronic hepatitis in alcoholics; (2) the concomitant presence of $\mathrm{HBV}$ infection and alcohol abuse enhances the severity of the disease. Histological features of $\mathrm{ACH}$ were present 
in 12 patients $(14 \%)$ (six $\mathrm{HBsAg}+\mathrm{ve}$, five antiHBc+ve and/or antiHBs + ve and one HBV negative) and of $\mathrm{CPH}$ in $13(15 \%)$ (six $\mathrm{HBsAg}+$ ve. three antiHBc/antiHBs+ve and four $\mathrm{HBV}-\mathrm{ve}$ ); four $\mathrm{HBs} \mathrm{Ag}+\mathrm{ve}$ patients had signs of acute hepatitis superimposed on cirrhosis. Thirty patients had cirrhosis $(11 \mathrm{HBsAg}+\mathrm{ve}$ and eight antiHBV+ve) and 27 steatosis (two $\mathrm{HBs} \mathrm{Ag}+\mathrm{ve}, 10$ antiHBV+ve and $15 \mathrm{HBV}$ negative). Liver tissue $\mathrm{HBcAg}$ was detected by indirect immunofluorescence in $50 \%$ of $\mathrm{HBs} \mathrm{Ag}+$ ve patients (but without relationship with serum $\mathrm{HBeAg} / \mathrm{antiHBe}$ positivity), in $33 \%$ of antiHBV+ve patients and in one of $30 \mathrm{HBV}$ serum negative patients. The clinical course had been very severe in $\mathrm{HBsAg}+$ ve patients: four aged 25, 31, 43, 44 years, died of liver failure, while none of the $\mathrm{HBs} \mathrm{Ag}$ negative died during a comparable follow up period. The prevalence of 'severe' liver disease (cirrhosis or $\mathrm{ACH}$ ) was $80 \%$ in the $\mathrm{HBsAg}+\mathrm{ve}, 61 \%$ in antiHBs/antiHBc+ve and $33 \%$ in $\mathrm{HBV}$ negative.

We conclude that (1) the HBV has a putative aetiopathogenic role in chronic hepatitis in alcoholics; (2) alcohol abuse enhances HBV pathogenicity and - vice versa - the course of alcoholic liver disease is accelerated by the HBV infection.

\section{P88 \\ Assessment of portal vein patency: value of ultrasound scanning}

N RABY, J KARANI, P POWELL-JACKSON, H MEIRE, AND R WILLIAMS (Liver Unit, King's College Hospital, and School of Medicine and Dentistry, Denmark Hill, London) The value of ultrasound scanning (USS) for estimating portal vein (PV) patency has not been assessed previously in a large series. In the present study the accuracy of USS was estimated either by comparison with the findings at operation (21 patients) or with the findings after aortoportography (94 patients). In the first group, USS was accurate in $18(86 \%)$. Non-visualisation of the PV by USS in one and misdiagnosis of PV occlusion in two was attributed in each instance to distortion of hepatic anatomy by shunt surgery in two and a Kasai operation in one. In the second group, confirmation of USS findings was obtained by aortoportography in $73(78 \%)$. Nonvisualisation of the PV by USS could be explained in eight of 11 patients as due to portal vein thrombosis (two), hepatic malignancy (four), aberrant PV (one) and previous shunt surgery (one). Misinterpre- tation of USS findings in five could be attributed to cavernous transformation of the PV (two), hepatic malignancy (two), and previous Kasai operation (one). In conclusion, the accuracy of USS for estimating PV patency is high but in cases complicated by previous Kasai operation or shunt surgery, aortoportography should also be carried out.

\section{P89}

Comparison of lactulose and lactitol on ileal and colonic pH

D $\mathrm{H}$ PATIL, D WEstaby, $Y$ R MAHIDA, $K$ R PALMER, R REES, M L CLARK, AND D B A SILK (Departments of Gastroenterology, Central Middlesex Hospital, London, and St Bartholomew's Hospital, London) Lactitol is an unabsorbed disaccharide with a defined laxative threshold. It has superior taste properties to lactulose and has been suggested as an alternative to lactulose for treatment of chronic hepatic encephalopathy. The aim of the present study was to compare the effects of these two sugars on luminal $\mathrm{pH}$ in the terminal ileum, colon and rectum of five normal subjects. The luminal $\mathrm{pH}$ was recorded every one to two hours using a $\mathrm{pH}$-sensitive radiotelemetering device, either after ingestion of a normal diet, or this supplemented with sufficient lactulose or lactitol to produce 2-4 semiformed stools daily. Neither sugar had an effect on terminal ileal $\mathrm{pH}$ (basal $7 \cdot 48 \pm 0 \cdot 40$; lactulose $7 \cdot 20 \pm 0 \cdot 48$; lactitol $7 \cdot 02 \pm 0 \cdot 31$, mean \pm SD). The $\mathrm{pH}$ of the right colon (basal $6 \cdot 36 \pm 0 \cdot 32$ ) was significantly lowered during ingestion of both lactulose $(5 \cdot 1 \pm 0 \cdot 89)$ and lactitol $(5.78 \pm 0.45 ; p<0.05$ or less). There was no significant difference between the acidification properties of the two sugars. Neither lactulose or lactitol had a significant effect on the $\mathrm{pH}$ of the left colon or rectum. If the mode of action of lactulose in the treatment of hepatic encephalopathy is dependent upon its ability to lower right sided colonic $\mathrm{pH}$, then our data lend support to the suggestion that lactitol may also have a role to play in the treatment of this condition.

\section{P90}

Effects of dietary protein on plasma and CSF amino acid levels: correlation with the degree of encephalopathy

S A JENKINS, N B ROBERTS, J N BAXTER, G SKERRITT, AND R SHIELDS (Departments of Surgery and Veterinary Anatomy, Univer- sity of Liverpool, Liverpool) There is little information on the precise relationship between diet and the development of hepatic encephalopathy (HE) after portacaval shunting (PCS). Therefore, we studied the effects of varying protein diets on plasma and CSF amino acid profiles and the development of HE in dogs with a PCS. Fasting blood and CSF samples were taken for amino acid and ammonia estimations from four dogs with a PCS at the end of 28 days of respectively protein free (control period), $15 \%$ and $40 \%$ protein diets. The degree of $\mathrm{HE}$ was assessed at the time of sampling. Normal fasting ranges of CSF and plasma amino acids were determined in dogs without a PCS. The degree of HE increased with increasing protein intake. There was a marked decrease in plasma levels of branched chain amino acids in non-shunted dogs which did not alter with increasing protein intake. In contrast, plasma phenylalanine, glycine and ammonia levels increased with higher protein intake. The marked encephalopathy at the end of the $40 \%$ protein regimen was associated with significant increases in CSF ammonia (52 to $316 \mu \mathrm{mol} / \mathrm{l}$ ), glutamine (1126 to $2919 \mu \mathrm{mol} / \mathrm{l}$ ), phenylalanine (51 to $75 \mu \mathrm{mol} / \mathrm{l}$ and glycine (22 to $172 \mu \mathrm{mol} / \mathrm{l})$ (Students $t$ test; $\mathrm{p}<0 \cdot 05$ ). However, CSF, GABA and tryptophan showed no consistent change. The results suggest; (1) portacaval shunting maintains low levels of branched chain amino acids irrespective of dietary protein intake; $(2)$ the effects of a high protein diet on CSF amino acids and ammonia may have important implications in the management of patients with $\mathrm{HE}$.

P91

Detection of CA-50 in serum from patients with malignant liver disease

N A HABIB, M hERShMAN, A GRAUER, M BLOUNT, L LINDHOLM, J HOLMGREN, AND C B wood (Department of Surgery, Royal Postgrauate Medical School, London, Department of Medical Microbiology, University of Goteborg, Sweden) Malignant transformation of the cell is accompanied by changes in surface glycolipids. A monoclonal antibody $\mathrm{C}-50$ was raised against a tumour associated antigen, CA50 which has been isolated as a complex mono sialoganglioside from a high percentage of various carcinomas. A solid-phase RIA-inhibition test was developed for detection of CA-50 in serum from tumour patients. A total of 137 patients were studied, 83 with liver tumours, 24 control 
and 30 normal subjects. Among the cancer patients studied there were 25 with hepatocellular carcinoma (HCC), 20 cholangiocarcinoma and 36 with secondary liver neoplasms and two with angiosarcomas. The control patients included 10 liver cirrhosis, six iatrogenic biliary stricutre. three haemangioma, two sclerosing cholangitis, two hydatid disease, two intrahepatic cholelithiasis, two liver cyst, two adenoma and one liver sarcoidosis.

The CA-50 RIA test was positive in 15 $(60 \%)$ HCC, $14(70 \%)$ cholangiocarcinoma and $26(72 \%)$ of those with secondary liver neoplasms. The test was negative in the two patients with angiosarcoma, all control patients and in all normal subjects. Therefore the CA-50 RIA test could help in the differential diagnosis of pathological liver conditions.

\section{P92}

Expression of oncogene related proteins in human malignant liver neoplasms

N A HABIB, H NIMAN, A THOMPSON, AND C B wood (Department of Surgery, Royal Postgraduate Medical School, London, and Department of Molecular Biology, Scripps Research Centre, La Jolla, USA) Proto oncogenes are responsible for normal cell growth and their conversion into activated cellular oncogenes are associated with cancer. We investigated the expression of ras-oncogene product in human liver with the use of monoclonal antibodies raised against $\mathrm{c}-\mathrm{Ki}$-ras oncogene normal product (Mo-EP). Using the peroxidase-antiperoxidase technique, liver tissue was stained with Mo-RAP to a concentration of $1: 200$. The patients studied were five normal, 10 hepatoma and 20 colorectal liver secondaries. Positive staining in the cytoplasm was found in six of the 10 hepatomas and 16 of the 20 liver secondaries. The remaining cancer patients and the five control patients (apart from weak nonspecific staining in the connective tissue) had negative hepatocytes staining. These findings suggest that liver tissue may express ras-oncogene in carcinoma and this may offer new diagnostic and therapeutic applications.

\section{P93}

Lack of osteomalacia in chronic active hepatitis on maintenance corticosteroid therapy

A J STELLON, J COMPSTON, AND R WILLIAMS
(Liver Unit, King's College Hospital, London SE5, and Department of Histopathology, St Thomas's Hospital, London SE1) Subnormal 25-hydroxyvitamin-D (25-OHD) levels have been reported to occur in $45-60 \%$ patients with chronic active hepatitis (CAH), although the number that developed osteomalacia is uncertain as diagnostic iliac crest histology was performed in few patients. We report serum 25-OHD levels and iliac crest histology to determine the incidence of osteomalacia in 36 patients, aged 20-66 years, 34 women, with biopsy-proven $\mathrm{CAH}$, in biochemical and histological remission, of whom 23 had cirrhosis on biopsy. All had received prednisolone therapy for one to 12 years (median 3.6 years) and the maintenance dose ranged $5-12.5 \mathrm{mg} /$ day (median $10 \mathrm{mg}$ ). All patients had an iliac crest biopsy to determine total trabecular bone volume (TBV), mean osteoid seam width (MOSW) and mineralisation lag time (MLT). Osteomalacia was defined if MOSW was $>15 \mu \mathrm{m}$ coupled with a MLT $>100$ days. 25-OHD levels were low in four $(11 \%)$ patients, TBV was significantly lower in the patients when compared to age and sex-matched controls $(19 \cdot 2 \pm 4.6$ vs $23.5 \pm 5 \cdot 8$ respectively; $p<0.001)$. No patient was found to have an MOSW $>15 \mu \mathrm{m}$ and the mean values were not significantly different from controls $(8.41 \pm 2.202$ vs $9 \cdot 59 \pm 2 \cdot 36$ respectively; $p=N S$ ) but MLT was significantly prolonged in the patients $(28 \cdot 4 \pm 310$ vs $13 \cdot 7 \pm 8 \cdot 4$ respectively; $\mathrm{p}<0 \cdot 01)$. Low TBV and absent osteomalacia suggests that osteoporosis is the metabolic bone disorder associated with steroidtreated $\mathrm{CAH}$

\section{P94}

Prophylactic chemotherapy after operations for hydatid disease - an animal study

D L MORRIS, JANET B CHINNERY, AND J D HARDCASTLE (Department of Surgery, University Hospital, Nottingham) There is approximately a $10 \%$ risk of recurrence after operation for hydatid cyst (Echinococcus granulosus). The surgical treatment of recurrent disease is associated with considerable morbidity and whilst chemotherapy with Mebendazole, and more recently Albendazole has been investigated in such patients, prevention of recurrence would have great advantages.

In order to study the effect of Albendazole on the development of cysts, 25 gerbils were given intraperitoneal infections of live
E granulosus protoscoleces. Vine gethil remained as untreated controls. Seres received Albendazole 11 me he oralls to one week before injection and cight ro ceived the same dosage for onc week afte infection. The animals were killed at vis months. A!l control animak dereloped peritoneal cysts. They had a mean number of $44 \cdot 1$ (SD16.5) custs per gerbil while in eight gerbils who received Albendazole after infection. two had no crist and the mean number of cysts was (SD) $(p<0 \cdot 01)$. The cysts which did develop in the treated animals were of similar s controls. There was no significant reduc tion in number of cysts in the animal treated before infection $(39.1)$. He conclude tht even a short postoperatise course of Albendazole is likcly to ignificantls reduce the number of spilled protoseoleces which are able to implant and grom in! cysts.

\section{P95}

Importance of clinical staging for prognosis in primary biliary cirrhosis

O EPSTEIN, E FRAGi, WD S SHIRIOH (Departments of Medicine and Surve's Royal Free Hospital Scheol of Medicine London) In PBC. the ancesment prognosis is important or individual pa. tients, interpretation of clinical trials and timing of liver transplantation. Based on group of 56 poor risk PBC patients who died of their liver disease. we hate devined a staging protocol to provide guidelines for the rational management of the disease. () 15 patients referred with bilirubin kele $>100 \mu \mathrm{mol} / 1,12$ died within two vears and all had succumbed within three vears. Fourteen of 24 patients referred with bili rubin levels $<34 \mu \mathrm{mol} / /$ survived for five w 13 years. Serum bilirubin kevels of all patients were pooled at vearly interval. indicated that on average. simptomatic patients with normal serum bilirubin level reach a level of $34 \mu \mathrm{mol} /$ within five vear and $100 \mu \mathrm{mol} / \mathrm{l}$ within 10 vears. Death usually occurs within two vears of reaching this level. Primary biliary cirrhosis can be divided into four stages. Stage $A$ : astrmptomatic, normal bilirubin (normal life ex. pectancy); stage B: symptomatic hilirubin $<34 \mu \mathrm{mol} / \mathrm{l}$ (survival seven to 1.3 vears). stage C: bilirubin $34-100 \mu \mathrm{mol} /$ (survival two to seven years): stage I): bilirubin $>100 \mu \mathrm{mol} / \mathrm{l}$ (survival lew than two vears) Stage A patients do not require specific treatmment. Clinical trials of medical treat. ment should focus on stage $B$ and ( discase 
and liver transplantation should be con- have preferred the recently described sidered in stage $\mathrm{D}$.

\section{P96}

Long term prognosis of Budd-Chiari syndrome

S GUPTA AND H J HODGSON (Department of Medicine, Royal Postgraduate Medical School, London) The Budd-Chiari syndrome is commonly considered a serious condition with progressive deterioration and a high mortality. It is, however, an heterogeneous condition, and we have analysed the histories of 18 patients seen over 20 years to elucidate determinants of prognosis.

In all patients diagnosis was based on liver biopsy and/or hepatic venography. In seven men and 11 women, mean age 37.6 (19-60 years range), symptoms had been present on average for 6.6 months before diagnosis. Patients were followed for 4.7 years (range 0.5-19). Eight patients died $(44 \%)$, two after surgery, two because of associated tumours, and four from complications of hepatic failure. Acturial analysis showed a one year mortality of $22.9 \%$, and three years of $51.1 \%$, but no further mortality beyond this period. A poor prognosis was associated with an associated malignancy, and bleeding from oesophageal varices, but in the absence of these features the prognosis is unexpectedly good. The 10 survivors all lead normal lives with control of symptoms by medical means, though in two surgical therapy (side-to-side shunt or removal of hepatic venous webs) has been necessary. Many patients with Budd-Chiari syndrome have only mild symptoms and a good prognosis.

\section{P97}

Liver biopsy in patients with impaired coagulation - which route?

M V TOBIN AND I T GILMORE (Gastroenterology Unit, Royal Liverpool Hospital, Liverpool) Histology is crucial in the investigation of hepatic disease but there is still a signifcant morbidity and mortality associated with conventional liver biopsy. Its safety, however, has usually been evaluated in patients with normal coagulation and the complication rate in those with prothrombin times greater than 15 seconds or platelet counts below $80 \times 10^{9} / \mathrm{l}$ is unknown.

In our unit during the past three years, in patients with impaired coagulation, we 'plugged' biopsy to the transvenous approach. Sixty five patients with prothrombin times prolonged by up to eight seconds or platelet counts as low as $20 \times 10^{9} / 1$ have been biopsied and the needle track filled with absorbable gelatin sponge. The technique is straightforward and there have been no complications. Specimens have all been satisfactory for histological examination and superior to those taken transvenously. Our results are sufficiently encouraging to recommend its use in this high risk group in preference to the laparoscopic or transvenous approach which both require more expertise, equipment and time.

P98

Long-term oral contraceptive use and serum total cholesterol and total bile acids

P R BAKER, J S BUMBRA, A D REID, P E PREECE, AND J D E KNOX (University Departments of Surgery and General Practice, Ninewells Hospital and Medical School, Dundee) Oral contraceptive steroids (OC) increase the cholesterol saturation index of bile and are associated with raised serum total cholesterol concentrations. Changes in serum bile acid levels might also be expected, especially after several years use of OC comprising ethinyloestradiol (EE) and a progestogen. Serum concentrations of total cholesterol (CHOD-PAP method) and total bile acids (TBA; Sterognost$3 \alpha$ Flu assay) were therefore determined in 10 women $(27 \cdot 8 \pm 4.7$ years (mean $\pm S D)$ with well documented long-term EE/progestogen OC intake and compared withlevels in 10 age-matched women (26.0 04.9 years) from the same general practice who had never taken OC (NON-OC). The OC were taken, as prescribed, continuously for 3-12 years (mean 5.6 years), and total oestrogen and progestogen intakes were estimated as 25-156 mg and 93-2948 mg respectively, and all were currently on 30 $\mu \mathrm{g} \mathrm{EE}$ and 50-250 $\mu \mathrm{g} \mathrm{L-Norgestrel.} \mathrm{Blood}$ was taken between 1800 and 1845 hours after a six hour fast and serum obtained within one hour. Total cholesterol (mM) were significantly higher in the $\mathrm{OC}$ group $(5.83 \pm 0.57$ (mean $\pm S D)$ vs $4.75 \pm 0.67$; $\mathrm{p}<0.05$, t-test) and four of these women had values $>5.7$ (suspicion limit) compared with only one in the NON-OC group. Serum TBA $(\mu \mathrm{M})$ was lower in women on OC $(3 \cdot 7 \pm 1.9$ vs $6 \cdot 1 \pm 2 \cdot 8)$ although the difference was of border-line significance (Mann-Whitney $U=24, z=1.968$ (cor- rected for ties); $t=2 \cdot 25)$. The TBA/ cholesterol molar ratio was significantly lower in the OC group $\left(0.7 \pm 0.4 \times 10^{-3} v s\right.$ $1 \cdot 3 \pm 0.7 \times 10^{-3} ; \mathrm{p}<0.05$, Mann-Whitney) and the two constituents exhibited a negative correlation $(r h o=0.51, p<0.025)$. There was, however, no correlation between total cholesterol or TBA and total duration or total amount of OC steroid intake. Oral contraceptive steroid intake over several years appears to result in a relatively large increase $(23 \%)$ in serum total cholesterol and a decrease in serum total bile acids which might reflect a change in the output of bile acids by the liver.

P99

Biopsy findings in liver allograft rejection

S HUBSCHER, D CLEMENTS, E ELIAS, AND P MCMASTER (Queen Elizabeth Hospital, Edgbston, Birmingham) It is difficult to distinguish liver transplant rejection from other causes of graft dysfunction on the basis of histological criteria alone. Early studies, based mainly on necropsy findings, reflect this problem and the histological features which characterise rejection remain the subject of controversy.

During the past 12 months we have routinely carried out needle biopsies in the assessment of abnormal liver function after transplantation. In all cases a diagnosis of rejection was based on excluding other known causes of graft dysfunction by microbiological, serological and radiological criteria. Changes ascribed to rejection were seen in 15 biopsies from five patients. The features of acute rejection were (1) a mixed portal inflammatory infiltrate and (2) infiltration of bile duct epithelium by polymorphonuclear leukocytes. In one patient this was followed by complete loss of small bile ducts and the need for retransplantation. In a second patient there was chronic bile duct damage resembling that seen in graft-versus-host disease. In the other three cases there was clinical and histological improvement following immunosuppressive therapy.

We conclude that liver biopsy is useful in the diagnosis and management of rejection after liver transplantation.

\section{P100}

Increased permeability to proteins of hepatic tight junctions in $\alpha$-naphthylisothiocyanate (ANIT)-treated rats

K S KAN, P J LOWE, AND $R$ COLEMAN 
(Department of Biochemistry, University of Birmingham, Birmingham) The movement of proteins from blood to bile has been studied using isolated perfused liver operating under one pass conditions. After a one minute perfusion pulse of horseradish peroxidase (HRP) two peaks were observed in bile, at five, and at 20-25 minutes (abolished by colchicine and probably representing a vesicle mediated transcytosis). The first HRP peak was substantially increased in rats pretreated with ANIT, known to increase paracellular permeability, probably through an effect on tight junctions. There was no decrease in bile flow within the time-period of the present experiments (until 15 hours), and thus the effects represent one of the earliest stages in ANIT-cholestasis.

Rats were treated with ANIT 0-15 hours before pulsing with HRP. Biliary concentration, in the five minute peak, of copulsed inulin (MWt 5000) rose steadily over the dose period, but the peak of HRP (MWt 40000 ) and of ovalbumin (MWt 40000 ) began to rise only after 10 hour exposure to ANIT, suggesting that the extent of ANIT-increased permeability is dependent upon the molecular weight. The five minute HRP peak was increased after only two hours of ANIT exposure in phenobarbitone-treated rats suggesting that ANIT metabolites, rather than ANIT alone, may be involved.

\section{COLORECTAL}

P101-117

\section{P101}

Laparotomy: still a valuable investigation in patients with bleeding from the intestine

S BREARLEY, P C HAWKER, N J DORRICOTT, R LEE, N S AMBROSE, P W DYKES, AND M R B KEIGHLEY (General Hospital, Birmingham) Bleeding lesions of the small intestine and colon are often difficult to diagnose despite the availability of a wide range of diagnostic techniques. In recent papers, laparotomy has not been recommended and particularly good results have been claimed for selective mesenteric angiography.

Sixty three patients who had had either colonoscopy or mesenteric angiography while being investigated for intestinal bleeding were reviewed. Twenty six had had trivial bleeding and were not consi- dered further. The remaining patients could be divided into two groups, 14 with occult bleeding and 23 who had had a major intestinal bleed. Colonoscopy was diagnostic on six of 37 occasions (two of 15 following occult bleeding and four of 22 after major haemorrhage). Angiography was diagnostic on three of 14 occasions (occult bleeding none of three, major bleeding three of 14). Thirteen undiagnosed patients had a laparotomy which was diagnostic in nine (occult bleeding three of three, major bleeding six of 10). Patients with intestinal bleeding should have upper and lower gastrointestinal endoscopy. Undiagnosed patients who continue to bleed should have a laparotomy with an endoscopist available to undertake on table panendoscopy. Angiography should be reserved for the few patients still undiagnosed after laparotomy and should be carried out in centres with special expertise in the technique.

\section{P102}

Modified oxygen electrode as a probe for detecting local blood flow in canine colon

C PIASECKI AND $S$ LAKE (INTRODUCED BY R POUNDER) (Department of Anatomy, Royal Free Hospital School of Medicine, London) There is a need for simple, fast, non-invasive probing of blood flow in areas of - for example $1 / 2 \mathrm{sq} \mathrm{cm}$. Postanastomotic colonic leakage might thus be prevented if local ischaemia was detectable peroperatively. A Clark type surface oxygen electrode was modified to perform this task. It does not measure $\mathrm{pO}_{2}$ because its oxygen consumption is high. Instead, it depletes the tissue of oxygen, the maintenance of which is dependent on inflow of blood. Thus the instrument's reading varies with blood flow. A $95 \%$ response is obtained in 20 seconds of application, thus sites can be probed at 15 second intervals.

The instrument was tested in six anaesthetised dogs. Electromagnetic blood flow in the inferior mesenteric artery was compared with probe reading on colon, at five levels of graded arterial constriction. A semi-linear relationship emerged $(r=0.91$; $\mathrm{p}<1 \%$ ), showing dependence on bloodflow. The electrode was more sensitive to flow changes at low flows that at high flows.

Being cheap, sterilisable, and simple to use, the instrument may prove valuable in detecting and grading areas with reduced flow.

\section{P103}

Comparison of low residue diet and purgation on different faecal occult blood tests

C Y YIU, L BAKER, P B BOULOS, AND C G CLARK (Department of Surgery, University College, London) It is generally accepted that a high fibre diet improves the yield of faecal occult blood tests in colonic lesions. It has been suggested that laxatives have a similar effect. We have examined this concept by testing stool specimens using all available test procedures. One hundred and thirty nine patients were included in the study and faecal occult blood testing was performed after a three day low residue diet and again after purgation with Picolax. Comparison was made between Hemo-Fec, Hema-Check, Haemoccult and FecaTwin tests. Patients were admitted for colonoscopy or surgery so that diagnosis was known.

The patients were divided into normal or pathological groups (cancer, polyp, diverticular, and inflammatory bowel diseases). The positive results in 74 patients with pathology before and 70 after purgation are compared with 42 normal subjects. Statistical analysis by the $\chi^{2}$ test showed no difference in the results before and after purgation. Hemo-Fec and FecaTwin were apparently statistically similar but better than Hema-Chek and Haemoccult which were not different. These results question the need for special bowel preparation for faecal occult blood testing and indicate that a positive occult blood test is not related to laxative intake. The choice of test will influence the diagnostic yield and the proportion of positive results in each pathological group.

\section{P104}

Is increased colonic prostaglandin $E_{2}$ a risk factor for colorectal cancer?

M R LEWIN, S PUGH, SIAN WILLIAMS, TINA BARTON, C G CLARK, AND P B BOULOS (Department of Surgery, University College, London) Several colorectal conditions are associated with an increased risk of colorectal malignancy. The commonest of these are ulcerative colitis and colorectal polyps. Previous studies have demonstrated that the synthesis of $\mathrm{PGE}_{2}$ by colonic mucosa is increased in the presence of UC. Other studies have shown it increased in colorectal cancer and postulated that $\mathrm{PGE}_{2}$ leads to a loss of normal growth restraint and the increased cyclooxygenase activity necessary to produce $\mathrm{PGE}_{2}$ pro- 
motes the formation of carcinogens from benzo(a)pyrene. We are interested in the adenoma-carcinoma sequence and have measured $\mathrm{PGE}_{2}$ synthesis in biopsies taken from polyps and cancers at colonoscopy. Normal mucosal samples were obtained at negative procedures. Biopsies were vortexed to stimulate $\mathrm{PGE}_{2}$ synthesis and released $\mathrm{PGE}_{2}$ measured by RIA. Results were (mean $\pm \mathrm{SD}$ in pg $\mathrm{PGE}_{2} / \mathrm{mg}$ wet weight): normals $102 \cdot 8 \pm 24 \cdot 3 n=11$, polyps $162 \cdot 1 \pm 29 \cdot 6 \quad \mathrm{n}=6 \quad(\mathrm{p}<0 \cdot 001$ vs normal $)$, cancers $177 \cdot 1 \pm 13 \cdot 1 \mathrm{n}=7$ ( $\mathrm{p}<0.001$ vs normals, NS vs polyps) and uninvolved mucosa of tumour bearing colons $117 \cdot 3 \pm 32 \cdot 6$ $\mathrm{n}=12(\mathrm{p}<0.002 v s$ polyps and cancers, NS $v s$ normals). We conclude that like other premalignant conditions of the colon, polyps synthesise increased quantities of $\mathrm{PGE}_{2}$ and that this may be a factor in the transformation of benign polyp to colonic cancer.

\section{P105}

In vitro binding and in vivo localisaiton of an anti CEA monoclonal antibody (C46)

N C ARMITAGE, K C BALLANTYNE, L DURRANT, R C HARRISON, A M L RILEY, I O ELLIS, A C PERKINS, AND J D HARDCASTLE (Departments of Surgery, Pathology and Medical Physics, University Hospital, Nottingham and Amersham International, Bucks) Antitumour monoclonal antibodies have been shown to localise in colorectal cancer by several workers. The directly measured tumour:non-tumour (T:NT) uptake in resected specimens after pre-operative injection of radiolabelled antibody has been only $2 \cdot 5-3 \cdot 3: 1$. A monoclonal antibody C46, raised against carcinoembryonic antigen was studied for in vitro binding and in vivo localisation to colorectal cancer.

Binding was measured by flow cytometry of disaggregated tumour cells from 15 primary and three metastatic/recurrent tumours and by immunoperoxidase staining in 18 cancers. Eight patients (seven primary, one recurrent) were injected preoperatively with ${ }^{111}$ In-labelled $\mathrm{C} 46$ and tumour and normal tissue from the resected specimens counted.

Binding of C46 was increased 10-fold, median fluorescence 463F1U (33-2203) compared with normal immunoglobulin 43F1U (24-86) $(U=20 \cdot 5, p<0 \cdot 0001)$. Immunohistologically intense staining was seen in $15 / 18$ sections, moderate staining in $2 / 18$ and only one section did not stain. The $\mathrm{T}: \mathrm{NT}$ uptake in resected specimens was mean $5 \cdot 8 \pm 1 \cdot 7: 1$ for primary cancers (seven) and 4.6:1 for the recurrence. All patients gave positive preoperative gamma camera images.

The high affinity and high T:NT ratio of $5 \cdot 8: 1$, considerably greater than previously reported, increases the prospects for effective targeting of antitumour agents with monoclonal antibodies.

\section{P106}

Duodenal bile acid profiles in patients with colorectal polyps

R J MOORHEAD, JOAN D DONALDSON, AND S T D MCKELVEY (Department of Surgery, The Queens University of Belfast, Belfast) It has been reported that patients with colorectal adenomas have increased concentrations of secondary bile acids in duodenal bile. To investigate this finding we have carried out an analysis of duodenal bile acids using gas liquid chromatography, in 38 patients with histologically proven adenomas and compared them with a group of controls matched for age and sex.

We have shown that the levels of chenodeoxycholic acid were significantly higher in those with polyps compared with controls (mean percentage $\pm S D$, 30.5\% $\pm 10 \cdot 6: 26 \cdot 5 \pm 9 \cdot 0: p<0 \cdot 04)$. The levels of cholic acid and deoxycholic acid did not differ significantly between the two groups. (Cholic acid: $47 \cdot 5 \% \pm 13 \cdot 0$ : $50 \% \pm 14 \cdot 1$ : deoxycholic acid $18 \cdot 7 \% \pm 7 \cdot 9$ : $22.2 \% \pm 12 \cdot 7)$. We have also shown an unidentified bile acid which was significantly more prominent in the polyp group compared with the controls $(2.9 \% \pm 4 \cdot 2$ : $0.9 \% \pm 1.6: p<0.02)$. The levels of chenodeoxycholic acid and of this unidentified bile acid correlated with the increasing malignant potential of the adenomas with respect to size, type and degree of dysplasia.

We have confirmed that the duodenal bile acids of patients with colorectal adenomas are abnormal when compared with controls. Contrary to the findings of the previous study we have shown the levels of chenodeoxycholic acid to be abnormally elevated in those with polyps, and have been unable to detect any significant differences in levels of deoxycholic acid. Further work is being done to identify the unknown bile acid

\section{P107}

\section{ABSTRACT WITHDRAWN}

P108

Influence of sialomucin at the resection margin on survival of patients with colorectal cancer

P M DAWSON, N A HABIB, R C N WILLIAMSON, AND C B Wood (Department of Surgery, Royal Postgraduate Medical School, London, and Bristol Royal Infirmary, Bristol) There is strong evidence to suggest that a predominant sialomucin production in the colonic mucosa represents a preneoplastic stage in the carcinogenic process. We therefore studied the relation between sialomucin at the resection margin and survival in patients with colorectal cancer. In a multicentre prospective trial, 204 patients have been followed for a mean of 14.8 months (SD 7.3 months). The presence or absence of sialomucins at the resection margin was studied histochemically using the High iron diamine-alcian blue (HID-AB) stain. There were 32 deaths relating to tumour recurrence: 15 deaths in the sialomucin positive group $(n=50)$ and 17 deaths in the negative group $(n=137)(p<0 \cdot 01)$.

Percentage survival was correlated with time and with the presence or absence of sialomucin in the resection margin. Regression analysis predicts $63.2 \%$ five year survival for patients with no sialomucin and $28.4 \%$ five year survival with sialomucin present. There was no significant statistical correlation between the sialomucin staining at the resection margin and Dukes' stage, tumour site or differentiation. Sialomucin production in either resection margin appears to be of poor prognostic significance.

\section{P109}

Incidence of colorectal cancer and polyps in a health care district: experience at one year of registration

M PONZ DE LEON, A ANTONIOLI, $S$ BONILAURI, K ARDUINI, A MERIGHI, G P RIGO, M PULVIRENTI, G GIBERTINI, $P$ DI DONATO, AND $F$ MANENTI (Istituto di Patologia Medica, Cattedra di Gastroenterologia, Divisione di Chirurgia generale, Università di Modena, Italy) From January 1984 a 'tumour registry' for colorectal cancer and polyps has been instituted in a predominantly urban population (263 546 inhabitants) of northern Italy. Based on the experience of the first year of registration, the purposes of this report were three-fold: (1) to determine the incidence of colorectal tumours in 
a rather homogeneous population; (2) to find out possible associated risk factors; (3) to ascertain if the data from registration could fit into the 'polyp-cancer theory'.

The observed incidence of colorectal cancer was 52.8 new cases $/ 100000 / 1984$ (53.4 in men, 52.2 in women). The incidence of polyps was 59.6 . cases $(83.4$ in men, 37.3 in women). The incidence in creased with age either for cancer or for polyps; however, polyps were more frequent than cancer until the sixties and the peak of incidence of polyps anticipated that of cancer by a five years period. Both cancer and polyps had a similar distribution in the large bowel, more than $60 \%$ being located in the left distal portion. No dietary (including alcohol) or occupational factor was clearly associated with colorectal cancer or polyps. Smoking was more frequent in patients with polyps than in those with cancer $\left(46.6 \%\right.$ vs $27.6 \%, \chi^{2}=5.61$, $\mathrm{p}<0.01$ ), presumably because of the male preponderance in the former group.

We conclude that the incidence of colorectal cancer in northern Italy is higher than that of many other european countries and comparable to that observed, on average, in the United States. No obvious risk factor could be detected during the first year of registration. The earlier rise of incidence of polyps - as compared to cancer - and the similar distribution in the various tracts of the large bowel lend further support to the 'polyp-cancer sequence'.

\section{P110}

Prospective comparison of ultrasonic scanning and static and dynamic isotope imag. ing in the pre-operative diagnosis of liver metastases from colorectal cancer

P J FINAN, S H LEVESON, G R GILES, P A WIGGINS, P J ROBINSON, AND H IRVING (Departments of Surgery and Diagnostic Imaging, St James's University Hospital, Leeds) The pre-operative detection of hepatic metastases from colorectal cancer is of importance for accurate staging and planning of adjuvant therapy. Assessment has relied previously on a variety of imaging techniques including static isotope scanning ultrasound and computerised tomography. Isotopically measured liver blood flow ratios have previously been described for the detection of hepatic metastases. We wish to present a prospective comparison of ultrasonic imaging together with static and dynamic scintigraphy in patients undergoing surgery for colorectal cancer; the results being correlated with the findings at subsequent laparotomy.

Forty five patients have been fully evaluated of whom 10 had metastatic disease at laparotomy. The sensitivities for ultrasound, static and dynamic scintigraphy were $50 \%, 50 \%$, and $70 \%$ respectively. The specificity for these three methods was $91 \%, 100 \%$, and $66 \%$. When either static scanning or ultrasound was used in combination with dynamic scintigraphy, the sensitivity was increased from the original $50 \%$ to $80 \%$.

It is known that at least $30 \%$ of patients with no evidence of liver metastases at surgery will subsequently develop overt disease and it has been shown that dynamic scintigraphy will identify patients harbouring occult metastases. Based on this study it is apparent that a combination of ultrasound or static isotopic imaging used in combination with flow scintigraphy increases the accuracy of either of these diagnostic procedures in the detection of metastatic colorectal disease.

\section{P111}

Diagnosis and surgical management of intractable constipation

A M ROE, D C C BARTOLO, AND $\mathbf{N} J$ MCC MORTENSEN (University Department of Surgery, Bristol Royal Infirmary, Bristol) Intractable constipation presents a clinical problem in diagnosis and management. We have investigated 52 patients using a protocol involving transit studies, manometry (anal sphincter pressures, rectal compliance and rectosigmoid motility), EMG measurements of volitional pelvic floor activity, and proctographic techniques in order to identify those patients who may be helped by surgery. Twenty eight patients ( 27 women, one man) had slow transit and seven patients have had nine procedures: two had internal sphincterotomy without objective improvement and subsequently had a colectomy. A further four had a colectomy and ileorectal anastomosis (IRA) with satisfactory results. One had a puborectalis division. Twenty four patients (17 women, seven men) had normal transit but symptoms of obstructed defaecation. Dynamic proctograms showed rectal intussusception in five, treated by rectopexy with good results in four. One patient had a rectopexy and IRA and one an excision of anterior mucosal prolapse. A combination of transit studies and a dynamic proctogram were the most helpful investigations.
Manometry and EMG studies did not yield any additional information. although sphincter manometry was important when surgery was considered. We have suggested an algorithm for the investigation and management of these difficult patients.

P112

Anorectal myectomy; a valuable treatment for chronic constipation

N D HEATON AND E R HOWARI) (King:s College Hospital, Denmark Hill, London Partial excision of smooth muscle from the internal anal sphincter and rectum (anorectal myectomy) has been suggested as a technique for the management of severe chronic constipation

We used a modified technique in the treatment of 53 new cases who had failed to respond to treatment with laxatives and anal stretch, (age range two months to 66 years, mean 8.5 years; men 31 , women 23 ) There were no clinical features of congenital aganglionosis (Hirschsprung's disease) in these patients

The resected strips of smooth muscle were assessed with neurohistochemical techniques, using acid phosphatase staining for ganglia, and assessing nerves for acetylcholinesterase activity and catecholamine fluorescence. Significant abnormalities were detected in 34 cases - hypoganglionosis (32), hyperganglionosis (one), and anganglionosis (one). There were minor abnormalities in five cases. Fourteen showed a normal pattern of innervation.

Postoperative assessment in 48 patients (follow up two months to five years; mean 14 months) showed an excellent result in 26 (54\%) and a significant improvement in eight $(17 \%)$. A poor result was found in 14 patients $(29 \%)$ and eight of these have subsequently undergone a large bowel resection.

Anorectal myectomy is valuable in the diagnosis of neuronal disorders of the hindgut, and is a useful therapeutic manoeuvre in a significant number of patients.

\section{P113}

Impaired recruitment of the pelvic floor musculature by intra-abdominal pressure in faecal incontinence

N R WOMACK, J F B MORRISON, AND $N$ WILliamS (University Departments of Surgery and Physiology, The General Infirmary, Leeds) Patients with idiopathic 
faecal incontinence (IFI) often report exacerbation of symptoms with activity that raises intra-abdominal pressure. Normally neural reflexes generate a compensatory increase in the activity of the pelvic diaphragm when intra-abdominal pressure (IAP) rises. To assess the integrity of these reflexes in incontinence 15 patients with IFI (12 women, three men, age $62 \pm 14$ years) were compared with 15 age and sex matched normal subjects (12 women, three men, mean age $59 \pm 17$ years; $p=N S$ ).

Intra-abdominal pressure, measured via an intrarectal balloon, was raised by a series of forced expirations to graded preset levels. Activity in the puborectalis muscle was recorded using a concentric EMG needle, and the signal rectified and integrated. In each subject there was a positive linear correlation between muscle activity and IAP $(R=0 \cdot 67-0 \cdot 98$, median $0 \cdot 88)$. Extrapolation of the regression line allowed measurement of the rise in IAP that was necessary to increase muscle activity. Since these muscles are tonically active this increase in activity depends on the sensory side of the reflex mechanism. In the control group recruitment occurred at $0.2 \pm 2.0 \mathrm{~cm}$ water, whereas in the IFI group recruitment required a significantly higher rise in IAP of $7 \cdot 6 \pm 5.0 \mathrm{~cm}$ water ( $<<0.01$ Mann Whitney $U$ test). This deficient response of the pelvic floor muscles to raised IAP in IFI explains the increase of symptoms with activity. It also suggests that IFI may not be entirely motor in origin, as has been postulated, there also being a deficient sensory input.

\section{P114}

Experimental support for a simple model of defecation

J J BANNISTER, C P GIBBONS, E A TROWBRIDGE, AND N W READ (Departments of Surgery and Medical Physics, Royal Hallamshire Hospital, Glossop Road, Sheffield) A simple model of the forces involved in the passage of a stool, through the anal canal, predicts that small stools will be more difficult to pass than large stools and that a linear relationship will be found between the intrarectal pressure required to pass a stool and the reciprocal of the radius of the stool. To test this model, in seven volunteers (four men, three women) the intrarectal pressure was measured whilst the subjects passed five incompressible spheres of known diameter. The smallest sphere (diameter $0.5 \mathrm{~cm}$ ) was passed by only two subjects, the largest (diameter $2 \cdot 0$ $\mathrm{cm}$ ) by all seven. Analysis of the pressure traces for the spheres, that were passed, shows that the intrarectal pressure and the time required to pass the largest sphere were significantly less than those required to pass the smallest (diameter $0.5 \mathrm{~cm}$ or 1.0 $\mathrm{cm})(\mathrm{p}<0 \cdot 01)$. Plotting the peak intrarectal pressure, to pass each sphere, against the reciprocal of the radius gave linear correlation coefficients of $0.75-0.98$ (median $0 \cdot 82)$.

These findings support our simple analysis of defecation and confirm the clinical impression that the size of the stool is an important contributory factor in difficulties in defecation.

\section{P115}

Urological abnormalities in patients with slow transit constipation

J J BANNISTER, W T LAWRENCE, D G THOMAS, AND N W READ (Department of Surgery, Royal Hallamshire Hospital, Sheffield, and Department of Urology, Lodge Moor Hospital, Sheffield) In a study of 24 young women with severe slow transit constipation, it was noted that a surprisingly high number $(75 \%)$ had symptoms of urinary dysfunction, including hesitancy, frequency, urgency, stress incontinence and symptoms of urinary infection. In 10 patients a combined radiological and manometric, urodynamic and anorectal evaluation was performed. The urodynamic assessment showed that all the subjects required bladder volumes larger than the normal range $(150-300 \mathrm{ml})$ to stimulate the first desire to micturate $(p<0.01)$ and their bladder capacity exceeded the normal range $(300-$ $500 \mathrm{ml})$ in all except one subject $(\mathrm{p}<0.01)$. Detrusor contraction was normal with no evidence of instability, the rate of micturition was normal with no radiological evidence of impaired bladder neck opening. The anorectal studies revealed that the constipated subjects required larger rectal volumes than normal to stimulate the desire to defecate $(200 \pm 50 \mathrm{ml}$ vs $110 \pm 10$ $\mathrm{ml}($ Mean \pm SEM) $; \mathrm{p}<0.05)$ and that their maximum tolerated volume was also larger $(380 \pm 30 \mathrm{ml}$ vs $290 \pm 20 \mathrm{ml}$ (Mean \pm SEM); $\mathrm{p}<0.05)$, other modalities of rectal sensation and compliance were normal. The similar findings in the bladder and anorectum suggest an analogous sensory defect in both organs, raising the possibility of a common abnormality in their extrinsic innervation.
P116

Investigation of colonic motility patterns in the irritable bowel syndrome using radiotelemetry

J R REYNOLDS, A G CLARK, D F EVANS, AND J D HARDCASTLE (Department of Surgery, University Hospital, Nottingham) An untethered pressure sensitive radiotelemetry capsule and portable receiving apparatus have been used to measure colonic motility for 24 hours in ambulatory subjects. Twenty one patients with irritable bowel syndrome (mean age $\pm S D$ 34.7 \pm 9.8 years) were compared with 10 healthy volunteers (24.8 \pm 5.67 years). All patients complained of abdominal pain with constipation in nine and diarrhoea in 12. Data were analysed using a microcomputer and a motility index derived for three periods: interfood (IF), postprandial (PP) and night (N). Significant differences between IF, PP and $N$ were found in controls $(7.52 \pm 0.91$, $13.14 \pm 1.47$ and $1.86 \pm 0.66 \mathrm{p}<0.01)$ and patient group $(10 \cdot 65 \pm 1 \cdot 35,18 \cdot 16 \pm 2 \cdot 04$, and $6.01 \pm 1.08 \mathrm{p}<0.02)$. Night time activity in the patient group $(6.01 \pm 1.08)$ was significantly higher than control $(p<0.05)$ and there was a similar trend, though not significant, in the interfood periods. Postprandial activity was significantly greater in patients with diarrhoea $(20.52 \pm 3.01$ $\mathrm{p}<0.05$ ) whereas no difference was found in the $\mathrm{PP}$ response in the constipation group $(15 \cdot 54 \pm 2 \cdot 59)$. This non-invasive method has identified a sub-group of $30 \%$ of patients who have periods of relative colonic hypermotility studied in their normal environment and subject to usual daily stress.

\section{P117}

Management and differential diagnosis of perianal hidradenitis

B J HARRISON AND L E HUGHES (Department of Surgery, University of Wales College of Medicine, Cardiff) Perianal skin is prone to involvement with hidradenitis suppurativa and is characterised by the development of recurrent skin nodules which progress to multiple chronically discharging sinuses. Natal cleft and buttock skin may be affected, superficial fistulae involving the distal anal canal have been described.

Since 1979,15 patients with perianal hidradenitis in whom conservative measures had failed required wide excision of perianal skin. In all cases active disease involving the axillae and/or puboinguinal 
region was present. The wounds were allowed to heal by granulation with the aid of silastic foam dressings and satisfactory results were obtained in all cases. Follow up of 12 patients (mean 2.5 years) has revealed no evidence of recurrent disease.

Careful examination usually differentiates hidradenitis from other perianal disease. Anorectal Crohn's and perianal fistulae are conditions commonly causing diagnostic difficulty. In the former, cavitating ulcers are found within the anal canal, in the latter, inflammation rarely spreads to involve the buttocks. Less common problems of diagnosis include primary perianal pilonidal sinus, postnatal pilonidal sinus, Paget's disease, Bowen's disease and colloid carcinoma.

A normal anal canal and hidradenitis at other sites are the most important clinical features in diagnosis.

PANCREATICO-BILIARY

P118-133

\section{P118}

Are bile acids involved in the regulation of mouth-to-caecum transit time (MCTT) in man?

R PENAGINI, R C SPILLER, D B A SILK, AND J J MISIEWICZ (Department of Gastroenterology and Nutrition, Central Middlesex Hospital, London) Bile acids can affect water and electrolyte movements in the human jejunum and ileum. After cholecystectomy, the postprandial peak luminal and blood concentration of bile acids is markedly lowered.

To test if this could delay intestinal transit we studied 10 patients two to four months after cholecystectomy (C) and compared them with 10 healthy controls (N). MCTT was measured in all subjects after a standard liquid $440 \mathrm{kcal}(1842 \mathrm{~kJ})$ meal containing lactulose $15 \mathrm{~g}$, using the hydrogen breath test. Blood samples were collected at $0,30,60,120,180,240 \mathrm{~min}(8$ $\mathrm{C}$ and $8 \mathrm{~N}$ ) for measurements of total bile acids (enzymatic method) and cholylglycine (RIA); peak incremental response (PIR) and area under the curve (AUC) were calculated. Analysis of results was done with the Mann-Whitney $U$ test. MCTT (mean $\pm S E M$ ) was $65.0 \pm 7.6 \mathrm{~min}$ in $\mathrm{N}$ vs $41 \cdot 0 \pm 5 \cdot 3$ in $\mathrm{C}(\mathrm{p}<0 \cdot 05)$. Cholylglycine PIR was $2 \cdot 17 \pm 0.48 \mu \mathrm{mol} / 1$ in $\mathrm{N} v s$ $1 \cdot 11 \pm 0.23$ in $\mathrm{C}(\mathrm{p}<0.05)$ and its AUC
$306 \cdot 15 \pm 53.7$ in $\mathrm{N}$ vs $204 \cdot 12 \pm 36 \cdot 1$ in $\mathrm{C}$ $(\mathrm{p}<0.02)$, while total bile acids PIR was $17.2 \pm 1.91 \mu \mathrm{mol} / \mathrm{l}$ in $\mathrm{N}$ vs $10.75 \pm 1.1$ in $\mathrm{C}$ $(p=0.025)$ and the AUC 2328.86 $\pm 328 \cdot 26$ in $\mathrm{N}$ vs $2893.39 \pm 208.77$ in $\mathrm{C}(\mathrm{p}=\mathrm{ns})$.

Contrary to our hypothesis patients after cholecystectomy appear to have a faster MCTT than healthy controls. As AUC of total bile acids was the same in $\mathrm{C}$ and $\mathrm{N}$ with lower AUC for cholylglycine in $\mathrm{C}$, higher concentrations of dihydroxy bile acids may be the responsible factor. Rapid MCTT may be relevant to the pathogenesis of post-cholecystectomy diarrhoea.

\section{P119}

Morphological and biochemical studies on rat pancreatic ducts maintained in tissue culture

$S$ ARKLE AND B E ARGENT (INTRODUCED BY A ALLEN) (Department of Physiological Sciences, University Medical School, Newcastle Upon Tyne) Recently, we have developed a technique for the isolation of viable small interlobular ducts from the pancreas of copper deficient rats. Copper deficiency causes a non-inflammatory atrophy of pancreatic acinar cells while the duct cells remain structurally and functionally intact. When isolated ducts were maintained in tissue culture their cut ends sealed within eight hours. This process was accompanied by an overall swelling of the duct, a marked dilatation of the lumen and a flattening of the epithelium against the surrounding connective tissue layer. Secretin $(0.1 \mathrm{nmol}$ to $1 \mu \mathrm{mol})$ caused a dose related increase in cyclic AMP content and, usually, further swelling of the ducts. Puncture of the cultured ducts caused a fall in duct size, largely accounted for by a reduction in lumen volume, and also increased the height of the epithelium.

Taken together these observations suggest that the duct swelling which occurs during maintenance in culture is because of an increased luminal pressure, resulting from fluid secretion into the closed luminal space.

\section{P120}

Cholesterol absorption by the human gall bladder.

M R JACYNA, P E ROSS, D HOPWOOD, AND I A D BOUCHIER (Department of Medicine, Ninewells Hospital and Medical School, Dundee, Scotland) Although guinea pig gall bladder is known to absorb significant amounts of luminal cholesterol, there are no data currently available relating to the human gall bladder. Consequently a modified Ussing Chamber was used to investigate cholesterol absorption and transport in human gall bladder mucosa using artificial biles of varying cholesterol saturation. Uptake and transport of cholesterol was determined by tissue and serosal fluid content of $1-\left({ }^{14} \mathrm{C}\right)$-cholesterol used as tracer in the artificial bile solutions while $\left({ }^{3} \mathrm{H}\right)$-Dextran was used to correct for adherent bile on the mucosal surface. Tissue viability during experiments was established by using electron.microscopy to confirm ultrastructural integrity and also by serial measurements of transmural potential difference and diffusion potentials.

In 33 human gall bladders studied so far, cholesterol was absorbed from the lumen and transported into the serosal fluid. During this process, almost $15 \%$ of the absorbed cholesterol was esterified. Absorption and transport rates increased with increasing cholesterol saturation, reaching a maximum value (of approximately $3.5 \mathrm{nmol} / \mathrm{cm}^{2} / \mathrm{min}$ ) when bile became supersaturated. These results show absorption and esterificiation of biliary cholesterol which may be important in the pathogenesis of human gall bladder disease.

P121

Molecular forms of cholecystokinin in human plasma after ingestion of fat

J B $M$ J JANSEN AND C B H W LAMERS (Departments of GastroenterologyHepatology, Universities of Nijmegen and Leiden, The Netherlands) There is substantial controversy about the nature of circulating $\mathrm{CCK}$ in response to meal stimulation. We therefore studied the molecular forms of CCK in basal plasma and 20 minutes after ingestion of $250 \mathrm{ml} 20 \%$ Intralipid by region-specific radioimmunoassays. CCK-like immunoreactivity (CCKLI) was concentrated from $10 \mathrm{ml}$ plasma samples from three healthy volunteers by C18 SEP-PAK cartridges eluted with a mixture of $80 \%$ acetonitril-20\% $1 \%$ trifluoroacetic acid. In addition, $5 \mathrm{ml}$ plasma samples from three gastrectomised patients with high plasma CCK responses to oral fat were extracted with ethanol. All samples were evaporated to dryness, dissolved in $1 \mathrm{ml}$ elution buffer and applied to Sephadex G-50 columns. The eluates were measured by radioimmunoassay using anti- 
body T204 (directed to the sulphated tyrosyl region of CCK) and antibody 1703 (binding to C-terminal CCK-peptides containing at least 14 amino acid residues). No CCK-LI was demonstrable in fractionated basal plasma. Chromatography revealed four peaks in fat stimulated plasma. Peak I eluted in the void volume and comprised $1-10 \%$ of CCK-LI, peak II eluted at $35 \%$ and comprised $3-35 \%$, peak III eluted at $50 \%$ and comprised $24-62 \%$, and peak IV eluted at $75 \%$ and comprised $15-45 \%$ of CCK-LI. No additional peaks were detected by antibody 5135 , directed to the C-terminus of CCK and gastrin.

We conclude that CCK in plasma after fat stimulation is heterogeneous. From the cross reactivity pattern it is also concluded that the small form of CCK is different from CCK-8.

\section{P122}

Cholecystokinin octapeptide-like material is produced from larger forms during circulation in man

C J SPRINGER AND J CALAM (Hammersmith Hospital, London) Cholecystokinin in plasma exists in forms containing 58,39 (CCK39), 33 (CCK33), and eight (CCK8) amino acid residues but the relationships between different forms is ill understood. In this study we have shown that CCK8like material is formed from CCK33/39 during circulation.

Six fasted normal volunteers received intravenous natural porcine CCK (Kabi Diagnostics) at a measured rate of $0 \cdot 7-2 \cdot 5$ $\mathrm{pmol} / \mathrm{kg} / \mathrm{min}$ for 15 minutes. CCK forms were separated on Sephadex-G50 and measured by C-terminal specific radioimmunoassay. CCK in infusates eluted chiefly in the characteristic position of CCK33 and CCK39 (CCK33/39). A second peak, eluting between CCK33 and CCK8, accounted for $0-15 \%$ and CCK8-like material accounted for less than $3 \%$ of immunoreactivity. During infusions CCK33/39-like immunoreactivity appeared in plasma and rose to a mean concentration of $49 \mathrm{pmol} / \mathrm{l}$ at the end of the infusion. In addition, CCK8-like material was detected during all infusions, rising about 3 minutes later than CCK33/39 to a mean concentration of 48 $\mathrm{pmol} / \mathrm{l}$ at the end of the infusion. A steady state was not achieved but both forms became undetectable $(<10 \mathrm{pmol} / \mathrm{l}) 11$ minutes after the infusion. The CCK-8-like material seen in normal human plasma may be the product of post secretory cleavage of larger forms.
P123

Methods to assess 'enzyme induction' in patients with idiopathic pancreatitis

L N SANDLE, D W K ACHESON, L P HUNT, A H GOWENLOCK, AND J M BRAGANZA (Departments of Biochemistry and Gastroenterology, and Faculty of Medicine Computation Group, Royal Infirmary, Manchester) Recent studies suggest that pancreatitis may be facilitated by an imbalance between enzyme induction and available antioxidants. There is a need to assess this induction/antioxidant axis. We have compared the information on induction provided by various tests done in the same week on 11 patients with idiopathic recurrent pancreatitis, without overt liver disease. The last attack of pain in these patients occurred between one week and 12 months before the tests: the time since their first symptoms varied widely, between two months and 13 years.

The group displayed: (1) rapid theophylline clearance, indicating induction of cytochromes P450 (median 179, vs $74 \mathrm{ml} / \mathrm{kg} / \mathrm{h}$ in controls, $\mathrm{p}<0.005)$; (2) accelerated early-phase disappearance of sulphobromophthalein, suggesting induction of ligandin (mean $\mathrm{k}_{1} 23.0$, vs $14.3 \% / \mathrm{min}$ in controls, $\mathrm{p}<0.025$ ); (3) increased D-glucaric acid excretion in 'spot' samples of urine, reflecting heightened 'phase II' reactions (median 3.7 , vs $2.9 \mathrm{mmol} / \mathrm{mol}$ creatinine in controls, $p<0.025$ ), (4) increased postsecretin bilirubin output, suggesting induction of haem oxygenase as well as 'phase II' reactions (median 8363 , vs $4000 \mathrm{u} / 30 \mathrm{~min}$ in controls, $\mathrm{p}<0 \cdot 025)$. Theophylline clearance was increased in nine of the 11 patients: none of the other induction 'markers' achieved this sensitivity.

The theophylline test is thus the obvious choice to assess the induction component of the induction/antioxidant axis in pancreatic disease.

\section{P124}

Modified sham feeding induces gall bladder contraction by an atropine-sensitive, CCKindependent mechanism

W P M HOPMAN, G M P HOUBEN, M C A VERMEULEN, J B J M JANSEN, G ROSENBUSCH, AND C B H W LAMERS (Departments of Gastroenterology-Hepatology, and Department of Radiology, Universities of Nijmegen and Leiden, The Netherlands) This study was undertaken to determine whether modified sham feeding induces gall bladder contraction, to assess the relative contribution of the cephalic phase to postprandial gall bladder contraction, and to elucidate the mechanism of cephalic stimulation of gall bladder contraction. On separate mornings eight fasting healthy volunteers (four men, four women, 20-65 years) underwent the following studies: sham feeding during 30 minutes, sham feeding after atropine $(0.015 \mathrm{mg} / \mathrm{kg}$ as bolus followed by infusion of $0.005 \mathrm{mg} / \mathrm{kg}$ / $h$ ), and ingestion of the same meal in 30 minutes. Gall bladder volumes were measured by ultrasonography and plasma CCK by a sensitive and specific radioimmunoassay. Sham feeding induced a significant gall bladder contraction of $33 \pm 4 \%$ of the original volume $(p<0 \cdot 0005)$. After ingestion of the meal gall bladder contraction was $67 \pm 47 \% \quad(p=0 \cdot 00001)$. Gall bladder contraction after modified sham feeding was abolished by atropine. Plasma CCK concentrations were not affected by sham feeding, whereas ingestion of the meal increased plasma $\mathrm{CCK}$ from $2 \cdot 3 \pm 0.6$ to $4 \cdot 6 \pm 1 \cdot 1 \mathrm{pM}(\mathrm{p}<0 \cdot 001)$.

We conclude that modified sham feeding induces gall bladder contraction by an atropine-sensitive, CCK-independent mechanism. The extent of gall bladder contraction after modified sham feeding was about half of that after ingestion of the meal.

\section{P125}

Diagnosis and management of pancreatic duct injuries in children: a report on four cases

R I Hall, M I LAVElle, AND C W Venables (Departments of Surgery and Radiology, Freeman Hospital, Newcastle upon Tyne) Major pancreatic injuries in children are difficult to diagnose and may go unrecognised for very long periods. Of crucial importance is the identification of those patients with damaged pancreatic ducts, because they require urgent surgical treatment. We have encountered four children, aged three to 13 years, with major pancreatic injuries. Although three had sustained the type of bicycle and sledging accidents associated with pancreatic injury, the diagnosis was delayed in all children for periods of up to one year. All children complained of persistent abdominal pain and vomiting. Traumatic pancreatitis was suggested by raised serum amylase concentrations in each case. Ultrasound scans identified pseudocysts in three, although the location was incorrect in one. Computed tomography scanning suggested a 
lacerated pancreas in one, but was unhelpful in another. ERCP was performed under general anaesthetic in all patients. The presence and location of the duct injury was correctly identified in every case. Distal injuries (two) were treated by distal pancreatectomy, proximal lacerations (two) were internally drained into Rouxen-Y loops. All patients recovered. ERCP should be performed in all children with traumatic pancreatitis and any duct injury identified must be treated by urgent surgery.

\section{P126}

Evidence for an inhibitory effect of bombesin on pancreatic polypeptide secretion in man

A J L DE JONG, J P M BLAaUWhoF, M C A VERMEULEN, AND C B H W LAMERS (Departments of Gastroenterology-Hepatology, Universities of Nijmegen and Leiden, The Netherlands) Bombesin containing nerves have been demonstrated in the pancreas. Because infusion of bombesin stimulates the secretion of pancreatic polypeptide (PP), it is possible that bombesin is involved in postprandial PP release. To determine the interactions between bombesin and food in the regulation of postprandial PP secretion, we have studied the effect of increasing doses of bombesin (1, 2.5 and $5 \mathrm{ng} / \mathrm{kg} / \mathrm{min}$ for two hours) on postprandial PP secretion in six healthy volunteers (four men, two women, 20-26 years). Thirty minutes after the start of the bombesin infusion the subjects ingested a liquid test meal. As expected the meal induced significant increases in plasma $P P$ from $17 \pm 3$ to $47 \pm 8 \mathrm{pM}(\mathrm{p}<0 \cdot 01)$. Infusion of bombesin did not stimulate, but rather inhibited and even abolished postprandial PP secretion in a dose-related manner. Integrated postprandial plasma PP secretion during saline infusion was $1850 \pm 362$ $\mathrm{pM} / 90 \mathrm{~min}, 1245 \pm 542 \mathrm{pM} / 90 \mathrm{~min}$ (ns) during $1 \mathrm{ng} / \mathrm{kg} / \mathrm{min}, 668 \pm 218 \mathrm{pM} / 90 \mathrm{~min}$ $(\mathrm{p}<0.05)$ during $2.5 \mathrm{ng} / \mathrm{kg} / \mathrm{min}$, and $-426 \pm 478 \mathrm{pM} / 90 \mathrm{~min}(\mathrm{p}<0.01)$ during 5 $\mathrm{ng} / \mathrm{kg} / \mathrm{min}$ bombesin. Infusion of the three doses of bombesin without the meal induced small, non-significant increases in plasma PP. After stopping the bombesin infusion, however, a steep, dosedependent increase in plasma $P P$ was found $(13 \pm 5 \mathrm{pM}$ after $1 \mathrm{ng} / \mathrm{kg} / \mathrm{min}, 29 \pm 7$ pM after $2.5 \mathrm{ng} / \mathrm{kg} / \mathrm{min}$ bombesin; $\mathrm{p}<0.05)$.

The findings of the present study suggest that bombesin stimulates the secretion of an inhibitor of PP release. The nature of this inhibitor is at the present time unknown.

\section{P127}

Partial purification of pancreotone

A A HARPER, A J C HOOD, J MUSHENS, J R SMY, C SNELL, P SNELL, AND $R$ K VEITCH (Department of Pharmacology, Sunderland Polytechnic, Medical School, Newcstle University, and $M R C$ Neuroendocrinology Unit, Newcastle General Hospital, Newcastle) Pancreotone is an aqueous alcohol peptide extract of distal but mucosa prepared by precipitation onto bile salts at $\mathrm{pH}$ 3.9. Pancreotone iv in chloraloseanaesthetised cats inhibits secretion of pancreatic juice (antisecretin effect) and gastric pepsin secretion. In cats and guinea pigs gall bladder contractility is also inhibited (anticholecystokinin effect).

Reprecipitation of crude pancreotone from aqueous alcohol at $\mathrm{pH} \mathbf{4} \cdot 1$ followed by extraction with acid alcohol and precipitation with acetone, increased the specific activity six-fold and reduced the bile salt content by $85 \%$. When these partly purified preparations were subjected to isoelectric focusing with ampholines in Ultrodex gel, two peaks of antisecretin activity were revealed. One at pI $8 \cdot 1-8 \cdot 3$ contained approximately $2 / 3$ of the recovered activity and the other at pI $4 \cdot 8-5 \cdot 1$ contained in addition all the recovered anticholecystokinin activity. Both fractions inhibited pepsin secretion. The material at $\mathrm{pI}$ $8 \cdot 1-8 \cdot 3$ cross reacted strongly with antibodies to PYY (S R Bloom, personal communication). Furthermore, when injected iv into cats it produced a small pressor response, whereas the pI 4.8-5.1 material produced a small depressor response.

The activities at pI4.8-5.1 do not coincide with those of characterised peptides of the distal gut and include all the effects of pancreotone.

\section{P128}

Preliminary evaluation of a modified PABA test

W $H$ BRADBURY, A $R$ W FORREST, C D HOLDSWORTH, A ROB, AND J R WORTERS (Department of Clinical Chemistry and Gastrointestinal Unit, Royal Hallamshire Hospital, Sheffield) The combined BT PABA $/{ }^{14} \mathrm{C}$ test is accepted as a specific and sensitive test of pancreatic function. The usual analytic method for urinary PABA is, however, subject to drug interference. We have investigated anthranilic acid, the orthoisomer of PABA as a substitute for ${ }^{14} \mathrm{C} \mathrm{PABA}$ in the BT PABA $/{ }^{14} \mathrm{C}$ test. Anthranilic acid is absorbed and metabolised independently of pancreatic chymotrypsin.

The test has been evaluated in normal volunteers, patients with known pancreatic steatorrhoea and patients with suspected pancreatic disease.

After fasting, BT PABA $1 \mathrm{~g}$ and anthranilic acid $340 \mathrm{mg}$ was taken with water. Urine was collected for six hours and both isomers were measured by high performance liquid chromatography (HPLC) using a previously unpublished method. An excretion ratio (\% PABA recovery/\% anthranilic acid recovery) was calculated.

The test clearly distinguished between normal subjects (excretion ratio $0 \cdot 63-1 \cdot 14$ ) and patients with known pancreatic steatorrhoea (excretion ratio $0 \cdot 13-0 \cdot 43$ ). Patients found to have no evidence of pancreatic disease had excretion ratios in the range of the normal subjects. Those with equivocal Lundh tests had excretion ratios of $0.467-0.837$. This modified test may become a useful alternative to the BT PABA $/{ }^{14} \mathrm{C}$ test, and eliminates problems with both drug interference and the administration and counting of ${ }^{14} \mathrm{C}$.

P129

Absorption of omeprazole in ZollingerEllison syndrome is accelerated by alkali

C B H W LAMERS, L TEUNISSEN, AND J B M J JANSEN (Departments of Gastroenterology and Hepatology, Universities of Nijmegenand Leiden, The Netherlands) Omeprazole is a potent inhibitor of gastric acid secretion in patients with Zollinger-Ellison syndrome. As omeprazole is inactivated by acid, an enteric-coated preparation has been developed from which the drug is released only when the $\mathrm{pH}$ is greater than six. About half of patients with ZollingerEllison syndrome, however, show low inhibition of gastric acid secretion in the first hours after ingestion of the drug. We have measured the absorption of $80 \mathrm{mg}$ omeprazole ingested either as enteric-coated preparation together with $250 \mathrm{ml}$ saline or as enteric-coated preparation together with $250 \mathrm{ml}$ (40 mmol) sodium bicarbonate or as uncoated preparation with sodium bicarbonate in six patients with ZollingerEllison syndrome (three men, 35 women; 35-63 years). Plasma samples for omepra- 
zole were obtained at regular intervals for three hours. There was a wide variation in omeprazole absorption with the entericcoated preparation and saline (AUC 0.0 $18 \cdot 8$, median $0 \cdot 6 \mu \mathrm{mol} / 1 / 3 \mathrm{~h}$ ). Ingestion of enteric-coated omeprazole with sodium bicarbonate resulted in significantly greater

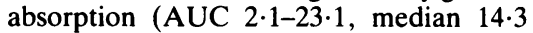
$\mu \mathrm{mol} / \mathrm{l} / 3 \mathrm{~h} ; \mathrm{p}<0 \cdot 05)$. Omeprazole absorption after uncoated omeprazole with sodium bicarbonate $(1 \cdot 4-31 \cdot 2$, median $4 \cdot 3$ $\mu \mathrm{mol} / \mathrm{l} / 3 \mathrm{~h}$ ) was slightly greater than that with the enteric-coated preparation and saline $(\mathrm{p}<0 \cdot 10)$, but not significantly different from that with enteric-coated omeprazole and sodium bicarbonate. The acid inhibitory effect of omeprazole was related to the absorption of the drug. In tests with an AUC of more than $0.2 \mu \mathrm{mol} / 1 / \mathrm{h}$ acid inhibition was greater than $80 \%$, whereas in tests with an AUC of less than 0.2 $\mathrm{mmol} / \mathrm{l} / \mathrm{h}$ inhibition ws smaller than $30 \%$.

We therefore conclude that addition of alkali accelerates absorption of omeprazole in patients with Zollinger-Ellison syndrome resulting in early inhibition of acid secretion.

\section{P130}

Ultrasonography in choledocholithiasis - a new look

M TOBIN, R M MENDELSON, G LAMB, AND I T GILMORE (Gastroenterology Unit and Department of Radiology, Royal Liverpool Hospital, Liverpool) Ultrasound (US) diagnosis of common duct stones has been disappointing. To assess its accuracy in a specialist centre and its role as a screening test in selecting patients requiring direct cholangiography, US was done by one of two experienced operators immediately before endoscopic cholangiography (ERC) in 104 consecutive patients referred for suspected biliary disease.

Of 36 patients with choledocholithiasis on ERC, US showed stones in 20 , common duct dilatation in a further 10 , and failed to visualise the common duct in five. The sensitivity was $64.5 \%$ and $55.5 \%$ for calculus visualisation and $97 \%$ and $83 \%$ for an abnormal common duct, excluding and including technical failures respectively. Of 39 normal cholangiograms, US agreed in $37(95 \%)$, was technically unsatisfactory in one, and incorrectly diagnosed a calculus in one. One further false positive US for calculus occurred in 16 patients showing ERC dilatation only. Using US visualisation of common duct calculus, dilatation or technical failure as criteria for proceeding to ERC would have resulted in the omission of only one patient with calculus and 14 'unnecessary' cholangiograms. Ultrasound is a sensitive screening test in suspected choledocholithiasis. A normal US virtually excluded choledocholithiasis in this series.

P131

Electrohydraulic lithotripsy of gall stones, and in vitro study

J D HARRISON, D L MORRIS, JULIE HAYNES, AND D C WHERRY (Department of Surgery, University Hospital, Nottingham) Electrohydraulic lithotripsy is widely used in the endoscopic management of urinary tract calculi. Its role in the management of gall stones has received little attention.

An electrohydraulic generator and probe $(\mathrm{ACM})$ with variable voltage, plus length and number of pulses was used to fragment 12 mixed pigment/cholesterol gall stones recently removed from five patients in $0.9 \%$ saline. Two stones $(6 \times 7,5 \times 4 \mathrm{~mm}$ diameter) were fragmented at 60 volts $(\mathrm{V})$, two required $80 \mathrm{~V}(9 \times 7,7 \times 5 \mathrm{~mm})$, two were fragmented at $100 \mathrm{~V}(13 \times 12,12 \times 13$ $\mathrm{mm}$ ) while two were not affected until 120 $\mathrm{V}$ was used $(12 \times 8,15 \times 13 \mathrm{~mm})$. In only one stone did we fail to achieve fragmentation $(28 \times 21 \mathrm{~mm})$. Three stones $(7 \times 5,5 \times 6$, and $7 \times 6 \mathrm{~mm})$ were then fragmented within human and ovine bile ducts at 60,60 and $120 \mathrm{~V}$ without obvious macroscopic evidence of damage to the ducts.

Direct contact of the end of the probe with bile duct or gall bladder wall produced a perforation even at $60 \mathrm{~V}$, but both were resilient to shock waves (rather than spark effect).

Most gall stones may be fragmented by the electrohydraulic lithotripter. This instrument may be useful to both endoscopist and surgeon for impacted bile duct calculi.

\section{P132}

Results of endoscopic stenting in malignant stricture of the biliary tract

J STOKER, J DEES, M VAN BLANKENSTEIN, AND G A J J NIX (Departments of Internal Medicine and Radiology, University Hospital Rotterdam, Rotterdam, The Netherlands) In 1983-1984 endoscopic placement of a biliary stent (EPS) by the Huibregtse-technique was attempted in 123 patients suffering from malignant stricture. The results were assessed in relation to the localisaiton of the stricture, a comparison between common duct and perihilar strictures being found to be relevant. Stenting was successful in 97 cases $(79 \%)$. In common duct strictures the failure rate was $11.8 \%$. After successful stenting early complications were seen in $10 \%$ and there was a satisfactory drainage in $94 \%$. In hilar tumours these percentages were 42,29 and 73 respectively. Early complications included haemorrhage, requiring transfusion in five patients and cholangitis in 11. Mean survival in 79 patients who were only treated by stent drainage was 18.6 weeks. Late complications were recurrent jaundice in 33 patients, and fever in four patients. Only eight patients were referred for stent replacement.

We conclude that (1) EPS is an effective and safe treatment for malignant strictures of the common bile duct. It is less successful in hilar strictures which may be more amenable to percutanous drainage. (2) Patients and their doctors should be allerted to the necessity of prompt stent replacement if fever or jaundice recur.

\section{P133}

Randomised trial comparing endoscopic and percutaneous prostheses in poor risk patients with malignant obstructive jaundice

A G SPEER, P B COTTON, A HATFIELD, $R$ R MASON, R C G RUSSELl, J LEUNG, T P YIN, J LENNARD-JONES, J BAILLIE, AND K MCCRAE (Departments of Gastroenterology, Radiology and Surgery, The Middlesex and London Hospitals; Cancer Research Campaign Centre, King's College Hospital, London) Bypass surgery for palliation of biliary obstruction due to malignancy has a high mortality in poor risk patients. We have compared the insertion of a prosthesis via the percutaneous transhepatic method (PTE) or endoscopically (EP) in a prospective randomised trial. Seventy five patients with primary tumours (pancreatic and cholangio-carcinoma) who were judged to be unsuitable for surgery were entered. Analysis was according to a sequential block design. The results are presented on a strict intention to treat basis. The two groups of patients were well matched apart from the incidence of hilar stricture - EP $49 \%$; PTE - $28 \%$.

Criterion for significance $(p \leqslant 0.016)$ was achieved for 30 day mortality using log rank analysis stratified according to site of lesion. The significantly increased early mortality and risk of complications of PTE were related to puncturing the liver - 
haemorrhage, biliary peritonitis and abscess formation. The endoscopic method is now the preferred route for insertion of biliary prostheses. The relative merits of prostheses and bypass surgery in fitter patients are being compared in another trial.

\section{ENDOSCOPY}

P134-135

\section{P134}

Balloons against bougies for dilatation of benign oesophageal stricture - a randomised prospective trial

J C COX, R K WINTER, R JONES, J F DYET, D R SUTTON, AND J R BENNETT (Hull Royal Infirmary, Hull) Balloons have been advocated as safer and more effective than bougies for dilating oesophageal strictures, but there is no evidence to support this.

Twenty six patients, aged 30-90 years, were randomly allocated to dilatation by bougie or balloon to a predetermined diameter. Stricture size was measured before, one week and one month afterwards using the barium sphere technique. Patients' acceptance of each technique was assessed by a simple scoring system.

All dilatations were achieved without complications. There was no significant difference in the mean change from the initial measurement between the two groups at one week or one month. In 12 patients measured at three months, four months, and five months after dilatation the diameter diminished more rapidly in the balloon group than in the bougie group $(p<0 \cdot 1)$. Two patients in each group required repeat dilatation because of dysphagia. There was no significant difference in the patients' acceptance score between the two groups.

Balloon dilatation appears to be a safe treatment for benign oesophageal strictures, but is neither more effective nor more acceptable to patients than bougienage.

\section{P135}

Endoscopic injection of adrenaline in bleeding peptic ulcers

J W C LEUNG AND S C S CHUNG (Combined Endoscopy Unit, Departments of Medicine \& Surgery, The Chinese University of Hong Kong, Hong Kong) Early endoscopy frequently reveals active bleeding lesions in patients with upper gastrointestinal haemorrhage. We report a simple method of endoscopic haemostasis in bleeding peptic ulcers using local injection of adrenaline. Between November 1984 and April 1985,206 patients were admitted with upper gastrointestinal haemorrhage. Twenty one patients (19 men, two women, mean age of 48 years) had an actively bleeding ulcer (17 DU, four GU) on endoscopy. Mean haemoglobin on admission was $9.5 \mathrm{~g} / \mathrm{dl}$, and 15 patients required blood transfusion (mean $=5$ units, range 1-12). Using a needle injector through an endoscope, alliquots $(0.5 \mathrm{ml})$ of $1: 10000$ adrenaline (volume $1-6 \mathrm{ml}$, mean $=3.2 \mathrm{ml}$ ) were injected submucosally around the bleeding site. No complication was observed. Initial haemostasis was achieved in all. Three patients rebled at four hours, three days and four days later, and two (one GU, one DU) required emergency surgery and the third (DU) improved with conservative treatment. Thus definitive haemostasis was achieved in 19/21 patients $(90.5 \%)$. Repeat endoscopy at eight weeks showed healed ulcer in 13 patients, while six patients are awaiting reassessment. Local injection of bleeding ulcers with adrenaline is a simple, effective and economical method for haemostasis in patients with bleeding peptic ulcers.

\section{PLENARY}

T1-6

\section{T1}

Dangers of surgical treatment for perianal Crohn's disease

M R B KEIGHLEY AND R N ALlaN (Department of Surgery, General Hospital, Birmingham) We have examined 202 consecutive patients with Crohn's disease to determine the current status of perianal disease together with the influence of surgical treatment on outcome. The mean duration of follow up was $7 \cdot 6$ years (range: $1-36$ years) and all except 35 patients $(17 \%)$ had undergone some form of intestinal resection.

One hundred and ten patients had evidence of perianal disease at some time in their illness $(54 \%)$. The principal lesions were skin tags $(n=75)$, anorectal abscess $(n=53)$, fistula $(n=52)$, fissure $(n=35)$ and stricture $(n=19)$. Seven fissures were treated by dilatation but only four were improved and one became incontinent. Twelve fistulae were laid open but only one resolved and six became incontinent Fifteen abscesses were drained but onlv five resolved and four developed a fistula None of the six strictures treated by dilatation were improved. Proctectomy was performed in 36 patients: 19 of 27 with perinanal disease have a persistent perineal sinus $(70 \%)$, compared with none in the nine having proctectomy and no perianal disease $(10 \%: p<0 \cdot 01)$. Seventeen of the 19 patients with an unhealed perineal sinus had a rectal stricture.

These results imply that local surger should be avoided for perianal Crohn s disease and that proctectomy for rectal stricture is usually associated with a persistant perineal sinus.

\section{$\mathrm{T} 2$}

Segmental colonic function in experimental steatorrhea-decreased capitance of the proximal colon

R C SPILLER, M L BROWN, AND S F PHIIIIPS (Mayo Clinic, Rochester. Minnesola, USA) In steatorrhea, long chain fatty acids impair colonic absorption. however, the importance of altered colonic transit in the associated diarrhoea is unknown. After passing an orocaecal manometry tube. we have infused the normal unprepared colon $(\mathrm{n}=6)$ at $2.5 \mathrm{ml} / \mathrm{min}$ with a solution simu lating postprandial colonic inflow in steatorrhea [oleic acid emulsion (OA), $\mathrm{g} / 100 \mathrm{ml}$. Seven control subjects received $0.9 \% \mathrm{NaCl}$; both solutions also contained $2.5 \mathrm{~g} / 1$ lecithin, $10 \mathrm{mmol} / 1 \mathrm{Na}$ taurocholatc and $20 \mathrm{mmol} / \mathrm{l}$ glycerol (all adjusted to $\mathrm{pH}$ $6 \cdot 4,290 \mathrm{mosmol} / \mathrm{kg}$ ) and were labelled with $1.2 \mathrm{mCi} / \mathrm{l}$ of ${ }^{111} \mathrm{In}$ DTPA. Passage of ${ }^{111} \mathrm{In}$ from ascending (AC) to transverse (TC) and descending (DC) colon and rectosigmoid (RS) were quantified by serial 1-min gamma scans.

Oleic acid emulsion induced episodic. prolonged $(>10 \mathrm{sec})$, propagated pressurc waves $(>60 \mathrm{mmHg})$ in the AC (mean \pm SEM, 75 $\pm 3 \mathrm{mmHg}, 30 \pm t \mathrm{sec})$ which were associated with cramps and mass movements of isotope caudally. Such waves occurred $4 \cdot 1 \pm 2 \cdot 4$ times/h during $\mathrm{OA}$ infusion, but only once in $33 \mathrm{~h}$ with saline. $\mathrm{p}<0.001$. Concomitantly. isotope overflowed from the $\mathrm{AC}$ earlier during $\mathrm{OA}$ $(19 \pm 3$ vs $39 \pm 6 \mathrm{~min})$ and accumulated in the DC and RS more rapidly, reaching $>50 \%$ infused dose by $106 \pm 14.8 \mathrm{~min}$ (range 34-135), $\mathrm{p}<0.00 \mathrm{l}$ is saline (all $>183 \mathrm{~min})$. Urgent defecation occurred 
after $312 \pm 20 \mathrm{ml}$ of $\mathrm{OA}$ compared with $1049 \pm 71 \mathrm{ml}$ of saline $(\mathrm{p}<0 \cdot 001)$. This novel research technique, the 'isotope colometrogram' which quantifies regional colonic transit, promises new insights into the pathophysiology of diarrhoea.

\section{T3}

Randomised trial of vasopressin and vasopressin plus nitroglycerin in the control of acute vericeal haemorrhage

A E S GIMSON, D WESTABY, J HEgARTY, A WATSON, AND R WILlIAMS Liver Unit, King's College Hospital and School of Medicine \& Dentistry, Denmark Hill, London) The systemic haemodynamic complications of vasopressin (VP) have been an important limitation to its use in management of variceal haemorrhage. Recent studies suggest that nitroglycerin (NG) may reverse these changes and augment the fall in portal pressure. A randomised trial was undertaken to compare the efficacy and complication rate of VP alone $(0.4$ units/min constant infusion (and VP + intravenous NG $(40-400 \mu \mathrm{g} / \mathrm{min}$ to maintain systolic blood pressure $\geqslant 100 \mathrm{mmHg}$ ) for a period of 12 hours. Seventy two bleeding episodes in 57 patients were included: VP alone on 34 and VP + NG on 38 occasions. At the end of the 12 hour period haemorrhage had stopped significantly more frequently in the VP + NG group (26 of $38: 68 \%$ ) compared with the VP group (15 of $34: 44 \%, \mathrm{p}<0.05$ ). Major complications 'requiring cessation of therapy were significantly less common in the VP + NG group than in the VP alone group (one and seven respectively, $\mathrm{p}<0.02)$. Hospital mortality was similar in both groups. In conclusion, the addition of NG to a VP infusion significantly reduces the complication rate and has been shown to be more effective in the management of active variceal haemorrhage.

\section{T4}

Non-steroidal anti-inflammatory drugs and bleeding peptic ulcer

K W SOMERVILLE, G FAULKNER, AND M J S LANGMAN (Department of Therapeutics, University Hospital, Nottingham) Nonaspirin non-steroidal anti-inflammatory drugs (NSAID) are widely believed to cause peptic ulceration or its complications but good supportive evidence is lacking because no planned study using appro-
priate controls has ever been done. Since
1983 we have carried out such a study in which patients over 60 years of age admitted to the Nottingham City and University Hospitals with a bleeding peptic ulcer have been questioned about immediate antecedent drug intake. For each patient a community control matched for age and sex was selected from the same general practice list. The same questions were also posed to an age and sex matched hospital control by a trained interviewer (GF) using the same structured questionnaire. Ninety per cent of the 193 community controls so far approached agreed to participate as did all the hospital controls.

Two hundred and thirty of the 289 eligible cases admitted during the two year study period, were directly questioned. Thirty five per cent were users of NSAIDs compared with $14 \%$ of 230 hospital controls and $15 \%$ of 173 community controls. Patients with bleeding peptic ulcers were nearly four times as likely to be NSAID takers as hospital or community controls (relative risk $3 \cdot 8, \chi^{2}=26 \cdot 1$ and $3 \cdot 7, \chi^{2}=21 \cdot 7$ respectively, $\mathrm{p}<0.001$ in both cases by McNemar's test). By extrapolation frrom these results, of about 1000 deaths annually of patients over the age of 60 admitted with bleeding peptic ulcers approximately 200 would be associated with NSAID use.

\section{T5}

Gluten sensitive oral ulceration in the absence of coeliac disease

C O'MAHONY, C O'FARRELLY, D G WEIR, T FINCH, AND C F FEIGHERY (Departments of Immunology and Clinical Medicine, St James's Hospital, Dublin, Eire) The clinical management of severe recurrent oral ulceration is often unsatisfactory and such ulceration may continue for life. Symptomatic treatment alone is used unless, as is the case in a small proportion of patients, an underlying systemic illness, such as coeliac disease, is found.

The purpose of this study was to determine if gluten sensitive oral ulceration occurred in the absence of coeliac disease. Nine patients, presenting primarily with severe recurrent oral ulceration, were investigated. All had normal small intestinal biopsies. Three patients had raised alphagliadin antibodies, however (raised levels are found in up to $85 \%$ of patients with coeliac disease). All three were HLA DR3 - the antigen found in up to $90 \%$ of our coeliac patients. A trial of gluten free diet was instituted in these three patients. Two had an excellent response with complete remission of the ulceration and alphagliadin antibody levels returned to normal A subsequent gluten challenge brought an acute relapse in oral ulceration although the small intestinal biopsy remained normal. Alpha-gliadin antibody remained elevated in the non-responding patient and dietary assessment showed non compliance.

Two of the remaining six patients with oral ulceration but negative alpha-gliadin antibodies also went on a gluten free diet but no clinical improvement was noted.

This study shows that in a subpopulation of patients with severe recurrent oral ulceration the lesion responds to gluten exclusion. Thus the clinical spectrum of gluten sensitive disease is wider than is often suspected.

\section{T6}

Influence of neuropeptide $Y$ on rabbit ileal mucosa

K J MORIARTY, N B HIGGS, M WOODFORD, J M ALLEN, $S$ R BLOOM, AND L A TURNBERG (Department of Medicine, Hope Hospital, Salford, and Department of Medicine, Hammersmith Hospital, London) Neuropeptide Y (NPY) has been shown in high concentration in the enteric nervous system and in particular in the submucosal plexuses of the small intestine of a variety of mammalian species including man. This distribution suggests that NPY may play a role in the control of mucosal fluid transport in the intestine and we therefore examined its effect on segments of rabbit ileal mucosa, stripped of muscle coats, and mounted in flux chambers. NPY, added to the serosal aspect of the mucosa in concentrations of $1.2 \times 10^{-9} \mathrm{M}$ to $1.2 \times 10^{-7} \mathrm{M}$, caused a rapid dose-dependent fall in short-circuit current and electrical potential difference across the mucosa, a significant response being observed at $1.2 \times 10^{-9}$ $M$. The maximal decrease in short-circuit current was $1.12 \pm 0.19 \mu \mathrm{mol} / \mathrm{cm}^{2} / \mathrm{h}$ $(p<0.001)$ and in potential difference was $1.62 \pm 0.29 \mathrm{mV}(\mathrm{p}<0.001)$ at $1.2 \times 10^{-7} \mathrm{M}$. A fall in short-circuit current and potential difference is usually associated with enhanced absorption and this response is similar to that induced by opiates, which influence the mucosa indirectly via a presumed neural intermediary, such as NPY. Application of morphine $\left(10^{-6} \mathrm{M}\right.$ and $10^{-4}$ $\mathrm{M})$ to the serosal aspect of the mucosa caused a decrease in short-circuit current and potential difference. The response of the ileum to morphine was not however 
influenced by pretreatment with NPY $\left(1.2 \times 10^{-7} \mathrm{M}\right)$.

We conclude that these findings support a role for NPY in the control of ileal ion absorption and suggest that NPY is not the neural mediator of opiate responses in the mucosa.

\section{BSG/BASL LIVER}

T7-17

\section{T7}

Liver copper content correlates poorly with severity of histological abnormality in Indian childhood cirrhosis (ICC)

I C TALBOT, M S TANNER, AND A M PRADHAN (Departments of Pathology and Child Health, University of Leicester and King Edward Memorial Hospital, Pune, India) Among 327 0-14-year-old children with liver disease in Pune, 139 (aged 7-66 months) had liver biopsies diagnostic of ICC. Characteristic features were: pericellular fibrosis $(96 \%)$; hepatocyte ballooning (92\%); Mallory's hyaline (91\%); foci of polymorphonuclear leucocytes $(96 \%)$; spotty necrosis $(64 \%)$; orcein and rhodanine staining (all). There was disruption of the limiting plate in $99 \%$. Mild bile duct proliferation was seen in only $33 \%$, cholestasis in only $18 \%$ (25 cases, including six necropsies), and fat was absent.

Histological features were graded 0 (absent) to 3 (severe). Liver copper, measured by atomic absorption spectrophotometry, was grossly raised (1610 \pm 997 $\mu \mathrm{g} / \mathrm{g}$ dry weight, normal $<100 \mu \mathrm{g} / \mathrm{g}$ ), and correlated with rhodanine $(p=0.009)$ and weakly with orcein $(p=0 \cdot 16)$, but did not correlate with any other histological feature. Raised hepatic copper in other disorders also did not correlate with histological severity.

Although the histological changes in ICC may result from copper overload, the severity of damage bears no relationship to copper content at the time of examination.

\section{T8}

Effects of a long acting somatostatin analogue (SMS 201-995) on the activity of the reticuloendothelial system (RES) in rats

S A JENKINS, J N BAXTER, AND R SHIELDS (Department of Surgery, University of Liverpool, Liverpool) Because the activity of the RES is markedly reduced in cirrhosis, the inability of the liver to detoxify enterically derived endotoxin may accentuate existing hepatic damage. Somatostatin (SRIF) has been shown to be effective in controlling acute variceal haemorrhage and preliminary reports suggest that it is cytoprotective with respect to the liver. The purpose of this study was to investigate the effects of a new long acting analogue of somatostatin (SMS 201-995) on RES function in rats. Male Wistar rats received $2 \mu \mathrm{g}$ SMS 201-995 bd subcutaneously for seven days. A control group of rats received similar injections of the same volume of isotonic saline. Reticuloendothelial system function was assessed by the uptake of technetium sulphur colloid, $\mathrm{Cr}^{51}$ red cells damaged by acetylphenylhydrazine and colloidal carbon by the liver and spleen. A further study was undertaken to establish whether SMS 201-995 would protect against $E$ coli endotoxaemia. Administration of SMS 201-995 significantly increased the liver to blood ratio $(6 \cdot 5 \pm 0.9$ to $27 \cdot 1 \pm 5 \cdot 1)(p<0.01$ Student's $t$ test) and spleen to blood ratio $(4 \cdot 66 \pm 1 \cdot 1$ to $29 \cdot 3 \pm 4 \cdot 4)$ of sulphur colloid. Similarly, SMS 201-995 stimulated the uptake of colloidal carbon and $\mathrm{Cr}^{51}$ red cells by the liver and spleen. Furthermore, SMS 201-995 significantly improved survival after intraperitoneal administration of $E$ coli endotoxin $(\mathrm{p}=0.004$, Log Rank Test). These results suggest that SMS 201-995 may stimulate the RES system and be of value in protecting against endotoxaemia in patients with cirrhosis.

\section{T9}

Hepatic infarction after orthotopic liver transplantation

P POWELL-JACKSON, R J POLSON, R Y CALNE, AND R WILliams (Liver Unit, King's College Hospital and School of Medicine \& Dentistry, Denmark Hill, London) Although the clinical features of hepatic infarction due to hepatic artery thrombosis (HAT) after orthotopic liver transplantation are well described, the picture that can occur with thrombosis of the portal vein or hepatic veins is less well documented. In $45 \%(5 / 11)$ of cases of hepatic infarction proven by necropsy or reoperation that occurred in 199 patients in our series, thrombosis of vessels other than the hepatic arteries was the cause - portal vein thrombosis in three and hepatic vein thrombosis in two cases. In all cases the clinical picture was characterised by a rapid deterioration of consciousness progressing to coma within 24 hours, hypotension and hypoxia with levels of aspartate aminotransferase $>600 \mathrm{IU} / \mathrm{l}$ and prothrombin time over $25^{\circ}$ seconds prolonged. Death within 12 days of onset of symptoms occurred in $91 \%(10 / 11)$ of these cases and was responsible for $13 \%(10 / 75)$ of all deaths occurring within six weeks of liver grafting. In only four patients (two with HAT) could technical difficulties be identified while possible aetiological factors in the remainder included prolonged hypotension in three and a presumed coagulopathy in one patient with Budd Chiari. In the one survivor of this series, a suitable donor became available within 12 hours of hepatic infarction and retransplantation was successfully carried out.

T10

Increased iron absorption after chronic ethanol feeding in rats

R MAZZANTI, S K SRAI, M A BOSS, E S DEBNAM, AND P GENTILINI (INTRODUCED BY O EPSTEIN) (Clinica Medica IV, Universita di Firenze, Italy, and Royal Free Hospital School of Medicine, London) Alcoholics often have an increased amount of iron in the liver, which may contribute to the development of alcoholic liver disease, however the mechanism is unknown. It has been shown that chronic alcoholism reduces the enterocyte turnover and increases galactose absorption. Whether chronic alcohol intake affects iron absorption is still controversial. The aim of this study was to investigate the effect of chronic alcoholism on whole body iron absorption in rats. Twenty eight adult male Sprague-Dawley rats were pair fed a liquid diet containing either ethanol as $36 \%$ of total calories or an isocaloric diet where fat was substituted for ethanol. On the 28th day, four hour fasted rats were given an oral dose of ${ }^{59} \mathrm{Fe}(0.5$ $\mu \mathrm{Ci})$ and then immediately counted by a whole body counting technique. ${ }^{59} \mathrm{Fe}$ levels were then monitored in the following nine days, using the same technique. Although ethanol fed and control rats had a similar hepatic iron levels $(59 \cdot 5 \pm 5 \cdot 8$ vs $60 \cdot 2 \pm 7 \cdot 41$ $\mu \mathrm{g} / 100 \mathrm{mg}$ dry liver weight (mean \pm SEM), the ${ }^{59} \mathrm{Fe}$ total body iron content ( $\%$ of the administered dose) was significantly greater in the ethanol group (75 \pm 3$)$ compared with control group $(45+4 ; \mathrm{p} 0.001)$. These results show that chronic ethanol intake increases iron absorption in rats. This phenomenon may be one explanation of the abnormally high liver iron levels in alcoholics. 
T11

The Birmingham liver transplantation programme: our early experience

D CLEMENTS, R M KIRBY, S HUBSCHER, W A JUREWICZ, M SEALY, E ELIAS, AND P MCMASTER (Queen Elizabeth Hospital, Edgbaston, Birmingham) Our indications for liver transplantation are primary liver tumours without evidence of dissemination, chronic liver disease at end stage (projected life expectancy less than six months), and acute liver failure. Of the patients referred for assessment approximately one quarter undergo transplantation; the remainder being too early in the course of their disease, receive other medical or surgical therapy, or are unsuitable for other reasons.

Twenty five grafts have been carried out in 24 patients. The diagnosis was primary biliary cirrhosis in eight, and primary liver tumour in eight. The other eight patients were grafted for $\alpha_{1}$-antitrypsin deficiency (two), cryptogenic cirrhosis (two), BuddChiari syndrome (two), chronic active hepatitis (one), and fulminant hepatic failure (one).

Fourteen of the 24 patients are alive (median seven months, longest survivor over three years). Seven patients have died as inpatients after the operation (mean 15 days postop) and the mean hospital stay for primary discharge was 32 days following transplantation. There have been three late deaths, two from recurrent hepatomas.

Five patients alive beyond 12 months are in normal health with minimal immunosuppression.

\section{T12}

Does male sex predispose to the HBsAg carrier state or to chronic liver disease?

M CHIARAMONTE, A FLOREANI, M ZAGOLIN, E PORNARO, AND R NACCARATO (Department of Gastroenterology, Policlinico Universitario, Padova, Italy) The male/female differences in response to $\mathrm{HBV}$ is a still discussed problem. In the attempt to clarify this point we studied 319 adult $\mathrm{HBsAg}$ carriers (aged 15 to 70 years) presented during epidemiological screening or blood testing for suspected liver disease. Two hundred and twenty two were men (M/ $\mathrm{F}=2 \cdot 3$ ). Out of the men $55 \%$ had CALD, $23 \%$ had $\mathrm{CPH}$ and $22 \%$ were healthy carriers, while among women $32 \%$ had CALD, $16 \%$ had $\mathrm{CPH}$ and $52 \%$ were healthy carriers. $\mathrm{M} / \mathrm{F}$ ratio was 0.98 in healthy carriers, 3.4 in $\mathrm{CPH}$ and 3.9 in
CALD. Age at presentation, prevalence of $\mathrm{HBsAg}$ and seroconversion rate to anti$\mathrm{HBe}$ were similar in men and women in each group, while cofactors such as drug addiction, alcohol abuse, Delta infection, infection in adulthood were significantly associated with liver disease and were more frequent in males. Evidence of intrafamilial infection was present in $16 \%$ of men and in $29 \%$ of women and was more frequent in the healthy carrier group (34\%), suggesting that, when the HBV infection occurs in the household and/or at early ages the risk of chronicity is the same for males and females. We tested this hypothesis in 86 silblings from high risk families: the $\mathrm{HBV}$ infection prevalence was $46.6 \%$ in men and $43.5 \%$ in women and the $\mathrm{HBsAg}$ carrier rate was $34 \%$ in men and $38 \%$ in women.

In conclusion, the difference in the HBsAg carrier rate between sexes is increasing with the severity of the disease. Other harmful factors (more frequent in men?) and/or the age at infection can partially explain this phenomenon.

T13

The enigma of asymptomatic primary biliary cirrhosis

$M$ R LUCEY, $J$ M NEUBERGER, AND $R$ WILliams (Liver Unit, King's College Hospital and School of Medicine \& Dentistry, London) Primary biliary cirrhosis in patients without symptoms of hepatic disease ('asymptomatic PBC') is well described. Although progression occurs in some cases, these patients are said to have normal life expectancy. In order to consider whether asymptomatic $\mathrm{PBC}$ is a benign condition we reviewed the clinical course of 231 patients with PBC followed from 1970 to 1984 of whom 31 (22 women) had no hepatic symptoms, as previously defined, up to the time of diagnosis. At diagnosis the mean age of symptomatic and asymptomatic patients was similar (55 vs 56 years) and disease severity was less in asymptomatic patients; serum bilirubin (median, range) $13 \mu \mathrm{mol} / 1,3-65$ (asymptomatic), $35 \mu \mathrm{mol} / 1,4-390$ (symptomatic). Life table analysis showed longer survival in asymptomatic patients; actuarial five year survival: asymptomatic $70 \%$, symptomatic $50 \%(p<0.05)$. In a median follow up period of 45 months, however, 18 (12 women) patients developed hepatic symptoms and their survival from the onset of symptoms was not different from that in patients with hepatic symptoms prior to diagnosis. These data suggest that many patients with asymptomatic PCB do become symptomatic and they should be considered a presymptomatic group in whom the apparent benign course is a consequence of lead time bias.

\section{T14}

Autonomic neuropathy and alcoholic liver disease

F BARTER AND A R TANNER (Department of Medicine II, Southampton General Hospital, North Tees General Hospital, Cleveland) Autonomic neuropathy (AN) has been assessed in 16 patients with proven alcoholic liver disease (ALD), 14 alcoholics from the community without evidence of liver disease and 30 sex and age matched controls attending for endoscopy. Tests of parasympathetic function were heart rate responses to Vasalva, to deep breathing and to standing. Sympathetic function was assessed by $B P$ response to standing and sustained handgrip. The presence of two or more abnormal tests was taken to indicate AN. Fifty six per cent of subjects with ALD, $14 \%$ of community alcoholics and none of the controls had AN. Female alcoholics were more likely to develop this complication $(80 \%$ vs $28 \%$; $p=0.004)$. There was no significant correlation between symptoms and objective signs of AN. Peripheral neuropathy was documented in $64 \%$ of both groups of alcoholics, but not in the controls. Alcoholics with AN were older, had been drinking longer and $91 \%$ had an associated peripheral neuropathy. Prospective studies in alcoholics with AN would be of interest since studies in diabetics have shown a high mortality and morbidity associated with objective signs of AN.

\section{T15}

Screening for haemochromatosis in the UK: preliminary results

A R TANNER, $S$ DESAI, W LU, AND R WRIGHT (Department of Medicine II, Southampton General Hospital, North Tees General Hospital, Cleveland) Recent studies in Europe and North America have indicated that the gene frequency for haemochromatosis in caucasian populations is much higher than previously suspected. In these populations the prevalence of heterozygotes (HO) has varied between $9 \%$ and $14 \%$ with a homozygote $(\mathrm{HH})$ frequency of $0 \cdot 3-0 \cdot 5 \%$. In the present study, serum 
ferritin, serum iron and iron binding saturation have been measured in 1800 consecutive blood donors in order to assess possible iron overload. The frequency of blood donation was such that little difference would be made to iron stores in $\mathrm{HH}$ subjects. Those subjects with raised serum ferritin $(>200 \mu \mathrm{g} / \mathrm{l})$, raised serum iron (>35 $\mu \mathrm{mol} / \mathrm{l})$ and increased iron binding saturation $(>48 \%)$ were classified as probable $\mathrm{HH}$ and those with elevated saturation and/or serum iron classified as possible $\mathrm{HO}$ subjects. Approximately $30 \%$ of known HO subjects have minor biochemical abnormalities. Five subjects fulfilled the criteria for $\mathrm{HH}$ giving a homozygote prevalence of $0.3 \% \quad(95 \%$ confidence limits $0 \cdot 1-0 \cdot 6 \%$ ) and the heterozygote frequency was approximately $12 \%$. Further studies are continuing in order to independently assess iron stores in these individuals and their families. This study indicates that biochemical screening of an asymptomatic population may be of value.

\section{T16}

Increased incidence of menstrual abnormalities and hysterectomy preceding primary biliary cirrhosis

A J STEllon AND R WILliams (Liver Unit, King's College Hospital and School of Medicine \& Dentistry, London) Menstrual disturbances have been reported in patients with chronic active hepatitis (CAH) and alcoholic liver disease (ALD) but no studies have been described in women with primary biliary cirrhosis $(\mathrm{PBC})$. In this prospective study menstrual, gynaecological and obstetric histories were obtained from PBC patients and compared both with age-matched control subjects and patients with other types of chronic liver disorders. Histories were obtained from 87 patients, aged 35-70 years, with $\mathrm{PBC}$ and compared with a control group of 100 age matched (35.71 years) hospital personnel and 80 age matched (34-73 years) female patients with either CAH (45) or ALD (35). A significantly higher rate of hysterectomy and D \& $\mathrm{C}$ was found in $\mathrm{PBC}$ when compared with control subjects $(p<0.025$ and $p<0.05$ respectively) and other patients with chronic liver disease $(p<0.005$ and $p<0.05$ respectively). Both hysterectomy and D \& $C$ were carried out a mean of 10.7 years and 13.2 years respectively, in the majority of patients, before the diagnosis of PBC. The main clinical indications for hysterectomy in $\mathrm{PBC}$ was menorrhagia while fibroids $(51 \%)$, endometrosis $(21 \%)$ and endometrial polyps $(7 \%)$ were the main operative findings. Endometrial hyperplasia was detected macroscopically in $24 \%$ PBC patients at hysterectomy and $33 \%$ patients in which histological material was obtained at D \& C. The findings would be consistent with an underlying hormonal disturbance favouring oestrogen excess during the presymptomatic stage of PBC.

\section{T17}

Prognostic features in chronic active hepatitis

J J KEATING, A J STELlON, P J JOHNSON, C J O'BRIEN, R D JOHNSON, B PORTMANN, J E HEGARTY, AND R WILlIAMS (Liver Unit, King's College Hospital and School of Medicine \& Dentistry, London) Results relating to survival in chronic active hepatitis $(\mathrm{CAH})$ vary between centres and are more likely to depend upon the nature and stage of the disease than the treatment used. We have, therefore, carried out an analysis of presenting features, histology, frequency of relapse, survival and relation to sex in 106 patients ( 21 men) with 'autoimmune' CAH, 69 patients (28 men) with 'cryptogenic' CAH and 29 patients $(26$ men) with $\mathrm{HBsAg}$ seropositive $(\mathrm{HBsAg}+)$ $\mathrm{CAH}$. Variceal bleeding and encephalopathy were more common presenting features in the cryptogenic group $(p<0.01)$ while the presence of oedema, ascites and jaundice did not differ between the groups (NS). Cirrhosis was more frequent at presentation in the cryptogenic group $(53 \%)$ than in the autoimmune $(30 \%)$ or the $\mathrm{HBs} \mathrm{Ag}+$ group $(35 \%)(\mathrm{p}<0 \cdot 002)$. Development of hepatocellular carcinoma (HCC) occurred in five men with $\mathrm{CAH}$ and in five men with $\mathrm{HBsAg}+\mathrm{CAH}$. The relapse rate per year in autoimmune $\mathrm{CAH}$ was $15 \%$ for those treated with prednisolone, $4.4 \%$ for those treated with prednisolone and azathioprine and $77 \%$ for those in whom treatment was withdrawn. This was similar to the relapse rate in the cryptogenic $\mathrm{CAH}$ of $15 \%, 6.2 \%$, and $72 \%$ respectively. The overall five year survival was $87 \%$ in the autoimmune $\mathrm{CAH}$ group compared with $65 \%$ in the cryptogenic group and $80 \%$ in the $\mathrm{HBsAg}+$ group $(p<0.001)$ although no significant difference in survival was observed in those presenting without cirrhosis. The response to immunosuppressive therapy is comparable in patients with and without autoimmune markers and the worse prognosis in the cryptogenic group appears related to the higher incidence of cirrhosis at presentation. Development of HCC appears to depend more on the sex of the patient rather than the HBV status.

SMALL BOWEL

T18-28

T18

Bacterial contamination in chronic renal failure

M HEALY, CATRIONA LITTLE, P O'CONNOR, MONA' O'MOORE, A SPEEKENBRINK, B KEOGH, C $T$ KEANE, D G WEIR, AND $R$ $R$ O'MOORE (Departments of Medicine, Clinical Biochemistry and Mircobiology, Trinity College, Dublin, Eire) Bacterial contamination of the upper small intestine (USI) in chronic renal failure (CRF) has been implicated in the causation of uraemic diarrhoea and decreased mental alertness possibly due to bacterial production of dimethylamine and trimethylamine (DMA, TMA).

The incidence and extent of contamination in CRF had been estimated as approximately $40 \%$ by the ${ }^{14} \mathrm{C}$ glycocholate breath test $\left({ }^{14} \mathrm{CBT}\right)$. Intubation and microbiological culture was carried out in 28 patients with positive ${ }^{14} \mathrm{CBT}$. The controls were 18 patients with contaminated small bowel syndrome and 20 normal subjects. Production of DMA, TMA was monitored serially during digestion of a meal (three hours). After receiving antimicrobial therapy, reassessment of mental alertness (Wechsler), was made in 11 , and microbial culture and plasma DMA, TMA levels in six CRF patients.

Twenty four of all 28 CRF patients were contaminated. The ${ }^{14} \mathrm{CBT}$ and anaerobic bacterial counts became normal in all CRF patients after antimicrobial treatment. There was also a significant increase in both weight and mental alertness $(p<0 \cdot 01)$. Serial plasma and intestinal DMA levels increased significantly during the meal $(\mathrm{p}<0 \cdot 001)$. Plasma DMA concentrations also decreased significantly following treatment.

Our findings suggest USI bacterial contamination may be clinically important and relatively common in CRF. Antimicrobial therapy lead to improvement of symptoms.

\section{T19}

Macrophages in the microenvironment of coeliac disease 
L K TREJDOSIEWICZ, G MALIZIA, J OAKES, L W POULTER, G JANOSSY, AND M S LOSOWSKY (Department of Medicine, St James's University Hospital, Leeds, and Academic Department of Immunology, Royal Free Hospital, London) Involvement of the immune system in coeliac disease is well documented; attention has hitherto been focused on antibody responses and cell mediated immune responses. Although there are many macrophages in the lamina propria of the small intestine in coeliac disease, these have not hitherto been studied. We have used simultaneous double labelling of jejunal biopsy cryostat sections with monoclonal antibodies to demonstrate macrophage subsets and their relationship to $\mathrm{HLA-DR}$ expression in individual cells in 19 patients with coeliac disease (11 treated, Grades 1 to 3; eight untreated, Grades 3 and 4) and 11 controls.

Antigen presenting macrophages, as identified by RFD1 antibody were a minor subpopulation. In the controls, all such cells expressed HLA-DR whereas up to $70 \%$ of antigen presenting cells in coeliac patients had lost their expression of HLADR. HLA-DR expression is believed essential for functioning of these cells. Scavenger macrophages, as indicated by RFD2 antibody, were increased about three-fold in coeliac disease as compared with controls, although theproportion of scavenger cells which appeared to be in the activated state, as judged by histochemical markers and HLA-DR expression, was unchanged. Regulatory macrophages have previously been shown ,to exist in functional assays and are now believed to be identified by the RFD7 marker. Some RFD7 cells in coeliac disease are of a distinctive type, not hitherto described. They are crescentic in shape and surround aggregates of lymphocytes. All these changes were proportional to the degree of pathological damage.

It is clear that macrophages are involved in the immunological disturbances in the intestinal mucosa in coeliac disease. The presence of regulatory macrophages surrounding lymphoid aggregates might suggest that they were in some way controlling the cells within, perhaps being responsible for reducing the expression of HLA-DR and thus reducing antigen presentation and minimising $T$ cell stimulation. The increase in scavenger cells may represent a response to the tissue damage.

T20

Inflammatory cell subpopulations in nor- mal and coeliac small intestinal mucosa

JACINTA KELLY, C O'MAHONEY, C O'FARRELLY, C FEIGHERY, AND D G WEIR (Departments of Immunology and Clinical Medicine, Trinity College, and St James's Hospital, Dublin, Eire) Coeliac disease is characterised by villous atrophy and chronic inflammatory cell infiltrate. Using an immunoperoxidase staining technique on frozen biopsies, the cell subpopulations defined by monoclonal antibodies were studied in untreated (10) and treated coeliac patients (four) and compared with normal controls (eight). A panel of monoclonal antibodies was used to identify Pan $T$ cells, $T$ helper cells, $T$ suppressor/cytotoxic (S/C) cells, (using Leu 2a and Leu 8) macrophages, and HLA-DR antigens.

Intraepithelial lymphocytes (IELs) were almost exclusively of the $\mathrm{S} / \mathrm{C}$ phenotype in both coeliac and normal small intestine. In the coeliac mucosa, however, the number of these IELs was greatly increased, often outnumbering the number of epithelial cells present. In some cases these IELs expressed HLA-DR antigens, suggesting that they are in an activated state. S/C IELs were also found in the crypt epithelium of the coeliac mucosa, but not in the normal crypts. The lamina propria contained $\mathrm{T}$ helper cells and macrophages in close association and both cell types were found in increased numbers in the coeliac mucosa.

HLA-DR expression was found along the surface epithelial cells of the normal small bowel, but was absent from the epithelial cells of the crypts. In coeliac mucosa however, expression of this antigen was not confined to the surface epithelium, but was found extensively on the crypt epithelium. HLA-DR antigens are involved in antigen presentation and immunological reactions; their increased expression in the coeliac mucosa demonstrates their involvement in maintaining an activated immunological state which may culminate in tissue destruction.

\section{T21}

Small round viruses in acute diarrhoeal disease in children

V LARCHER, A OLIVER, D LEWIS, AND A PHILliPS (Queen Elizabeth Hospital for Children, London) Electron microscopy of stools from children with acute diarrhoeal disease (ADD) is of major importance in the specific identification of viral pathogens, for example, rotavirus. Small round viruses (SRV) which lack characteristic morphology are found in
$1-2 \%$ of stool samples from children withADD but their specific clinical associations are ill defined. We therefore used Freon enhancement and immuno-electron microscopy (IEM) to further categorise stool SRVS in ADD and retrospectively analysed their clinical sssociation.

Sixty one stool samples (1.6\% of total) contained SRV. Stools were available for analysis in 50, and a specific diagnosis possible in 45 . These comprised previously unrecognised structured viruses (astrovirus 13, calici two, morwalk 1), adeno associated virus (AVV) 15, parvovirus six, enterovirus six, parvo and entero one, and hepatitis A one.

Astrovirus was associated with mild ADD, had an equal sex distribution, median age six months, a winter peak and high rate of hospital acquisition (six). AVV was associated with a history of failure to thrive (eight), previous gastroenteritis (eight), and atopy (six). There was a male preponderance, median age 12.5 months, and no clear winter peak. Parvo and entero viruses each produced mild ADD, but without specific features.

Morphological enhancement with Freon and IEM permits a specific viral diagnosis in $90 \%$ cases of ADD associated with SRVs. Prospective studies may define more specific clinical associations than those detailed above.

\section{T22}

Toddler's diarrhoea - intestinal hurry?

R GUERRERO, G A BROWN, AND A S MCNEISH (Institute of Child Health, Birmingham) Toddler's diarrhoea, one of the forms of irritable bowel syndrome (IBS), is a commonly diagnosed condition with an undefined aetiology. It has previously been suggested that children with this syndrome have decreased mouth to caecum transit time, but data are few. Using the breath hydrogen test (BHT) we have measured the mouth to caecum transit time (MCTT) of $10 \mathrm{~g}$ of lactulose in a group of 22 children aged $1-4$ years (mean $2 \cdot 5$ years) presenting with IBS-toddler's diarrhoea. The results were compared with a group of 13 healthy children age matched (mean 3.5 years). The mean MCTT in the IBS group was 42 minutes (SD 8.81), significantly longer than that observed in the control group $(32 \cdot 7$, SD $8 \cdot 80),(p<0 \cdot 01)$. Eight of the children in the IBS group had a second BHT after 3-13 months (mean 8.6 months). Seven of them were said by their parents to have improved, and their MCTT 
decreased towards control values. No drugs or basic dietary modification had been used. One child had relapsed one month before the test, after being well over the previous year, and her MCTT increased.

The results of this study show, contrary to what has been accepted, that children with IBS-toddler's diarrhoea have prolonged small bowel transit which decreases as the condition resolves.

\section{T23}

Study of postoperative gastrointestinal motility in man using radiotelemetry

D L MORRIS, A G CLARK, D F EVANS, AND J D HARDCASTLE (Department of Surgery, University Hospital, Nottingham) Abnormal motility has been shown in the stomach and duodenum after operation but has not been measured simultaneously in the stomach, small bowel and colon in man.

In 10 patients undergoing cholecystectomy intraluminal pressure was measured by three radiotelemetry capsules. One untethered capsule was swallowed 12 hours before operation to allow it to reach the caecum followed by two capsules tethered in the gastric antrum and proximal jejunum. After a period of recording when fasting migrating motor complexes (MCCs) and colonic motility were confirmed, patients underwent surgery. Motility was continuously monitored for up to 72 hours after the operation. In two patients recordings were of insufficient quality for analysis. Fasting jejunal activity returned quickly after operation (mean 100.4 min $\pm 47 \mathrm{SD}$ ) but with shorter interval (mean 36.6 min $\pm 32 \mathrm{SD}$ ) compared with normal (approximately $120 \mathrm{~min}$ ). Normal fasting patterns denoted by a gastroduodenal MMC were not seen in any patient during the recording period, but a typical gastric activity was seen in three patients between 12-24 hours. Colonic motility returned variably from 1-50 hours in six patients, but was absent in two. We have confirmed that gastrointestinal motility is disrupted by anaesthesia and surgery and returned at a variable rate in the stomach and colon and although recovery was more rapid in the jejunum, it was abnormal in type.

\section{T24}

Clinical efficacy of peripheral intravenous nutritional support
C M ROYCE, M MULLEE, AND S J KARRAN (University Surgical Unit, Southampton General Hospital, Southampton) Total parenteral nutrition is of proven efficacy in the perioperative period but remains unpopular. Blackburn pioneered the use of istotonic amino acids for nutritional support but their value remains controversial.

Forty six consecutive patients who underwent oesophagectomy for carcinoma were randomly allocated on the day after surgery to receive one of three peripheral intravenous support regimens: (a) an isotonic amino acid solution (Perifusin) at a rate of $1 \mathrm{~g} \alpha \alpha / \mathrm{kg} /$ day. (b) an isotonic amino acid solution as above plus $500 \mathrm{ml} 20 \%$ intralipid/day. (c) 4 th dextrose and $0 \cdot 18 \%$ $\mathrm{n} /$ saline in equivalent volumes.

Groups (a) and (b) were designated as being 'fed' and group (c) formed the 'unfed' clinical control group. The regimen was continued until adequate oral fluid intake was reestablished. Patients in the three groups were well matched for age, nutritional status, stage and grade of tumour, operative procedure, surgeon, duration and blood loss

Postoperative complications were reduced in 'fed' patients (a) and (b), compared with (unfed) group (c) $(p=0 \cdot 004)$. The reduction was due to a much lower incidence of nutritionally associated complications (NAC), mainly sepsis. Technical (T) and non-nutritionally associated complications (NNAC), - for example, myocardial infarction, were similar in all groups.

\section{T25}

Influence of human and murine giardiasis on intestinal permeability

F ANDRÉ, C ANDRÉ, J GUZMAN, AND S CAVAGNA (INTRODUCED BY $R$ N ALLAN) (Groupe d'Immunopathologie Digestive INSERM, Centre Hospitalier LYON SUD, Pierre Bénite, France) Reports of an association of giardiasis with urticaria and bronchial asthma suggest that troubles of intestinal permeability may be provoked by this parasite. Using gas chromatography, we have measured five hour urine clearance of $5 \mathrm{~g}$ mannitol and of $5 \mathrm{~g}$ lactulose ingested as markers of intestinal permeability, respectively to small and to large molecules. This study was undertaken in seven patients with untreated giardiasis, four of these patients after effective treatment with metronidazole, and in 90 controls.

Mean mannitol excretion was $14.11 \%$ and mean lactulose excretion was $11.26^{\prime} ;$ in controls. In patients with giardiasis. the results were $12.91 \%$ and $1.25 \%$; befor treatment. The results were 14.70$)^{\prime} ;$ and $0.63 \%$ after treatment.

During the spontaneous elimination of giardiasis by $\mathrm{BALB} / \mathrm{c}$ mice. the number of intestinal mast cells, the histamine mucosial content and the intestinal permeability (o) mannitol and lactulose were measured at weekly intervals during eight weeks

The experimental disease was associated with an increase of the number of mast cells and of mucosal histaminc content, and with the same abnormalities of gut permeat bility as detected in humans. Ahorption of lactulose was increased three-fold. Micc receiving $6 \mathrm{mg} / \mathrm{kg}$ histamine orally alse developed gut hyperpermeability to lactulose: absorption of lactulose was also in creased threefold.

These results suggest that the type one hypersensitivity reaction to giardia infec tion induces an increase of gut permeability to macromolecules. Therefore this infective episode may be the occasion of food sensitisation.

\section{T26}

Effect of bicarbonate on efficacy of oral rehydration therapy in a rat model of secretory diarrhoea

E J ELLIOTT, M J KELLY, A I 11 H IISOS, I WALKER-SMITH, ANI) M I (; FARIHIN (Department of Gastroenterology and Academic Department of Child Health, S Bartholomew's Hospital, London) ('ontroversy exists regarding the necessity for inclusion of bicarbonate (Bic) and other base precursors in oral rehvdration solutions (ORS). Our previous work in rat proximal small intestine indicates that $\mathrm{Bic}$ enhances cholera toxin (CT)-induced water and sodium secretion. Recent clinical studies suggest that the absence of $\mathrm{Bic}$ doc not alter clinical efficacy of ORS. Ti investigate this further we hate now per fused the entire rat small intestine (SI) with the widely used UK oral rehydration formulation $\mathrm{NaCl}$ and glucose oral powder compound' ( $\mathrm{Na} 35, \mathrm{~K} 20$. (1 37. BiC is. Glucose $200 \mathrm{mmol} / \mathrm{l}$; British National Formulary) and an equivalent solution in which Bic was replaced by (1. Perfusions were done before and after induction of at secretory state by $2 \mathrm{~h}$ pre-exposure to $75 \mu \mathrm{g}$ $\mathrm{CT}$. In the normal SI water absorption was significantly greater from the $\mathrm{Bic}$ containing ORS $(+108 \cdot 8 \pm 28 \mu \mathrm{l}$ ming $\mathrm{dr}$ weight) than the Bic-free ( $)$ RS $(+72 \cdot 8+22$ 
$\mathrm{p}<0.01$ ). In the secreting SI, however, net water absorption was two-fold greater with Bic-free ORS $(+25 \cdot 1 \pm 14)$ than Biccontaining ORS $(+11 \cdot 1 \pm 16 ; \mathrm{p}<0.05)$. Both solutions failed to produce net $\mathrm{Na}$ absorption in normal and secreting SI, $\mathrm{Na}$ secretion being significantly greater with Bic-free ORS $(-16 \cdot 8 \pm 4$ vs $-9.6 \pm 5$; $\mathrm{p}<0.02)$ in the secreting SI.

These findings indicate that Bic does not contribute to the promotion of water absorption during secretory diarrhoea. Fail ure to achieve net $\mathrm{Na}$ absorption from ORS in the SI suggests an important role for the colon during oral rehydration therapy.

\section{T27}

Effect of ileal and intravenous lipid infusions on feeding and satiety in humans

1 MCL WELCH AND N W READ (Clinical Research Unit, Royal Hallamshire Hospital, Glossop Road, Sheffield) The effect of ileal infusion of a lipid emulsion, containing $50 \%$ corn oil and $3 \%$ albumen, on food intake and satiety was measured in paired experiments in six healthy volunteers. Subjects ate for shorter periods of time during ileal lipid infusions compared with infusions of albumen and saline $(25 \pm 1$ vs $32 \pm 3$ min, $\mathrm{p}<0.025)$ and consumed less food $(670 \pm 23$ vs $884 \pm 89 \mathrm{~g}$ or $1016 \pm 79$ vs $1591 \pm 228 \mathrm{Kcal}, \mathrm{p}<0 \cdot 05)$. The quantity of liquid drunk and the rates of eating and drinking were not affected by the lipid infusion. In five further experiments, ileal infusion of lipid emulsion delayed gastric emptying compared with infusion of albumen and saline $(\mathrm{t} 1 / 2: 203 \pm 48$ vs $68 \pm 12 \mathrm{~min}$, $\mathrm{p}<0.02$ ). Food intake was not affected by intravenous infusions of intralipid compared with saline in six volunteers suggesting that the above observations were not related to the effect of absorbed fat. Intestinal lipid may interact with ileal receptors to induce early satiety; this result is probably explained by early gastric distension caused by delayed gastric emptying, although the release of an ileal mechanism having a direct action on the satiety centre cannot be excluded.

\section{T28}

Abnormal c-myc oncogene product expression in coeliac small intestinal epithelium

J STEWART, G EVAN, K SIKORA, AND P CICLITIRA (Ludwig Institute for Cancer Research, MRC Centre, Cambridge, and Gas. troenterology Research Unit, Rayne Institute, St Thomas's Hospital, London) Oncogenes are sections of DNA that are involved in normal cellular growth control. There is evidence that they may be associated with the rapid cellular transformation resulting in neoplastic change. Molecular cloning has allowed characterisation of the amino acid sequences of several oncogenes including c-myc. Production of a monoclonal antibody to a solid-phase synthesised peptide, permitted investigation of the distribution of the oncogene product in human tissue.

The pathogenesis of coeliac disease is not understood. We have investigated the distribution of the c-myc oncogene product in normal $(n=5)$, treated $(n=5)$ and untreated $(n=5)$ coeliac small intestinal biopsies. The method used peroxidase staining of the c-myc gene product in paraffin embedded sections. Normal subjects and treated coeliac patients express very low levels of the oncogene product while untreated coeliac patients or those on a gluten free diet subjected to a gluten challenge exhibited raised levels in the enterocytes of the upper third of the villi.

OESOPHAGO-GASTRO-DUODENAL

T29-39

T29

\section{Late failures of the Angelchik prosthesis}

R L WOlverson AND J G TEMPLe (Queen Elizabeth Hospital, Edgbaston, Birmingham) Since its introduction in 1979 the Angelchik prosthesis has gained widespread popularity as a simple and safe procedure for the treatment of gastrooesophageal reflux. We reported our early favourable results using this device, but recently increasing numbers of significant problems have been encountered. Between 1981 and September 1983 we inserted 17 prostheses in 25 patients, six of these (24\%) have now had to be removed. In two of the six this was because of disruption of the securing tapes on the prosthesis. One of the patients had a second prosthesis inserted and this subsequently had to be removed as it migrated into the posterior mediastinum and caused dysphagia by angulating. Another prosthesis was removed again for a similar reason. Two further prostheses were removed for dysphagia thought to be due to fibrous capsule formation around the Angelchik and therefore around the gastro-oesophageal junction.

The technical problem of the tape disruption has been solved by the manufacturers. A failure rate of $3 / 25(16 \%)$, however, is still unacceptably high. Detailed follow up of our remaining 19 patients indicates that $3 / 19(15.8 \%)$ are developing symptoms related to swallowing and may well require removal of their prosthesis and subsequent alternative antireflux surgery carried out.

\section{T30}

Patterns of gastroesophageal reflux associated with oesophagitis

S SADEK, W CHEADLE, G VITALE, C CRANFORD, N W CARTER, AND A CUSCHIERI (Department of Surgery, Ninewells Hospital and Medical School, Dundee) Prolonged ambulatory $\mathrm{pH}$ monitoring in normal subjects and patients with varying degrees of reflux injury as assessed by endoscopy can provide information on the evolution of oesophageal disease. A comparative study was therefore carried out between the following groups: Group 1: asymptomatic normal volunteers $(n=50)$; group 2: symtomatic patients with normal endoscopy $(n=26)$; group 3: symptomatic patients with oesophagitis $(n=46)$; group 4: symptomatic patients with ulcerative oesophagitis and/or strictures $(n=31)$.

Comparison between groups 1 and 2 that is, the development of symptoms showed an increase in acid exposure exclusively in the erect posture due to increase in the number of short events. The transition from group 2 to 3 (development of oesophagitis) involved changes in the supine posture and decrease in oesophageal clearance. The transition from group 3 to 4 (development of ulcerative oesophagitis and/or stricture) was associated with increased acid exposure and a reduction in the oesophageal clearance of acid in both the erect and supine positions.

T31

Hydrostatic balloon dilatation of oesophageal strictures

B J M JONES, G F MASKELl, AND A $R$ W HATFIELD (Department of Gastroenterology, The London Hospital, London) Hydrostatic balloons are now available for dilatation of oesophageal strictures other than achalasia. We report here our pre- 
liminary experience with polyvinyl balloon catheters (W Cook) of 10, 15, and $22 \mathrm{~mm}$ diameter on full inflation.

Seventeen consecutive patients with benign (13), malignant (two) or postradiation stricture (two) underwent 25 dilatations. The balloons were passed over an endoscopically placed guide wire in succession and positioned across the stricture under radiological control. Each balloon was inflated with dilute contrast medium for three minutes and the expansion of the 'waist' in the balloon at the site of the stricture observed radiologically.

In nine procedures $(36 \%)$ full dilatation to $22 \mathrm{~mm}$ was achieved and in the remaining $16(64 \%)$ some degree of waisting persisted. To assess the significance of the residual 'waist' on the $22 \mathrm{~mm}$ balloon, Eder-Puestow olives were passed in nine patients and the effective stricture diameter was found to vary from 11 to $15 \mathrm{~mm}$. In these patients a greater degree of dilatation was then obtained with E-P olives or Celestin bougies.

The balloons were very easy to pass over the oropharynx with minimal discomfort but some patients experienced marked retrosternal pain on full inflation. In one patient with a post radiotherapy stricture a small localised perforation occurred after full dilatation which was successfully managed conservatively.

In conclusion balloon dilatation was simple and particularly suitable for elderly patients with cervical spine deformity but very narrow strictures were more difficult to dilate completely and additional conventional bouginage was often necessary.

\section{T32 \\ Does Valsalva's manoeuvre cause variceal bleeding?}

S W HOSKING AND A G JOHNSON (University Surgical Unit, Royal Hallamshire Hospital, Sheffield) Large increases in variceal pressure recorded during Valsalva's manoeuvre may cause variceal bleeding but no studies have measured intraoesophageal pressure simultaneously. This prevents measurement of the pressure difference across the varix wall which is a more likely predictor of variceal rupture. We have measured intraoesophageal and intravariceal pressure simultaneously during Valsalva's manoeuvre to determine this pressure difference. Thirteen patients with oesophageal varices were studied before sclerotherapy. A perfused manometer line was passed into the oesophagus followed by an Olympus GIF-Q10 endoscope to approximately $4 \mathrm{~cm}$ above the oesophagogastric junction. A perfused variceal injector was used to obtain intravariceal pressure readings. At rest, corrected intravariceal pressure (intravariceal minus intraoesophageal pressure) varied between patients from 6-22 $\mathrm{mm} \mathrm{Hg}$. During volun tary Valsalva's manoeuvre, uncorrected intravariceal pressure rose to between 16 and $74 \mathrm{~mm} \mathrm{Hg}(\mathrm{p}<0.001$ Paired t-test $)$. After correcting for intraoesophageal pressure, the change in pressures were from -9 to $+18 \mathrm{~mm} \mathrm{Hg}$ (not significant), and showed no correlation with readings obtained at rest. Repeated Valsalva's manoeuvre within each patient showed a similar change on each occasion. These results suggest that Valsalva's manoeuvre causes only a small rise or even a fall in the pressure across the varix wall, and seems unlikely to initiate variceal haemorrhage.

\section{T33}

Follow up of laser palliation for malignant dysphagia

S G BROWN, K MATTHEWSON, C P SWAIN, AND C G CLARK (Department of Gastroenterology University College Hospital, London) We treated 18 patients aged 57 to 88 with endoscopic $\mathrm{Nd}$ YAG laser therapy to palliate dysphagia from advanced malignancy of the oesophagus and gastric cardia and were able to restore satisfactory swallowing in 14 . Failure was caused by massive extrinsic tumour in three and a laser perforation in one. The other 14 were followed up. Thirteen have died. Three died without further dysphagia after eight, 11 and 42 weeks (the first of these was the only patient also to receive radiotherapy, which he tolerated poorly). Four had poorly defined difficulty with swallowing near to the time of death from disseminated disease after four, five, 14 and 14 weeks. Three had recurrent dysphagia attributable to exophytic tumour at four, five and 11 weeks. Two of these had excellent results from further laser therapy, one survived a further 19 weeks without dysphagia and the other is still swallowing well after a further 28 weeks. The third had a Celestin tube inserted but its introduction caused a tracheobronchial fistula from which she died after three weeks. The other four had recurrent stenosis due to extrinsic tumour at $10,12,14$ and 16 weeks. Intubation was attempted in three with bad results; one perforated, one aspirated and one died 24 hours postoperatively.
Necropsy histology in cases with good results showed extensive fibrosis in the laser treated areas, even in the absence of previous radiotherapy. This treatment appears effective in cases with obstruction due primarily to exophytic tumour. Recurrent exophytic tumour responds well to further laser therapy, but other treatments for recurrent obstruction have poor results.

\section{T34}

Ambulatory oesophageal pH monitoring in achalasia

H L SMART, P N FOSTER, D F EVANS, B SLEVIN, AND M ATKINSON (University Hospital, Queen's Medical Centre, Nottingham) Radiotelemetric ambulatory oesophageal $\mathrm{pH}$ monitoring was performed in $12 \mathrm{pa}$ tients with symptomatic achalasia, seven of whom had a dilated oesophagus with retained food residue. $\mathrm{pH}$ Monitoring revealed that classical episodes of gastrooesophageal reflux occurred in only one patient. Overall an abnormally high percentage acid exposure time (AET), was found for $\mathrm{pH}<5(44.4 \%)$ and $\mathrm{pH}<4(20.3 \%)$ prior to treatment. In patients with food residue these values were significantly higher than those found in patients without retained food. Repeat studies one week after pneumatic dilatation showed a fall in AET in patients with initial food residue ( $\mathrm{pH}<5$ from $65.1 \%$ to $51.7 \%$ ) but an increase was seen in those without initial food residue ( $\mathrm{pH}<5$ from $7 \cdot 8 \%$ to $46 \cdot 2 \%$ ) Gastro-oesophageal reflux occurs infrequently in untreated achalasia and the abnormally high AET is presumably because of fermentation of retained food material. The fall in AET after pneumatic dilatation is explained by improvement in oesophageal emptying in those patients with initial food residues whereas the rise in AET in those without initial residue is probably attributable to gastro-oesophageal reflux after dilatation

\section{T35}

Altered drug pharmacokinetics in smokers - an effect of smoking on gastric emptying

D A JOHNSON, E J S BOYD, AND K G WORMSLEY (Ninewells Hospital, Dundee, Scotland) Gastric inhibition by antisecretory drugs is impaired by cigarette smoking. We undertook studies to determine whether this effect is attributable to an alteration of drug pharmacokinetics. Eight habitual smokers underwent two studies on sepa- 
rate days. The stomach was intubated, Among these patients, 25 were receiving resting contents aspirated, and $300 \mathrm{ml}$ of a cimetidine ( $400 \mathrm{mg}$ nocte), 21 placebo (2 meal containing Oxo meat broth and PEG tablets nocte), and 16 no therapy except for $4000(2.5 \mathrm{~g} / \mathrm{l})$ was introduced into the antacids when needed. Each patient constomach. Gastric contents were sampled tinued the treatment unchanged during the after 10 minutes and aspirated completely nine month follow up period. Endoscopic after 20 minutes. Gastric secretory re- reexaminations took place after three and sponses and the volume of gastric contents nine months, and at symptoms occurrence, discharged into the duodenum were calcu- whereas clinical examinations were perlated by the method of Hunt. On one of the study days, in random order, subjects smoked at a rate they found comfortable. On the other day cigarettes were prohibited. Ten habitual smokers underwent two studies on separate days. On each day either. ranitidine $150 \mathrm{mg}$ (five subjects) or cimetidine $200 \mathrm{mg}$ (five subjects) was taken orally with a meal. Blood levels of ranitidine or cimetidine were measured at 0,15 , $30,45,60,90,120,150,180,240$, and 360 minutes after dosing. Cigarettes were smoked on only one study day. Ten further smokers underwent similar studies in which they received either ranitidine $50 \mathrm{mg}(\mathrm{n}=5)$ or cimetidine $200 \mathrm{mg} n=5$ ) intravenously.

When cigarettes were smoked the volume of gastric contents discharged into the duodenum during the meal increased by $23 \%$. Drug absorption after oral dosing was more rapid, and peak plasma levels achieved sooner, when cigarettes were smoked. For any given time after peak plasma levels had been achieved, however, plasma drug levels were lower when cigarettes were smoked. Smoking did not alter the pharmacokinetics of intravenously administered drugs.

We conclude that cigarette smoking alters the pharmacokinetics of antisecretory drugs in a manner which may contribute to the impaired therapeutic response. The effect is attributable solely to an increase in the rate of gastric emptying.

\section{T36}

\section{Natural history of silent duodenal ulcer}

G BIANCHI PORRO, M LAZZARONI, M PETRILLO, F PARENTE, AND F PACE (Gastrointestinal Unit, L Sacco Hospital, Milano, Italy) Endoscopic follow up of duodenal ulcer patients during maintenance treatment with $\mathrm{H}_{2}$-blockers have raised the problem of asymptomatic recurrence of duodenal ulcer. In order to define the natural history and the clinical significance of this subset of ulcer, we followed up during nine months 62 patients with a silent recurrence of duodenal ulcer, detected in the course of a routine endoscopic examination of patients undergoing long-term ulcer treatment. formed at bimonthly intervals. The cumulative rate of spontaneous ulcer healing after nine months was $39 \%$ : $48 \%$ in $\mathrm{H}_{2}$ blockers group, $37 \%$ in the group without any therapy, and $29 \%$ in placebo group, respectively $(p>0 \cdot 05)$. The cumulative frequency of symptoms occurrence was $50 \%$ : $40 \%$ in patients receiving cimetidine, $44 \%$ in those receiving no therapy, and $67 \%$ in those receiving placebo $(p>0.05)$. The percentages of unhealed asymptomatic ulcer after nine months were $12 \%$ in the $\mathrm{H}_{2}$-blockers treated group, $19 \%$ in the no-treatment group, and $49 \%$ in the placebo treated group $(p>0 \cdot 05)$. One patient receiving no treatment bled from his ulcer during the follow up period.

\section{T37}

Immediate effects of vagotomy on parietal and oxyntic cell function

P D SCOTT AND R F MCcLoY (University Department of Surgery, Manchester Royal Infirmary, Oxford Road, Manchester)

The time course and pathophysiology of changes in gastric secretion by vagotomy remain unclear. Grassi suggested that gastric acidity falls to $>\mathrm{pH} 5.5$ immediately but gastric function tests in the early postoperative period reveal the $\mathrm{pH}$ is often $<\mathrm{pH} 2$.

Gastric acidity and pepsin concentration were measured in samples of gastric juice aspirated hourly in 11 patients undergoing vagotomy (seven proximal gastric vagotomy, four truncal vagotomy and pyloroplasty) for duodenal ulcer disease. Standard pre- and postoperative basal/sham/ pentagastrin tests were performed to assess the changes in basal and stimulated gastric acid outputs.

In nine of 11 patients there was a rise in $\mathrm{pH}$ above 5.5 within two hours of completion of vagotomy. The $\mathrm{pH}$ remained $>4$ for a mean duration of 20.8 hours (range this time period and postoperative reduction in BAO. The $\mathrm{pH}$ returned to preoperative levels in all patients within 14-54 hours (mean 31.4). Pepsin concentrations did not mirror this pattern and showed a 4-41). There was no correlation between variable response.

These findings suggest that the operation of vagotomy leads to a near total inhibition of parietal and oxyntic cell function which then recovers to expected levels by the third day.

\section{T38}

Human gastric enterochromaffin-like (ECL) cells - demonstration of histamine content and its cholinergic nerve supply

W M HUI, H C LIU, AND S K LAM (Departments of Medicine and Anatomy, University of Hong Kong, Queen Mary Hospital, Hong Kong) The source of histamine in the human stomach has not been established. To examine for possible relationship between the nerve supply and the endocrine ECL cells of the stomach and whether the latter contain histamine, endoscopic biopsies of the gastric fundus of four healthy subjects and eight patients with duodenal ulcer were meticulously studied. Modified silver impregnation method was used to stain up simultaneously the ECL cells and nerve fibres, and cholinesterase activity of nerve fibres were examined histochemically. Modified ophthalaldehyde fluorescence method was used to examine for possible histamine content of the ECL cells, which were then counter-stained for ECL cells by Grimelius silver method. The results were (i) ophthalaldehyde staining was taken up by the mast cells and the ECL cells, which corresponded to the argyrophil staining cells. (ii) Nerve fibres possessing acetylcholinesterase activity ramified to the basement membrane of the ECL and parietal cells, which were in close proximity to each other. This intimate anatomical relationship and the demonstration for the first time that human ECL cells contain histamine strongly suggest that the human ECL cells play an important role in the control of acid secretion, possibly under vagal influence.

\section{T39}

Thromboxanes and gastric mucosal damage

C A PRICE, G PIPKIN, A CURRINGTON, L DAVIES, L DARLING, AND M E PARSONS (Smith Kline \& French Research Limited, The Frythe, Welwyn, Hertfordshire) Thromboxane (TX) synthetase inhibitors reduce experimental gastric damage in the rat. If they act by preventing the formation of potentially damaging TX then a TX anta- 
gonist should also be effective. Dazoxiben (TX synthetase inhibitor, 30 and $60 \mathrm{mg} / \mathrm{kg}$ po) reduced ethanol induced damage in the conscious rat. At $60 \mathrm{mg} / \mathrm{kg} \%$ area of mucosa damaged was reduced from $16 \cdot 3 \pm 2 \cdot 3 \quad(n=8) \quad$ to $5 \cdot 9 \pm 2 \cdot 0 \% \quad(n=8$, $\mathrm{p}<0.01)$. The TX antagonists SK\&F 88046 (10 and $50 \mathrm{mg} / \mathrm{kg}$ po) and BM13177 (50 $\mathrm{mg} / \mathrm{kg} \mathrm{po}$ ) also reduced this form of damage. SK\&F $88046(50 \mathrm{mg} / \mathrm{kg})$ reduced \% area of mucosa damaged from $9 \cdot 8 \pm 2.7$ $(n=7)$ to $0 \cdot 1 \pm 0 \cdot 1 \%(n=6, p<0 \cdot 01)$. The duration of action of SK\&F 88046 against U46619 (TX mimetic) induced hypertension was short $(40 \mathrm{~min})$ in the rat, therefore in the rat ex vivo gastric chamber preparation SK\&F 88046 was given as an iv bolus $(20 \mathrm{mg} / \mathrm{kg}$ ) followed by an infusion (40 $\mathrm{mg} / \mathrm{kg} / \mathrm{h})$. This dose reduced blood and albumin loss into the gastric chamber after two hours exposure to acidified $\mathrm{Na}$ taurocholate $(50 \mathrm{mM})$. Blood $\left({ }^{51} \mathrm{Cr}\right.$ red blood cells) loss, was reduced from $11.9 \pm 3.4$ to $2 \cdot 8 \pm 0 \cdot 6 \mathrm{ml} \times 10^{-3}(\mathrm{p}<0 \cdot 05)$. SK\&F 88046 antagonised the effect of U46619 on rat platelet rich plasma $\left(\mathrm{IC}_{50} 4 \cdot 2 \mu \mathrm{M}\right)$ and on the rat fundus strip $\left(\log K_{B} 7 \cdot 53\right)$ confirming that SK\&F 88046 acted as a TX antagonist in the rat, as in other species. These results suggest that TX may be involved in the pathogenesis of ethanol and bile induced damage in the rat.

BASIC SCIENCE

F1-12

F1

\section{Identification of human progastrin}

H P DESMOND, S PAUWELS, R DIMALINE, AND G J DOCKRAY (Department of Physiology, University of Liverpool, Liverpool, and Centre de Medecine, Nucleaire, University of Louvain, Brussels, Belgium) The gene sequence encoding the human gastrin precursor, progastrin, has been elucidated, but little else is known of the biosynthesis of this hormone. We have raised antibodies to a synthetic analogue of the C-terminal hexapeptide of progastrin; unlike other gastrin antibodies, these are expected to react with the intact precursor as well as fragments of it. They should therefore help elucidate biosynthetic pathways. In human antral mucosal extracts fractionated on Sephadex G50 we found two peaks of immunoreactivity: a major one $(84 \pm 2 \%$ of total; $n=10$ ) corresponded to the $C$ - terminal tryptic fragment of progastrin $\left(K_{a v} 0.65\right)$, and a minor one was of higher apparent molecular weight $\left(\mathrm{K}_{\mathrm{av}} 0 \cdot 20\right)$. In contrast, in three of eight gastrinomas, the latter material accounted for over $50 \%$ of total immunoreactivity (mean $39 \pm 6 \%$; $\mathrm{n}=8$ ). Digestion of the high molecular weight form with trypsin liberated peptides identified by antibodies to the $\mathrm{N}$-terminus of $\mathrm{G} 17$ and of G34, indicating a structure extending from the $\mathrm{C}$-terminus of progastrin to beyond the $\mathrm{N}$-terminus of $\mathrm{G} 34$.

We conclude that: (1) material with the properties of intact progastrin is found in antral mucosa and gastrinomas. (2) In some gastrinomas it is the predominant form of gastrin. (3) There are differences between gastrinomas and antral mucosa in the biosynthetic processing of progastrin.

\section{F2}

Recombinant urogastrone-EGF can provide a proliferative signal after small resection in parenterally fed rats

R A GOODLAD, W LENTON, H GREgory, a P SAVAGE, K G MCCULlaGH, AND N A WRIGHT (Department of Histopathology, Royal Postgraduate Medical School, Hammersmith Hospital, London, ICI, Alderley Park, Macclesfield, and G D Searle, High Wycombe, Bucks) It is now known that animals maintained on total parenteral nutrition (TPN) do not show the dramatic proliferative response to partial small bowel resection seen in orally fed animals, suggesting that the presence of food in the lumen is an important signal. If this proliferative signal is hormonal it might be expected that hormone(s) themselves could initiate this process. The response of the gastrointestinal tract to urogastroneEGF was investigated in rats maintained on TPN with or without $75 \%$ small bowel resection. Orally fed rats ( \pm resection) were also studied. Two way analysis of variance showed that resection caused a significant increase $(p<0.01)$ in proliferation below the anastomosis and in the ileum of TPN rats; however, the response of the ileum was much less than that observed in orally fed rats, which confirms the importance of 'luminal nutrition' in the response to resection. There was no evidence for a significant positive interaction (synergistic effect) between the effects of urogastrone-EGF and resection. Continuous infusion of $60 \mu \mathrm{g} / \mathrm{rat} /$ day of recombinant beta urogastrone significantly increased proliferation (measured by the accumulation of vincristine arrested metaphases) in the stomach $(\mathrm{p}<0 \cdot 05)$, small intestine and colon $(p<0.001)$ in resected and unresected rats maintained by TPN. Thus urogastrone-EGF has the novel property of being capable of stimulating a proliferative response in the resected intestine of parenterally fed rats.

\section{F3}

Serotonin, a physiological role in gastrointestinal motility?

G B HOPKINSON, J HINSDALE, AND B JAFFE (INTRODUCED BY J B ELDER) (Department of Surgery, Downstate Medical School, Brooklyn, New York, USA) Freyburger in 1951 showed a spasmogenic action for $5 \mathrm{HT}$ in the canine jejunum, but its physiological significance was unknown. Five chronic conscious dogs fitted with gastric and jejunal strain gauges were infused intravenously with 5HT in doses between $0.25 \mu \mathrm{g} / \mathrm{kg} / \mathrm{min}$ and $120 \mu \mathrm{g} / \mathrm{kg} / \mathrm{min}$ over 20 minute periods during the quiescent phase $(\mathrm{Ph} \mathrm{I})$ of the interdigestive myoelectrical complex (IDMEC). Over 200 such infusions were carried out. Coeliac artery 5HT levels were monitored by radioimmunoassay. Below $1 \mu \mathrm{g} / \mathrm{kg} / \mathrm{min}$ no contractile response occurred. Between $1-4 \mu \mathrm{g} / \mathrm{kg} / \mathrm{min}$ three dogs showed a response. At $8 \mu \mathrm{g} / \mathrm{kg} /$ min all dogs showed responses to intravenous $5 \mathrm{HT}$. The gastric contraction rate increased from $2 \cdot 1 \pm 0 \cdot 50$ (contractions per minute $(\mathrm{CPM}) \pm \mathrm{SEM}$ ) before infusion, to $4 \cdot 6 \pm 0 \cdot 21 \mathrm{CPM}$ during infusion of $5 \mathrm{HT}$ at 8 $\mu \mathrm{g} / \mathrm{kg} / \mathrm{min}(\mathrm{p}<0.001)(\mathrm{n}=20)$. The gastric contraction force increased from $16 \cdot 1 \pm 6 \cdot 20 \mathrm{mV} / \mathrm{mins}$ before infusion, to $145 \cdot 8 \pm 14 \cdot 1 \mathrm{mV} / \mathrm{mins}$ during infusion $(p<0 \cdot 001)$. The jejunal contraction rate increased from $1.2 \pm 0.57 \mathrm{CPM}$ before infusion, to $16 \cdot 4 \pm 0 \cdot 50$ CPM $(p<0 \cdot 001)$ $(n=20)$, with an increase in contraction force from $6 \cdot 1 \pm 3 \cdot 10 \mathrm{mV} / \mathrm{mins}$ before infusion to $125 \cdot 2 \pm 15 \cdot 2 \mathrm{mV} / \mathrm{mins}$. Arterial levels before infusion of 5HT were $658.3 \pm 187.6 \mathrm{ng} / \mathrm{ml}$ of whole blood and increased to $719.5 \pm 68.7 \mathrm{ng} / \mathrm{ml}$ during infusion. The contraction force during $5 \mathrm{HT}$ infusion was similar to that found during the spontaneous maximum contraction of the bowel. During infusion of $5 \mathrm{HT}$ at 8 $\mu \mathrm{g} / \mathrm{kg} / \mathrm{min}$ serotonin appears a major mediator of intestinal motility.

F4

Glucocorticoid-induced $\mathrm{Na}$ and $\mathrm{K}$ channels in the apical membrane of rat distal colon 
G I SANDLE (Department of Medicine, University of Manchester School of Medicine, Hope Hospital, Salford) $\mathrm{Na}$ and $\mathrm{K}$ channel blockers (amiloride and tetraethylammonium chloride (TEA), respectively) have been used with microelectrodes to study stimulation of $\mathrm{Na}$ absorptive and $\mathrm{K}$ secretory processes in rat distal colon by dexamethasone $(600 \mu \mathrm{g} / 100 \mathrm{BW} /$ day for three days). In dexamethasone treated animals $(n=15)$, transepithelial voltage $\left(\mathrm{V}_{\mathrm{t}}:-31 \pm 4 \mathrm{mV}\right)$ and total conductance $\left(\mathrm{G}_{\mathrm{t}}: 8 \cdot 5 \pm 0.5 \mathrm{mS} / \mathrm{cm}^{2}\right)$ were higher than in controls $(-6 \pm 1 \mathrm{mV}, \mathrm{p}<0.001$ and $5 \cdot 3 \pm 0 \cdot 2$ $\mathrm{mS} / \mathrm{cm}^{2}, \mathrm{p}<0.001$ respectively, $\mathrm{n}=12$ ); these changes reflected an increase in basolateral membrane voltage, and decreases in apical membrane voltage and the basolateral/apical conductance ratio. Mucosal amiloride $\left(10^{-4} \mathrm{M}\right)$ and then TEA (30 $\mathrm{mM})$ had no effects in control animals In dexamethasone treated animals, amiloride reduced $V_{t}$ to the control value, decreased $G_{t}$ from $8 \cdot 5 \pm 0.5$ to $6.9 \pm 0.3 \quad F$ $\mathrm{mS} / \mathrm{cm}^{2} \quad(\mathrm{p}<0.001)$, hyperpolarised the Intestinal tissue oxygen tension measureapical membrane by $13 \mathrm{mV}(\mathrm{p}<0 \cdot 005)$, and ment using a surface electrode

increased the basolateral/apical conductance ratio by $63 \%$, indicating inhibition of $M$ B HALLETT, A SHANDALL, R H LOWNDES, apical $\mathrm{Na}$ channels and electrogenic $\mathrm{Na} \mathrm{H}$ L YOUNG (INTRODUCED BY J V PSAILA) transport. Subsequent addition of TEA (University Department of Surgery, Univerdecreased $G_{t}$ from $6 \cdot 9 \pm 0 \cdot 3$ to $6 \cdot 4 \pm 0.4$ sity of Wales College of Medicine, Heath $\mathrm{mS} / \mathrm{cm}^{2}(\mathrm{p}<0 \cdot 001)$, depolarised the apical Park, Cardiff) If a surface electrode truly membrane by $8 \mathrm{mV}(\mathrm{p}<0.025)$, and in- measures tissue oxygen tension $\left(\mathrm{TO}_{2}\right)$, this creased the basolateral/apical conductance could be used to assess intestinal perfusion/ ratio by $66 \%$, indicating inhibition of apical viability. To determine this we have $\mathrm{K}$ channels. Thus, stimulation of $\mathrm{Na}$ studied the relationship between $\mathrm{TO}_{2}$ absorptive and $\mathrm{K}$ secretory processes in rat measured with the Clark electrode, blood distal colon by dexamethasone involves an flow $(F)$ measured by $\mathrm{Xe}^{133}$ clearance and increase in the conductance of the apical arterial $\mathrm{O}_{2}$ tension $\left(\mathrm{PaO}_{2}\right)$ measured by membrane to both $\mathrm{Na}$ and $\mathrm{K}$.

\section{F5}

Is gall bladder emptying really exponential?

P HOWARD, G M MURPHY, AND R H DOWLING (Gastroenterology Unit, Division of Medicine, UMDS of Guy's and St Thomas' Hospitals, London) Previous ultrasound studies of gall bladder (GB) emptying have used standard Lundh meal or CCK stimuli and long intervals $(>15 \mathrm{~min})$ between imaging. The pattern of response to a normal, dual phase (liquid plus solid) meal, is unknown. Therefore, in 10 control subjects, we measured GB size with frequent ultrasound recordings, after a meal of baked beans on buttered toast with milk.

In nine of 10 subjects, the GB emptied before the meal, the mean reduction in GB vol ( $\Delta$ vol) recorded during this "cephalic phase' being $5.28 \pm$ SEM $1.76 \mathrm{ml}$. After the meal, all 10 subjects showed the same triphasic pattern of response with: (i) an early phase of GB emptying from a mean $11 \cdot 21 \pm 2.35(\mathrm{p}<0.05)$ at $17 \cdot 1 \pm 5.4 \mathrm{~min}$; (ii) a net refilling phase to $16 \cdot 6 \pm 3.24 \mathrm{ml}$ at phase to a final nadir vol of $5.6 \pm 1.51 \mathrm{ml}$ at $1.38 \pm 9.9 \mathrm{~min}$. In four subjects, US imaging at more frequent intervals ( $1 / \mathrm{min})$ was punctuated by min to min fluctuations in vol with mean filling and emptying rates

ern of GB emptying after a dual phase meal is not a simple exponential but is interrupted by an episode of net refilling before the final nadir is reached, with
superimposed minute by minute fluctuations in volume throughout.

arterial $\mathrm{O}_{2}$ tension $\left(\mathrm{PaO}_{2}\right)$ measured by
blood gas analysis, in a rabbit experimental model.

Using serial devascularisation in nine rabbits $\mathrm{F} \& \mathrm{TO}_{2}$ were measured in midileum and mid-sigmoid colon. In six rabbits inspired $\mathrm{O}_{2}\left(\mathrm{FiO}_{2}\right)$ was varied between $0-100 \%$ with $\mathrm{PaO}_{2}$ measured on rabbit ear as above.

Using known physiological parameters of oxygen capacity, oxygen supply, oxygen consumption, oxygen diffusion and haemoglobin saturation a formula relating $\mathrm{F}, \mathrm{PaO}_{2}$ and $\mathrm{TO}_{2}$ was derived. Curves based on this showed the expected sigmoid relationship between $\mathrm{F}$ and $\mathrm{TO}_{2}, \mathrm{PaO}_{2}$ and $\mathrm{TO}_{2}$, which fitted the experimental data with a correlation of $\mathrm{r}=0.93, \mathrm{p}<0.001$ $\left(\mathrm{TO}_{2}\right.$ vs F), $\mathrm{r}=0.96, \mathrm{p}<0.001\left(\mathrm{PaO}_{2}\right.$ vs $\mathrm{TO}_{2}$ ) on linearising the equation. This relationship would not be expected if the electrode was merely detecting capillary $\mathrm{O}_{2}$, or if ambient air was significantly arterial blood, and $\mathrm{TO}_{2}$ on ileum and colon influencing the measurement.

We conclude that the Clark electrode is a true measure of tissue oxygen tension and can be used clinically for this purpose.

\section{F7}

Dissociated effect of atropine on hypergastrinaemia induced by single dose and repeated omeprazole treatment

F HALTER, F EIGENMANN, AND H R KOELZ (Gastrointestinal Unit, University Hospital, Inselspital Berne, Switzerland) Omeprazole has been shown to increase serum gastrin and antral G-cell density in the rat. Acute hypergastrinaemia following acid inhibition induced by histamine $\mathrm{H}_{2}$ antagonists can be blocked by high doses of atropine, both in fasting and fed rats. We studied whether hypergastrinaemia induced by single or repeated dose treatment with omeprazole can be prevented by additional atropine.

Gastric $\mathrm{pH}$ and serum gastrin were measured in 10 chronic gastric fistula rats before and four hours after sc omeprazolee (O, $40 \mu \mathrm{mol} / \mathrm{kg})$; omeprazole combined with atropine $(\mathrm{O}+\mathrm{A}, 40 \mu \mathrm{mol} / \mathrm{kg}$ and 3 $\mathrm{mg} / \mathrm{kg}$, respectively); atropine (A, 3 $\mathrm{mg} / \mathrm{kg}$ ); or the omeprazole solvent (S, $40 \%$ PEG). Gastric $\mathrm{pH}$ of all animals treated with $\mathrm{O}$ or $\mathrm{O}+\mathrm{A}$ became neutral within four hours. After $\mathrm{O}$, fasting serum gastrin levels rose from $34 \pm 4$ to $110 \pm 9 \mathrm{pmol} / \mathrm{l}(\mathrm{x} \pm \mathrm{SEM}$, $\mathrm{p}<0.001$ ), but were not influenced in the other groups. Four groups of six intact, fed animals received similar treatment for 10 days. O was given once daily, A twice daily. In contrast to single dose treatment, both $\mathrm{O}$ and $\mathrm{O}+\mathrm{A}$ increased mean serum gastrin levels by approximately seven-fold as measured four and 12 hours after the last dose of $\mathrm{O}$ or $\mathrm{O}+\mathrm{A}$. Treatments $\mathrm{A}$ and $\mathrm{S}$ did not influence serum gastrin.

We conclude that atropine blocks the acute rise of serium gastrin after a single dose omeprazole administration. The more pronounced hypergastrinaemia following prolonged omeprazole treatment, however, is atropine resistant, suggesting a change in the regulatory mechanisms of G-cells. It appears thus unlikely that G-cell hyperplasia following prolonged omeprazole treatment represents a simple work hyperplasia directly related to acid inhibition.

\section{F8}

Prostaglandin $\mathbf{E}_{2}$ stimulates chloride secretion in guinea-pig isolated gastric mucosa 
C F SPRAGGS AND K T BUNCE (Department of Neuropharmacology, Glaxo Group $R e$ search Ltd, Ware, Herts) The effect of prostaglandins on gastric mucosal ion transport has been investigated in vitro mainly in amphibian mucosa and little information is available on the effect of prostaglandins in mammalian tissue. We have investigated the effects of prostaglandin $\mathrm{E}_{2}\left(\mathrm{PGE}_{2}\right)$ on sodium and chloride transport and short circuit current (SCC) in guinea-pig isolated gastric mucosa in which acid secretion had been inhibited by omeprazole $(100 \mu \mathrm{M})$.

$\mathrm{PGE}_{2}(1 \mu \mathrm{M})$ produced increases in SCC of $73 \pm 5 \mu \mathrm{A} \mathrm{cm}$. The ionic basis of this response was determined by ${ }^{36} \mathrm{Cl}$ and ${ }^{22} \mathrm{Na}$ flux studies in mucosae pretreated with omeprazole $(n=7)$. Under control conditions the net secretion of ${ }^{36} \mathrm{Cl}(2.90 \pm 0.69$ $\left.\mu \mathrm{Eq} \mathrm{cm}^{-2} / 30 \mathrm{~min}\right)$ was not significantly different from SCC $\left(4.30 \pm 0.39 \mu \mathrm{Eq} \mathrm{cm} \mathrm{cm}^{-2}\right.$, $30 \mathrm{~min}, \mathrm{p}>0.05)$, while the net absorption of ${ }^{22} \mathrm{Na}\left(-0.02 \pm 0.08 \mu \mathrm{Eq} \mathrm{cm}{ }^{-2} / 30 \mathrm{~min}\right)$ was significantly different $(p<0 \cdot 001)$. $\mathrm{PGE}_{2}(1 \mu \mathrm{M})$ stimulated a significant increase in both SCC $(5.36 \pm 0.31 \mu \mathrm{Eq}$ $\left.\mathrm{cm}^{-2} / 30 \mathrm{~min}, \mathrm{p}<0.001\right)$ and ${ }^{36} \mathrm{Cl}$ secretion $\left(5.53 \pm 0.63 \mu \mathrm{Eq} \mathrm{cm} \mathrm{cm}^{-2} / 30 \mathrm{~min}, \mathrm{p}<0.001\right)$, but had no significant effect on net ${ }^{22} \mathrm{Na}$ absorption $\left(-0.27 \pm 0 \cdot 12 \mu \mathrm{Eq} \mathrm{cm} \mathrm{cm}^{-2} / 30 \mathrm{~min}\right.$, $\mathrm{p}>0.05$ ).

These results show that $\mathrm{PGE}_{2}$ stimulates electrogenic chloride secretion in guineapig isolated gastric mucosa, and provide an ionic basis for the stimulation of a $\mathrm{NaCl}$ rich secretion by $\mathrm{E}$-prostaglandins in mammalian gastric mucosa in vivo.

\section{F9}

Adaptive cytoprotection: evidence against mediation by prostaglandins

C J HAWKEY, R T KEMP, R P WALT, N K BASKAR, J DAVIES, AND B FILIPOWICZ (Department of Therapeutics, University Hospital, Nottingham) Mild irritants - for example, $20 \%$ ethanol - increase gastric mucosal resistance to subsequent necrotising stimuli - for example, $100 \%$ ethanol. We have investigated the proposition that this phenomenon (adaptive cytoprotection) occurs because mild irritants stimulate prostaglandin (PG) synthesis.

Male Wistar rats were dosed orally with vehicle or indomethacin $2.5 \mathrm{mg} / \mathrm{kg}$ or 10 $\mathrm{mg} / \mathrm{kg}$. One hour later $20 \%$ ethanol $(1 \mathrm{ml})$ was introduced into the stomach followed 15 minutes later by $100 \%$ ethanol $(1 \mathrm{ml})$ and mucosal necrosis subsequently quantitated macroscopically. Other rats were killed 15 minutes after $20 \%$ ethanol and ex vivo release of $\mathrm{PGE}_{2}$ from mucosal fragments measured by radioimmunoassay.

In control rats release of $\mathrm{PGE}_{2}$ was $28 \pm 3$ $\mathrm{pg} / \mathrm{mg} / \mathrm{minute}$ (mean $\pm \mathrm{SEM}, \mathrm{n}=5$ ) $36 \pm 10 \%$ of the mucosa was necrosed by $100 \%$ ethanol $(n=7)$. After pretreatment with $20 \%$ ethanol $\mathrm{PGE}_{2}$ release was $99 \pm 12 \%$ of control values but mucosal necrosis induced by $100 \%$ ethanol was reduced to $6 \pm 2 \% \quad(p<0 \cdot 05)$. After pretreatment with indomethacin and $20 \%$ ethanol $\mathrm{PGE}_{2}$ release was reduced by $62 \pm 15 \%$ (indomethacin $2.5 \mathrm{mg} / \mathrm{kg}$, $\mathrm{p}<0.01$ ) and $80 \pm 8 \%$ (indomethacin 10 $\mathrm{mg} / \mathrm{kg}, \mathrm{p}<0.001$ ) but there was only $8 \pm 1 \%$ $(\mathrm{p}<0.01)$ and $16 \pm 4 \%(\mathrm{p}<0.05)$ mucosal necrosis respectively.

These observations show that adaptive 'cytoprotection' can occur in the face of reduced prostaglandin synthesis and may involve other mechanisms.

\section{F10}

Arachidonic acid metabolism and leukocyte infiltration, as determined by myeloperoxidase activity in a model of IBD

N K BOUghton-Smith, J L WALlace, AND B J R WHITtLE (Department of Mediator Pharmacology, Wellcome Research Laboratories, Beckenham, Kent) A chronic model of IBD in the rat, which has the pathological features of Crohn's disease can be induced by colonic administration of trinitrobenzene sulphonic acid (TNB). We have investigated colonic ${ }^{14} \mathrm{C}$ arachidonic acid (AA) metabolism and, as a measure of leukocyte infiltration, myeloperoxidase (MPO) activity, during the development of colonic inflammation in this model.

The distal colons of rats were removed at various times (one hour to one week) after a single intracolonic application of TNB ( $20 \mathrm{mg}$ in $0.25 \mathrm{ml}$ of $30 \% \mathrm{EtOH}$ ). Segments of colon $(200 \mathrm{mg})$ were homogenised, incubated $\left(30 \mathrm{~min}, 37^{\circ} \mathrm{C}\right)$ with ${ }^{14} \mathrm{C}$-AA $(0.25 \mu \mathrm{Ci} / \mathrm{ml})$ and the ${ }^{14} \mathrm{C}$-AA metabolites separated by TLC. Cell free supernatants of colon were also used for spectrophotometric (at $460 \mathrm{~nm}$ ) determination of MPO activity.

The relative formation of eicosanoids from ${ }^{14} \mathrm{C}$-AA by control colon was PGE $_{2}>6$-keto-PGF - $_{1 \alpha}>$ HETE $>$ PGE $_{2}>$ $\mathrm{PGF}_{2 \alpha} \mathrm{TXB}_{2}$. After TNB administration there was a marked increase in metabolite formation, at 24 hours HETE formation was $317 \%$ control; 6 -keto-PGF - $_{1 \alpha} 157 \%$ control and $\mathrm{TXB}_{2} 133 \%$ control (all $\mathrm{p}<0.05)$. MPO activity was also markedly increased (16-fold over control; $\mathrm{p}<0.05$ ). Formation of HETE returned to control levels by 72 hours, but formation of 6-keto$\mathrm{PGF}_{1 \alpha}$ and $\mathrm{PGF}_{2 \alpha}$ was increased $(160 \%$ and $133 \%$ control; $p<0.05)$. MPO activity increased further ( 35 fold, $\mathrm{p}<0.05$ ) peaking between 54 and 72 hours. The MPO activity remained raised at one week, at which time ${ }^{14} \mathrm{C}$-AA metabolism had returned to control levels.

A significant increase in ${ }^{14} \mathrm{C}$ - $\mathrm{AA}$ metabolite formation was apparent during the acute phase of TNB induced colonic inflammation which coincided with an increased leukocyte infiltration (MPO activity). In the chronic phase of the inflammation, however, there was little change in ${ }^{14} \mathrm{C}$-AA metabolism despite the persistance of leukocyte infiltration. These results suggest a greater importance of these AA metabolites in acute compared with chronic inflammation.

F11

Segmental variability of ionic conductances in rat colonic epithelium

G I SANDle (Department of Medicine, University of Manchester School of Medicine, Hope Hospital, Salford) Segmental differences exist in colonic ion transport. Microelectrodes and ion substitutions have been used to study passive (paracellular) transport in rat proximal and distal colon. In proximal colon $(n=6)$ bathed in $\mathrm{NaCl}$ Ringer, transepithelial voltage $\left(\mathrm{V}_{\mathrm{t}}:-5 \pm 1\right.$ $\mathrm{mV}$ ) was lower, and total conductance $\left(G_{t}: 11 \cdot 4 \pm 0.8 \mathrm{mS} / \mathrm{cm}^{2}\right)$ was higher, than in distal colon $(-9 \pm 1 \mathrm{mV}, \mathrm{p}<0.05$ and $5.9 \pm 0.5 \mathrm{mS} / \mathrm{cm}^{2}, \mathrm{p}<0.001$ respectively, $\mathrm{n}=9$ ), and there was no amiloride-sensitive $\mathrm{Na}$ conductance in either segment. Paracellular shunt and apical membrane conductances were higher in proximal colon $\left(5 \cdot 8 \pm 0.9 \mathrm{mS} / \mathrm{cm}^{2}\right.$ and $5.0 \pm 1 \cdot 1$ $\mathrm{mS} / \mathrm{cm}^{2}$ respectively) than in distal colon $\left(2.8 \pm 0.4 \mathrm{mS} / \mathrm{cm}^{2}, \mathrm{p}<0.01\right.$ and $2.2 \pm 0.3$ $\mathrm{mS} / \mathrm{cm}^{2}, \mathrm{p}<0.02$ respectively); basolateral membrane conductance was similar in both segments. With Cl-free Ringer, total conductance in proximal colon decreased $\left(\Delta G_{t}: 6 \cdot 1 \pm 1 \cdot 2 \mathrm{mS} / \mathrm{cm}^{2}, \mathrm{n}=7\right)$ to a greater extent than in distal colon $\left(\Delta G_{t}: 2 \cdot 6 \pm 0 \cdot 4\right.$ $\mathrm{mS} / \mathrm{cm}^{2}, \mathrm{p}<0.02, \mathrm{n}=7$ ), without a change in the basolateral/apical conductance ratio. With Na-free Ringer, there were smaller decreases in proximal and distal colonic conductances $\left(\Delta G_{t}: 2 \cdot 5 \pm 0 \cdot 5 \mathrm{mS} / \mathrm{cm}^{2}\right.$ and $1.3 \pm 0.5 \mathrm{mS} / \mathrm{cm}^{2}$ respectively, $\mathrm{n}=6$ ). Thus: (i) proximal colon has a greater paracel- 
lular conductance than distal colon, which mainly reflects its permeability to $\mathrm{Cl}$; (ii) proximal colon has a greater apical conductance than distal colon, which may reflect $\mathrm{K}$ channels, as there appear to be no $\mathrm{Na}$ or $\mathrm{Cl}$ channels in this membrane.

\section{F12}

Activation of intestinal epithelial protein kinases by calcium

G WARHURST, G S SMITH, A TONGE, AND L A TURNBERG (Department of Medicine, University of Manchester School of Medicine, Hope Hospital, Salford) Intestinal secretagogues such as acetylcholine and 5-HT are believed to mediate their actions by raising cytosolic $\mathrm{Ca}$ concentrations. The cellular events which follow and which lead to ion secretion are largely unexplored but may involve the phosphorylation of key proteins by specific protein kinases. We therefore investigated $\mathrm{Ca}$ activated protein kinase activity in cytosolic and particulate fractions from rat enterocytes. Endogenous protein phosphorylations determined in cell homogenates incubated with ${ }^{32} \mathrm{P}$ ATP revealed a $\mathrm{Ca}$ dependent phosphorylation of several proteins, the most apparent being of $M_{r}=50000$. Labelling of this protein was stimulated at $3 \times 10^{-8} \mathrm{M} \mathrm{Ca}$ and was maximal at $10^{-6} \mathrm{M} \mathrm{Ca}$. Inclusion of calmodulin (CDR) had no effect on the level of phosphorylation, although the CDR antagonist TFP inhibited labelling suggesting the involvement of CDRdependent protein kinase activity.

Using a specific histone protein as exogenous substrate a second $\mathrm{Ca}$ activated kinase could be demonstrated. This enzyme was located in the $100000 \mathrm{~g}$ cytosolic fraction and was dependent on the presence of phosphatidylserine (PS) for full activity. PS produced a dosedependent stimulation of activity $(4 \mu \mathrm{g} / \mathrm{ml}$, $142 \% ; 18 \mu \mathrm{g} / \mathrm{ml}, 235 \%$ of control). In conclusion this study shows the presence in rat enterocytes of two distinct $\mathrm{Ca}$ activated protein kinase activities - both of which may serve to mediate the secretory events initiated by increases in intracellular $\mathrm{Ca}$.

GASTRODUODENAL

F13-24

\section{F13}

Comparison between enprostil and ranitidine in the treatment of gastric ulceration and subsequent follow up (interim report)
A G MORGAN, W A F MCADAM, C PACSOO (Endoscopy Unit, Airedale General Hospital, Keighley, West Yorkshire) So far 48 patients with benign gastric ulceration have been enrolled in a double blind endoscopically controlled study, and randomly allocated to treatment with either enprostil, a synthetic dihydro-prostaglandin E2 (70 $\mu \mathrm{g}$ twice daily) or ranitidine. Endoscopic examination was repeated at monthly intervals for three months or until healing. Dyspeptic symptoms were recorded on a diary card and a return drug count and safety screening performed at each endoscopic visit.

The results of the treatment were similar for the two drug regimes. With enprostil $63 \%$ had healed ulcers at one month, $91 \%$ at two months and three months. The healing rates for ranitidine were $50 \%$, $83 \%$, and $96 \%$ respectively. Diary card analysis showed that both drugs rapidly relieved dyspeptic symptoms. No clinically important side effects were encountered. A years follow up after ulcer healing and without maintenance therapy is planned. So far there have been 20 recurrences out of the 32 patients who have completed the first six months of follow up.

Enprostil appears to be an effective and safe drug in the treatment of gastric ulceration.

\section{F14}

Enprostil (E) versus ranitidine (R) in duodenal ulcer (DU)

K D BARDHAN, K BOSE, R F C HINCHLIFFE, LESLEY WHITTAKER, PAMELA MORRIS, HELEN MASSEY, AND MOIRA THOMSON (District General Hospital, Rotherham, and Syntex Research, Maidenhead, Berks) We have investigated enprostil ( $E)$, a new synthetic prostaglandin $\mathrm{E}_{2}$ derivative with antisecretory and mucosal-protective effects, in DU healing. In a double blind double dummy study, 85 patients with DU were randomly allocated to receive either E $35 \mathrm{mcg}(n=44)$ or $R 150 \mathrm{mg}(\mathrm{n}=41)$ both taken twice daily. The patients were interviewed at two, four, and six weeks and endoscoped at four weeks and again at six weeks if unhealed earlier.

Patients in both treatment groups were well matched for age, sex, length of history, smoking, and ulcer size. Healing in the two groups was: at four weeks, E $46 \%$, R 93\% (p<0.01); at six weeks E 82\%, R $97 \%$ (ns). Smoking retarded healing but ulcer size and length of history had no effect. Reduction of daytime and night- time pain was equally quick with both drugs.

The main adverse events noted were: abdominal pain (E $16 \%, \mathrm{R} 0 \%$ ), diarrhoea (E 5\%, R 2\%), nausea (E 7\%, R 2\%), dizziness (E 2\%, R 5\%), and depression (E $0 \%, \mathrm{R} 5 \%)$; and three patients (E1, R2) were withdrawn because of continuing or recurrent abdominal pain. There was no major treatment related haematological or biochemical abnormality.

In conclusion, at this dose $\mathrm{E}$ heals $\mathrm{DU}$ less rapidly than $R$ but is equally effective in relieving ulcer pain.

\section{F15}

Natural history of chronic antral gastritis in duodenal ulcer (DU) and its reponse to treatment with prostaglandin E1 (misoprostol)

W H HUI, J HO, S K LAM, I LUI, M T NG, C L LAI, AND A LOK (Departments of Medicine \& Pathology, University of Hong Kong, Queen Mary Hospital, Hong Kong) The natural history of chronic antral gastritis in relation to healing of DU and its response to treatment, if any, are unknown. We carried out a double blind controlled trial using an oral prostaglandin E1, misoprostol (Searle), in 213 patients with active DU randomised to receive placebo $(n=69)$, misoprostol $200 \mu \mathrm{g}(\mathrm{n}=73)$, or misoprostol $300 \mu \mathrm{g}(\mathrm{n}=71)$ qid respectively. Healing of DU was assessed bi-weekly up to 12 weeks by endoscopy at which at least two antral and two fundal biopsies were taken. The activity and chronicity of gastritis as assessed histologically by the infiltration of, respectively, polymorphs and chronic inflammatory cells were graded blind by the pathologist as nil, mild, moderate or severe. Before treatment, $80 \%$ of patients had moderate to severe antral gastritis and $1.5 \%$ had fundal gastritis. In the placebo group, healed DU was associated with significantly $(p<0.01$, life table analysis) higher rates of regression of antral gastritis (nil or mild as end point) than unhealed DU ( $30 \%$ vs $4 \%$ at week 8$)$. Irrespective of whether DU was healed or unhealed, significantly $(p<0.01)$ more patients on misoprostol $(50 \%$ at week 8$)$ showed regression of antral gastritis than the placebo group. The chronicity of antral gastritis showed similar changes.

In conclusion, healing of DU was associated with improvement of chronic antral gastritis, which, as shown for the first time, could be further enhanced by a therapeutic agent - prostaglandin E1. 
F16

Will overnight response to cimetidine predict healing of duodenal ulcers?

M DEAKIN, J RAMAge, ANGIE PAUL, Jo SHOULER, S P GRAY, J BILLINGS, D G COLINJONFS, AND J G WILlIAMS (Department of Gastroenterology and Biochemistry, Royal Naval Hospital, Haslar, Department Gastroenterology, Queen Alexandra Hospital, Portsmouth, Devon) We have studied prospectively the evening and nocturnal $\mathrm{pH}$ profiles, nocturnal acid and pepsin outputs of 33 patients with endoscopically diagnosed acute duodenal ulcers. The study was carried out before treatment and while taking cimetidine $400 \mathrm{mg}$ bd $(0800$ and 2300 hours). All patients were reendoscoped after six weeks treatment with cimetidine: in 13/33 the ulcer had not healed, in $7 / 33$ an erosive duodenitis remained and in 13/33 complete healing had occurred.

All 13 patients whose ulcers had healed had a profound pharmacological response to cimetidine $400 \mathrm{mg}$ with a mean overnight $\mathrm{pH}$ of $6.06 \pm 0.46$ SEM compared with $1.92 \pm 0.14$ before treatment and a $97 \%$ fall in nocturnal acid output, $22.46 \pm 3.6$ to $0.75 \pm 0.35 \mathrm{mmol}$ between 0030-0730 hours. While taking cimetidine few overnight specimens contained detectable peptic activity. Mean fall in pepsin output was $28 \cdot 1 \pm 5.39$ to $3 \cdot 45 \pm 1.55$ IU.

The 13 patients with unhealed ulcers had smaller $\mathrm{pH}$ changes overnight $(1.47 \pm 0.05$ to $3.74 \pm 0.62)(p<0.01)$, a smaller reduction in mean acid output, $57.29 \pm 18.07$ to $13.28 \pm 5.12 \mathrm{mmol}(\mathrm{p}<0.01)$ and pepsin output $45 \cdot 96 \pm 11 \cdot 71$ to $22 \cdot 16 \pm 5 \cdot 6$ IU $(\mathrm{p}<0 \cdot 01)$.

A poor response to cimetidine overnight will predict slow healing of duodenal ulceration. This may be because of inadequate inactivation of pepsin as well as poor inhibition of acid.

F17

Is persistent duodenal prostaglandin $\mathbf{E}_{2}$ deficiency the cause of relapse in DU?

S PUgh, Sian williams, M ishaque, $M$ R LEWIN, TINA BARTON, K BOSE, K BARDHAN, AND C G CLARK (Department of Surgery, University College London, and Department of Gastroenterology, Rotherham District General Hospital, Rotherham) It has been shown that the ability of the duodenal mucosa to synthesise $\mathrm{PGE}_{2}$ is deficient in association with DU. As $\mathrm{PGE}_{2}$ may be an important mediator of duodenal defences such a deficiency may be causally related to DU. We report a two centre study on the effects of treatment with $\mathrm{H}_{2}$ receptor antagonists and the healing of the $\mathrm{DU}$ on duodenal $\mathrm{PGE}_{2}$ synthesis. At endoscopy, biopsies were obtained from the duodenum in normals (22), untreated DU rim (18), patients with healed $\mathrm{DU}$ but still on $\mathrm{H}_{2}$ receptor antagonist treatment (22), patients with healed DU off treatment (6) and also patients being treated with $\mathrm{H}_{2}$ receptor antagonists for GU or oesophagitis (the patients act as treatment controls (20)). All biopsies were treated similarly by inducing synthesis of $\mathrm{PGE}_{2}$ by vortexing and measuring released $\mathrm{PGE}_{2}$ by RIA. Results were (mean $\pm \mathrm{SD}$ in pg $\mathrm{PGE}_{2} / \mathrm{mg}$ wet wt), normals $110 \cdot 2 \pm 32 \cdot 2$, untreated DU rim $60 \cdot 3 \pm 22.5$ ( $\mathrm{p}<0.001$ vs normal), healed DU on treatment $84.7 \pm 38.2$ $(\mathrm{p}<0.025$ vs normal), healed DU off treatment $75.7 \pm 26 \cdot 1$ ( $\mathrm{p}<0.02$ vs normal, NS vs healed DU on treatment) and patients on treatment for conditions other than duodenal disease $121 \cdot 6 \pm 40.2$ (NS vs normal, $\mathrm{p}<0.02 v s$ healed DU on treatment).

We conclude that the initial deficiency of $\mathrm{PGE}_{2}$ in association with $\mathrm{DU}$ is confirmed and that this deficiency persists despite treatment with $\mathrm{H}_{2}$ receptor antagonists. This persistent deficiency may be one of the causes of the rapid recurrence of DU in most patients off treatment

\section{F18}

Prostaglandin $E_{2}$ in the prevention of gastric stress bleeding

H A VAN ESSEN, M VAN BLANKENSTEIN, J H P WILSON, B VAN DEN BERG, AND H A BRUINING (Departments of Internal Medicine and Surgery, University Hospital, Rotterdam, The Netherlands) The effect of prostaglandin $\mathrm{E}_{2}\left(\mathrm{PGE}_{2}\right)$ in the prevention of acute gastric stress bleeding in intensive care patients was investigated in a prospective, double blind, placebo controlled study. Ninety patients with two or more risk factors (major surgery, multiple trauma, respiratory insufficiency, renal insufficiency, jaundice, hypotension, peritonitis, sepsis) were randomised for treatment with either PGE $_{2} 0.5 \mathrm{mg}$ every four hours via a nasogastric tube, or placebo. Blood loss in 24 hour gastric aspirates was measured by a peroxidase test (orthotolidine) and by ${ }^{51} \mathrm{Cr}$-labelled autologous erythrocytes, a loss $\geqslant 15 \mathrm{ml} /$ day being the critierion of bleeding.

Fifty seven patients could be evaluated after at least three days: 29 had received $\mathrm{PGE}_{2}$ and 28 placebo. Bleeding occurred in nine $(31 \%)$ of $\mathrm{PGE}_{2}$ treated patients and in $13(46 \%)$ placebo treated patients (NS). No correlation was found between the blood content of gastric aspirates as measured by the ${ }^{51} \mathrm{Cr}$-method and the peroxidase test.

It is concluded that (1) $\mathrm{PGE}_{2} 0.5 \mathrm{mg}$ administered intragastrically four hourly did not provide adequate protection against stress bleeding. (2) Peroxidase tests cannot be used to quantify blood loss in gastric aspirates. The results of previous trials on the prevention of stress bleeding using peroxidase tests are therefore questionable.

\section{F19}

Effect of aluminium on bicarbonate secretion by isolated amphibian gastroduodenal mucosa

J R CRAMPTON, L C GIBBONS, AND W D W REES (Department of Medicine, Hope Hospital, University of Manchester School of Medicine, Salford) Aluminium containing antacids provide symptomatic relief of dyspepsia despite the negligible buffering capacity of doses commonly used. Recent evidence suggests that aluminium antacids may possess cytoprotective properties although the possible mechanism of such action is not clear. The effect of neutral aluminium salts on bicarbonate secretion by bullfrog (Rana catesbeiana) fundic, antral, and duodenal stripped mucosa has therefore been examined. An isolated chamber preparation has been used enabling measurement of bicarbonate secretion by $\mathrm{pH}$ stat titration of the luminal solution with recording of transmucosal potential difference. Addition of neutral aluminium sulphate $3 \times 10^{-3} \mathrm{M}$ (equivalent to one tablet of aluminium hydroxide in 2 l) caused a marked increase in bicarbonate secretion by antrum (mean $\pm S E$ : $214 \pm 63 \%, n=4, p<0.05)$, fundus (mean \pm SE: $144 \pm 48 \%, n=5 \%, p<0.05$ ) and duodenum (mean $\pm \mathrm{SE}: 133 \pm 44 \%$, $n=6, p<0 \cdot 005)$. Transmucosal potential difference was not altered during these experiments. These results demonstrate that aluminium is a potent stimulant of mucosal bicarbonate secretion in concentrations which may be achieved in vivo. The mechanism of this stimulation deserves further evaluation since it may provide a clue to the therapeutic effect of aluminium containing antacids in peptic disorders. 
F20

Experimental studies of new mechanical methods of endoscopic haemostasis: stitching, banding, clamping, and ulcer removal

C P SWAIN, T N MILLS, AND T C NORTHFIELD (The Norman Tanner Gastroenterology Unit, St James' Hospital and Department of Medical Physics, University College Hospital, London) Mechanical occlusion of bleeding vessels in the gastrointestinal tract at endoscopy might offer greater security of haemostasis than thermal methods. We have designed and tested new mechanica methods for occlusion of bleeding vessels at endoscopy including: (1) an improved endoscopic sewing machine (SM); (2) an ulcer clamp (C); (3) a method for delivering rubber bands (B) or self-retaining plastic ties over a suction polyp at endoscopy; (4) banding or tying of a suction polyp over an acute ulcer followed by monopolar snare ulcer removal (UR). Forty five standard bleeding canine ulcers were randomised to endoscopic treatment with SM, B, C, UR or control. Bleeding was terminated by SM in $9 / 10, C 10 / 10$, B $9 / 10$, UR $10 / 10$. Controls did not stop spontaneously. No secondary rebleeding or perforation occurred in these survival experiments. Mechanical methods were compared with thermal methods; hot squeeze bipolar forceps (HS), heater probe (HP), monopolar probe (MP), Nd-YAG laser (YAG) and argon laser (A) in bleeding mesenteric vessels and isolated arteries of 1-4 mm, measuring bursting pressure of vessel occlusion. Mechanical occlusion achieved higher $(\mathrm{p}<0: 01)$ bursting pressures (mean \pm SEM $1200 \pm 230 \mathrm{mmHg}$ ) than thermal methods $(320 \pm 120 \mathrm{mmHg})$ (SM+ $\mathrm{C}>\mathrm{HS}+\mathrm{B}+\mathrm{UR}>\mathrm{HP}+\mathrm{YAG}$ with coaptation $>\mathrm{MP}+\mathrm{YAG}>\mathrm{A}$ ).

We conclude that permanent mechanical occlusion of acute experimental ulcers by means of stitching, banding, clamping and ulcer removal is feasible and can occlude large vessels more securely than thermal methods.

\section{F21}

Trial of the 7 FG bipolar probe in bleeding peptic ulcers

J D O'BRIEN AND W R BURNHAM (Department of Gastroenterology, Oldchurch Hospital, Romford, Essex) Four hundred and sixty patients with upper gastrointestinal bleeding over a 27 month period were gastroscoped by two endoscopists. Two hundred and four patients examined within
24 hours who had peptic ulcers with active bleeding, visible vessel or adherent clot were allocated randomly to electrocoagulation with the probe (101 patients) or not (103 patients). Otherwise all patients were treated identically. Groups were stratified by ulcer site to give similar numbers in each. Management decisions and assessment of rebleeding were made by a clinician unaware of the randomisation.

The treated patients were older than controls (mean age 68.7 years vs 64.6 years; $p=0.054$ ) had a lower initial mean haemoglobin $(9.8 \mathrm{~g}$ vs $10.2 \mathrm{~g})$ and lower mean transfusion requirement after endoscopy $(4 \cdot 6$ units vs $7 \cdot 3$ units; $\mathrm{p}=0 \cdot 13)$. Seventeen treated patients continued bleeding or rebled compared to 34 controls $\left(\chi^{2}=6.28, p<0.015\right)$; benefit was most marked in those actively bleeding; seven had surgery (10 controls) and nine died after rebleeding (12 controls). One third of the mortality and nearly one quarter of the rebleeds in the treated group were in the first seven patients treated suggesting that inexperienced application of the probe may be hazardous.

\section{F22}

Risk of gastric cancer after benign ulcer surgery

G D CORCORAN, J WARE, D W DAY, R F A LOGAN, AND S GRAY (Departments of Surgery and Pathology, University of Liverpool, and Department of Community Health, Nottingham University, Nottingham) The gastric adenocarcinoma (GC) registrations between $1970-79$ for the Mersey Region have been reviewed and a case controlled study from five inner city hospitals done to estimate the relative risk (RR) of late malignancy (OSC) after ulcer surgery.

Of the total number of $\mathrm{GC}, 1.8 \%$ were OSC cases (116/6613), GC mean age 68.6 years and OSC, 66.4 years. The mean interval between operation and diagnosis of OSC was 21.8 years while the three operative categories, numbers and age at operation were: gastric resection (GR) 80 , $44.9 \mathrm{yr}$; gastrojejunostomy (GJ) $27,42.2$ $\mathrm{yr}$; and vagotomy and drainage, nine, 42.4 yr. There were 1610 registrations including 38 OSCs from five hospitals. These cases were matched for age, sex, time of death and hospital with necropsy controls. The overall RR was 1.4 (95\% conf limits $0 \cdot 8-2 \cdot 3)$ and the RR for GR $(n=28)$ was $1.3(0.7-2 \cdot 2)$ and for GJ $(n=10)$ was 2.0 $(0 \cdot 7-5 \cdot 8)$.
It is concluded that OSC represents only a small number of all gastric cancers. Moreover, it is suggested that the larger RR for OSC previously reported may reflect the character of the control material rather than a real risk.

\section{F23}

Pathologists problems in the recognition of early gastric cancer and gastric dysplasia

A B PRICE, G WILliams, H THOMPSON, AND BIBA UNWIN (Departments of Pathologies: Northwick Park Hospital, London, University Hospital of Wales, Cardiff, Birmingham General Hospital, and Department of Surgery, Leeds) This is preliminary pathological data from a multicentre investigation of early gastric cancer (EGC), and the natural history of gastric dysplasia. This report concerns interobserver variation of 41 cases of EGC, 22 with pregastrectomy biopsies, and a second biopsy group with a consensus opinion of dysplasia from 13 non-operated patients (follow up three weeks - two years). Assessment was by three pathologists using a proforma of 20 attributes.

For 41 cases of EGC there was full agreement in 40 surgical specimens. There were six disagreements amongst the 22 pregastrectomy biopsies from this group, with never more than one dissenting opinion. Only once was there dissention over the actual presence of dysplasia, five of the six disagreements involved grades of dysplasia.

Of the 13 non-operated cases with at least one biopsy classified dysplasia, the initial 'blind' assessment produced total agreement in only four. In six at least one opinion was against dysplasia regardless of grade. This reflects the pathologist's problem with the lesser grades of dysplasia predominant in this group in contrast to the EGC group and borne out by analysis of the proforma attributes by Kappa statistics and positive predictive values. Clearly the interpretation of graded gastric dysplasia, like dysplasia in colitis, suffers interpretative difficulties, while follow up from this study will determine any clinical significance.

\section{F24}

BSG early gastric cancer/dysplasia survey: the first 104 cases

F T DE DOMBAL, B J UNWIN, P COTTON, G R GILES, A G MORGAN, A B PRICE, H THOMPSON, 
AND G T WILLIAMS (University of Leeds, Leeds) At the BSG/SKF International Workshop on early gastric cancer (EGC) in 1982 , it was decided to set up a register of patients diagnosed as having 'EGC' or 'gastric dysplasia' in Britain, and create a databank of information about these patients. This interim report outlines some initial findings of the survey.

By May 1985, some 59 BSG members from 22 hospitals had contributed 104 fully evaluated patients (a further 40 patients await review). After evaluation by the BSG panel (three independent pathologists) only 41 cases were confirmed as having EGC; 21 cases were classified as 'advanced gastric cancer', 25 patients as 'dysplasia' and 17 as other conditions.

All but five EGC cases presented with pain, usually epigastric. The commonest mode of presentation (15 cases) was finding cancer in association with an existing gastric ulcer. Eleven patients were on long term $\mathrm{H}^{2}$ blocking drugs when their cancer was discovered. Only two patients had undergone previous gastrectomy.

These interim results emphasise (i) differences between UK and Japanese presentation, a high proportion of UK cancers occurring in 'benign' gastric ulcers; and (ii) dangers in prescribing $\mathrm{H}^{2}$ blockers for 'benign' gastric ulcer without regular biopsy.

COLORECTAL

F25-38

F25

Collagenous colitis: a report of five cases

C H MASON AND D P JEWELL (Departments of Histopathology and Gastroenterology, John Radcliffe Hospital, Headington, Oxford) We have studied five cases of collagenous colitis occurring in four women and one man, varying from 62 to 79 years of age. Four patients had a history of watery diarrhoea. The fifth case had a 20 year history of intermittent diarrhoea with occasional bleeding suggestive of ulcerative colitis. Diagnosis was made on colorectal biopsy specimens by the presence of a subepithelial collagen band greater than $10 \mu$ in thickness.

Two patients had borderline collagen in the rectum $(5-17 \mu)$ but had a well developed band $(12-50 \mu)$ throughout the rest of the colon similar to that seen in the rectum of the other three. The collagen band showed marked variability in thickness. All cases showed a mild, non-specific inflammation. One case had had multiple rectal biopsies over several years. Initially, these showed non-specific chronic inflammation but subsequently a collagenous band appeared. Immunohistochemistry showed the collagen bands to be composed mainly of Type III collagen with some fibronectin. One case responded dramatically to steroid enemas and two showed partial response to oral sulphasalazine.

Collagenous colitis may exhibit minimal rectal involvement and the diagnosis could be missed on rectal biopsy. Clinical observation and histochemical staining are compatible with collagen developing in response to an inflammatory stimulus.

\section{F26}

Does super-efficient starch absorption promote diverticular disease?

J R THORNTON, A DRYDEN, J KELLEHER, AND M S LosowsKy (Department of Medicine, St James's University Hospital, Leeds) Populations eating a relatively low fibre diet have an increased prevalence of diverticular disease, but the factors determining individual susceptibility to this disease remain unclear. We, and others, have shown previously that dietary starch is incompletely absorbed and that unabsorbed starch is a quantitively important source of colonic carbohydrate additional to that provided by fibre. The degree of starch malabsorption shows considerable variation between individuals.

We tested the hypothesis that superefficient starch absorption, by reducing the provision of colonic carbohydrate, may promote diverticular disease. Eight patients with extensive, symptomatic diverticular disease were compared with eight age- and sex-matched healthy controls. On separate days, all subjects consumed, in random order, a standardised potato meal providing $60 \mathrm{~g}$ starch or $6.5 \mathrm{~g}$ lactulose. Breath $\mathrm{H}_{2}$ was measured every 15 minutes for up to 12 hours. The relative quantities of $\mathrm{H}_{2}$ generated enabled calculation of the amount of malabsorbed potato starch. The amount of unabsorbed potato starch provides a good approximation of unabsorbed starch from all food sources.

Percentage unabsorbed starch was low in all patients and was only about one quarter of that found in the controls (mean \pm SEM: $3.3 \% \pm 0.5 \%$ vs $12 \cdot 4 \% \pm 1.8 \%, \mathrm{p}<0.01)$. For the average Briton consuming $150 \mathrm{~g}$ starch and $21 \mathrm{~g}$ fibre daily, this difference represents nearly $14 \mathrm{~g}$ of unabsorbed starch, equivalent to almost two-thirds of the colonic carbohydrate provided by consumption of fibre. Mouth-to-caecum transit time of unabsorbed potato starch was similar (patients $321 \mathrm{~min} v s$ controls 272 min, NS)

Super-efficient starch absorption, by reducing the provision of colonic carbohydrate, may promote the development of diverticular disease.

\section{F27}

Effect of ampicillin on the colonic salvage of carbohydrate

S S C RAO, C A EDWARDS, C J AUSTEN, V A BEATTIE, N W READ, AND C D HOLDSWORTH (Clinical Research Unit, Royal Hallamshire Hospital, Sheffield) The colon normally salvages unabsorbed carbohydrate by bacterial conversion to volatile fatty acids, which are then rapidly absorbed together with water. Impairment of bacterial fermentation may therefore result in an osmotic diarrhoea in people ingesting unabsorbable carbohydrate. We have tested this hypothesis by studying the effect of 500 mg ampicillin tid on stool weight and frequency and breath hydrogen production in 13 normal volunteers before and after administration of $20 \mathrm{~g}$ lactulose. Studies were separated by two weeks and dietary intake was similar during each study. Administration of lactulose did not increase stool weight and frequency under control conditions $(190 \cdot 1 \pm 31.4$ g/day vs $195.4 \pm 28.6 \mathrm{~g}$, mean \pm SEM and $1.38 \pm 0.28$ motions/day vs $1.46 \pm 0.13$ ) but after administration of ampicillin stool weight $(273.3 \pm 62.2 \mathrm{~g}$ vs $390.7 \pm 43 \mathrm{~g}, \mathrm{p}<0.02)$ and stool frequency were significantly increased $(1.38 \pm 0.26$ vs $2 \cdot 30 \pm 0 \cdot 35, \mathrm{p}<0.01)$. Ampicillin did not significantly increase basal stool weight and frequency under basal conditions. There was no significant change in the breath hydrogen response to lactulose after ampicillin, although in two subjects the response was nearly abolished. Mouth-to-caecum transit of the lactulose meal was prolonged during antibiotic ingestion $(49 \pm 5.9 \mathrm{~min}$ vs $75 \pm 7.4 \mathrm{~min}$, $\mathrm{p}<0.05$ ) but there was no significant change in the whole gut transit time. These results suggest that antibiotic associated diarrhoea could result from impaired salvage of carbohydrate.

\section{F28}

Emergence of Clostridium difficile and 
disturbance of faecal flora after single dose intravenous antibiotic administration

R G TUDOR, N S AMBROSE, M JOHNSON, D YOUNGS, D W BURDON, AND M R B KEIGHLEY (Department of Surgery, The General Hospital, Birmingham) We have studied the effect on faecal flora and the emergence of $\mathrm{Cl}$ difficile (CD) over a two week period after a single dose of eight cephalosporins and seven penicillins. Each antibiotic was administered to six volunteers (total 90 volunteers) and a further group of six volunteers served as controls. Stool samples were obtained prior to antibiotic administration and at $1,4,7$, and 14 days subsequently, and at similar time intervals in the controls. Total viable counts of individual bacterial and fungal species were obtained and the presence of $\mathrm{Cl}$ difficile and its toxin specifically sought.

Alteration in faecal flora by antibiotics was estimated by expressing the number of individual bacterial species present in all five specimens as a percentage of the total number of species identified.

These results show that the cephalosporins produce a more marked disturbance in faecal flora and this is often associated with emergence of $\mathrm{Cl}$ difficile.

F29

Use of monoclonal antibodies to rasoncogene product in the differentiation between benign and malignant diseases of the colon

N A HABIB, H NIMAN, A THOMPSON, R C N WILlIAMSON, AND C B WOOD (Department of Surgery, RPMS, London, Department of Surgery, Bristol Royal Infirmary, and Department of Molecular Biology, Scripps Res Center, La Jolla, California, USA) Proto oncogenes are responsible for normal cell growth and their conversion to a cellular oncogene leads to abnormal cell proliferation.

The expression of c-ras oncogene on chromosome 12 has been demonstrated in carcinoma of the colon and rectum. Using the peroxidase-anti-peroxidase technique colonic tissue (obtained from mounted paraffin blocks) was stained with a monoclonal antibody against ras-oncogene product (Mo-RAP) to a concentration of $1: 200$. The patients studied were five normal subjects and 25 patients with various pathological conditions (five Crohn's disease, five ulcerative colitis, five diverticular disease, 10 colorectal carcinoma). A sharp contrast was found between the strong positive staining in the cytoplasms of all 10 carcinomas and the weak cryoplasmic staining mainly at the crypt base in normal and inflamed large intestine. Therefore, staining of colorectal tumour tissue with Mo-RAP may open new avenues for diagnostic and therapeutic modalities. These findings suggest a much stronger expression of ras-oncogene in cancer tissue compared with normal or inflammatory tissue, and that Mo-RAP staining offers new diagnostic and therapeutic opportunities in colorectal malignancy.

\section{F30}

Histological grading of rectal cancer: a multivariate analysis

J R JASS AND W S ATKIN (St Mark's and St Bartholomew's Hospitals, London) The pathological grading of rectal carcinoma is a subjective exercise associated with considerable interobserver variation. The aim of this study was to identify and rank prognostic factors in order to refine current methods of grading.

Tissue sections through the primary tumours from a consecutive series of 447 patients were examined. All patients had survived radical surgery for rectal cancer for at least 28 days and had been followed for up to 20 years. Histological factors graded subjectively were: architecture (regular, irregular, no glands), nuclear polarity (easily discerned, just, lost), pattern of growth (expanding, infiltrating), lymphocyte infiltration at growing edge (marked, moderate, little) and fibrosis (little, moderate, marked). Lymph node status was not known. Multivariate analysis using the Cox regression model was employed.

Factors most strongly related to survival were ranked: (1) lymphocyte infiltration, (2) pattern of growth, (3) architecture, (4) nuclear polarity, (5) fibrosis. A prognostic model was constructed by adding each factor in turn to the first. Prediction of survival was not improved beyond architecture. When lymph node status and extent of spread were added to the model, only lymphocyte infiltration was found to be significant $(p<0 \cdot 001)$. The overriding influence of lymphocyte infiltration upon survival has not been demonstrated previously.

\section{F31}

Frequency of colorectal cancer among the first-degree relatives of patients with cancer or polyps of the large bowel

M PONZ DE LEON, A ASCARI, A ANTONIOLI, F MANENTI, G MELOTTI, C PEZCOLLER, I PICCAGLI, A GRISENDI, D MAZZEO, AND A Misell (Istituto di Patologia Medica, Cattedra di Gastroenterologia, Divisione di Chirurgia Generale, Università di Modena, Italy) Despite the importance of environmental factors there is evidence that cancer of the large bowel may involve a genetic component. The institution of a registry for colorectal tumours in our health care district gave us the opportunity to test if close relatives of patients with colorectal cancer or polyps are more likely to develop large bowel cancer than members of the general population. For each registered patient a careful clinical history was taken and the genealogic tree, limited to the first-degree relatives, was drawn. Particular attention was given to relatives affected or deceased of neoplastic diseases. Each patient was matched to a control that is, a patient of the same age ( \pm 5 years) and sex hospitalised but not for neoplastic or colonic diseases. At one year, a total of 139 cases of cancer and 157 of polyps were registered; there were 2202 first-degree relatives in the diseased group (1325 alive) and 2203 in the controls (1328 alive). Among the relatives of patients with tumours we found 71 cases of colorectal cancer as compared to 16 in the controls (Relative $\mathrm{Risk}=\mathrm{RR}=4 \cdot 55, \chi^{2}=34 \cdot 1$, $\mathrm{p}<0.001$ ). As for the parents there were 23 cases vs $10(\mathrm{RR}=2 \cdot 35, \mathrm{p}<0.02)$; among the siblings 44 vs $4(\mathrm{RR}=12 \cdot 2, \mathrm{p}<0 \cdot 001)$; as for sons 4 vs 2 (ns). When considered separately, an increased frequency of cases of colorectal cancer among first-degree relatives was found either in the cancer or in the polyps group.

It is concluded that large bowel cancer occurs four times more often in relatives of patients with colorectal cancer or polyps than in controls. Nearly $20 \%$ of the registered tumours may be defined as familial. Since a familial aggregation was observed both in the cancer and in the polyps groups, our findings provide further evidence to the 'polyp-cancer theory'.

\section{F32}

Use of monoclonal antibodies against rasoncogene products to inhibit the metabolism of human colorectal cancer cells in vitro

N A HABIB, C B WOOD, H L NIMAN, B FERMOR, 
M O SYMES, AND R C N WILliamson Department of Surgery, Royal Bristol Infirmary, Bristol, Department of Surgery, Royal Postgraduate Medical School, London, and Department of Molecular Biology, Scripps Institute, La Jolla, USA) Proto-oncogenes are responsible for normal cell growth. During malignant cell transformation they become activated oncogenes and produce growth factors. c-ras oncogene is specifically expressed in colorectal carcinomas. To test their potential therapeutic role, monoclonal antibodies against rasoncogene products (Mo-RAP) were applied to disaggregated human colorectal cancer cells obtained from nine primary tumours. After 24 hours exposure in tissue culture for Mo-RAP, the tumour cells were cultured to a further 24 hours with $1 \mu \mathrm{Ci} / \mathrm{ml}$ of radioactive selenomethionine $\left({ }^{75} \mathrm{Se}\right)$. Protein synthesis was then measured in terms of incorporated radioactivity.

Mo-RAP caused marked inhibition of protein synthesis by colorectal cancer cells obtained from four out of the nine patients. The isotope uptake relative to untreated cells was significantly reduced in four tumours $(\mathrm{p}<0.05,<0.02,<0.001$ and $<0.005$ ). In all these four patients a cytospin preparation of the tumour cells stained specifically with Mo-RAP. The widespread expression of oncogenes and their encoded proteins in human malignancies could thus provide possible therapeutic targets.

\section{F33}

Monoclonal antibody binding to primary and metastatic colorectal cancer

K C BALLANTYNE, L G DURRANT, N C ARMITAGE, $R$ A ROBINS, $R$ W BALDWIN, AND J $D$ HARDCASTLE (Departments of Surgery and Cancer Research, University of Nottingham, Nottingham) The pattern of antigen distribution in primary colorectal tumours has been defined by monoclonal antibodies. The distribution and degree of antibody binding to metastatic, however, compared with primary colorectal cancer has not been fully evaluated. Using flow cytometry and immunohistology we assessed the binding of the monoclonal antibodies 791T/36 - antiosteosarcoma, C14/1/46 - anticolonic adenoma and C161/25 - anticarcinoembryonic antigen, to 35 primary colorectal cancers, 13 lymph node metastases and nine hepatic/omental metastases.

After disaggregation tumour cell binding was measured by flow cytometry using indirect immunofluorescence. Fluoresc- ence values were corrected for non-specific binding using normal mouse immunoglobulin. Immunohistology was carried out using the indirect peroxidase technique.

The median linear fluorescence (fluorescence units FIU) for each antibody was: 791T/36 162 FIU (primary), $180 \mathrm{FIU}$ (node), 239 FlU (metastasis), C14/1/46 407 FIU (primary), 623FIU (node), 833 FIU (metastasis), C161/25 899 FIU (primary), 380 FIU (node), 1312 FIU (metastasis). Immunohistology demonstrated that the antigen distribution of primary colorectal cancer is retained in metastatic tumour deposits.

Confirmation that metastases retain similar pattern with increased antigen expression to primary colorectal cancer provides further evidence that targeted immunotherapy may effectively treat metastatic colorectal cancer.

\section{F34}

T lymphocyte subpopulations in the blood, primary tumour and normal colonic mucosa of patients with colorectal carcinoma

T W J LENNARD, A WARFORD, B K SHENTON, G PROUD, R M R TAYLOR (INTRODUCED BY I D A JOHNSTON) (Departments of Surgery and Pathology, University of Newcastle upon Tyne, Newcastle upon Tyne) The degree of 'host response' within tumours has been related to prognosis. The immunoregulatory $\mathrm{T}$ lymphocyte subpopulations in 36 primary colorectal carcinomas have been characterised using cryostat immunohistochemistry and a panel of monoclonal antibodies to pan T (OKT3), helper (OKT4) and suppressor/cytotoxic (OKT8) lymphocytes. Normal colonic mucosa from the proximal resection line of 26 of the tumours was also analysed. The mean ratio of helper to suppressor/cytotoxic lymphocytes $\pm \mathrm{SD}$ in the stroma of the tumours was $0 \cdot 55 \pm 0 \cdot 21$, and in the lamina propria of normal mucosa $1.68 \pm 0.34(p=<0.001)$ (Student's paired $t$ test). The mean pheripheral blood ratio $\pm S D$ in 34 patients with colorectal carcinomas was $1 \cdot 5 \pm 0 \cdot 28$. The finding of a significant increase in suppressor/cytotoxic lymphocytes within colorectal carcinomas compared to normal mucosa and peripheral blood may contribute to down regulation of the host immune response in situ. These findings were independent of histological grade or stage and the presence or absence of venous invasion by tumour.
F35

Cell cycle kinetics during experimental colonic carcinogenesis

T COOKE, J L MATTHEWS (INTRODUCED BY A PARKINS) (Charing Cross Hospital, Fulham Palace Road, London) Increases in crypt cell production rate, maximal in the descending colon, occurs during induced carcinogenesis. To determine its mechanism, cell cycle kinetics in colonic crypts were investigated.

At week 25 , rats treated with azoxymethane or saline sc for 12 weeks were given vincristine $1 \mathrm{mg} / \mathrm{kg}$ ip, to arrest cells in metaphase, and killed at 15 minute intervals. Metaphases were counted in 100 descending colon crypts per animal expressed as a percentage of total crypt count and plotted against time. Entry into mitosis was calculated from the slope of the resulting regression line and cell cycle time derived as its reciprocal.

There was a significant hyperplastic response in treated rats compared with controls increasing from $36 \cdot 69 \pm 2.71$ to $48.84 \pm 4.64$ cells crypt $(p<0 \cdot 001)$. The proliferation zone increased from 23 to 29 cells although the proportion of dividing cells (growth fraction) did not alter between controls $(0.62)$ and carcinogen groups $(0 \cdot 59)$. Rate of entry into mitosis decreased significantly from control values of $6.48 \pm$ to $0.87 \%$ cells per hour $(p<0.001)$ and cell cycle time increased from 30.86 to 59.09 hours.

Absolute increases in the numbers of proliferating crypt cells, despite a slowing down of cell division, explains the previously observed elevation in crypt cell production rate (1), advancing our understanding of the mechanism of colonic carcinoma development.

\section{F36}

Specialist investigation of obscure gastrointestinal haemorrhage

R SALEM, J N THOMPSON, A P HEMINGWAY, H C REES, H J F HODGSON, C B WOOD, D J ALLISON, AND J SPENCER (Departments of Surgery, Radiology and Medicine, Royal Postgraduate Medical School, Hammersmith Hospital, London) The cause of gastrointestinal haemorrhage is not identified by routine investigations in about $5 \%$ of cases. Over six years 131 patients with 'obscure' gastrointestinal bleeding have been investigated. The median age was 62 years (range 10-95) and 70 patients were 


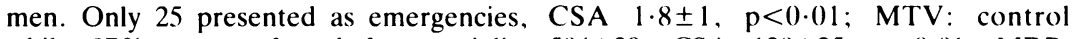
while $87 \%$ were referred for specialist $504 \pm 29$. CSA 120 $\pm 25, p<0 \cdot() 1$; MRP: investigation. The mean presenting feature control $104 \pm 5$, CSA $54 \pm 8, p<() \cdot() 1$; SL: was melaena (55 cases), anaemia (35), control 3.5 $\pm(0 \cdot 25$, CSA $2 \cdot 4 \pm 0 \cdot 2, p<() \cdot(2)$; rectal bleeding (34), haematemesis (six), and ileostomy bleeding (one). The median duration of symptoms was 50 weeks (wange 1 day-36 years) with a median two previous hospital admissions (range 0-20). Twenty six had undergone previous surgery.

The lesions identified were colonic angiodysplasia (52 patients), small bowel vascular anomalies (16), Meckel's diverticula (nine), leiomyomas (seven), gastric vascular anomalies (four), chronic pancreatitis (three), colonic diverticular disease (three), and 16 single other causes. Sixty per cent of lesions were first shown on visceral angiography, $22 \%$ at surgery, $10 \%$ on endoscopy, $5 \%$ on barium examinations and $3 \%$ at ERCP. Seventy eight patients underwent surgery. No lesion was found in 21 cases $(16 \%)$.

Specialist investigation, especially expert angiography, identified the cause of obscure gastrointestinal haemorrhage in the majority of cases. In a significant proportion, however, the cause was not found until exploratory laparotomy.

\section{F37}

Functional changes after mucosal proctectomy with colo-anal anastomosis (CSA) for chronic radiation rectal injury

J S VARMA, A N SMITH, AND A BUSUTtIL (University Department of Surgery/Urology and Department of Pathology, Western General Hospital, Edinburgh) Despite its success in dealing with the complications of chronic radiation rectal injury, marked urgency and frequency of defecation and anorectal incontinence occasionally follow CSA. To elucidate the cause, anorectal physiology was compared in eight patients and matched control subjects. Conventional manometric techniques were used to measure rectal compliance (RC, $\mathrm{ml} / \mathrm{cm}$ $\mathrm{H}_{2} \mathrm{O}$ ), maximal tolerable volume (MTV, $\mathrm{ml} \mathrm{H}_{2} \mathrm{O}$ ), resting (MRP) and squeeze (SP) anal pressures $\left(\mathrm{cm} \mathrm{H}_{2} \mathrm{O}\right)$, sphincter length (HPZ, cm) and the rectosphincteric reflex (RSR). Concentric needle EMG determined pelvic floor activity during contraction, straining and balloon rectal distension. Resected rectal specimens were examined using conventional techniques for histopathology.

There is significant reduction in $R C$. MTV, MRP and SL but not in SP after CSA (RC: control $8 \cdot 7 \pm 1 \cdot 1$, mean \pm SEM,
Wilcoxon's signed rank sum test). Four CSA patients had an absent RSR, four expelled the balloon at the MTV and four showed increased pelvic floor EMG activity on straining and rectal distension (none of the controls). Myenteric plexus abnormalities, including paucity and vacuolation of ganglion cells and nerve fibre proliferation, was a prominent feature in all the excised specimens and may be responsible for many of these abnormalities.

F38

Outcome of surgery in colonic angiodysplasia

R R SALEM, J $N$ THOMPSON, H C REES, A $P$ HEMINGWAY, D J ALLISON, J SPENCER, AND C B WOOD (Departments of Surgery, Histopathology and Diagnostic Radiology, Royal Postgraduate Medical School, London) Bleeding from colonic angiodysplasia may be treated by endoscopic coagulation or by resection. Twenty nine patients who were diagnosed as having angiodysplasia by selective visceral angiography or colonoscopy underwent resection for persistent gastrointestinal bleeding.

Peroperative colonoscopy with transillumination was undertaken in 10 patients and in eight this was valuable in visualising the lesions and determining their extent. Histology on 28 of the 29 resected specimens (with barium injections in 17) confirmed the diagnosis in $20(71 \%)$. There were three postoperative deaths. Of the remaining 26 patients, five bled subsequently (median follow up $=24$ months) one from a definite source and two from less clearly defined sources. In two of these patients additional lesions were resected at the same operation while in seven other patients resection of the angiodysplasia was not undertaken because alternative lesions more likely to have bled were identified at laparotomy.

Endoscopic coagulation is being used increasingly to arrest haemorrhage in angiodysplasia, however resection may be required if this is unsuccessful. In $19 \%$ of patients, however, bleeding recurred despite successful resection of an area of proven angiodysplasia. An extensive search for concurrent pathology appears indicated to identify alternative sources of haemorrhage.
INFLAMMATORY BOWEL DISEASE/

PANCREATICO-BILIARY

F39-52

\section{F39}

Smoking and inflammatory bowel disease

M V TOBIN, R F A LOGAN, M J S LANGMAN, R B MCCONNELL, AND I T GILMORE Gastroenterology Unit, Royal Liverpool Hospital, Liverpool, Departments of Therapeutics and Community Health, Queen's Medical Centre, University of Nottingham, Nottingham) While the intriguing association of ulcerative colitis (UC) with non-smoking is now established, the association of smoking and Crohn's disease (CD) has yet to be confirmed and it is uncertain whether these associations are not secondary to developing inflammatory bowel disease (IBD). We have, therefore, investigated smoking habits in 280 patients (157 UC, $123 \mathrm{CD}$ ) and 280 general practice controls matched for age, sex and locality, with over $95 \%$ of subjects returning a postal questionnaire.

Compared with the controls $C D$ patients were more likely to report being current smokers $(48 \%$ relative risk (RR) 1.9 $\mathrm{p}<0.25)$ and UC patients less likely $(14 \%$ RR $0.17 \mathrm{p}<0 \cdot 001)$. Crohn's disease patients were also more likely to have ever smoked (76\% RR $3.2 \mathrm{p}<0.001)$ and UC patients less likely ( $50 \%$ RR 0.53 $\mathrm{p}<0.025)$. Before the onset of disease CD patients were again more likely to be smokers than their controls (63\% RR $4 \cdot 1$ $\mathrm{p}<0.001)$ and UC patients less likely $(17 \%$ RR $0.24 \mathrm{p}<0 \cdot 001)$. Compared to never smokers ex-smokers had small but nonsignificant increased risks of both UC (RR 1.4) and CD (RR 1.8). Smokers with IBD are almost three times as likely to have $C D$ as UC.

Both associations are strong, consistent and antedate disease onset and use of identical methods minimises the possibility of systematic biases. By confirming the contrasting associations of smoking habit in UC and CD this study strengthens the claim for an aetiological role of cigarette smoking in IBD.

\section{F40}

Indirect evidence against the viral hypothesis in Crohn's disease in the Lyons area

C ANDRÉ, L DESCOS, AND S DANIÈRE (INTRODUCED BY R N ALLAN) (Groupe d'Immunopathologie Digestive INSERM, Centre Hospitalier, LYON SUD, Pierre Bénite, 
France) Many discrepancies exist with regard to the direct demonstration of the presence of an infectious agent in Crohn's disease. A general agreement does exist with regard to two indirect elements, (1) the high prevalence of lymphocytotoxic antibodies suggest that a viral agent may be involved in the pathogenesis, (2) Crohn's disease ultrafiltrates produce lymphoma in athymic mice.

Crohn's disease is infrequent in France and particularly in the Lyons area. Thus the same studies were repeated on patients from this region. Lymphocytotoxic antibodies were screened by an objective technique measuring the lymphocyte viability of a panel of eight donors by the determination of the residual ATP content (average killing of $20 \%$ or more of target cells from at least four donors).

Serum lymphocytotoxic antibodies were detected in three out of $\mathbf{5 6}$ healthy controls $(5 \%)$, in two out of 56 patients with Crohn's disease $(3.5 \%)$, in 16 out of 57 patients with ulcerative colitis $(28 \%)$ and in 11 out of 13 patients with infectious mononucleosis $(85 \%)$.

Twenty patients with Crohn's disease and 23 patients with ulcerative colitis were studied both when the disease was active and quiescent. No evident relationship could be established between the presence of lymphocytotoxic antibodies and clinical activity.

Mucosal and mesenteric lymph node homogenates from 10 patients with Crohn's disease were injected into 100 nude mice. Mice were killed after seven to 14 months. None developed a lymphoma.

If an infective agent is responsible for Crohn's disease it does not seem to be present in the Lyons area or possibly it differs in its characteristics from those agents demonstrated in other countries.

\section{F41}

How can the excess mortality from Crohn's disease be reduced?

$\mathrm{H}$ A ANDREWS AND $\mathrm{R} N$ ALLAN (The Gastroenterology Unit, General Hospital, Steelhouse Lane, Birmingham) A recent statistical study has shown a two-fold excess mortality among patients with Crohn's disease. The present study analyses how this excess mortality might be reduced.

Of 792 patients under review between $1944-1984,142$ have died. The pattern of unrelated deaths (52) was similar to that experienced in the general population.

There were 90 Crohn's disease related deaths. Twenty nine died postoperatively mostly (20) from sepsis. Sepsis was the main cause of death in a further 13 patients. Cancer of the gastrointestinal tract was the primary cause of death in 22 patients. Other less common problems included pulmonary embolism (eight), steroid related deaths (seven), amyloidosis (four), others (six) and early in the series electrolyte imbalance (10).

We conclude that the use of peroperative antibiotic prophylaxis and the identification and treatment of sepsis at other times should improve mortality rates. Changes in peroperative management should reduce the incidence of thromboembolic disease. Finally, screening for colorectal cancer should be considered in patients with longstanding extensive colitis.

\section{F42}

\section{Adhesive $\boldsymbol{E}$ coli in ulcerative colitis}

D A BURKE AND A T R AXON (Gastroenterology Unit, The General Infirmary, Leeds) $E$ coli from patients with ulcerative colitis have been studied for adhesive properties using a buccal epithelial cell (BEC) adhesion assay. This technique has several advantages over HeLa cells as it allows quantitation of adhesive properties and assessment of host factors.

Suspensions of BEC were incubated with $E$ coli isolates in the presence of Dmannose for 30 minutes. An 'adhesion index' was obtained for each assay by counting the number of BEC (out of 100) with greater than 50 adherent organisms. $E$ coli isolates from colitics $(n=18)$ adhered significantly more than those from controls $(n=12)$. Colitic isolates; median adhesion index $=43.5$ (18-68): control isolates; median $=2 \cdot 0(0-15) \mathrm{p}<0 \cdot 0001$. Using a single adhesive strain there was no significant difference between the adhesion to BEC's obtained from colitics $(n=12$ median 67 $(45-84))$ and those from controls $(n=12$ median 69 (59-78)). Similarly for nonadhesive $E$ coli.

This study shows different populations of $E$ coli in the two groups. The BEC adhesion assay clearly separates colitic $E$ coli from controls by their adhesive properties raising the possibility of a pathogenic role for adhesive organisms in ulcerative colitis.

F43

Abnormal presence of lactosylceramide detected in Crohn's disease by thin layer chromatography
C STEVENS, V OBERHOLZER, J WALKER-SMITH, AND A PHILLIPS (Queen Elizabeth Hospital for Children, London) We are currently investigating the involvement of phospholipids and related compounds in Crohn's disease. Lipids were extracted from mucosal biopsy homogenates with chloroform, methanol and water. Two dimensional thin layer chromatography was used to separate the phospholipid fraction. Small and large bowel samples (from adults and children) were studied from 10 patients with Crohn's disease, 11 patients with active ulcerative colitis (UC), and 11 patients with normal colonic histology. Samples from involved sites in nine patients with Crohn's disease strongly displayed two abnormal compounds of chromatography. These were faintly present in eight of the 11 patients with UC and the remaining patients with Crohn's disease, but did not appear on any other chromatography. Orcinol and diphenylamine tests showed the compounds to be glycolipids. They were also isolated from neutrophil-enriched peripheral leucocytes of healthy adults and co-migrated with purified lactosylceramide from human neutrophils (donated by Dr B A Macher, California). We therefore have a biochemical marker which appears to discriminate between Crohn's disease and UC. The degree of mucosal neutrophil infiltration was similar in the samples from Crohn's disease and UC and thus cannot fully explain the strong presence of lactosylceramide in Crohn's disease. Additional mucosal sources of lactosylceramide are being sought, as is its presence in other inflammatory diseases.

\section{F44}

Rapid bowel preparation for outpatient flexible sigmoidoscopy

$S$ $H$ SILVERMAN AND $M$ R B KEIGHLEY (Department of Surgery, General Hospital, Birmingham) Fibreoptic flexible sigmoidoscopy (FFS) can easily be done at the initial outpatient attendance provided that efficient bowel preparation is possible. In a prospective randomised study the efficiency of two preparations, phosphate enema (Fletchers phosphate PHARMAX) and Micralax microenema (SK\&F) were compared in unstarved and unpurged outpatients at a Rectal Clinic.

Faecal loading was assessed during rigid sigmoidoscopy and patients then received randomly either a phosphate enema $(n=32)$ or Micralax microenema $(n=24)$. The patient having relieved himself, FFS 
was performed and faecal loading reassessed. Faecal loading was graded as $I=$ no faeces, $I I=$ minor residue, $I I I=$ gross residue.

Before preparation faecal loading was equivalent in the two groups Phosphate enema produced a highly significant reduction in faecal loading $\left(\chi^{2}=9.43, p<0.001\right)$ but Micralax did not $\left(\chi^{2}=0.9 \mathrm{p}=\mathrm{NS}\right)$. After preparation faecal loading was significantly lower in the phosphate group than the Micralax group $\left(\chi^{2}=11.25 \mathrm{p}<0 \cdot 001\right)$. Phosphate enema is superior to Micralax in preparing unpurged unstarved patients for FFS; furthermore, purging prior to FFS is unnecessary as a single phosphate enema gave adequate preparation in $29 / 32(91 \%)$ of cases.

\section{F45}

Azodisalicylate for the treatment of active ulcerative colitis (UC)

A IRELAND, W S SELBY, G D BARR, C H MASON, AND D P JEWELL (Gastroenterology Unit, Radcliffe Infirmary, Oxford) Sodium azodisalicylate (ADS) consists of a dimer of 5-aminosalicylic acid (5-ASA), the active ingredient of sulphasalazine. Azodisalicylate has been assessed, double blind, in both enema and oral form in patients with mildly active distal UC. All patients were assessed clinically, sigmoidoscopically and histologically. For the enema trial, 60 patients were randomised to receive either ADS enema $1 \mathrm{~g}$ nightly or a dummy enema for two weeks. Nineteen of 29 on ADS improved, nine remained unchanged and one deteriorated. Twelve of 28 on dummy improved, 14 remained unchanged and two deteriorated. These differences were not significant. Sigmoidoscopic responses showed a similar pattern. Response was unrelated to previous sulphasalazine therapy or length of history. For the oral trial, 40 patients were randomised to receive either ADS capsules 2 g/day or dummy capsules for two weeks. Sulphasalazine was stopped on entry. Thirteen of 20 on ADS improved, six remained unchanged and one deteriorated. On dummy, eight of 20 improved, three remained unchanged, and nine deteriorated. These differences were statistically significant $(\mathrm{p}<0 \cdot 02)$. Sigmoidoscopic responses were also better in the ADS group $(p<0.05)$. Responses were unrelated to length of history or previous sulphasalazine. The drug was well tolerated in both trials, and adverse reactions were minimal. Azodisalicylate in oral form is therefore effective in mildly active distal
UC, and is a useful alternative to sulphasalazine.

F46

High performance liquid chromatography (HPLC) of plasma PABA - a sensitive assay for pancreatic exocrine dysfunction

I M CHESNER, J BERG, N LAWSON, AND $P$ ASQUITH (The Metabolic Unit and Department of Clinical Chemistry, East Birmingham Hospital, Birmingham) The NBTPABA test has a recognised role in the investigation of pancreatic dysfunction. Conventionally PABA excretion is measured in the urine by chemical methods. The assay is subject to interference by a wide range of drugs - for example, aspirin and paracetamol, and the method depends upon normal hepatic and renal function, plus a complete six hour urine collection. Using an HPLC assay for the detection of PABA in plasma we have studied nine patients with proven pancreatic steatorrhoea, seven patients with chronic pancreatic disease without steatorrhoea, and 11 healthy controls. The test was carried out in the standard way using $1 \mathrm{~g}$ NBT-PABA, $25 \mathrm{~g}$ casein and $5 \mathrm{ml} \mathrm{C}^{14}$ PABA taken orally. Serial blood specimens were taken at one, two, three and four hours. Separation between the three groups was evident at two, three and four hours and was maximal at three hours. The three hour mean (SD) for healthy controls was 47.9 $( \pm 10.4)$ that for the pancreatic disease group without steatorrhoea $17.6( \pm 5.4)$ $(p<0.01)$. In the group with proven pancreatic steatorrhoea eight of the nine had an undetectable three hour level, the other a level of $9.3 \mu \mathrm{mol} / \mathrm{l}(\mathrm{p}<0.001)$.

We conclude that an HPLC assay of PABA in plasma is a rapid and accurate method of assessing pancreatic exocrine function. A single three hour plasma level will discriminate between normals, pancreatic damage and pancreatic malabsorption.

\section{F47}

Use of fresh frozen plasma in the treatment of acute pancreatitis

T LEESE, $\mathrm{K}$ P WEST, AND A W HALL (The Department of Surgery and Pathology, University of Leicester, Leicester) Administration of fresh frozen plasma (FFP) may reduce mortality in acute pancreatitis, possibly by replenishing the plasma antiproteinase system. An animal study has been undertaken to assess further the value of FFP in acute pancreatitis. Acute haemorrhagic pancreatitis was induced in male AS rats $250-300 \mathrm{~g}$ by transduodenal infusion of $0.2 \%$ enterokinase and $3.5 \%$ sodium taurocholate into the pancreatic duct system. Animals underwent right internal jugular vein cannulation and, on recovery from anaesthetic, 30 animals were randomised to each of three intravenous fluid regimes. Group A received $8 \mathrm{ml}$ of normal saline and $16 \mathrm{ml}$ of dextrose saline per 24 hour. Group B received $8 \mathrm{ml}$ of 'Haemacel' and $16 \mathrm{ml}$ of dextrose saline and group $\mathrm{C}$ received $8 \mathrm{ml}$ of FFP and 16 $\mathrm{ml}$ of dextrose saline. Infusions were repeated each 24 hour for 72 hours.

There were nine survivors $(30 \%)$ at 72 hours in group A, $13(43 \%)$ in group B and $22(73 \%)$ in group C. Using a $\chi^{2}$ test the improved survival in the FFP group reached significance when compared with the crystalloid controls $(p<0.001)$ and the colloid controls $(p<0 \cdot 05)$.

A randomised prospective trial is now underway comparing FFP ( 2 units per day for three days) to plasma protein fraction (400 $\mathrm{ml}$ per day for three days) as part of the intravenous fluid administered to patients admitted with acute pancreatitis.

\section{F48}

Ultrasound assessment of bile duct obstruction: level, cause, and tumour resectability

R N GIBSON, E YEUNG, H A BRADPIECE, J N THOMPSON, D H CARR, A P HEMINGWAY, I S BENJAMIN, D J ALLISON, AND L H BLUMGART (Departments of Radiology and Surgery, Royal Postgraduate Medical School, Hammersmith Hospital, London) In a prospective study of 65 patients with bile duct obstruction the role of ultrasound was evaluated in relation to other radiological modalities. Computed tomography (CT) was carried out in 51 patients, direct cholangiography in 57 , and angiography in 32. Ultrasound determined the correct level of obstruction in 61 patients and in predicting cause was correct in 56 , incorrect in three and indeterminate in five. The corresponding results for CT were $45,32,3$ and 16.

Thirty seven of the 58 patients with malignant obstruction had hilar tumours. Of this group irresectability was established radiologically in 27 and operatively in a further two. Ultrasound alone predicted irresectability in 21 and in two of these it was the only modality to do so. One patient judged by ultrasound to be 
probably irresectable was in fact resect- F50

able. Computerised tomography was able Is cholecystectomy needed after endoscopic to predict irresectability in only 11 . out of 25 removal of common bile duct stones in the cases. In 21 patients with non-hilar malig- elderly?

nant obstruction ultrasound assessment of resectability disagreed with the combined prediction of the other modalities in only five cases and in three of these the ultrasound prediction was correct on operative findings.

We conclude that good quality ultrasound is the most useful and frequently the only necessary imaging modality for patients with bile duct obstruction.

F49

Acid stable lipase in the treatment of pancreatic steatorrhoea

S M GRIFFIN, D ALDERSON, AND J R FARNDON (INTRODUCED BY M B CLAGUE) (Department of Surgery, New Medical School, Framlington Place, Newcastle upon Tyne) Pancreatic exocrine insufficiency in cystic fibrosis and chronic pancreatitis results in steatorrhoea with concomitant poor nutrition and social embarrassment. Long term conventional treatment has been unsatisfactory because up to $90 \%$ of the lipase content of such therapy is inactivated by gastric acid. This results in a need for large volumes of medication to provide adequate supplementation. The aim of this study was to investigate the efficacy of a new acid resistant agent - fungal lipase in the treatment of pancreatic exocrine deficiency steatorrhoea.

Eleven dogs with pancreatic insufficiency were studied while taking a fixed dietary intake of fat. All animals were randomly allocated to fungal lipase, pancreatin and placebo for two week courses of treatment regimens. Ten grams $(60000$ $\mathrm{U}$ lipase) of pancreatin was compared with $400 \mathrm{mg}$ (24000 U lipase) of fungal lipase given with each meal against a placebo. Mean faecal fat concentrations over a three day period were performed. Data were analysed using the Wilcoxon's rank sum test for paired data. There was no significant difference between pancreatin and lipase treated animals. Both groups had significantly reduced steatorrhoea when compared with placebo $(p<0 \cdot 01)$. This study shows that a markedly reduced volume of treatment in the form of fungal lipase controls steatorrhoea as effectively as pancreatin, and represents a potentially valuable new therapy for pancreatic exocrine insufficiency.
D F MARTIN AND D E F TWEEDLE (University Hospital of South Manchester, Manchester) Between July 1981 and December 1983, 35 patients aged between 50 and 94 years (mean 79) underwent successful endoscopic clearance of common bile duct (CBD) stones. They presented with a combination of obstructive jaundice ( 25 patients), acute cholangitis (10), acute pancreatitis (two) and biliary colic (11). Ten patients had a history of myocardial infarction or stroke and three others had been treated for bronchial carcinoma. Twenty five patients remain alive and symptom free 19 to 46 months (mean 28 months) after treatment. Seven patients have died, none as a result of gall bladder disease. One patient, aged 50 , underwent elective cholecystectomy but had been symptom free for four months since endoscopy. Two patients have required cholecystectomy for acute cholecystitis five and six months after common duct clearance. In both the gall bladder had filled at ERCP. Exploration of the CBD was not necessary. These results suggest that endoscopic treatment alone for CBD stones is indicated in elderly high risk patients with gall bladders, subsequent cholecystectomy proving necessary in less than $10 \%$. Lack of filling of the gall bladder at ERCP does not appear to be a useful indicator of the future need for cholecystectomy.

\section{F51}

Does drainage increase the risk of subhepatic collection following cholecystectomy? - a prospective study

J R T MONSON, H IRVING, A W TANNER, J MACFIE, AND T G BRENNAN (St James's University Hospital, Leeds, West Yorkshire) Intraperitoneal drainage after cholecystectomy is traditional but unsupported by scientific data. In an uncontrolled study in 1983, Elboim demonstrated with ultrasound a significant incidence of subhepatic collections following cholecystectomy, with the figure much higher in drained patients, suggesting a causitive link. We have evaluated the influence of intraperitoneal drains on the incidence of these collections in a randomised prospective trial. Ninety three patients undergoing cholecystectomy were randomised at the end of the operation into a drainage, $\left({ }^{11}\right.$ suction drain for 48 hours $(n=44))$, or non-drainage group $(n=49)$. Patients with perforated gall bladders or undergoing exploration of the common bile duct were excluded. All patients had abdominal ultrasound carried out 72 hours postoperatively. The number of patients with acute cholecystitis was similar in the drainage and non-drainage group ( $11 \%$ vs $12 \%)$

Ultrasound detected six collections in the drainage group and one collection in the non-drainage group $\left(p<0.05 \chi^{2}\right)$. The average volume of the collections was 300 $\mathrm{ml}$. None was clinically significant. These results suggest that drains may actually increase the risk of developing a subhepatic collection after cholecystectomy. Further prospective studies are required.

\section{F52}

Cholecystokinin provocation test in suspected acalculous biliary pain - three and a half years of clinical use

T W J LENNARD, J R FARNDON, AND R $M$ TAYLOR (INTRODUCED BY I D A JOHNSTON) (Department of Surgery, University of Newcastle, Newcastle upon Tyne) A double blind placebo controlled infusion of cholecystokinin (CCK) has been used to attempt to reproduce the presenting symptom in 123 patients with unexplained right upper quadrant abdominal pain. Sixty two patients (53 women, nine men, mean age 44 years) developed pain with CCK and not with saline infusions (CCK positive). Fifty nine patients ( 46 women and 13 men, mean age 43 years) developed no pain during either infusion (CCK negative) and two patients developed pain during both infusions. Fifty four patients who were CCK positive ve have undergone cholecystectomy to date, and of these $51(94 \%)$ have been relieved of their pain and have had no response to postoperative $\mathrm{CCK}$ placebo infusions (mean follow-up 11.9 months, range two months to 3.5 years). Gall bladder histology was abnormal in 48 cases (chronic cholecystitis and/or cholesterolosis) and a small gall stone was found in two cases. Cholecystokinin negative patients have been followed up and nine have spontaneously improved. Fifteen remain undiagnosed and in 35 an alterantive cause for their pain has been found. The cholecystokinin provocation test will identify those patients who are likely to have a good resonse to cholecystectomy. 